\title{
Electrochemical detection of mercury, cadmium, lead, and copper using boron -doped diamond electrodes
}

Carol M. Babyak

West Virginia University

Follow this and additional works at: https://researchrepository.wvu.edu/etd

\section{Recommended Citation}

Babyak, Carol M., "Electrochemical detection of mercury, cadmium, lead, and copper using boron -doped diamond electrodes" (2004). Graduate Theses, Dissertations, and Problem Reports. 2065.

https://researchrepository.wvu.edu/etd/2065

This Dissertation is protected by copyright and/or related rights. It has been brought to you by the The Research Repository @ WVU with permission from the rights-holder(s). You are free to use this Dissertation in any way that is permitted by the copyright and related rights legislation that applies to your use. For other uses you must obtain permission from the rights-holder(s) directly, unless additional rights are indicated by a Creative Commons license in the record and/ or on the work itself. This Dissertation has been accepted for inclusion in WVU Graduate Theses, Dissertations, and Problem Reports collection by an authorized administrator of The Research Repository @ WVU.

For more information, please contact researchrepository@mail.wvu.edu. 


\title{
ELECTROCHEMICAL DETECTION OF MERCURY, CADMIUM, LEAD, AND COPPER USING BORON-DOPED DIAMOND ELECTRODES
}

\author{
Carol M. Babyak \\ Dissertation submitted to the \\ Eberly College of Arts and Sciences \\ at West Virginia University \\ in partial fulfillment of the requirements \\ for the degree of \\ Doctor of Philosophy \\ in \\ Chemistry \\ Ronald B. Smart, Ph.D., Chair \\ Fred L. King, Ph.D. \\ Aaron T. Timperman, Ph.D. \\ Paul W. Jagodzinski, Ph.D. \\ John J. Renton, Ph.D. \\ C.E. Bennett Department of Chemistry \\ Morgantown, West Virginia \\ 2004
}

Keywords: boron-doped diamond, anodic stripping voltammetry, mercury, cadmium, lead, ultrasound 


\begin{abstract}
Electrochemical Detection of Mercury, Cadmium, Lead, and Copper using Boron-Doped Diamond Electrodes
\end{abstract}

Carol M. Babyak

Anodic stripping voltammetry (ASV) and boron-doped diamond (BDD) electrodes were used to detect mercury, cadmium, lead, and copper at low part-per-billion (ppb) concentrations. Two types of BDD electrodes were used, free-standing polished electrodes, and unpolished BDD films grown on silicon substrates. The electrochemical detection of mercury was difficult in all of the matrices investigated: nitrate, chloride, thiocyanate, phosphate, and sulfate. Precipitation of mercuric or mercurous salts on the electrode surface was the likely cause. The addition of an auxiliary element improved the detection of mercury. The detection of cadmium and lead was more straightforward. The addition of copper improved the detection of lead, but not cadmium. The BDD electrode was used to determine the complexing capacity of a river water sample for lead. The application of ultrasound during the deposition step of ASV improved the detection of cadmium, but eventually damaged both types of BDD electrodes. 


\section{Dedication}

This is for my parents 


\section{Acknowledgements}

There are a lot of people I need to thank for the help and support they've given me over the past six years. First, I want to thank all the wonderful teachers I've had at WVU as a graduate student. It was a privilege to be in their classes. I also want to acknowledge my undergraduate advisor, Dr. Caryle Fish of Saint Vincent College, who encouraged me to enter graduate school.

I want to thank the members of my Examining Committee, Dr. Smart, Dr. King, Dr. Timperman, Dr. Jagodzinski, and Dr. Renton, for taking the time to read this dissertation. I appreciate and was impressed with their insightful questions and suggestions. I especially want to thank Dr. Jagodzinski who reviewed this document with unbelievably careful attention to detail. I am also grateful for the letters of recommendation provided by Dr. Smart, Dr. King, and Dr. Jagodzinski during my job search.

I want to thank my parents, Paul and Regina Babyak, and my brother, Robert Babyak, for the support they have given me not only during graduate school but always. I also want to thank Rosa Valero, whose friendship is one of the best things that ever happened to me during my time in graduate school.

The person to whom I am most indebted is my advisor, Dr. Smart. I don't think I could have survived this journey without his help, support, and patience. Thanks to him, I'll remember my years here as fun, positive, and productive, even though there were some trying times. Thanks for believing in me and encouraging me. As he once said, "If this is the hardest thing you ever have to go through, then you're lucky." 


\section{Table of Contents}

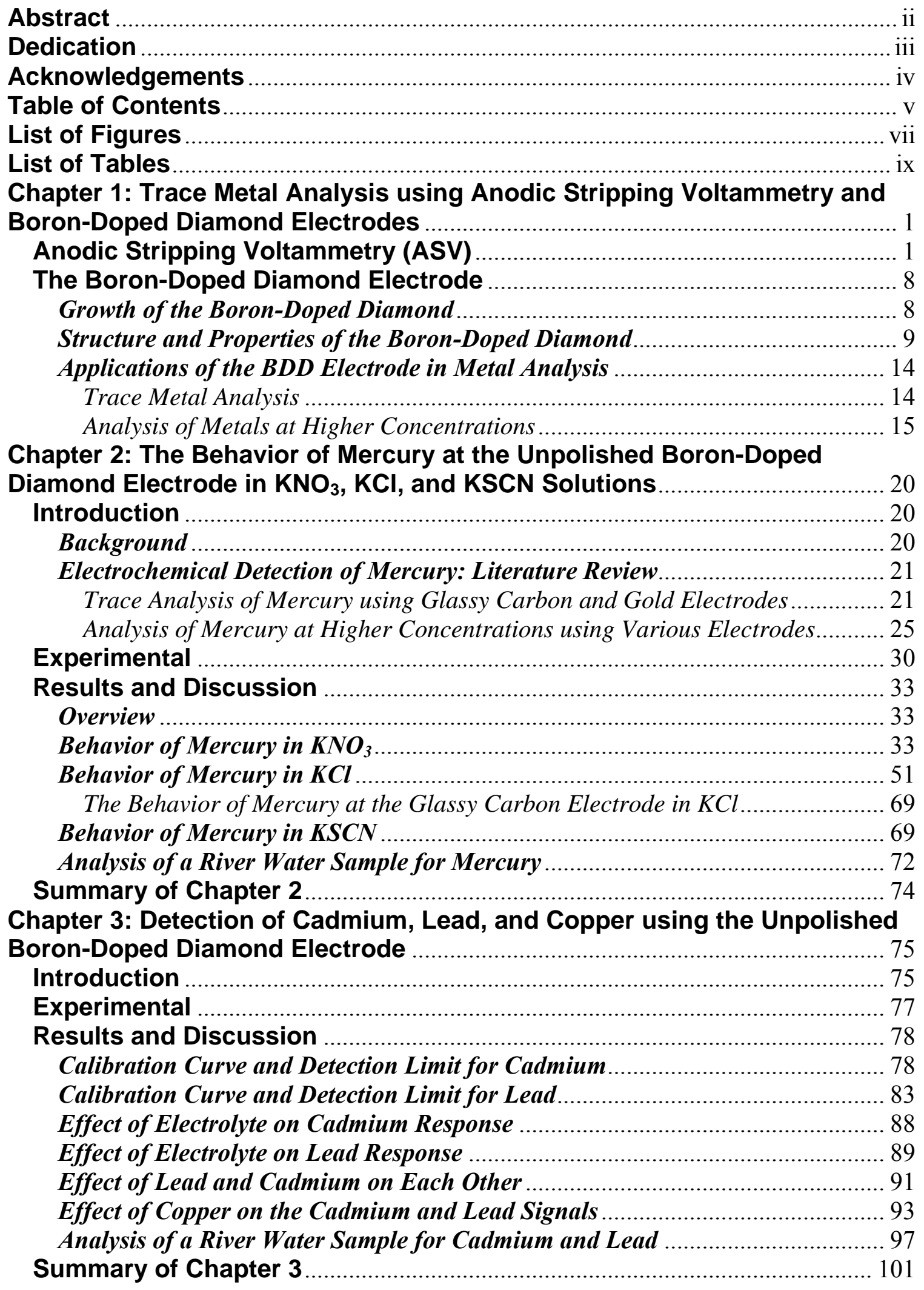


Chapter 4: The Behavior of Mercury at the Polished Boron-Doped Diamond

Electrodes in $\mathrm{KNO}_{3}, \mathrm{KCl}, \mathrm{KH}_{2} \mathrm{PO}_{4}$, and $\mathrm{K}_{2} \mathrm{SO}_{4}$ Electrolytes ........................ 102

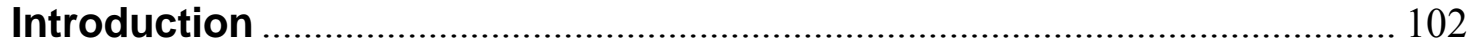

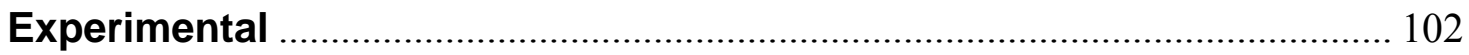

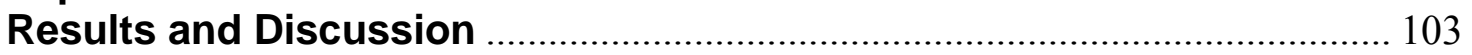

Calibration, Linear Ranges, and Reproducibility ............................................. 103

Trends of the Mercury Stripping Currents …………....................................... 109

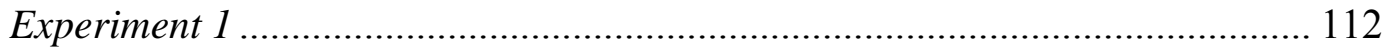

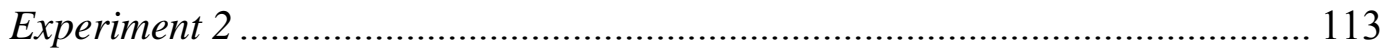

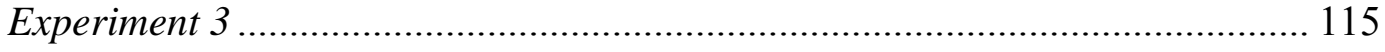

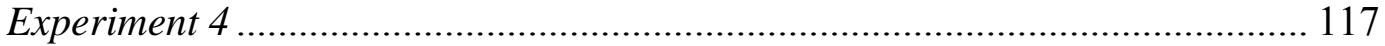

Comparison of Polished and Unpolished BDD Electrodes ................................ 117

Detection of Hg Concentrations Below the Linear Range ( $\leq 20 \mathrm{ppb}$ )................... 119

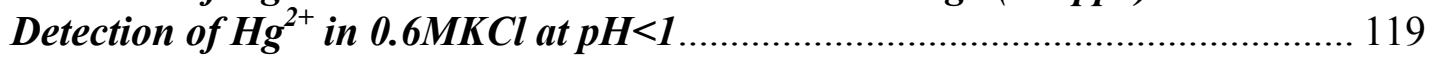

Summary of Chapter 4............................................................................... 123

Chapter 5: Effect of Ultrasound on the Electrochemical Detection of

Cadmium and Mercury using Polished and Unpolished Boron-Doped

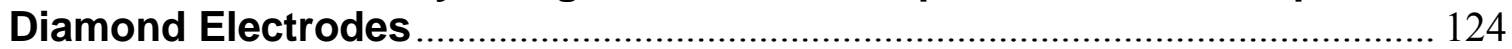

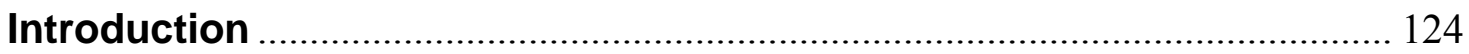

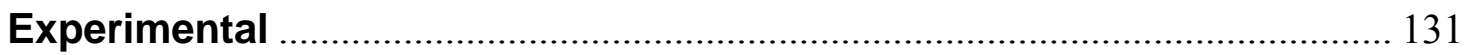

Results and Discussion ........................................................................... 132

The Unpolished Boron-Doped Diamond: Effects of Ultrasound on Electrode

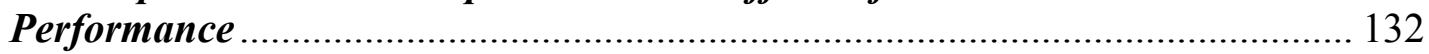

The Polished Boron-Doped Diamond Electrode .............................................. 145

Effects of Ultrasound on Electrode Performance ………................................. 145

Effect of Ultrasound on Cadmium Detection .................................................... 152

Effect of Ultrasound on Mercury Detection.................................................... 158

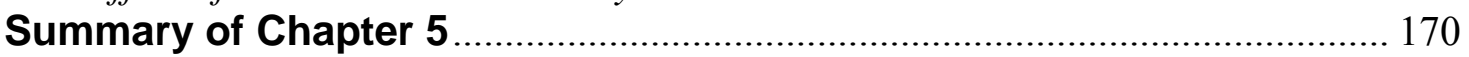

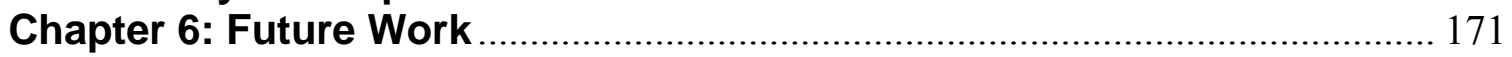

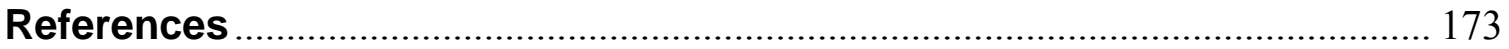




\section{List of Figures}

Figure 1. Structure of the Electrode-Solution Interface and Double Layer........................ 2

Figure 2. Osteryoung Square Wave Stripping Voltammetry ............................................ 5

Figure 3. The Three-Electrode Cell used in Voltammetry ................................................ 7

Figure 4. Diagram of the Electrochemical Cell ........................................................... 31

Figure 5. Comparison of $200 \mathrm{ppb} \mathrm{Hg}^{2+}$ in $1 \mathrm{M} \mathrm{KNO}_{3}$ and $1 \mathrm{M} \mathrm{KCl} \ldots \ldots \ldots \ldots \ldots \ldots \ldots \ldots \ldots \ldots . . . . .34$

Figure 6. Behavior of $200 \mathrm{ppb} \mathrm{Hg}^{2+}$ in $1 \mathrm{M} \mathrm{KNO}_{3}$ at the Unpolished BDD Electrode... 36

Figure 7. Behavior of $200 \mathrm{ppb} \mathrm{Hg}^{2+}$ in $1 \mathrm{M} \mathrm{KNO}_{3}$ at the Glassy Carbon Electrode....... 37

Figure 8. Proposed Model to explain the Behavior of $\mathrm{Hg}^{2+}$ in $\mathrm{KNO}_{3}$ at the Unpolished

BDD Electrode

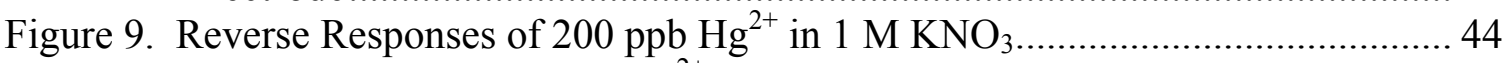

Figure 10. The Behavior of $200 \mathrm{ppb} \mathrm{Hg}^{2+}$ in $1 \mathrm{M} \mathrm{KNO}_{3}$ using a Deposition Potential of -

$1.0 \mathrm{~V}$

Figure 11. Effect of Electrochemical Cleaning on 200 and $250 \mathrm{ppb} \mathrm{Hg}^{2+}$ in $1 \mathrm{M} \mathrm{KNO}_{3} 48$

Figure 12. Effect of Deposition Time on $200 \mathrm{ppb} \mathrm{Hg}^{2+}$ in $1 \mathrm{M} \mathrm{KNO}_{3} \ldots \ldots \ldots \ldots \ldots \ldots \ldots \ldots . . . . . . . . . .50$

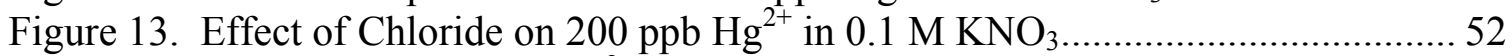

Figure 14. Behavior of $200 \mathrm{ppb} \mathrm{Hg}^{2+}$ in $1 \mathrm{M} \mathrm{KCl}$ in Different Experiments .................. 54

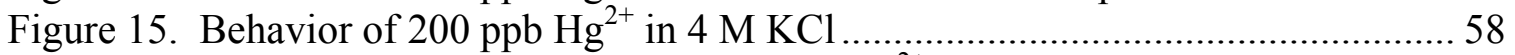

Figure 16. Effect of Deposition Time on $200 \mathrm{ppb} \mathrm{Hg}^{2+}$ in $4 \mathrm{M} \mathrm{KCl}$............................59

Figure 17. The Behavior of $200 \mathrm{ppb} \mathrm{Hg}^{2+}$ in $1 \mathrm{M} \mathrm{KCl}$ using a "Pre-Conditioned"

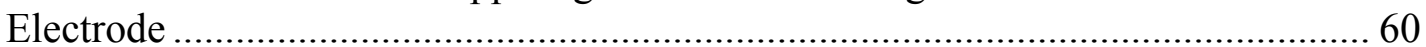

Figure 18. Effect of Electrochemical Cleaning on $\mathrm{Hg}^{2+}$ in $0.1 \mathrm{M} \mathrm{KCl}+0.9 \mathrm{M} \mathrm{KNO}_{3} \ldots 62$

Figure 19. Calibration of 50-100 ppb Hg ${ }^{2+}$ using an Auxiliary Element......................... 66

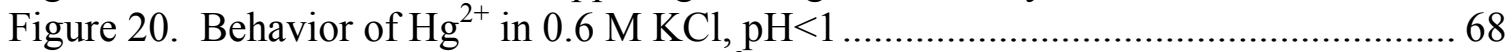

Figure 21. Voltammograms of $200 \mathrm{ppb} \mathrm{Hg}^{2+}$ in $1 \mathrm{M} \mathrm{KCl}$ at the Glassy Carbon Electrode

Figure 22. Standard Addition of $\mathrm{Hg}^{2+}$ to an Acidified River Water Sample in the

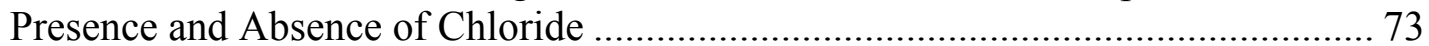

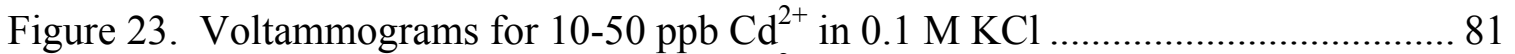

Figure 24. Calibration Curve for 1-50 $\mathrm{ppb} \mathrm{Cd}^{2+}$ in $0.1 \mathrm{M} \mathrm{KCl}$ using a 10-minute

Deposition Time...

Figure 25. Voltammograms for $1-15 \mathrm{ppb} \mathrm{Pb}^{2+}$ in $0.1 \mathrm{M} \mathrm{KCl}$ showing Nucleation and

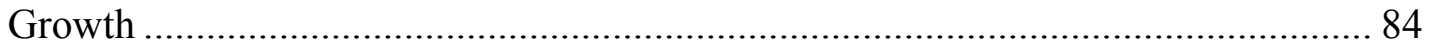

Figure 26. Calibration Curve for $\mathrm{Pb}^{2+}$ in $0.1 \mathrm{M} \mathrm{KCl}$................................................ 85

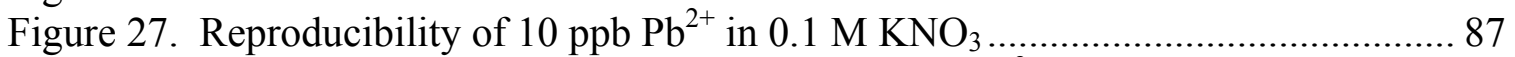

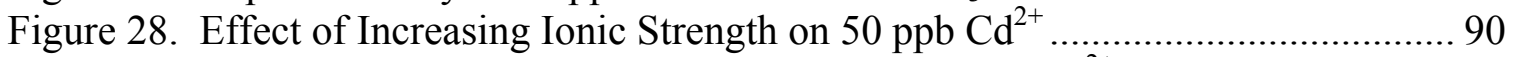

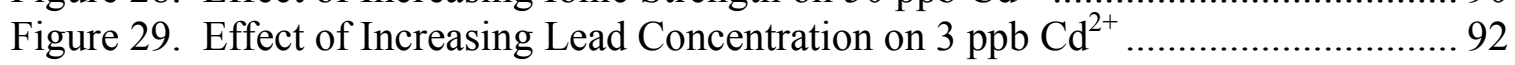

Figure 30. Effect of Copper on the Calibration of Lead ................................................ 94

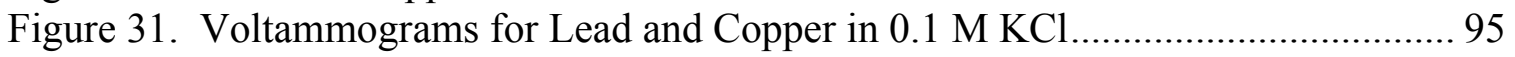

Figure 32. Standard Addition of Lead in Various Matrices........................................... 99

Figure 33. Calibration of $\mathrm{Hg}^{2+}$ in Various Electrolytes ............................................... 104

Figure 34. Relative Standard Deviations for $60-300 \mathrm{ppb} \mathrm{Hg}^{2+}$ in Various Electrolytes 107

Figure 35. Effect of Deposition Time on $100 \mathrm{ppb} \mathrm{\textrm {Hg } ^ { 2 + }}$ in $0.1 \mathrm{M} \mathrm{KNO}_{3} \ldots \ldots \ldots \ldots \ldots \ldots \ldots . . . . . . .108$ 
Figure 36. Effect of Electrochemical Cleaning and Acid-Washing on $200 \mathrm{ppb} \mathrm{Hg}^{2+}$ in 0.1

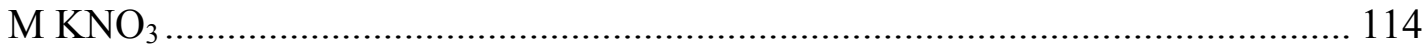

Figure 37. Effect of Waiting on an Un-Electrochemically Cleaned Surface................. 116

Figure 38. Effect of Waiting on an Electrochemically Cleaned Surface ....................... 118

Figure 39. Comparison of $\mathrm{Hg}^{2+}$ in $0.6 \mathrm{M} \mathrm{KCl}(\mathrm{pH}<1)$ at the Unpolished and Polished

BDD Electrodes ………............................................................................ 120

Figure 40. The Behavior of $\mathrm{Hg}^{2+}$ in $0.6 \mathrm{M} \mathrm{KCl}$ showing the Reduction of Calomel ... 122

Figure 41. Illustration of Acoustic Streaming and the Variables in an Ultrasound

Experiment

Figure 42. Voltammograms for 50-150 $\mathrm{ppb} \mathrm{Hg}^{2+}$ using Ultrasonic Deposition at the

Unpolished BDD Electrode

Figure 43. Effect of Ultrasound on the Unpolished BDD Electrode ............................. 137

Figure 44. Comparison of $10 \mathrm{ppb} \mathrm{Cd}^{2+}$ Before and After Exposure to Ultrasound....... 138

Figure 45. Cyclic Voltammograms of $0.001 \mathrm{M} \mathrm{Fe}(\mathrm{ClO} 4)_{2}$ in $0.1 \mathrm{M} \mathrm{H}_{2} \mathrm{SO}_{4}$ Before and

After Ultrasound ........................................................................................ 139

Figure 46. Rejuvenation of the Unpolished BDD Electrode: Effect on $10 \mathrm{ppb} \mathrm{Cd}^{2+}$ in 0.1

$\mathrm{M} \mathrm{KCl}$

Figure 47. Rejuvenation of Unpolished BDD Electrode: Effect on the CV of $0.1 \mathrm{M} \mathrm{KCl}$

Figure 48. Voltammograms and Calibration of 100-300 $\mathrm{ppb}^{2+}$ using $1,000 \mathrm{~W} / \mathrm{cm}^{2}$

Ultrasound at the Polished BDD Electrode

Figure 49. Effect of High-Intensity Ultrasound on the Polished BDD Electrode: Blank

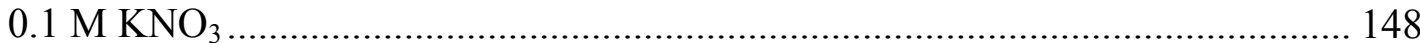

Figure 50. Effect of High-Intensity Ultrasound on $200 \mathrm{ppb} \mathrm{Hg}^{2+} \ldots \ldots \ldots \ldots \ldots \ldots \ldots \ldots \ldots \ldots \ldots . . . . .150$

Figure 51. Cyclic Voltammogram of $0.001 \mathrm{M} \mathrm{Fe}\left(\mathrm{ClO}_{4}\right)_{2}$ in $0.1 \mathrm{M} \mathrm{H}_{2} \mathrm{SO}_{4}$ Before and

After High-Intensity Ultrasound using the Polished BDD Electrode

Figure 52. Effect of Ultrasound Intensity on $100 \mathrm{ppb} \mathrm{Cd}^{2+}$ in $0.1 \mathrm{M} \mathrm{KCl}$ at Various

Distances using the Polished BDD Electrode

Figure 53. Effect of Ultrasound Intensity on $1 \mathrm{ppb} \mathrm{Cd}^{2+}$ in $0.1 \mathrm{M} \mathrm{KCl}$ using the Polished

BDD Electrode

Figure 54. Effect of Ultrasound on Large and Small Nuclei ......................................... 156

Figure 55. Effect of Ultrasound Intensity on $100 \mathrm{ppb} \mathrm{Cd}^{2+}$ at Different Deposition Times

Figure 56. Calibration Curves for 1-10 ppb $\mathrm{Cd}^{2+}$ in $0.1 \mathrm{M} \mathrm{KCl}$ using Ultrasound and

Stirred Deposition

Figure 57. Effect of Ultrasound Intensity on $200 \mathrm{ppb} \mathrm{Hg}^{2+}$ in $0.1 \mathrm{M} \mathrm{KCl}$ at Various

Distances using the Polished BDD Electrode

Figure 58. Calibration Curves for $200-400 \mathrm{ppb} \mathrm{Hg}^{2+}$ in $0.1 \mathrm{M} \mathrm{KCl}$ using Ultrasound and

Stirring at the Polished BDD Electrode

Figure 59. Voltammograms for $200 \mathrm{ppb} \mathrm{Hg}^{2+}$ in $0.1 \mathrm{M} \mathrm{KCl}$ Before and After Ultrasound 


\section{List of Tables}

Table 1. Typical Parameters used in the CVD Synthesis of BDD Thin Films ................ 10

Table 2. Effect of Stripping Parameters on Current and Background ............................. 65

Table 3. Reproducibility of Cadmium ....................................................................... 79

Table 4. Slopes of Calibration Curves for Free Lead in Various Matrices..................... 100

Table 5. Slopes and $\mathrm{R}^{2}$ Values for 100-300 $\mathrm{ppb} \mathrm{Hg}^{2+}$ in Various Electrolytes ............. 106

Table 6. Set of Experiments to Study the Trends in Current for Mercury in Various

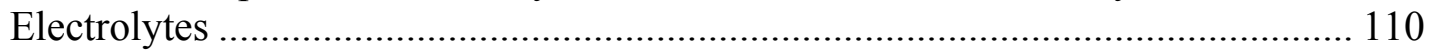

Table 7. Relevant Reaction used to determine Precipitate Formation during the Stripping

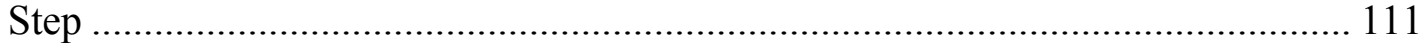

Table 8. Examples of Trace Metal Analysis using Ultrasound and Electrochemical

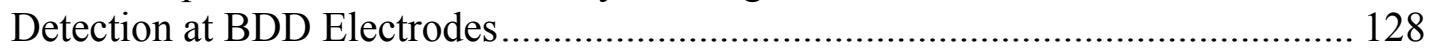

Table 9. Deposition and Stripping Parameters used for Mercury and Cadmium .......... 133

Table 10. Effect of Ultrasound on Currents obtained with Stirring using the Polished

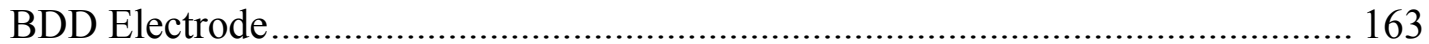

Table 11. Conditions under which Two Stripping Peaks have been observed for Mercury 


\section{Chapter 1: Trace Metal Analysis using Anodic Stripping Voltammetry and Boron-Doped Diamond Electrodes}

\section{Anodic Stripping Voltammetry (ASV)}

Low detection limits and high precision are demanded of analytical methods in applications involving trace metal analysis. Of the many methods used in trace metal analysis, anodic stripping voltammetry (ASV) is capable of providing detection limits for metals in the low part-per-billion concentration range, ${ }^{1}$ while offering the advantages of relatively low cost and portability. ${ }^{2}$ The success of this method is due in part to a preconcentration step, in which metals accumulate on an electrode surface for a given period of time. Quantification of the metals occurs in a second step during which the metals are removed from the electrode surface.

ASV is a subset of voltammetry, in which current at a working (WKG) electrode is measured as a function of the potential applied to it. In the pre-concentration step of $\mathrm{ASV}$, a potential cathodic to the formal potential of the metal ion in solution is applied to the WKG electrode, resulting in reduction of the metal at the electrode. The applied potential in the pre-concentration step is constant, and is maintained for any period of time chosen by the analyst. This step is also called the "deposition step", because the metals "deposit" onto the electrode surface in their reduced forms.

For the metal ion to deposit onto the electrode it must travel from the bulk solution, so the solution is often stirred. The metal ion then must diffuse across a stagnate layer near the electrode surface, unaffected by stirring, known as the diffusion layer. Figure 1 shows the structure of the electrode-solution interface. ${ }^{1}$ A double layer forms, because excess negative charge localized at the electrode surface attracts an excess 


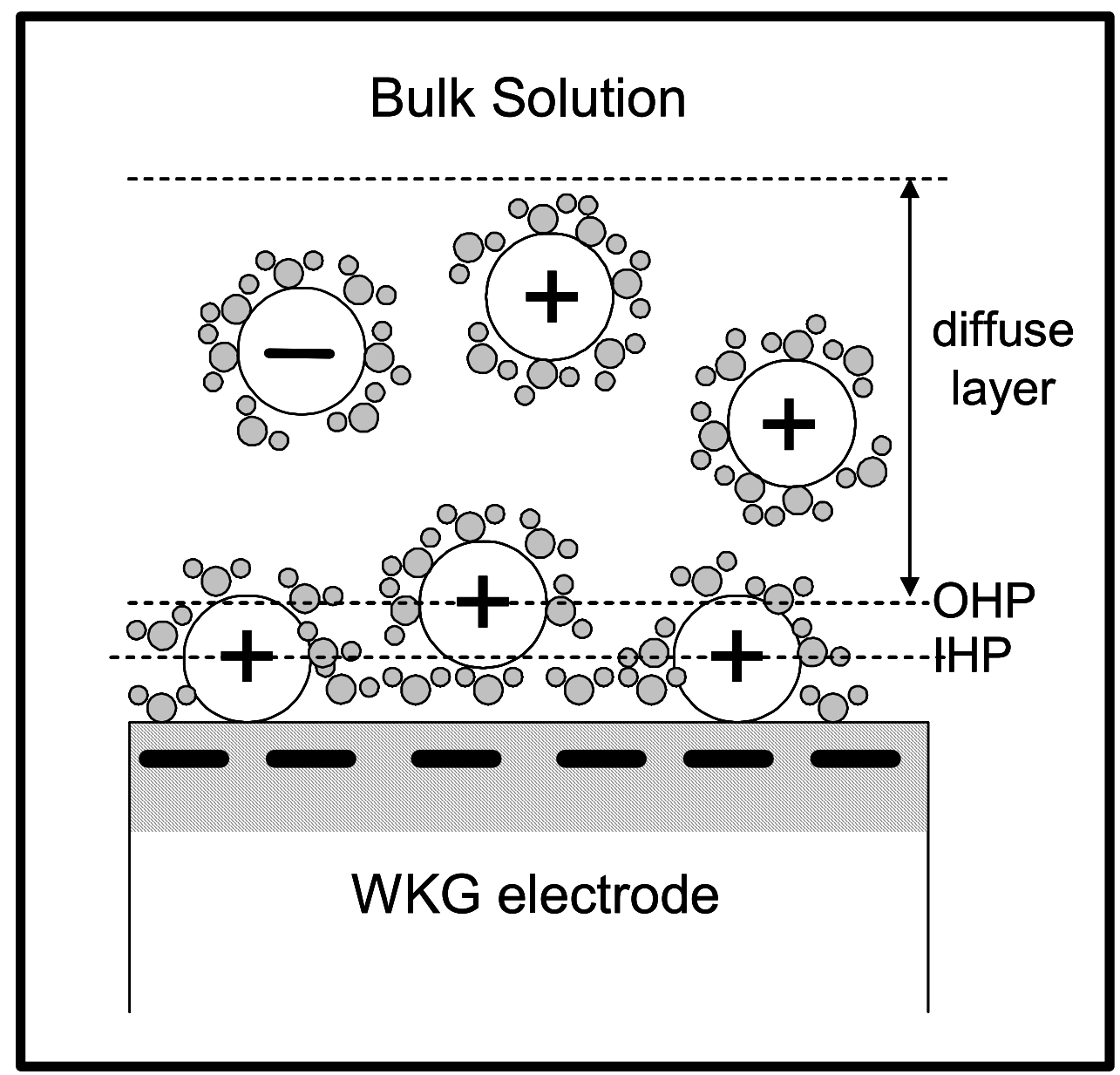

Figure 1. Structure of the Electrode-Solution Interface and Double Layer

$\mathrm{IHP}=$ Inner Hemholz Plane, an imaginary boundary passing through the center of specifically adsorbed ions; $\mathrm{OHP}=$ Outer Hemholz Plane, an imaginary boundary passing through the center of non-specifically adsorbed ions. Specifically adsorbed ions have lost their hydration shell, while non-specifically adsorbed ions have not. ${ }^{1}$ 
of positively charged ions from solution. Some of the ions are specifically adsorbed to the electrode surface, whereas others are non-specifically adsorbed, and these ions define the inner and outer Hemholtz planes, respectively. Further away from the electrode is the diffuse layer, which still contains an excess of positively charged ions. Adsorption of ions in the supporting electrolye can affect the deposition process of metal ions from solution.

Quantification of the metal ion occurs in the second step of ASV, known as the stripping step. In the stripping step, the potential of the WKG electrode is scanned in the positive direction, and when the formal potential of the metal is reached, it is oxidized. As the metal is oxidized, it is liberated, or "stripped," from the surface of the electrode, and returns to solution as the metal ion. The current measured during the stripping step is plotted versus the potential scanned during the stripping step to generate a voltammogram. The oxidation current of the metal is proportional to its concentration in solution.

The low detection limits in ASV are possible because of the deposition step; however, the mechanism by which metal deposition occurs can also affect the detection limit. Many metals, such as lead, ${ }^{3-5}$ copper, ${ }^{5}$ mercury, ${ }^{6-7}$ and silver, ${ }^{6}$ deposit onto solid electrodes according to a "nucleation and growth" mechanism. This mechanism states that certain sites on the electrode are more active toward metal deposition than others. The metal ion, therefore, deposits first onto these more active sites to form nuclei, and this is then followed by growth of the nuclei. The reason that this mechanism affects the detection limit in ASV is that a critical number ${ }^{6}$ of reduced metal atoms are required to form a nucleus, and without nucleation, growth can't occur. 
Nucleation and growth also affect the shape of the stripping peak in ASV. There is often a large stripping peak corresponding to oxidation of the metal from the nuclei, followed by a smaller peak (or shoulder) at more positive potentials due to the oxidation of the nuclei from the bare electrode surface. ${ }^{8}$

The detection limit in ASV is affected by the stripping step. Although the potential of the WKG electrode can be scanned linearly during the stripping step, pulsed waveforms are often used to reduce the background current. ${ }^{1}$ The background current arises from the capacitance of the electrode-solution interface. The capacitance of the electrode-solution interface gives rise to charging current, which can obscure the faradaic current, the desired quantity. Both charging and faradaic currents decrease with time; however, the charging current decreases more quickly (exponentially), whereas faradaic current decreases only as the square root of time. ${ }^{1}$ By applying a series of potential pulses, the measurement of the current can be made at the end of the pulses, where charging current has decreased significantly and faradaic current is still high.

Common pulsed waveforms include differential pulse ${ }^{9}$ and Osteryoung square wave $(\mathrm{OSW})^{10}$. Figure $2 \mathrm{a}$ shows the waveform used in OSW and the variables that can be controlled, along with the current response. The waveform is composed of a series of pulses, in which the applied potential is held constant for about 30 milliseconds for each pulse. The potential of half of the pulses is applied in the positive direction, and these are the forward pulses (labeled $i_{1}$ in Figure 2a); the potential of the other half is applied in the negative direction, and these are the reverse pulses ( $i_{2}$ in Figure 2a). The sum of one forward and reverse pulse is the recripocal of the frequency. The scan rate is the product of frequency and step potential. 


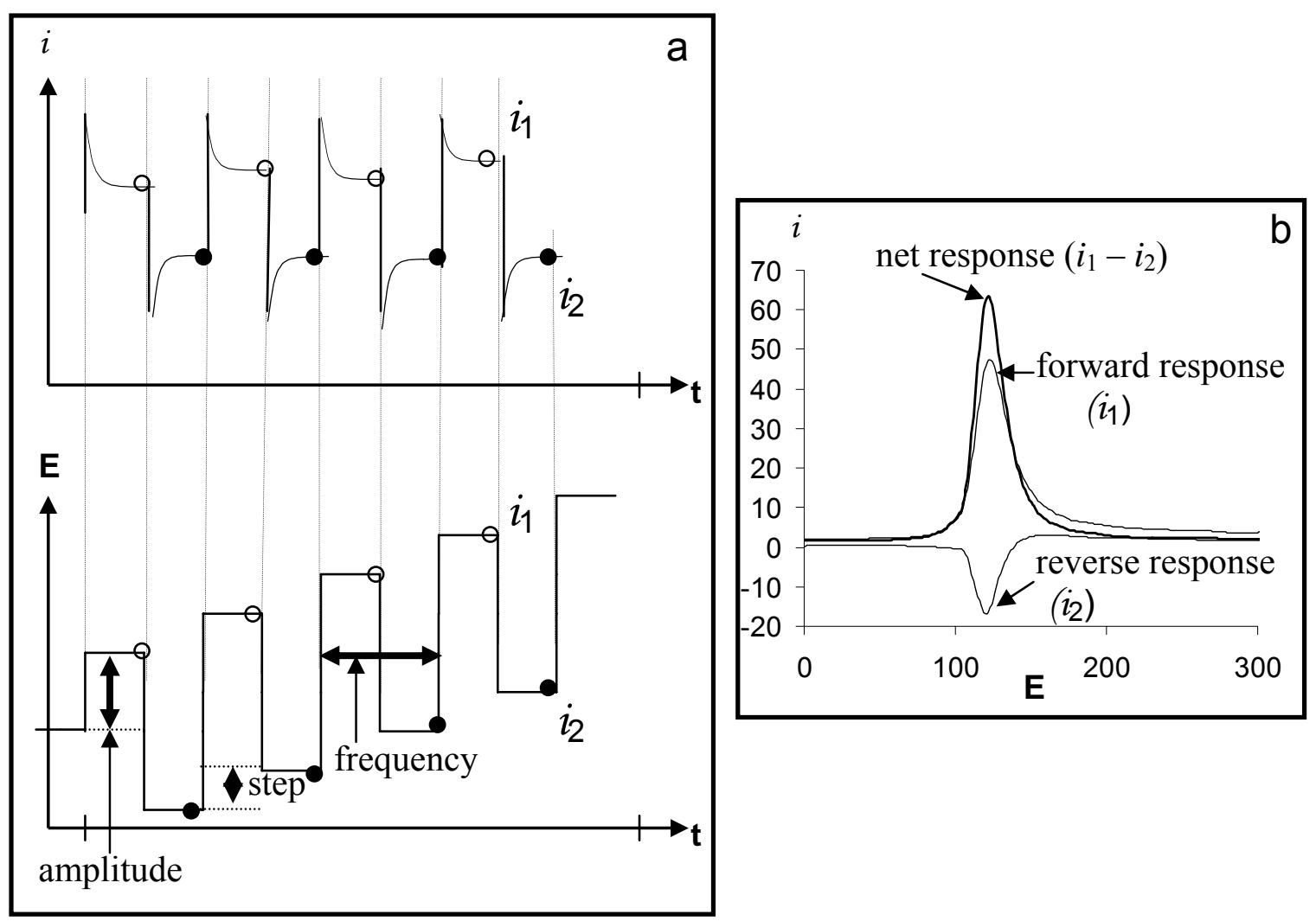

Figure 2. Osteryoung Square Wave Stripping Voltammetry

a) Potential waveform (bottom) and the current response (top); b) Voltammogram showing forward, reverse, and net responses. 
The current measured at the forward pulse (shown by the open circles in Figure 2a) is due to oxidation of the metal from the electrode surface, and it is anodic, as shown in Figure 2b. The current measured at the reverse pulse is cathodic, and it is due to the re-reduction of the metal ion. The net response is the difference between the forward and reverse currents, which results in a signal enhancement, as shown in Figure $2 b$.

Reversible behavior in OSW is defined as when the forward and reverse currents are equal in magnitude (and opposite in sign). ${ }^{11}$ Irreversible behavior, in which the forward and reverse currents are unequal, is often observed; in fact, sometimes the reverse response is anodic. This implies that the stripped metal wasn't re-reduced during the reverse pulse. ${ }^{11-12}$ The magnitude of the square wave amplitude,,${ }^{10}$ the frequency of the stripping step, ${ }^{12}$ the diffusion coefficient of the metal ion, ${ }^{12}$ and the nature of the substrate $^{11}$ from which the metal is stripped all affect the reversibility of the stripping step.

To conduct an experiment in ASV, a three electrode cell is needed, as shown in Figure 3. The reaction of interest occurs at the working (WKG) electrode to which the deposition potential and stripping waveform are applied. In Figure 3, cadmium ions are being reduced at the WKG electrode. The potential applied to the WKG electrode is measured against a reference electrode (REF), which is usually a $\mathrm{Ag} / \mathrm{AgCl} / \mathrm{sat}$ 'd $\mathrm{KCl}$ or calomel electrode. The auxiliary electrode (AUX) is usually a platinum wire, which completes the current path, as shown in Figure 3. The potentiostat controls the cell voltage and passes current through the WKG and AUX electrodes. A stirring mechanism is often included (not shown in Figure 3) to increase mass transport of the analyte to the WKG electrode. 


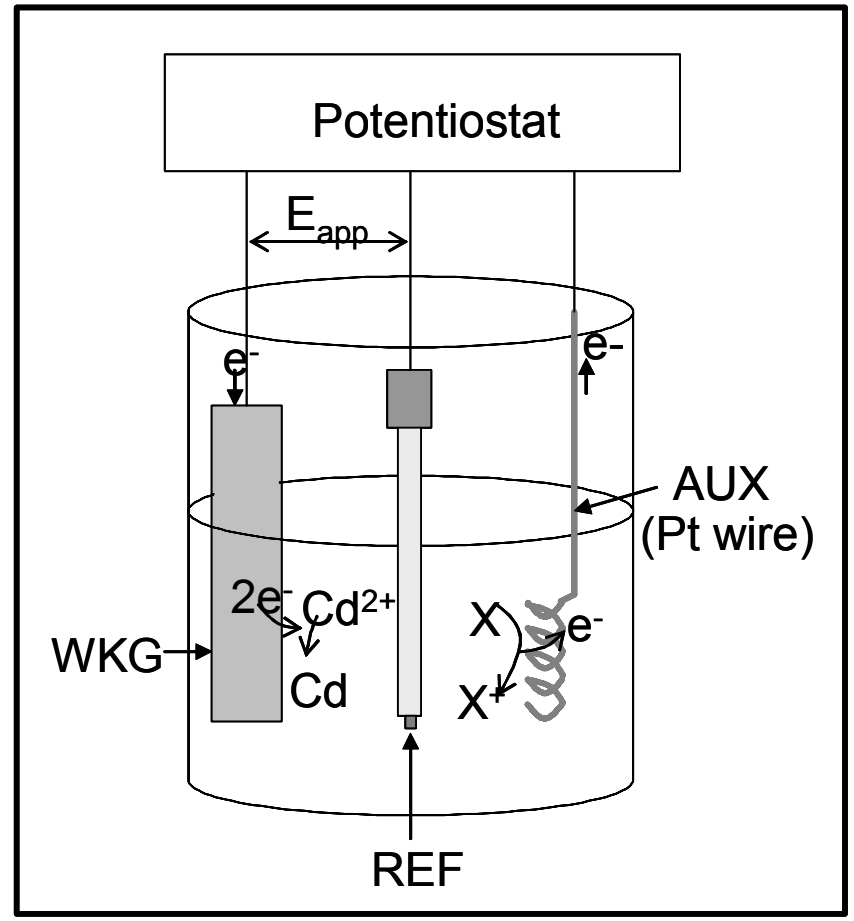

Figure 3. The Three-Electrode Cell used in Voltammetry

$\mathrm{WKG}=$ Working Electrode, $\mathrm{REF}=$ Reference Electrode, $\mathrm{AUX}=$ Auxiliary Electrode. 
In summary, ASV has excellent detection limits for trace metal analysis, because pre-concentration (or deposition) can occur for as long as desired. When Osteryoung square wave is used in the stripping step, the background current decreases and the faradaic current is enhanced. The deposition mechanism of the metal can affect the detection limit and the shape of the voltammogram. ASV experiments are performed in a three-electrode cell, and the important variables that can be controlled are the deposition time and potential, and the stripping parameters.

\section{The Boron-Doped Diamond Electrode}

In ASV the reactions of interest--the reduction and oxidation of the metal--occur at the WKG electrode. There are many characteristics desired of the WKG electrode including a wide potential window, low background current, and impermeability. The boron-doped diamond (BDD) electrode possesses all of these desirable characteristics. ${ }^{13}$ Other WKG electrodes often used in ASV are the glassy carbon (GC), platinum, hanging mercury drop electrode (HMDE), and mercury thin film electrode (MTFE). The BDD electrode will be the focus of this section, but comparison to the other electrodes will be made throughout the discussion where possible.

\section{Growth of the Boron-Doped Diamond}

Boron-doped diamond films are synthesized by chemical vapor deposition (CVD). ${ }^{14-15}$ This type of synthesis is often referred to as "growth", because a substrate is "seeded" with diamond particles, which serve as nuclei from which the growth process 
begins. Growth occurs as gaseous carbon radicals deposit onto the diamond seeds by forming carbon-carbon bonds with the nuclei.

The gas phase in CVD is usually composed of methane and hydrogen. The hydrogen gas is split into radicals by either a hot filament or microwave plasma. The hydrogen radicals react with methane gas to form carbon radical species, which then deposit onto the substrate as diamond. However, since graphite is more stable than carbon, graphitization of the diamond layer must be prevented. This is accomplished by the hydrogen radicals, which react with the deposited carbon atoms before graphitization can occur. In addition, hydrogen radicals create active sites on the growing diamond layer by abstracting hydrogen from carbon atoms.

Table 1 shows some of the typical parameters used in CVD-growth of diamond films by hot filament ${ }^{16-20}$ or microwave plasma ${ }^{21-23}$. Given the important role of hydrogen radicals, hydrogen is used as the carrier gas, and the concentration of methane is kept relatively low. When boron is used as a dopant, it is added either in the gas phase or as a solid pellet. Common substrates used in CVD are silicon, graphite, and tungsten. The thickness of the diamond film is determined by how long growth takes place. Freestanding diamond films can be prepared by etching away the silicon substrate in hydrofluoric acid after growth. ${ }^{24}$

\section{Structure and Properties of the Boron-Doped Diamond}

The structure of CVD-grown diamond is a lattice of carbon atoms which are $\mathrm{sp}^{3}$ hybridized. Each carbon atom is bonded tetrahedrally to its neighbor, resulting in layers of carbon atoms, which are stacked in the "chair" conformation. ${ }^{15}$ At the surface, the 
Table 1. Typical Parameters used in the CVD Synthesis of BDD Thin Films

\begin{tabular}{|c|c|c|c|c|c|}
\hline Filament & $\begin{array}{c}\text { Type of } \\
\text { Filament }\end{array}$ & $\begin{array}{c}\text { Carbon Source } \\
\text { Gas }\end{array}$ & Boron Source & $\begin{array}{c}\text { System } \\
\text { Pressure }\end{array}$ & $\begin{array}{c}\text { Substrate } \\
\text { Temp }\end{array}$ \\
\cline { 2 - 6 } & $\begin{array}{c}\text { Tungsten, } \\
\text { Tantalum } \\
\left(\sim 2000^{\circ} \mathrm{C}\right)\end{array}$ & $1-4 \% \mathrm{CH}_{4}$ in $\mathrm{H}_{2}$ & $\begin{array}{c}1-3 \mathrm{ppm} \mathrm{B}\left(\mathrm{CH}_{3}\right)_{3} \text { in } \\
\mathrm{H}_{2} ; \text { diborane }(\mathrm{g}) ; \mathrm{BN} \\
\text { pellet }\end{array}$ & 50 Torr & $760-800{ }^{\circ} \mathrm{C}$ \\
\hline Plasma & $\begin{array}{c}\text { Plasma } \\
\text { Power }\end{array}$ & $\begin{array}{c}\text { Carbon Source } \\
\text { Gas }\end{array}$ & Boron Source & $\begin{array}{c}\text { System } \\
\text { Pressure }\end{array}$ & $\begin{array}{c}\text { Substrate } \\
\text { Temp }\end{array}$ \\
\cline { 2 - 6 } & $\begin{array}{c}1150 \mathrm{~W}- \\
1500 \mathrm{~W}\end{array}$ & $\begin{array}{c}1-4 \% \mathrm{CH}_{4} \text { in } \mathrm{H}_{2} ; 9: 1 \\
\mathrm{v} / \mathrm{v} \text { acetone/MeOH } \\
\text { in } \mathrm{H}_{2}\end{array}$ & $\begin{array}{c}\mathrm{B}_{2} \mathrm{O}_{3} \text { pellet; } \mathrm{BN} \\
\text { pellet }\end{array}$ & $\begin{array}{c}20-115 \\
\text { Torr }\end{array}$ & $800-1000{ }^{\circ} \mathrm{C}$ \\
\hline
\end{tabular}


carbon atoms are bound by hydrogen, making the BDD surface hydrophobic. ${ }^{16}$

Approximately one of every 1,000 carbon atoms is replaced by the dopant atom, boron, which fits into the carbon lattice. ${ }^{15}$

Diamond in its undoped form has unique properties such as extreme hardness, high thermal conductivity, and optical transparency $(\lambda 2.5 \mu \mathrm{m}-230 \mathrm{~nm})$. It is an insulating material with a wide band gap of $\sim 5.5 \mathrm{eV}$, but when doped with boron, it behaves as a p-type semiconductor. ${ }^{13}$

The unique properties of CVD-grown BDD are an advantage in electrochemical applications where it functions as the working electrode. For example, the hardness of the BDD is an advantage when performing electrochemical experiments in the presence of ultrasound. ${ }^{25-31}$ The optical transparency of the BDD has allowed its surface to be monitored by attenuated total reflection infra-red (ATR-IR) simultaneously as electrochemical experiments were performed. ${ }^{32}$

The surface of the BDD consists of small (1-10 $\mu \mathrm{m})$ crystallites. The grain boundaries between the crystallites can contain non-diamond carbon impurities such as $\mathrm{sp}^{2}$ carbon. ${ }^{17}$ The quality of the BDD is usually assessed by its $\mathrm{sp}^{3}$ carbon content; low quality BDD refers to diamond with greater than $200 \mathrm{ppm} \mathrm{sp}{ }^{2}$ carbon. ${ }^{17}$ Raman spectroscopy is used to determine the quality of the BDD. ${ }^{33}$ XPS studies of freshly grown CVD have found that even high quality diamond can contain oxygen and nitrogen impurities, and even impurities from the substrate, such as silicon. ${ }^{33-36}$ A silicon carbide layer has been found between the silicon substrate and diamond, and may affect adhesion of the BDD layer to the substrate. ${ }^{37}$ Secondary ion mass spectrometry (SIMS) has been used to determine the boron content of the BDD, which is typically $10^{20} \mathrm{~cm}^{-3} \cdot 34$ 
The features of the BDD electrode which distinguish it from most other working electrodes are its hydrogen-terminated surface and $\mathrm{sp}^{3}$ character. These properties are responsible for the wide potential window and low background current of the BDD electrode. Hydrogen termination results in an electrode surface with few adsorption sites for species such as dissolved oxygen or the intermediate products of water oxidation and reduction; hence, a wide potential window exists in which other electrochemical reactions may be observed. ${ }^{13,24,34}$ The hydrogen-terminated surface of the BDD electrode contrasts with that of glassy carbon which is terminated with oxygen-containing functional groups such as carbonyl, carboxylic acids, and quinine. ${ }^{38}$ These groups can behave as adsorption sites for the species mentioned earlier, which narrows the potential window of the GC electrode. In addition, the oxygen-containing functional groups can be electrochemically active, which increases the background current of the GC electrode compared to the BDD electrode.

As mentioned earlier, high-quality CVD-grown BDD can contain some $\mathrm{sp}^{2}$ carbon impurities in the grain boundaries. The electrochemical activity of these $\mathrm{sp}^{2}$ impurities has been revealed by the presence of a redox couple in blank sulfuric acid. ${ }^{16}$ The assignment of this redox couple to $\mathrm{sp}^{2}$ carbon in grain boundaries was based on the observation that single crystal BDD did not exhibit this redox couple in solutions of blank sulfuric acid. ${ }^{17}$

Unusual behavior observed at the BDD electrode is usually attributed to the presence of $\mathrm{sp}^{2}$ carbon. For example, the overpotential for the reduction of dissolved oxygen in sulfuric acid decreased after the potential of the BDD electrode had been swept to $+1.4 \mathrm{~V}^{21}$ It was proposed that application of $+1.4 \mathrm{~V}$ activated $\mathrm{sp}^{2}$ carbon, which then 
catalyzed the reduction of dissolved oxygen. Most likely, the $\mathrm{sp}^{2}$ carbon had been oxidized by application of $+1.4 \mathrm{~V}$, and these oxygen-containing groups enhanced the rate of oxygen reduction. It wasn't mentioned if the rest of the BDD (the $\mathrm{sp}^{3}$ component) was oxidized by this treatment, or if application of a negative potential could reduce these catalytic, oxygen-containing $\mathrm{sp}^{2}$ groups.

In the above study, the potential was merely swept to $+1.4 \mathrm{~V}$, and this was enough to affect (most likely oxidize) the $\mathrm{sp}^{2}$ carbon impurities. Other research has shown that $\mathrm{sp}^{2}$ impurities can be removed by more extreme electrochemical treatment. ${ }^{39-40}$ The $\mathrm{sp}^{2}$ carbon is most likely removed through the process of gasification as shown by the reactions below: ${ }^{39}$

$$
\begin{array}{cl}
\mathrm{C}+\mathrm{H}_{2} \mathrm{O} \leftrightarrow \mathrm{CO}+2 \mathrm{H}^{+}+2 \mathrm{e}^{-} & \mathrm{E}^{\circ}=0.376 \mathrm{~V}(\mathrm{vAgCl}) \\
\mathrm{C}+2 \mathrm{H}_{2} \mathrm{O} \leftrightarrow \mathrm{CO}_{2}+2 \mathrm{H}^{+}+2 \mathrm{e}^{-} & \mathrm{E}^{\circ}=-0.015 \mathrm{~V}(\mathrm{vAgCl})
\end{array}
$$

Cycling the potential of the BDD electrode between -700 and $+700 \mathrm{mV}$ in $\mathrm{KOH}$ for several hours has been shown to selectively etch away sp ${ }^{2}$ carbon impurities. ${ }^{40}$ SEM analysis of the surface after this treatment revealed small pits located primarily at the grain boundaries, and it was proposed that the pits were caused by the gasification reactions shown above. XPS didn't confirm that the oxygen content of the BDD increased as a result of this potential cycling treatment; however, it was proposed that the BDD surface was in fact oxidized, but that the oxygen atoms were located deep inside the pits created by etching. A more stringent electrochemical treatment which has been used is the application of $\sim+2.5 \mathrm{~V}$ in $\mathrm{KOH}$ for $75 \mathrm{~min}^{41-43}$ This treatment also removed $\mathrm{sp}^{2}$ carbon, and SEM revealed that the surface was etched. ${ }^{42-43}$ 
The nature of the oxygen-containing groups on oxidized BDD electrodes is emerging from XPS and electrochemical studies. XPS data indicates the presence of carbonyl, ether, and alcohol groups on oxidized BDD electrodes. ${ }^{42}$ In one study, the presence of carbonyl groups on oxidized BDD was confirmed electrochemically using the $\mathrm{Fe}^{2+/ 3+}$ redox couple, which is sensitive to the presence of carbonyl groups. ${ }^{44}$ The peak separation $\left(\Delta \mathrm{E}_{\mathrm{p}}\right)$ for $\mathrm{Fe}^{2+/ 3+}$ decreased on oxidized BDD, indicating carbonyl groups were present; however, the observed decrease in $\Delta \mathrm{E}_{\mathrm{p}}$ was less than that observed at $\mathrm{GC}$ electrodes. This indicated that the nature of the carbonyl groups at oxidized BDD and GC electrodes are different; most likely, those at the BDD are aliphatic, whereas those at the GC are quinone-like.

\section{Applications of the BDD Electrode in Metal Analysis}

\section{Trace Metal Analysis}

Reports of trace metal detection in the low part-per-billion ( $\mathrm{ppb}$ ) range using ASV and BDD electrodes are very limited, but various approaches have been successful. A mercury-plated BDD was used to detect 6 and 20 picomoles of lead and copper, respectively, in acetate buffer $(\mathrm{pH} 4)$ using flow injection analysis and a deposition time of only 1 minute. ${ }^{4}$ The same type of electrode was used by Peilin et al. ${ }^{45}$ to detect $2 \mathrm{ppb}$ lead in a pure water sample.

Trace metal analysis has also been performed at bare BDD electrodes. A 15minute deposition time resulted in detection of $0.83 \mathrm{ppb}$ lead from potassium chloride solutions, although no calibration curve was provided for this concentration range. ${ }^{46}$ The detection of $0.14 \mathrm{ppb} \mathrm{Hg}^{2+}$ in $0.1 \mathrm{M} \mathrm{KNO}_{3}$, (pH 1) was achieved using a deposition time 
of 20 minutes, and the linear range was 0.14 to $0.68 \mathrm{ppb}^{47}$ Low levels of silver, ${ }^{25}$

manganese, ${ }^{26}$ and lead ${ }^{27}$ have been detected using the BDD in the presence of ultrasound, but these examples will be discussed in Chapter 5.

BDD electrodes can also be fabricated as microelectrodes using photolithography techniques. ${ }^{48-49}$ An array of BDD microelectrodes was used to analyze silver and copper in solutions of $0.2 \mathrm{M} \mathrm{KNO}_{3}$. The detection limit for silver was $0.5 \mathrm{ppb}$ using a deposition time of 10 minutes, and the linear range for copper was 20-120 ppb using a deposition time of 5 minutes. The deposition potential was not constant in this work. A very cathodic potential of $-1.4 \mathrm{~V}$ was applied for the first 30 seconds of the deposition step to initiate nucleation of the metals. The rest of the deposition step occurred at -400 and $-600 \mathrm{mV}$ for silver and copper, respectively.

These examples illustrate that the BDD is a good working electrode for the detection of trace metals, and that many opportunities in trace metal detection using the BDD still remain unexplored.

\section{Analysis of Metals at Higher Concentrations}

A great deal of information has been gathered on the behavior of metals at BDD electrodes from electrochemical studies involving relatively higher metal concentrations. The role of $\mathrm{sp}^{2}$ carbon seems to be important in metal deposition. For example, Nakabayashi et al. ${ }^{50}$ studied the deposition and stripping of $1 \mathrm{mM} \mathrm{Cu}^{2+}$ in $0.1 \mathrm{M} \mathrm{Na}_{2} \mathrm{SO}_{4}$. A peculiar result was obtained in the cyclic voltammogram of this solution: there was a reduction peak for copper, but no stripping peak. This implied that $\mathrm{Cu}^{2+}$ ions were reduced to $\mathrm{Cu}^{0}$, but that the reduced copper was not "trapped" on the BDD surface. 
Instead, the $\mathrm{Cu}^{0}$ particles, or colloids, diffused into the bulk electrolyte. It was speculated that there were two sites on the BDD for metal deposition, $\mathrm{sp}^{3}$ and $\mathrm{sp}^{2}$, but that only the $\mathrm{sp}^{2}$ sites could trap the $\mathrm{Cu}^{0}$. In a separate experiment, it was found that if a cathodic potential $(-0.22 \mathrm{~V})$ was applied continuously for 40 minutes, $\mathrm{Cu}^{0}$ was in fact trapped on the BDD surface; however, it wasn't concluded that continuous cathodic polarization created more trapping sites. Instead, it was thought that a small amount of $\mathrm{Cu}^{0}$ was trapped, but then growth occurred during the 40-minute electrolysis.

In a subsequent paper ${ }^{51}$ by the same researchers, it was found that $\mathrm{Cu}^{0}$ could be trapped after the BDD was pre-treated by application of $-1.8 \mathrm{~V}$ for 10 minutes in $\mathrm{Na}_{2} \mathrm{SO}_{4}$. After this treatment, the cyclic voltammograms for copper did in fact reveal a stripping peak. It was proposed that certain sites on the BDD surface were changed from nontrapping to trapping as a result of this treatment, and that these sites were $\mathrm{C}-\mathrm{O}$ groups from non-diamond impurities. It wasn't explicitly stated that the C-O groups were reduced during the pre-treatment; it was only stated that the groups were "changed" electrochemically.

It is clear from the above examples that the BDD contains sites of different activities, which can be activated by electrochemical treatment. Repeated use of the BDD can also activate, or change, certain sites. Bouamrane et al. ${ }^{36}$ observed the underpotential deposition (UPD) of copper from a solution containing $1 \mathrm{mM} \mathrm{CuSO}_{4}$ in 0.1 $\mathrm{M} \mathrm{H}_{2} \mathrm{SO}_{4}$ at $\mathrm{BDD}$ electrodes which had been used extensively. UPD is the deposition of a metal at a potential more positive than its Nernstian potential due to a strong attraction between the metal and electrode. However, UPD of copper was not observed when a freshly-grown $\mathrm{BDD}$ was used. When the fresh $\mathrm{BDD}$ was exposed to $-2.0 \mathrm{~V}$ for a few 
seconds, UPD of copper was in fact observed. It was stated that this treatment activated certain sites on the BDD surface which facilitated the UPD of copper; however, the nature of these sites wasn't known.

The electrochemical behavior of millimolar concentrations of lead was studied at the BDD using cyclic voltammetry (CV) and scanning electron microscopy (SEM), and both methods revealed that lead deposited onto the BDD according to the nucleation and growth deposition mechanism discussed earlier. ${ }^{3-4}$ Evidence of nucleation and growth in the CV was that the current of anodic scan was cathodic. During the anodic scan, reduced lead should have been oxidized, but the presence of nuclei promoted the deposition of lead from solution at less negative potentials. The SEM images revealed that lead deposited onto the BDD surface as isolated clusters (or nuclei), which indicated that certain sites on the BDD were more active than others toward deposition. If the deposition potential were made more cathodic, a more uniform deposit was observed. Although this indicated that the less active sites on the BDD could be activated by application of more negative potentials, it was also suggested that poor electrical contact between the BDD layer and substrate explained why certain sites were less active than others. $^{3}$

The cyclic voltammogram $(\mathrm{CV})$ of $2.5 \times 10^{-5} \mathrm{M} \mathrm{Cu}^{2+}$ in $0.1 \mathrm{M} \mathrm{HNO}_{3}$ also revealed evidence of nucleation and growth for copper deposition on BDD electrodes. ${ }^{5}$ The current of the anodic scan was cathodic, similar to what was observed for lead. In this case, however, the cathodic current was due to hydrogen evolution on the surfaces of copper nuclei. Note that in the copper investigation of Bouamrane et al., ${ }^{36}$ nucleation and 
growth of copper weren't discussed; in that study, however, $\mathrm{H}_{2} \mathrm{SO}_{4}$ was the supporting electrolyte.

Two groups reported the incomplete stripping of silver from BDD electrodes. Saterlay et al., ${ }^{28}$ cycled a BDD electrode from -0.25 to $+0.75 \mathrm{~V}$ in solutions of $1 \mathrm{mM} \mathrm{Ag}^{+}$ in nitric acid. SEM and X-ray Photoelectron Spectroscopy (XPS) revealed that the silver deposit had remained on the BDD surface. Vinokur et al. ${ }^{6}$ observed that $\mathrm{Ag}^{0}$ deposits remained on the BDD even after potentials up to $+1.9 \mathrm{~V}$ were applied.

The deposition of certain metals appears to proceed differently at BDD and GC electrodes. Prado et al. ${ }^{5}$ studied the simultaneous deposition of lead and copper at BDD electrodes using cyclic voltammetry in $0.1 \mathrm{M} \mathrm{HNO}_{3}$. The $\mathrm{CV}$ of the anodic scan contained an unexpected reduction peak, which was attributed to hydrogen evolution on copper nuclei. It was inferred that during the cathodic scan, copper nuclei formed first, and then deposition of lead took place on top of the copper nuclei. During the anodic scan, lead was oxidized, exposing the copper nuclei to acidic solution. Others had observed that the deposition of lead and copper on GC electrodes proceeded via intermetallic mixing of the two metals. ${ }^{52-55}$ An explanation for the disparate deposition mechanisms for these metals on the BDD versus the GC electrode wasn't provided.

These examples which used higher metal concentrations have revealed important features about the behavior of metals at BDD electrodes. Non-diamond carbon appears to play a role, and can be electrochemically treated to facilitate deposition. Nucleation and growth clearly occurs on BDD electrodes, indicating that the sites for metal deposition have various activities. The deposition of lead and copper occurs differently at $\mathrm{BDD}$ and glassy carbon electrodes. This information was pertinent to us as we began 
our endeavor to detect trace concentrations of mercury, cadmium, lead, and copper using the BDD electrode. 


\section{Chapter 2: The Behavior of Mercury at the Unpolished Boron-Doped Diamond Electrode in $\mathrm{KNO}_{3}, \mathrm{KCl}$, and $\mathrm{KSCN}$ Solutions}

\section{Introduction}

\section{Background}

The goal of this work was to detect mercury in samples collected from the flue gas of coal-burning power plants using anodic stripping voltammetry and the BDD electrode. This work is vital to our understanding of the sources of mercury into the environment, and can impact regulations and the design of pollution control systems. Although the use and disposal of mercury is strictly regulated, mercury still enters the environment via the atmosphere through the burning of coal which contains trace amounts of mercury. ${ }^{56}$

The samples are collected from power plants according to the Ontario Hydro Method, ${ }^{57}$ which separates the oxidized and elemental forms of mercury. The flue gas passes through a filter which captures particulate mercury, and then is bubbled through a series of solutions where speciation occurs. Oxidized mercury is captured in chloridecontaining solutions; this form of mercury is stabilized by the formation of a complex with chloride ions. Elemental mercury is captured in either peroxide or permanganate solutions; as soon as the elemental mercury is bubbled into these solutions, it is oxidized and hence trapped. Although this sample collection method distinguishes oxidized mercury from elemental mercury, the collection solutions all contain the oxidized form. Our work has focused on the detection of mercury in the presence of chloride, which would correspond to the solution used to capture the oxidized form of mercury. 
Cold vapor atomic absorption spectrophotometry is a widely accepted method for trace analysis of mercury in aqueous samples. This method yields detection limits in the parts-per-trillion range, and some commercial manufacturers offer automated instruments which can be installed directly at the smoke stack. However, these types of field instruments are expensive, bulky, and often yield questionable results. ${ }^{58}$ An electrochemical method would have the advantages of smaller size and portability at a cheaper cost. The diamond electrode is an attractive material for this type of analysis due to its inertness, ruggedness, and has been used successfully to detect trace amounts of other metal ions, ${ }^{4,45-49}$ as mentioned in Chapter 1.

\section{Electrochemical Detection of Mercury: Literature Review}

Since the goal of this work is to detect low ppb levels of $\mathrm{Hg}^{2+}$ in solutions containing high chloride, a review of the progress made in this area is appropriate. A review of successful analyses of mercury at the low ppb level using glassy carbon and gold electrodes in various solutions has been made. The only report ${ }^{47}$ in the literature of trace analysis of mercury using BDD electrodes was mentioned in Chapter 1. The reduction and oxidation of higher concentrations of mercury are also reviewed, particularly those studies which considered the possibility of calomel formation.

\section{Trace Analysis of Mercury using Glassy Carbon and Gold Electrodes}

The detection of $\mathrm{Hg}^{2+}$ is more difficult at carbon electrodes than at gold electrodes, due to the weaker attraction between elemental mercury and the carbon electrode substrate, ${ }^{59}$ and the "nucleation and growth" deposition mechanism of mercury 
at carbon electrodes. ${ }^{7}$ Therefore, analysis of mercury using carbon electrodes usually involves "special measures," such as depositing for extremely long times, ${ }^{65-67}$ rotating the electrode to increase mass transport of $\mathrm{Hg}^{2+}$ ions, ${ }^{65-66}$ or adding an auxiliary element to provide a "support" on which the $\mathrm{Hg}^{0}$ may deposit. ${ }^{64-66}$

Meyer et al. ${ }^{60}$ observed linear behavior for $0.01 \mathrm{ppt}-0.2 \mathrm{ppt} \mathrm{Hg}^{2+}$ in $1 \mathrm{M} \mathrm{KSCN}$ (pH 3) using a rotating glassy carbon disk electrode and a deposition time and potential of 40 minutes and $-1.5 \mathrm{~V}$, respectively. Thiocyante is a good medium for mercury detection, due it its ability to complex mercuric ions. The RSD's for these concentrations were not given, but the error bars for $5 \times 10^{-14} \mathrm{M}(0.01 \mathrm{ppt})$ and $1 \times 10^{-13} \mathrm{M}(0.02 \mathrm{ppb})$ almost overlapped in the calibration curve. Other linear ranges at higher concentrations were also observed using 30 and 20-minute deposition times.

Kiekens et al. ${ }^{61}$ also were successful in detecting mercury using a rotating glassy carbon disk electrode in $\mathrm{SCN}^{-}$medium. In $1 \mathrm{M} \mathrm{NaSCN}+0.01 \mathrm{M} \mathrm{HClO}_{4}, 0.4 \mathrm{ppb} \mathrm{\textrm {Hg } ^ { 2 + }}$ was detected using a deposition time and potential of 20 minutes and $-1.5 \mathrm{~V}$, respectively. This was lower than what Meyer ${ }^{60}$ detected at 20 minutes of deposition. The relative standard deviation for $0.4 \mathrm{ppb} \mathrm{Hg}^{2+}$ was $22 \%$, and the linear range extended to almost 20 ppb. The low detection limit was due to the addition of $10^{-6} \mathrm{M} \mathrm{Cd}^{2+}$ as an auxiliary element. Without $\mathrm{Cd}^{2+}$ and with no $\mathrm{SCN}^{-}$present, 1 ppb $\mathrm{Hg}^{2+}$ was detected in $0.1 \mathrm{M}$ $\mathrm{HClO}_{4}$, but longer deposition times were needed. The auxiliary element was chosen based on its strong affinity for the carbon substrate and its ability to dissolve $\mathrm{Hg}^{0}$. Kiekens ${ }^{61}$ noted that although copper would have made a suitable auxiliary element, its deposition was hindered at the extremely negative potentials required for this work. 
A one-hour deposition time was used to detect part-per-trillion (ppt) levels of $\mathrm{Hg}^{2+}$ in acidified seawater at a graphite electrode by Fukai et al. ${ }^{62}$ The solution was stirred during deposition, and medium exchange, in which the stripping step occurred in a separate solution, was performed. The stripping solution was $0.005 \mathrm{M} \mathrm{HClO}_{4}$. The calibration curve for $10-60 \mathrm{ppt} \mathrm{Hg}^{2+}$ curved upward, but linear behavior was observed when the square root of the current was plotted against mercury concentration. Using

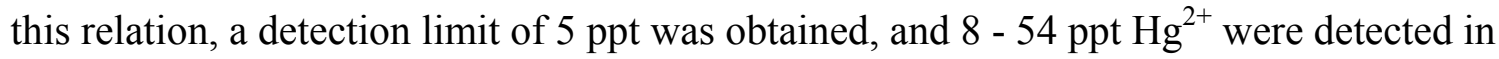
sea water samples. This concentration was similar to the mercury concentrations reported by others for sea water samples.

It is clear from the above examples that detection of $\mathrm{Hg}^{2+}$ at carbon electrodes requires long deposition times and very negative deposition potentials. The work done at gold electrodes generally requires shorter deposition times; in fact, the EPA standard method ${ }^{64}$ for electrochemical detection of $\mathrm{Hg}^{2+}$ uses a thin film of gold plated onto a glassy carbon electrode, and provides detection limits of 0.1 and 3 ppb using 10- and 1minute deposition times. Sipos et al. ${ }^{65}$ used a twin disc rotating gold electrode, and achieved detection of $40 \mathrm{ppt} \mathrm{Hg}^{2+}$ in sea water using a 15-minute deposition time. Scholtz et al. ${ }^{66}$ exploited the strong affinity of $\mathrm{Hg}^{0}$ for gold in the analysis of air samples. The deposition mechanism was simply sorption of $\mathrm{Hg}^{0}$ vapor onto a rotating gold-plated platinum electrode. The electrode was then transferred to a stripping solution (sat'd $\mathrm{K}_{2} \mathrm{SO}_{4}+30 \mathrm{ppm} \mathrm{SCN}$ ), where calibration and quantification were performed. The detection limit in the air samples was $1.7 \mathrm{ng}$, but the calibration was non-linear below 40 ng. 
The most striking difference between how deposition of mercury occurs on carbon and gold electrodes was provided by Yoshida et al., ${ }^{59,67}$ who used atomic absorption spectroscopy in conjunction with electrochemical methods. Underpotential deposition (UPD) of mercury was observed at gold electrodes, but not at glassy carbon. Using the gold electrodes, ${ }^{67} 0.2-200 \mathrm{ppb} \mathrm{Hg}^{2+}$ was deposited from $0.5 \mathrm{M} \mathrm{HNO}_{3}$ at -500 $\mathrm{mV}$. The electrode was then removed from solution and analyzed in a quartz tube furnace where elemental mercury was desorbed from the electrode using a temperature ramp. The $\mathrm{Hg}^{0}$ desorbed from the gold electrode in distinct stages, which corresponded to the different stages of deposition: monolayer formation, adatom formation, and bulk deposit formation.

A higher mercury concentration, $240 \mathrm{ppb}$, was studied at the glassy carbon electrode by the same group. ${ }^{59}$ The purge gas was monitored via atomic absorption (AA) after it passed through the deposition solution, which was $0.5 \mathrm{M} \mathrm{HNO}_{3}$. Elemental $\mathrm{Hg}^{0}$ actually was detected in the purge gas, and the $\mathrm{Hg}^{0}$ concentration in the vapor increased over the course of the deposition step. The maximum was obtained when the potential was stepped to $+1.0 \mathrm{~V}$, that is, when the oxidation of the mercury deposit commenced. These observations implied that during deposition, $\mathrm{Hg}^{2+}$ ions were reduced to elemental mercury, but that the elemental mercury did not adhere to the glassy carbon surface; instead, it diffused away from the electrode and into the bulk solution, where it was purged out of solution. When the potential was stepped, an oxidation current was measured, but most of the mercury deposit was stripped from the electrode surface without being oxidized to $\mathrm{Hg}^{2+}$. This behavior was dependent on the $\mathrm{Hg}^{2+}$ concentration in solution; at $\mathrm{Hg}^{2+}$ concentrations $\leq 150 \mathrm{ppb}$, most of the $\mathrm{Hg}^{0}$ was purged out of the 
solution and very little actually deposited on the electrode surface. It was found that a longer deposition time or more negative deposition potential did not result in a larger amount of $\mathrm{Hg}^{0}$ deposit on the electrode when using solutions containing $\leq 150 \mathrm{ppb} \mathrm{Hg}^{2+}$.

\section{Analysis of Mercury at Higher Concentrations using Various Electrodes}

Studies involving higher concentrations of mercury are important, because they have revealed information regarding the mechanism of reduction and oxidation of mercury. Stulikova ${ }^{8}$ used the ideas of "active sites" and "nucleation and growth" to explain the shape of mercury stripping peaks which often contained small shoulders more

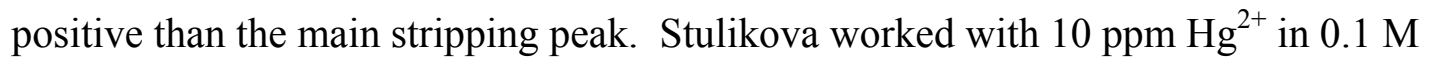
$\mathrm{HNO}_{3}$, a non-complexing electrolyte, and he suggested that the main stripping peak corresponded to the oxidation of mercury from a mercury nucleus (or substrate), while the shoulder corresponded to the oxidation of the mercury nucleus from the bare glassy carbon surface. When relatively positive deposition potentials were used, only one shoulder was observed meaning that mercury nuclei were oxidized from one site on the glassy carbon surface; however, when a more negative deposition potential was applied, more shoulders appeared, implying that the mercury nuclei were oxidized from different sites on the electrode surface. Therefore, it was concluded that the glassy carbon electrode contained sites of various activities toward $\mathrm{Hg}^{2+}$ deposition, and their activities are increased at more negative deposition potentials. The shoulders were not observed in $\mathrm{SCN}^{-}$medium. Although Stulikova did not explain this observation, it may be related to the complexing property of the $\mathrm{SCN}^{-}$medium as opposed to the $\mathrm{NO}_{3}{ }^{-}$medium. 
Kiekens et al. ${ }^{61}$ observed similar behavior in $0.1 \mathrm{M} \mathrm{KNO}_{3}+0.01 \mathrm{M} \mathrm{HNO}_{3}$ using $1 \mathrm{ppm} \mathrm{Hg}^{2+}$ and a rotating GC electrode. A main stripping peak $(+500 \mathrm{mV})$ and a smaller shoulder $(+600 \mathrm{mV})$ were observed. Kiekens explained the shoulder at $+600 \mathrm{mV}$ as the stripping of a monolayer from the GC surface, although this explanation contradicts the earlier work of Yoshida's studies (of $240 \mathrm{ppb} \mathrm{Hg}^{2+}$ ), who concluded that no monolayer formed between $\mathrm{Hg}^{0}$ and glassy carbon, ${ }^{64}$ as well as that of Stulikova who stated that deposition occurred only at active sites on the GC surface. ${ }^{8}$

Dhaneshwar et al. ${ }^{68}$ worked in $1 \mathrm{M} \mathrm{KNO}_{3}+0.02 \mathrm{M} \mathrm{HNO}_{3}$ with a rotating vitreous carbon electrode (VCE) to study the reduction of $\mathrm{mM}$ levels of $\mathrm{Hg}^{2+}$. The potential was scanned repeatedly from $+600 \mathrm{mV}$ to $0 \mathrm{mV}$. It was found that the reduction of $\mathrm{Hg}^{2+}$ proceeded directly to $\mathrm{Hg}^{0}$ on the bare VCE, as shown below:

$$
\mathrm{Hg}^{2+}+2 \mathrm{e}^{-} \rightarrow \mathrm{Hg}^{0}
$$

The bare VCE was generated by application of a cleaning potential of $+800 \mathrm{mV}$ for 1 minute between each run. When the cleaning potential was not applied between scans, the reduction of $\mathrm{Hg}^{2+}$ occurred according to the two reactions below:

$$
\begin{array}{ll}
\mathrm{Hg}_{2}{ }^{2+}+2^{-} \rightarrow \mathrm{Hg}^{0} & \mathrm{E}_{1 / 2}=+400 \mathrm{mV} \\
\mathrm{Hg}^{2+}+2 \mathrm{e}^{-} \rightarrow \mathrm{Hg}^{0} & \mathrm{E}_{1 / 2}=+300 \mathrm{mV}
\end{array}
$$

Since the cleaning potential was not applied before the scan, mercurous ion could form through the disproportionation of $\mathrm{Hg}^{2+}$ ions which reacted with $\mathrm{Hg}^{0}$ remaining on the electrode surface after the scan to $0 \mathrm{mV}$ :

$$
\mathrm{Hg}^{2+}+\mathrm{Hg}^{0} \rightarrow \mathrm{Hg}_{2}{ }^{2+} \quad \mathrm{K}=1.3 \times 10^{2}
$$


The mercurous ions were reduced presumably on the $\mathrm{Hg}^{0}$ droplets at $+400 \mathrm{mV}$, followed by the reduction of $\mathrm{Hg}^{2+}$ ions at $+300 \mathrm{mV}$. It wasn't clear if reaction 4 took place between runs under open circuit conditions.

The oxidation of $\mathrm{Hg}^{2+}$ was studied by Kiekens et al. ${ }^{61}$ in $0.1 \mathrm{M} \mathrm{HClO}_{4}$, a noncomplexing electrolyte, and NaSCN, a complexing electrolyte, using a glassy carbon rotating ring disk electrode. In $\mathrm{ClO}_{4}{ }^{-}$medium, mercurous ions were detected at the ring, but in $\mathrm{SCN}^{-}$, they were not. It was proposed that in both complexing and noncomplexing electrolytes, oxidation of the $\mathrm{Hg}^{0}$ deposit occurred directly to $\mathrm{Hg}^{2+}$; however, in the non-complexing electrolyte, the $\mathrm{Hg}^{2+}$ reacted with $\mathrm{Hg}^{0}$ remaining on the GC surface to form $\mathrm{Hg}_{2}{ }^{2+}$ (reaction 4). In the complexing electrolyte, as soon as elemental $\mathrm{Hg}^{0}$ was oxidized, the $\mathrm{Hg}^{2+}$ ions were immediately bound by $\mathrm{SCN}^{-}$which formed a soluble, stable complex so that reaction 4 couldn't occur. This also explained why lower stripping currents were typically observed in non-complexing electrolytes: $\mathrm{Hg}^{2+}$ ions consumed a large portion of the $\mathrm{Hg}^{0}$ deposit (reaction 4), so that less $\mathrm{Hg}^{0}$ was oxidized during the stripping step.

If disproportionation occurs in the presence of chloride, the mercurous ions can precipitate with chloride to form the slightly soluble calomel salt: ${ }^{69}$

$$
\mathrm{Hg}_{2} \mathrm{Cl}_{2} \leftrightarrow \mathrm{Hg}_{2}{ }^{2+}+2 \mathrm{Cl}^{-} \quad \mathrm{K}_{\mathrm{sp}}=1.3 \times 10^{-18}
$$

Chloride can also act as a complexing agent for mercuric ions as shown by the complex formation reactions below: ${ }^{69}$

$$
\begin{array}{ll}
\mathrm{Hg}^{2+}+\mathrm{Cl}^{-} \rightarrow \mathrm{HgCl}^{+} & \beta_{1}=5.5 \times 10^{6} \\
\mathrm{Hg}^{2+}+2 \mathrm{Cl}^{-} \rightarrow \mathrm{HgCl}_{2} & \beta_{2}=1.7 \times 10^{13} \\
\mathrm{Hg}^{2+}+3 \mathrm{Cl}^{-} \rightarrow \mathrm{HgCl}_{3}^{-} & \beta_{3}=1.2 \times 10^{14}
\end{array}
$$




$$
\mathrm{Hg}^{2+}+4 \mathrm{Cl}^{-} \rightarrow \mathrm{HgCl}_{4}{ }^{2-} \quad \quad \beta_{4}=1.2 \times 10^{15}
$$

As mentioned earlier, the oxidation of mercury in complexing electrolytes such as $\mathrm{Cl}^{-}$ should proceed directly to the mercuric ion; however, if the chloride concentration is not high enough to complex the stripped mercuric ions, calomel can form during the stripping step through the reaction between the mercuric ions, elemental mercury on the electrode surface, and chloride ions in the supporting electrolyte. ${ }^{63,70}$ Calomel can also form under open circuit conditions if there is elemental mercury on the electrode surface; this has been observed at mercury thin film electrodes $(\mathrm{MTFE})^{70-72}$. However, there is conflicting information in the literature regarding the conditions necessary for calomel formation and its electrochemical behavior.

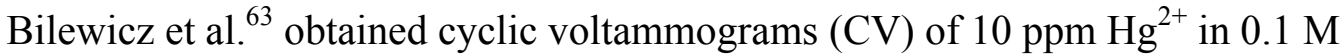
$\mathrm{HCl}$ between $-300 \mathrm{mV}$ and $+500 \mathrm{mV}$ at graphite electrodes. During the first scan in the negative direction, reduction of $\mathrm{Hg}^{2+}$ commenced at $\sim-100 \mathrm{mV}$, but during the second cathodic scan, the reduction commenced at a more positive potential, $\sim+50 \mathrm{mV}$. This implied that $\mathrm{Hg}_{2} \mathrm{Cl}_{2}$ had formed on the electrode surface over the course of the anodic scan, and made the reduction of mercury "easier" in the second scan. The identity of the reduction peak of the second scan (which occurred at a more positive potential) wasn't clear. They didn't state if it was the reduction of $\mathrm{Hg}_{2} \mathrm{Cl}_{2}$, or the reduction of $\mathrm{Hg}^{2+}$ ions on a calomel-coated surface. However, in a separate experiment, mercury films of various thicknesses were deposited on the graphite electrode from $\mathrm{SCN}^{-}$solution, and then transferred to $0.1 \mathrm{M} \mathrm{NaCl}$. On the relatively thinner films, two reduction peaks were observed, one at $\sim 0 \mathrm{mV}$, and the other more negative, at $\sim-600 \mathrm{mV}$. These were attributed to the reduction of calomel in contact with $\mathrm{Hg}^{0}$ droplets $(0 \mathrm{mV})$ or the bare 
graphite surface $(-600 \mathrm{mV})$. In short, the reduction of calomel was observed on both $\mathrm{Hg}^{0}$ and the bare carbon surface.

When calomel forms at the MTFE, its reduction peak is observed between -800 and $-300 \mathrm{mV}$, and can interfere with the detection of metals that are oxidized in this region. The conditions under which calomel may form depends on chloride concentration. Jagner et al. ${ }^{71}$ observed calomel formation at $\mathrm{Cl}^{-}$concentrations less than $3 \mathrm{M}$, but Nolan et al. ${ }^{72}$ observed calomel at $\mathrm{Cl}^{-}$concentrations less than $0.5 \mathrm{M}$. Jagner monitored the electrode surface during the deposition and stripping steps microscopically, and observed that $\mathrm{Hg}^{2+}$ could deposit under or in between the calomel crystals at high $\mathrm{Hg}^{2+}$ concentrations and long deposition times. It was observed that calomel was only reduced when in contact with the elemental mercury, which conflicts with the observation by Bilewicz that calomel could be reduced at both $\mathrm{Hg}^{0}$ and bare graphite.

There is a peculiar feature about the reduction of calomel formed at the MTFE under open circuit conditions: it is not reduced during the deposition step. It is reduced during the stripping step when the potential is scanned positive, at about $-600 \mathrm{mV}$. Although this is counterintuitive, it has been proposed (by both Jagner and Nolan), that calomel is stable at negative potentials because of its crystalline orientation on the electrode surface. Jagner monitored the current during deposition at $-850 \mathrm{mV}$ and observed cathodic peaks over the course of the deposition, even though calomel was not reduced at this potential. The cathodic peaks were attributed to the "reorientation" of calomel on the electrode surface. But Nolan suggested another explanation: the cathodic peaks were the result of the reduction of calomel which was electrochemically generated, 
implying that there can be two forms of calomel on the electrode surface, one nonelectrochemically generated under open circuit conditions between runs, and the other electrochemically generated during the stripping of the Hg-film. ${ }^{70}$ The so-called electrochemically-generated calomel wasn't formed by the direct oxidation of $\mathrm{Hg}^{0}$ to $\mathrm{Hg}_{2}^{2+}$; it was formed during the stripping step by the reaction between the stripped $\mathrm{Hg}^{2+}$ ions and the $\mathrm{Hg}^{0}$ remaining on the surface (reaction 4).

These studies which involved higher concentrations of mercury were useful to us as we set out to detect trace levels of mercury in the presence of high chloride using the BDD electrode.

\section{Experimental}

Anodic stripping voltammetry (ASV) was performed at unpolished boron-doped diamond (BDD) electrodes, which were grown on silicon substrates using chemical vapor deposition as described elsewhere. ${ }^{46}$ A small square $\left(\approx 1 \mathrm{~cm}^{2}\right)$ of the BDD was placed in a homemade electrochemical cell, shown in Figure 4. The entire cell is shown in Figure $4 \mathrm{a}$, and consisted of a water-jacketed glass vessel threaded at the bottom. As shown in Figure $4 \mathrm{~b}$, the BDD electrode rested on a copper plate with the silicon side touching the copper. The copper plate was connected to a solid copper rod, which was housed in a Delrin tube. Connection to the potentiostat was made at the bottom of the copper rod. The BDD electrode was secured by placing an o-ring on top of it, followed by a Delrin cap, which was pressed tightly onto the o-ring. The cap was secured by screws which made contact with the Delrin tube. The cap was machined with threads to allow easy placement of the entire assembly into the glass cell shown in Figure 4a. Installation of 


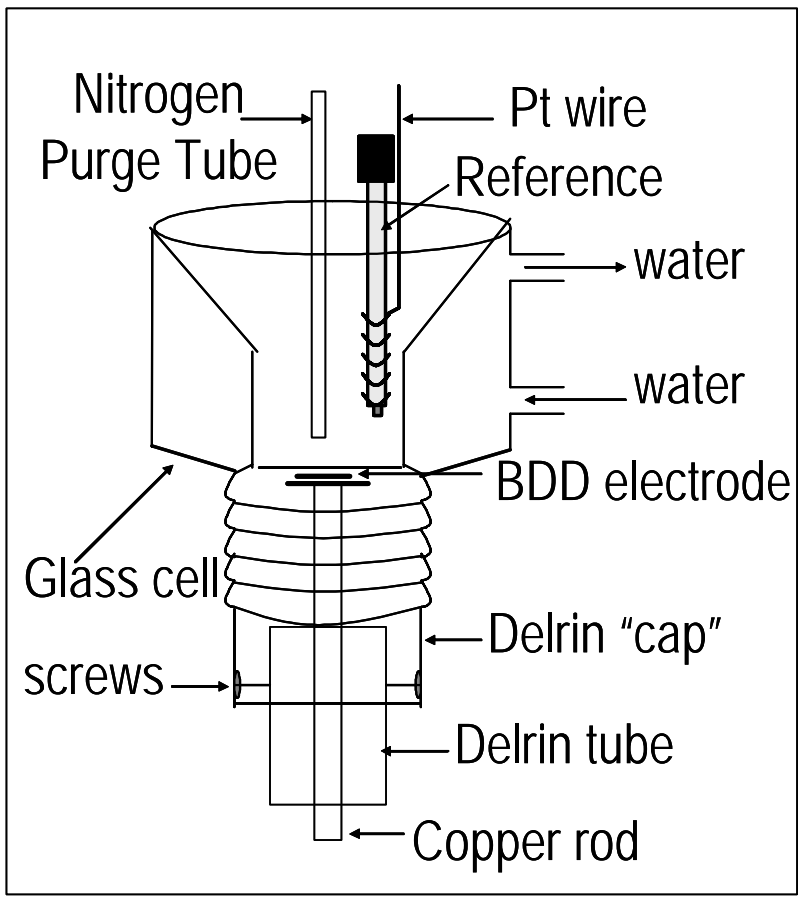

(a)

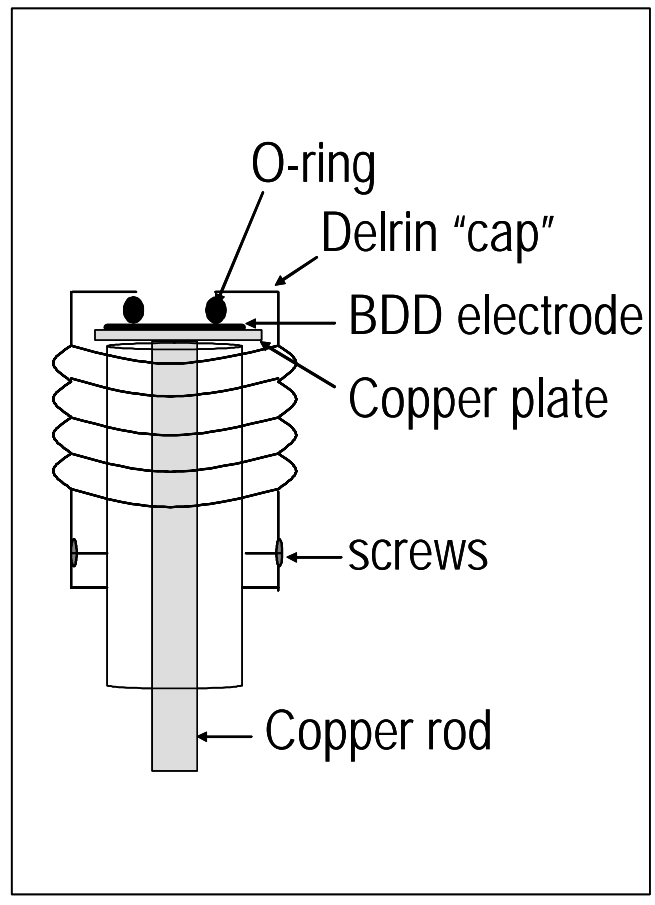

(b)

Figure 4. Diagram of the Electrochemical Cell

(a) The entire cell; (b) Diagram showing how the BDD electrode is placed into the cell. 
the BDD electrode in this manner provided a water-tight seal, along with the flexibility to change BDD electrodes easily without using epoxy.

The BDD electrode was acid-washed with either concentrated or $50 \% \mathrm{v} / \mathrm{v}$ nitric acid. The reference and auxiliary electrodes were a double junction $\mathrm{Ag} / \mathrm{AgCl} / \mathrm{sat}$ 'd $\mathrm{KCl}$ and a platimum wire, respectively. In some experiments, a 7-mm bare glassy carbon electrode (Bioanalytical Systems, West Lafayette, IN) was used. It was polished with $0.05 \mu \mathrm{m}$ alumina particles and polishing cloth prior to analysis.

Osteryoung square wave anodic stripping voltammetry was performed using a Bioanalytical Systems (Lafayette, IN) Model 100B electrochemical analyzer. The deposition time and potential were varied, but were between 2 and 20 minutes and -500 $\mathrm{mV}$ and $-1.00 \mathrm{~V}$, respectively. The stripping parameters were also varied but usually were as follows: frequency, $15 \mathrm{~Hz}$; square wave amplitude, $25 \mathrm{mV}$; and step potential, 4 $\mathrm{mV}$. All solutions were stirred by purging with nitrogen during the deposition step, and the stripping step was performed under quiet conditions.

The supporting electrolyte was prepared from reagent grade salts of potassium nitrate, potassium chloride, or potassium thiocyanate. Certified 1000 ppm mercury reference solution (Fisher) was diluted to make a $100 \mathrm{ppm}$ stock solution, which was used in the standard addition experiments. An Eppendorf micropipette with disposable tips was used to add microliter amounts of the stock solution to the cell with negligible dilution of the sample. Only nanopure water $(\Omega<18)$ was used in the preparation of all solutions. A 50.0-mL aliquot of supporting electrolyte was delivered to the cell and sparged with nitrogen gas for at least 15 minutes. Before the ASV experiments, three 
cyclic voltammograms (CV's) were acquired from $-1.00 \mathrm{~V}$ to $+0.60 \mathrm{~V}$ at a scan rate of $100 \mathrm{mV} / \mathrm{s}$.

\section{Results and Discussion}

\section{Overview}

Our intention was to detect mercury in samples containing high chloride and low $\mathrm{pH}$, but the detection of mercury was not straightforward. Although we began working in chloride solutions, unstable currents led us to investigate the behavior of mercury in nitrate and thiocyanate solutions, where calomel formation didn't complicate the analysis. We also compared the behavior of mercury at the BDD electrode to that at the GC electrode. All the results discussed below were obtained with unpolished BDD electrodes.

\section{Behavior of Mercury in $\mathrm{KNO}_{3}$}

The behavior of $\mathrm{Hg}^{2+}$ was studied in $\mathrm{KNO}_{3}$ medium in order to avoid any complications arising from calomel formation in chloride medium. Although this section is focused on the behavior of $\mathrm{Hg}^{2+}$ in $\mathrm{KNO}_{3}$ at the $\mathrm{BDD}$ electrode, some observations in $\mathrm{KCl}$ are made for comparison. Also, the behavior of $\mathrm{Hg}^{2+}$ in $\mathrm{KNO}_{3}$ at the $\mathrm{BDD}$ electrode is contrasted to that at the GC electrode.

Voltammograms for $200 \mathrm{ppb} \mathrm{Hg}^{2+}$ in $\mathrm{KNO}_{3}$ and $\mathrm{KCl}$ using the $\mathrm{BDD}\left(15^{\text {th }}\right.$ repetition each) are shown in Figure 5. The stripping potentials in $\mathrm{KCl}$ and $\mathrm{KNO}_{3}$ are -56 $\mathrm{mV}$ and $+300 \mathrm{mV}$, respectively, and the respective stripping currents are 0.2767 and $0.08173 \mu \mathrm{A}$. The stripping peak obtained in $\mathrm{KCl}$ is much sharper than that in $\mathrm{KNO}_{3}$, due 


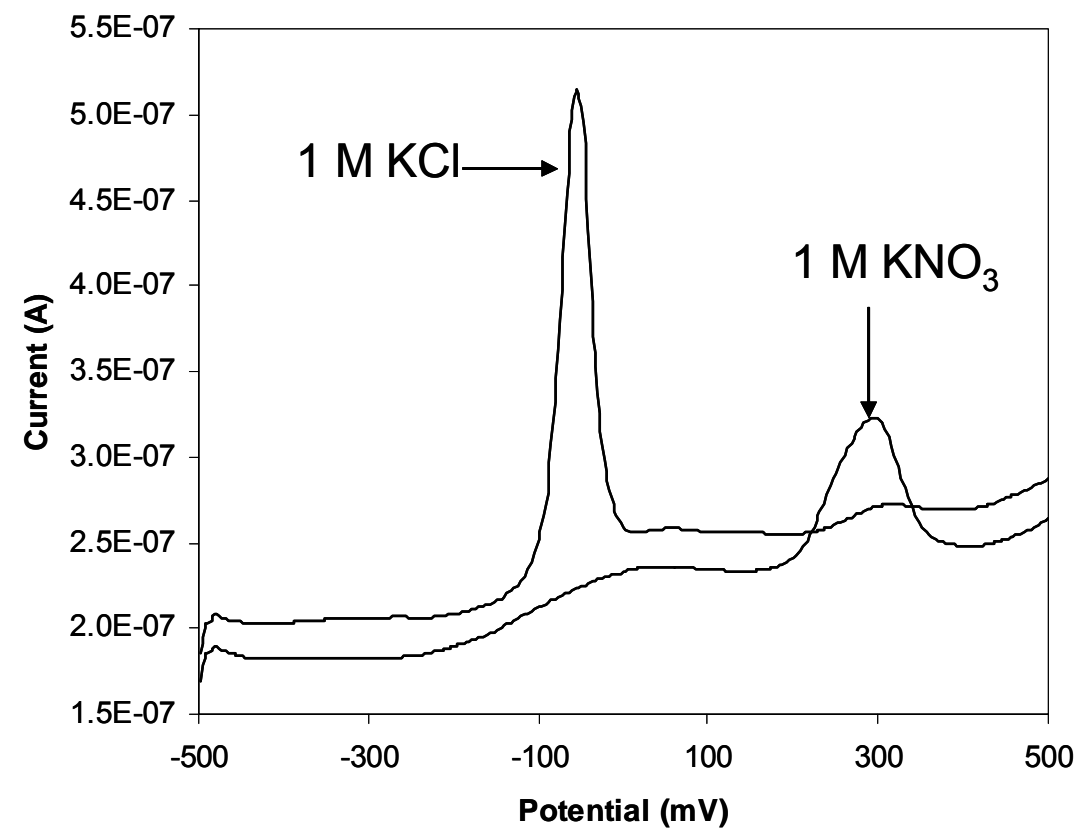

Figure 5. Comparison of $200 \mathrm{ppb} \mathrm{Hg}^{2+}$ in $1 \mathrm{M} \mathrm{KNO}_{3}$ and $1 \mathrm{M} \mathrm{KCl}$

$\mathrm{pH} \sim 5$, Unpolished BDD, Deposition Potential $=-500 \mathrm{mV}$, Deposition Time $=2$ minutes, Final Potential $=+500 \mathrm{mV}$, Frequency $=15 \mathrm{~Hz}$, Pulse Amplitude $=25 \mathrm{mV}$, Step Potential $=4 \mathrm{mV}$, Stirred Deposition. 
to complex formation between $\mathrm{Hg}^{2+}$ ions and chloride.

The behavior of $200 \mathrm{ppb} \mathrm{Hg}^{2+}$ in $1 \mathrm{M} \mathrm{KNO}_{3}$ at the BDD electrode using 2- and 5minute deposition times was investigated. As shown in Figure 6, repeated measurements of $200 \mathrm{ppb} \mathrm{Hg}^{2+}$ (with the exception of the $2^{\text {nd }}$ measurement) resulted in stripping currents that decreased with repetition. Interestingly, the opposite trend was observed at the glassy carbon (GC) electrode, as shown in Figure 7, where the stripping current for $200 \mathrm{ppb} \mathrm{Hg}^{2+}$ increased with repetition. The peak potential of mercury at the BDD electrode was $+300 \mathrm{mV}$, while that at the $\mathrm{GC}$ electrode was $+190 \mathrm{mV}$. The reason why the current decreased on the BDD electrode, and increased on the GC electrode is not known. An attempt to explain this behavior will consider the formation of a mercuric oxide precipitate at both electrodes.

It is possible for mercuric oxide to precipitate near the surface of the electrode, because the concentration of $\mathrm{Hg}^{2+}$ ions generated in the diffusion layer during the stripping step can be much greater than that in the bulk solution, and may in fact exceed the solubility product for $\mathrm{HgO}$. After mercury is stripped, the $\mathrm{Hg}^{2+}$ ions can either be complexed by hydroxide ions, according to reactions $7 \mathrm{a}-7 \mathrm{~d}$ ( $0 \mathrm{M}$ ionic strength), or can react with water to form the $\mathrm{HgO}$ precipitate, whose solubility product is shown in reaction $8 .^{69}$

$$
\begin{array}{ll}
\mathrm{Hg}^{2+}+\mathrm{OH}^{-} \leftrightarrow[\mathrm{HgOH}]^{+} & \beta_{1}=4 \times 10^{10} \\
\mathrm{Hg}^{2+}+2 \mathrm{OH}^{-} \leftrightarrow\left[\mathrm{Hg}(\mathrm{OH})_{2}\right] & \beta_{2}=6 \times 10^{21} \\
\mathrm{Hg}^{2+}+3 \mathrm{OH}^{-} \leftrightarrow\left[\mathrm{Hg}(\mathrm{OH})_{3}\right]^{-} & \beta_{3}=7 \times 10^{20} \\
2 \mathrm{Hg}^{2+}+\mathrm{OH}^{-} \leftrightarrow\left[\mathrm{Hg}_{2} \mathrm{OH}\right]^{3+} & \beta_{2 \mathrm{a}}=5 \times 10^{10} \\
3 \mathrm{Hg}^{2+}+3 \mathrm{OH}^{-} \leftrightarrow\left[\mathrm{Hg}_{3}(\mathrm{OH})_{3}\right]^{3+} & \beta_{3 \mathrm{a}}=4 \times 10^{35}
\end{array}
$$




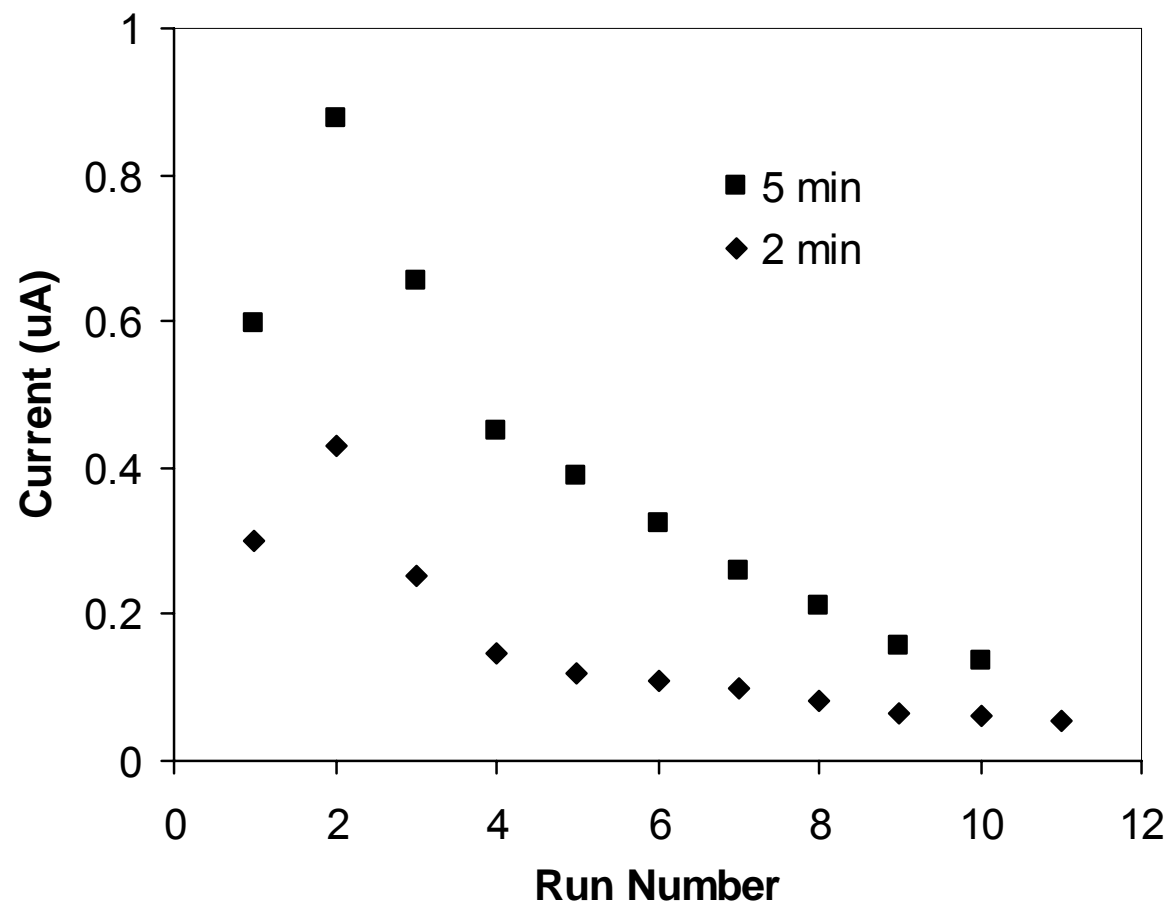

Figure 6. Behavior of $200 \mathrm{ppb} \mathrm{Hg}^{2+}$ in $1 \mathrm{M} \mathrm{KNO}_{3}$ at the Unpolished BDD Electrode

$\mathrm{pH} \sim 5$, Deposition Potential $=-500 \mathrm{mV}$, Final Potential $=+500 \mathrm{mV}$, Frequency $=$ $15 \mathrm{~Hz}$, Pulse Amplitude $=25 \mathrm{mV}$, Step Potential $=4 \mathrm{mV}$, Stirred Deposition. 


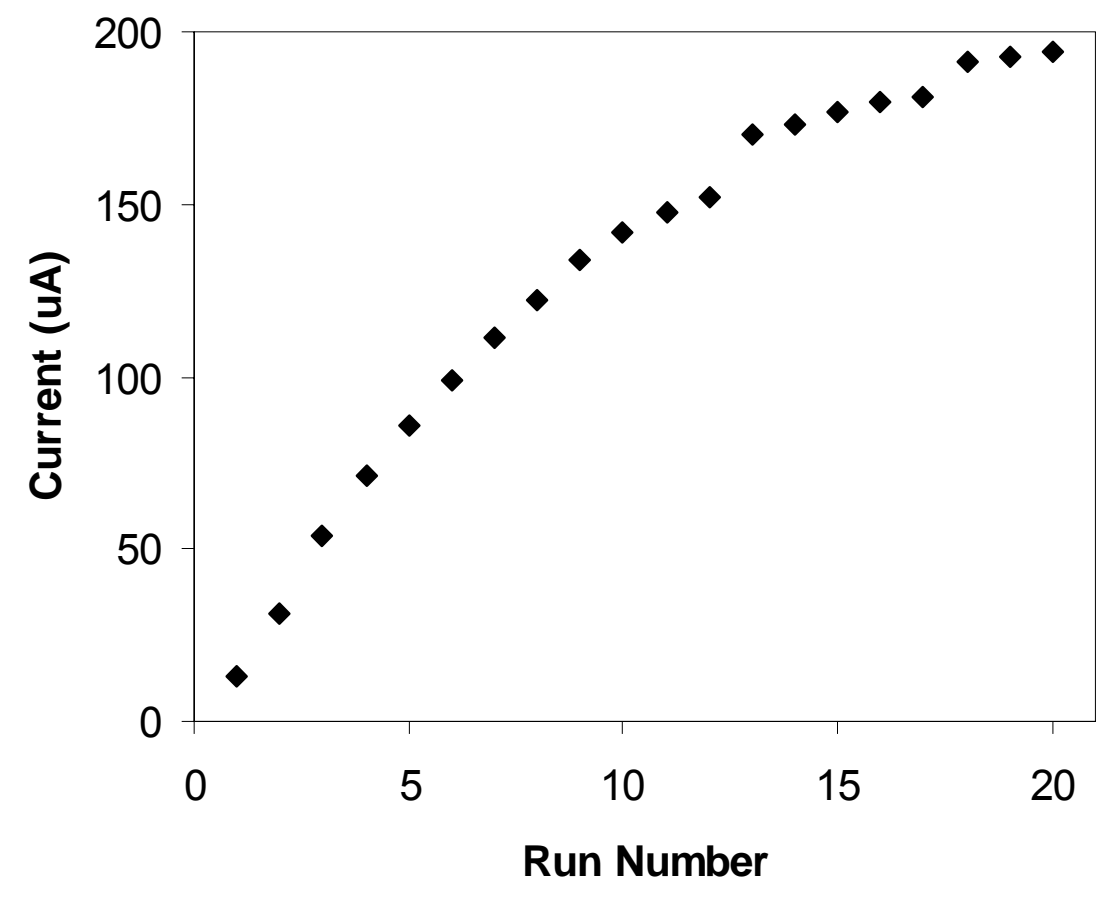

Figure 7. Behavior of $200 \mathrm{ppb} \mathrm{Hg}^{2+}$ in $1 \mathrm{M} \mathrm{KNO}_{3}$ at the Glassy Carbon Electrode

$\mathrm{pH} \sim 5$, Deposition Potential $=-500 \mathrm{mV}$, Final Potential $=+500 \mathrm{mV}$, Frequency $=$ $15 \mathrm{~Hz}$, Pulse Amplitude $=25 \mathrm{mV}$, Step Potential $=4 \mathrm{mV}$, Stirred Deposition. 


$$
\mathrm{HgO}_{(\mathrm{s})}+\mathrm{H}_{2} \mathrm{O} \leftrightarrow \mathrm{Hg}^{2+}+2 \mathrm{OH}^{-} \quad \quad \mathrm{K}_{\mathrm{sp}}=3.6 \times 10^{-26}
$$

The $\mathrm{HgO}$ precipitate is electrochemically active, as shown by the standard reduction halfreaction in equation 9.

$$
\mathrm{HgO}+\mathrm{H}_{2} \mathrm{O}+2 \mathrm{e}^{-} \leftrightarrow \mathrm{Hg}^{0}+2 \mathrm{OH}^{-} \quad \mathrm{E}^{0}=0.09777 \mathrm{~V} \text { vs. SHE }
$$

One can predict whether the concentration of stripped ions will exceed the solubility product with anions in solution by using the criterion derived by Buffle. ${ }^{73}$ The criterion was developed for mercury thin film electrodes (MTFE) and linear scan ASV. Buffle's criterion is shown in equation 10,

$$
\left(\mathrm{C}_{\mathrm{ox}}{ }^{\mathrm{s}}\right)\left(\mathrm{t}_{\mathrm{dep}}\right) \leq 1.28\left(\mathrm{~K}_{\mathrm{sp}} / \mathrm{C}_{\mathrm{A}}^{\mathrm{b}}\right)^{1 / \mathrm{a}}
$$

where $\mathrm{C}_{\mathrm{ox}}{ }^{\mathrm{s}}$ is the bulk concentration of $\mathrm{Ox}$ in molarity, $\mathrm{t}_{\mathrm{dep}}$ is the deposition time in seconds, $\mathrm{K}_{\mathrm{sp}}$ is the solubility product for the solid $\mathrm{Ox}_{\mathrm{a}} \mathrm{A}_{\mathrm{b}}$, $\mathrm{a}$ and $\mathrm{b}$ are the number of moles of $\mathrm{Ox}$ and $\mathrm{A}$ respectively in the solid, and $\mathrm{C}_{\mathrm{A}}$ is the bulk concentration of the anion in molarity. The criterion states that the product of $\mathrm{C}_{\mathrm{ox}}{ }^{\mathrm{s}}$ and $\mathrm{t}_{\mathrm{dep}}$ must be less than the right-hand side of the equation 10 to avoid precipitation. The constant (1.28) in equation 10 was calculated by Buffle using a scan rate of $30 \mathrm{mV} / \mathrm{sec}$ in the following equation

$$
\left.1.28=7.41\left[\delta^{\mathrm{d}} /\left(v \mathrm{D}_{\mathrm{ox}}\right)^{1 / 2}\right)\right]
$$

where $\delta^{\mathrm{d}}$ is the thickness of the diffusion layer during the deposition step, $v$ is the scan rate, and $D_{o x}$ is the diffusion coefficient of Ox. Substituting in our scan rate of 60 $\mathrm{mV} / \mathrm{sec}$, and typical values for $\delta^{\mathrm{d}}$ and $\mathrm{D}_{\mathrm{ox}}\left(3 \times 10^{-3} \mathrm{~cm}\right.$ and $\left.10^{-5} \mathrm{~cm}^{2} / \mathrm{sec}\right)$, one obtains the following criterion modified for our experiments:

$$
\left(\mathrm{C}_{\mathrm{ox}}^{\mathrm{s}}\right)\left(\mathrm{t}_{\mathrm{dep}}\right) \leq 0.908\left(\mathrm{~K}_{\mathrm{sp}} / \mathrm{C}_{\mathrm{A}}^{\mathrm{b}}\right)^{1 / \mathrm{a}}
$$

In our experiments involving $200 \mathrm{ppb} \mathrm{Hg}^{2+}$ in $\mathrm{KNO}_{3}$, the following values were substituted into equation $12: \mathrm{C}_{\mathrm{ox}}^{\mathrm{s}}=\left[\mathrm{Hg}^{2+}\right]_{\text {free }}=1.54 \times 10^{-10} \mathrm{M}, \mathrm{t}_{\mathrm{dep}}=120$ or $300 \mathrm{sec}, \mathrm{K}_{\mathrm{sp}}=$ 
$3.6 \times 10^{-26}, \mathrm{C}_{\mathrm{A}}=\left[\mathrm{OH}^{-}\right]=1 \times 10^{-9} \mathrm{M}(\mathrm{pH} 5), \mathrm{a}=1$, and $\mathrm{b}=2$ for 2 moles of $\mathrm{OH}^{-}$involved in the precipitation reaction (see equation 8). The bulk free concentration of $\mathrm{Hg}^{2+}\left(\mathrm{C}_{\mathrm{ox}}{ }^{\mathrm{s}}\right)$ was calculated from a mass balance and the equilibria in equations 7a-e. Using these values we find the following:

$$
\begin{aligned}
& 1.85 \times 10^{-8}<3.30 \times 10^{-8} \text { for a deposition time of } 120 \text { seconds, and } \\
& 4.62 \times 10^{-8}>3.30 \times 10^{-8} \text { for a deposition time of } 300 \text { seconds. }
\end{aligned}
$$

Thus, the Buffle criterion predicts that $\mathrm{HgO}$ will precipitate if the deposition time is 5 minutes, but none should precipitate if the deposition time is 2 minutes. The trends shown in Figure 6 for $200 \mathrm{ppb} \mathrm{Hg}^{2+}$ were similar at 2 and 5 minute deposition times, even though the Buffle equation predicts that $\mathrm{HgO}$ will precipitate at the electrode surface for only the 5-minute deposition time. Although the result of our calculation for 2 minutes, $1.85 \times 10^{-8}$, was less than the Buffle criterion, it wasn't that much less. In addition, one must also consider the thickness of the diffusion layer, $\delta$, which will affect the concentration of ions during the stripping step (if $\delta$ is thin, ions are more concentrated and vice versa). Buffle developed the criterion in equation 4 for a MTFE electrode, not a BDD or GC electrode, and assumed that $\delta$ was $3 \times 10^{-3} \mathrm{~cm}$. If the diffusion layers at the BDD or GC electrodes are smaller than $3 \times 10^{-3} \mathrm{~cm}$, the ions generated during the stripping step may by more concentrated, and thus precipitation of $\mathrm{HgO}$ may occur, even at a 2minute deposition time.

Carbon electrodes impregnated with $\mathrm{HgO}$ have been used as “portable” MTFE's, and it was shown that $\mathrm{HgO}$ was in fact reduced to elemental mercury. ${ }^{74}$ If precipitation of $\mathrm{HgO}$ can occur at both BDD and GC electrodes during the stripping step for a 2minute deposition time, it could attach to the electrode surface, and could be reduced to 
$\mathrm{Hg}^{0}$ during the deposition step of the next run. The elemental $\mathrm{Hg}^{0}$ formed from reduction of $\mathrm{HgO}$ can then act as a nucleation site for further deposition of $\mathrm{Hg}^{2+}$ ions from solution. (The electrode will behave like the impregnated $\mathrm{HgO}$ electrode mentioned above.) For the first run of an experiment, elemental $\mathrm{Hg}^{0}$ will be deposited onto the bare electrode surface. It is then stripped off, and the stripped $\mathrm{Hg}^{2+}$ ions react with $\mathrm{OH}^{-}$and form particles of $\mathrm{HgO}$ which attach to the electrode surface. In the next run, the deposition potential is applied to an electrode that is no longer bare, as shown in Figure 8a. It is (partially) covered with $\mathrm{HgO}$ particles that get reduced, and promote deposition of more $\mathrm{Hg}^{2+}$ ions than the first run by behaving as nucleation centers, as shown in Figure 8b. In this stripping step, more $\mathrm{HgO}$ is formed, since more elemental $\mathrm{Hg}^{0}$ was deposited. Thus, the current of the second run is larger than that of the first run. At the beginning of the $3^{\text {rd }}$ run, there are even more $\mathrm{HgO}$ particles on the surface to act as nucleation sites for $\mathrm{Hg}^{2+}$ reduction; hence, more $\mathrm{Hg}^{0}$ will be deposited on the electrode surface, and larger stripping currents will be obtained. Thus, all subsequent measurements will have larger currents. If this is the phenomenon that occurs, it should occur on both electrodes. The fact that the current increased at the $\mathrm{GC}$ electrode in $\mathrm{KNO}_{3}$ but decreased at the BDD electrode must be explained.

The $\mathrm{HgO}$ particles must have attached to the bare BDD electrode after the first run, since the current for the second run is larger than the first run. The $\mathrm{HgO}$ particles from the first run must have been reduced to $\mathrm{Hg}^{0}$ and behaved as nucleation sites for the deposition of $\mathrm{Hg}^{2+}$ in the second run. After the stripping step of the second run, there are even more $\mathrm{HgO}$ particles on the electrode (since more $\mathrm{Hg}^{0}$ was deposited). The current for the third run was smaller than that of the second run, as shown in Figure 6. At the 


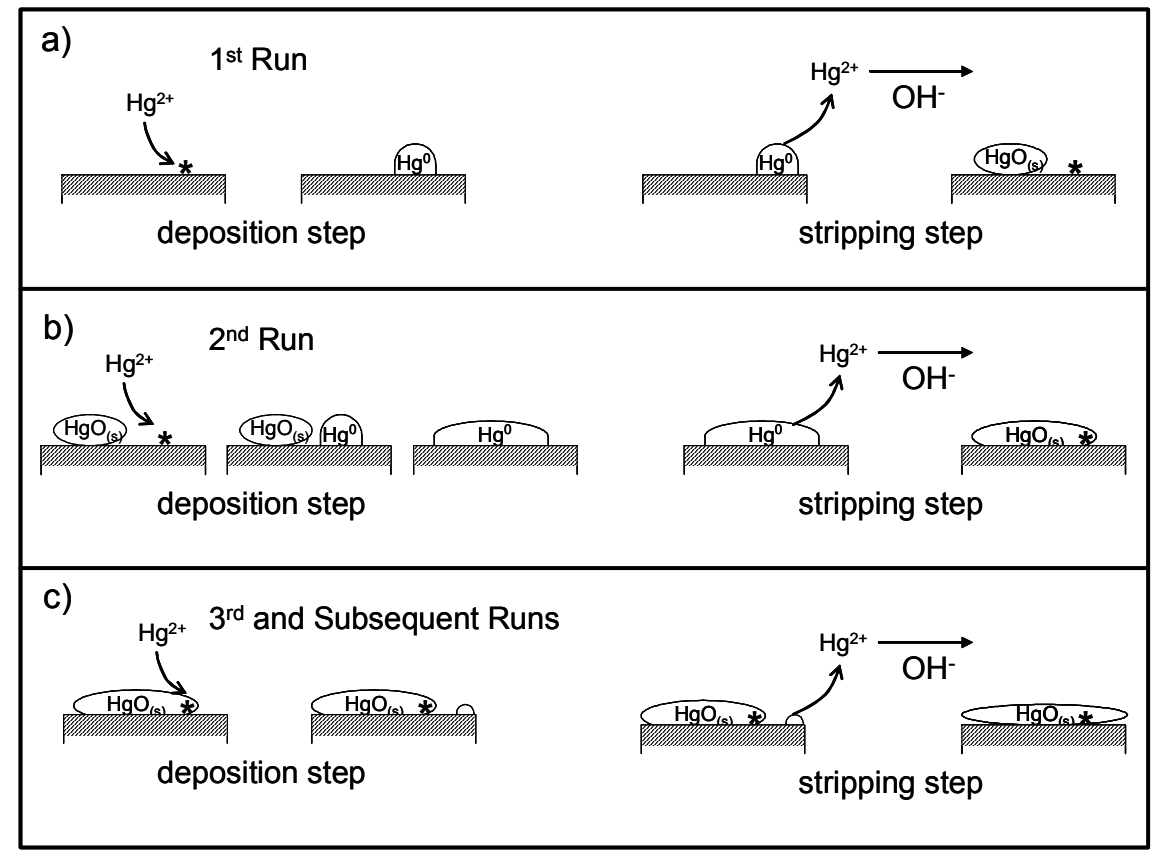

Figure 8. Proposed Model to explain the Behavior of $\mathrm{Hg}^{2+}$ in $\mathrm{KNO}_{3}$ at the Unpolished BDD Electrode

a) In the $1^{\text {st }}$ run, deposition occurs on the bare electrode. The asterisk represents an active site. $\mathrm{HgO}$ is formed in the stripping step of the $1^{\text {st }}$ run; b) In the $2^{\text {nd }}$ run, the electrode is no longer bare. Any $\mathrm{HgO}$ in contact with $\mathrm{Hg}^{0}$ is reduced during deposition; c) In the $3^{\text {rd }}$ run, so much $\mathrm{HgO}$ has formed that active sites are covered and less $\mathrm{Hg}^{2+}$ is reduced. 
beginning of the $3^{\text {rd }}$ run, the electrode surface is (partially) covered with $\mathrm{HgO}$. For some reason, not as many $\mathrm{HgO}$ particles are getting reduced to $\mathrm{Hg}^{0}$ nucleation sites during the deposition step of the third--and subsequent runs. It may be that reduction of $\mathrm{HgO}$ occurs only (or more rapidly) when the $\mathrm{HgO}$ particles are in contact with $\mathrm{Hg}^{0}$. This was reported for a calomel precipitate on a GC electrode, where only those calomel particles in contact with elemental $\mathrm{Hg}^{0}$ were reduced. With this in mind, the following situation is proposed. The third run begins with the electrode partially covered with $\mathrm{HgO}$. During deposition, the $\mathrm{HgO}$ that is in contact with elemental $\mathrm{Hg}^{0}$ is reduced. This means that reduction of $\mathrm{Hg}^{2+}$ ions to $\mathrm{Hg}^{0}$ occurs first on the most active sites of the bare BDD. Any $\mathrm{HgO}$ "next to" the deposited $\mathrm{Hg}^{0}$ (from $\mathrm{Hg}^{2+}$ ) is then reduced. However, any $\mathrm{HgO}$ which is not in contact with $\mathrm{Hg}^{0}$ is not reduced and remains on the electrode surface. It may be that during the deposition step of this $3^{\text {rd }}$ run, $\mathrm{HgO}$ particles are blocking $\mathrm{Hg}^{2+}$ ions from the most active sites of the BDD surface, as shown in Figure 8c. The HgO can't get reduced, because it's not in contact with elemental $\mathrm{Hg}^{0}$, and if the $\mathrm{HgO}$ is attached to an active site, it blocks the deposition of $\mathrm{Hg}^{2+}$ from solution. The implication here is that deposition of $\mathrm{Hg}^{2+}$ onto the bare BDD surface happens only on certain sites, which are less uniform (or fewer) than those on the GC surface. $\mathrm{Had}$ the $\mathrm{Hg}^{0}$ nuclei been located more uniformly (or more densely) on the BDD electrode, there would have been a greater likelihood of them being in contact with the $\mathrm{HgO}$ particles, which then could have been reduced to nucleation sites, resulting in larger currents upon repetition.

Essentially, with each run, the BDD electrode is coated with more and more $\mathrm{HgO}$ which is electrochemically inactive if not in contact with $\mathrm{Hg}^{0}$, and which blocks the deposition of $\mathrm{Hg}^{2+}$ from solution. The $\mathrm{HgO}$ is not in contact with $\mathrm{Hg}^{0}$, because the sites 
for $\mathrm{Hg}^{2+}$ deposition of the BDD electrode are not distributed uniformly on the electrode. Contrarily, at the $\mathrm{GC}$ electrode, the $\mathrm{HgO}$ can be reduced, because it is in contact with $\mathrm{Hg}^{0}$, implying that the sites for $\mathrm{Hg}^{2+}$ deposition are located uniformly all over the $\mathrm{GC}$ surface (or maybe there are more of them). Perhaps these sites on the GC electrode are regions of $\mathrm{sp}^{2}$ carbon which are more abundant compared to the BDD surface, which contains them only as impurities. In addition, the GC surface is known to possess oxygen-containing functional groups, which may promote the deposition of $\mathrm{HgO}$ by acting as adsorption sites, whereas the BDD surface is hydrogen-terminated.

The different behavior of $\mathrm{Hg}^{2+}$ on the $\mathrm{BDD}$ and $\mathrm{GC}$ electrodes in $\mathrm{KNO}_{3}$ was also investigated by examination of the reverse current for $\mathrm{Hg}^{2+}$ at these two electrodes. The reverse scans for repeated runs of $200 \mathrm{ppb} \mathrm{Hg}^{2+}$ in $\mathrm{KNO}_{3}$ are shown in Figures $9 \mathrm{a}$ and $9 \mathrm{~b}$ for the BDD and GC electrodes, respectively. Figure 9a shows that there were two anodic features at $+275 \mathrm{mV}$ and $+430 \mathrm{mV}$ at the $\mathrm{BDD}$ electrode during the $2^{\text {nd }}$ run, which then blurred into one, broad anodic feature by the $10^{\text {th }}$ run. It should be noted that the peak at $+430 \mathrm{mV}$ did not appear in the net response, because both the forward and reverse responses were anodic and of equal magnitude, and they were cancelled out in the net response. Typically, the reverse response should be cathodic, indicating that the oxidized product of the forward scan was reduced on the reverse scan. Here, the magnitude of the square wave amplitude may not have been large enough to re-reduce the $\mathrm{Hg}^{2+}$ ions generated during the forward scan. However, given the possibility of $\mathrm{HgO}$ formation, the $\mathrm{Hg}^{2+}$ ions generated during the forward scan may be combining with $\mathrm{OH}^{-}$ ions to form the $\mathrm{HgO}$ solid, which does not get reduced during the reverse response at the BDD. The anodic feature at $+275 \mathrm{mV}$ is probably due to the stripping of the remaining 

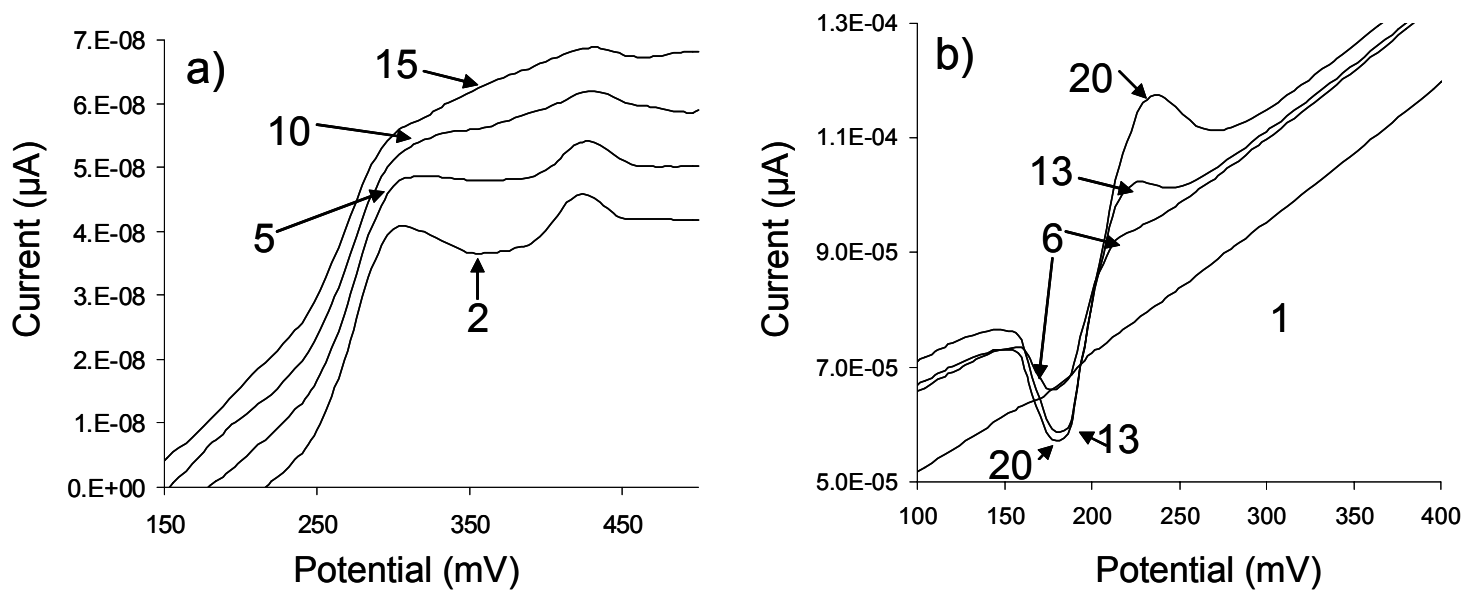

Figure 9. Reverse Responses of $200 \mathrm{ppb} \mathrm{Hg}^{2+}$ in $1 \mathrm{M} \mathrm{KNO}_{3}$

a) Unpolished BDD Electrode; b) Glassy Carbon Electrode. The number indicates the repetition number. $\mathrm{pH} \sim 5$, Deposition Potential $=-500 \mathrm{mV}$, Deposition Time $=2$ minutes, Final Potential $=+500 \mathrm{mV}$, Frequency $=15 \mathrm{~Hz}$, Pulse Amplitude $=25 \mathrm{mV}$, Step Potential $=4 \mathrm{mV}$, Stirred Deposition. 
$\mathrm{Hg}^{0}$ nucleus. The stripped $\mathrm{Hg}^{2+}$ may also disproportionate during stripping. Perhaps the peak at $+430 \mathrm{mV}$ is due to the oxidation of $\mathrm{Hg}_{2}{ }^{2+}$.

Figure $9 \mathrm{~b}$ shows that there was only one cathodic feature at $+190 \mathrm{mV}$ in the reverse response obtained using the $\mathrm{GC}$ electrode. $\mathrm{The}^{2+}$ ions liberated during the forward scan form $\mathrm{HgO}$ particles which can be reduced during the reverse scan at the GC surface, unlike the $\mathrm{BDD}$. The $\mathrm{HgO}$ particles can be reduced, because they are in contact with $\mathrm{Hg}^{0}$ nuclei or oxides on the GC surface.

It has been shown in previous studies of mercury film electrodes that application of more negative deposition potentials resulted in a more uniform distribution of mercury droplets. $^{7,8,11}$ A deposition potential of $-1.0 \mathrm{~V}$ was therefore used with the BDD electrode in $1 \mathrm{M} \mathrm{KNO}_{3}$, with the intention of activating more sites on the BDD toward $\mathrm{Hg}^{2+}$ deposition. The results are peculiar, as shown in Figure 10, and are difficult to interpret. The first run revealed only one stripping peak at the expected potential of $+300 \mathrm{mV}$. After the first run a new peak appeared at $\sim 100 \mathrm{mV}$, and this peak increased over the next several repetitions. The peak potential of $-100 \mathrm{mV}$ is similar to the potential obtained in $\mathrm{KCl}(1 \mathrm{M})$, suggesting that this peak may be attributed to $\mathrm{Hg}$-stripping in the presence of chloride. Since a double junction reference electrode was used, the source of chloride could only be from the $\mathrm{KNO}_{3}$ salt, which contained $0.0004 \% \mathrm{Cl}^{-}$. Thus, a solution of $1 \mathrm{M} \mathrm{KNO}_{3}$ prepared from this salt may contain up to $0.01 \mathrm{mM} \mathrm{Cl}^{-}$. As will be discussed shortly, as little as $0.08 \mathrm{mM} \mathrm{Cl}^{-}$in $\mathrm{KNO}_{3}$ can shift the mercury stripping peak nearly $100 \mathrm{mV}$ negative (from $+330 \mathrm{mV}$ to $+244 \mathrm{mV}$ ); however, a "new" peak such this one at $-100 \mathrm{mV}$ was never observed. The identity of this peak is not known, but we observed similar behavior for mercury at the $\mathrm{GC}$ electrode in $\mathrm{KCl}$ solution. 


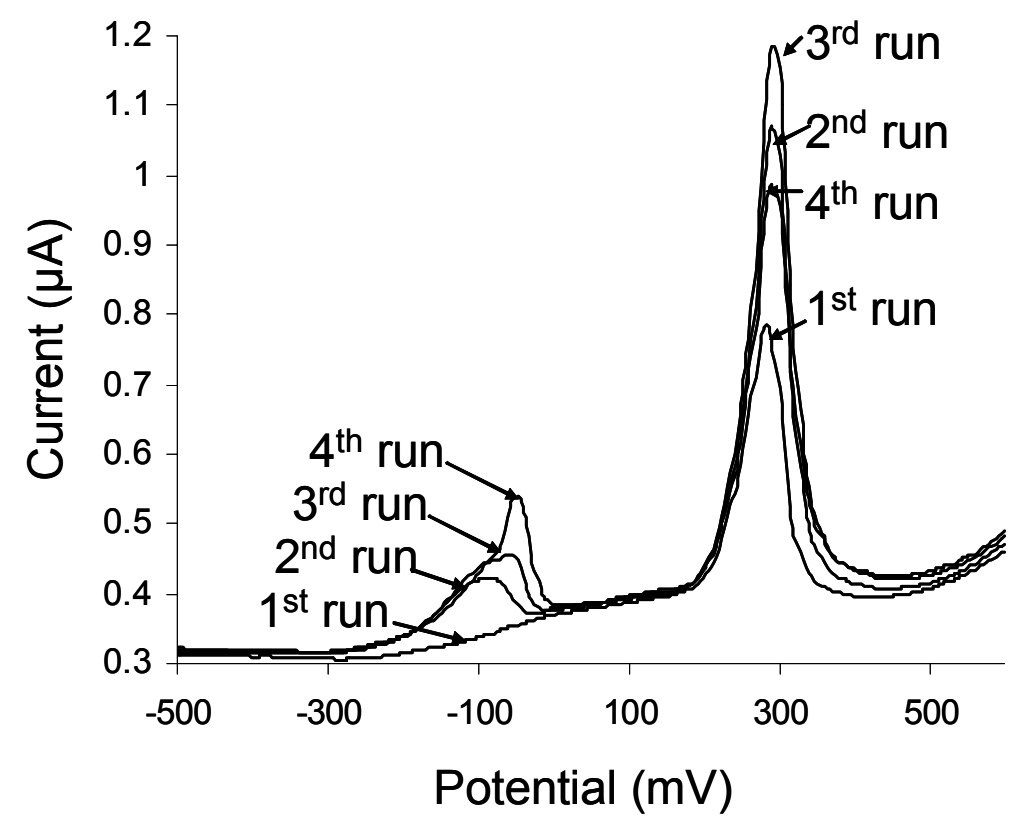

Figure 10. The Behavior of $200 \mathrm{ppb} \mathrm{Hg}^{2+}$ in $1 \mathrm{M} \mathrm{KNO}_{3}$ using a Deposition Potential of $-1.0 \mathrm{~V}$

$\mathrm{pH} \sim 5$, Unpolished BDD, Deposition Time $=5$ minutes, Final Potential $=+500$ $\mathrm{mV}$, Frequency $=15 \mathrm{~Hz}$, Pulse Amplitude $=25 \mathrm{mV}$, Step Potential $=4 \mathrm{mV}$, Stirred Deposition. 
Figure 11 shows the behavior of the peak at $-100 \mathrm{mV}$ and the usual peak at +300 $\mathrm{mV}$ obtained in $1 \mathrm{M} \mathrm{KNO}_{3}$ using a deposition potential of $-1 \mathrm{~V}$. The $+300 \mathrm{mV}$ peak followed the usual trend seen previously at a deposition of $-500 \mathrm{mV}$ : it increased, then decreased with repetition. The unknown peak at $-100 \mathrm{mV}$ increased gradually over 4 runs, remained constant for about 3 runs, and then began to decrease. Before the $10^{\text {th }}$ run, a cleaning potential of $+600 \mathrm{mV}$ was applied for 1 minute between each of the repetitions, with the hope that the electrode surface would be in the same condition for each repetition. The unknown peak at $-100 \mathrm{mV}$ (open squares in Figure 11) decreased after application of the cleaning potential, and was undetectable after the second electrochemical cleaning (see $11^{\text {th }}$ run in Figure 11). The usual peak at $+300 \mathrm{mV}$ (open diamonds in Figure 11) increased for only one repetition after electrochemical cleaning, and then decreased--even though the cleaning potential was applied before each run. Although the last four runs performed with electrochemical cleaning appeared to have stabilized, the relative standard deviation was $23.5 \%$. In addition, when more mercury was added (triangles in Figure 11), the current was unstable, but followed a similar trend as the five runs for $200 \mathrm{ppb}$ performed with electrochemical cleaning.

The effect of electrochemical cleaning on the behavior of mercury in $\mathrm{KNO}_{3}$ is difficult to explain. The current of the first run increased after electrochemical cleaning, but the subsequent runs decreased. It appears, then, as if electrochemical cleaning only works the first time it is done. The application of a cleaning potential typically removes unstripped species from the electrode surface, so that the electrode is in the same condition (bare) before each run. Since the current increased (for one run) after electrochemical cleaning, the cleaning potential must have removed some species which 


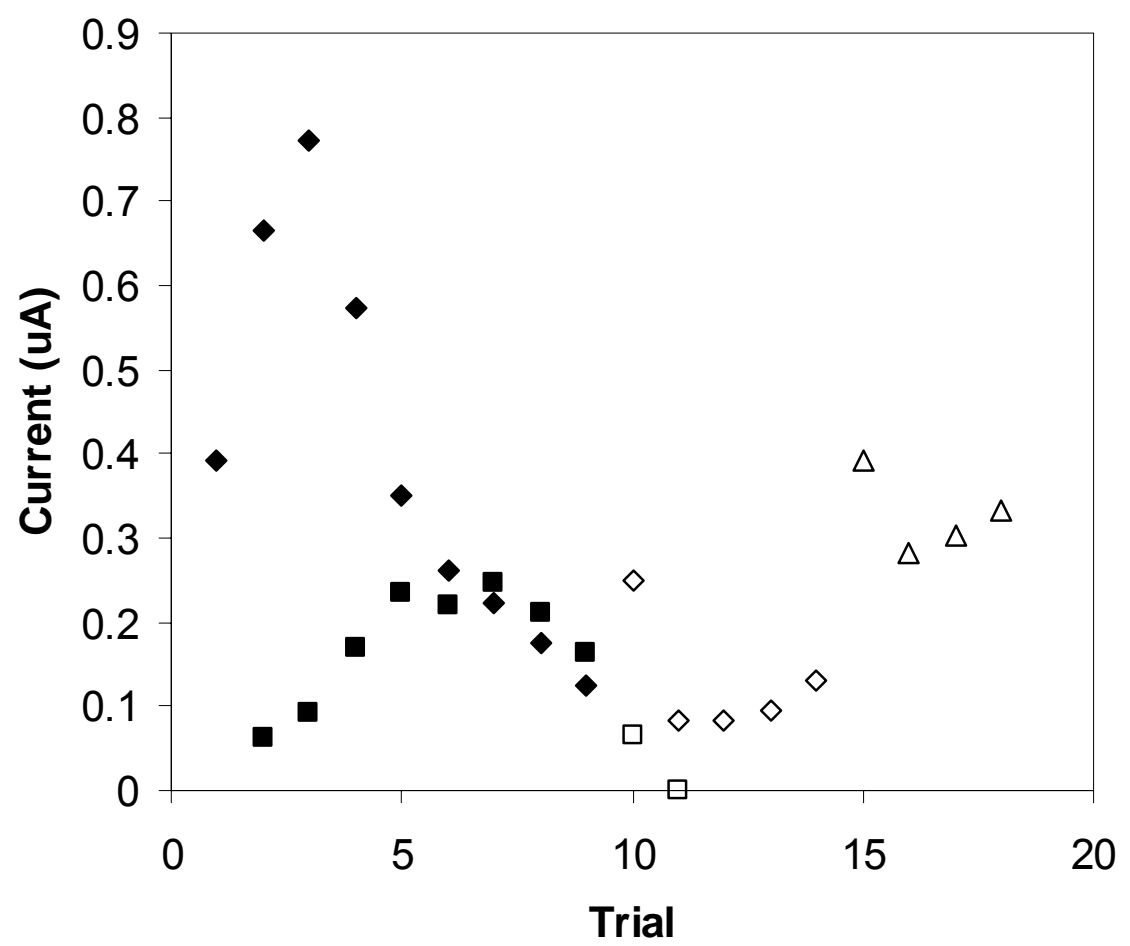

Figure 11. Effect of Electrochemical Cleaning on 200 and $250 \mathrm{ppb} \mathrm{Hg}^{2+}$ in $1 \mathrm{M}$ $\mathrm{KNO}_{3}$

Squares $=$ unknown peak at $-100 \mathrm{mV}$ for $200 \mathrm{ppb} \mathrm{Hg}^{2+}$; Diamonds $=$ peak at +300 $\mathrm{mV}$ for $200 \mathrm{ppb} \mathrm{Hg}^{2+}$; Triangles = peak at $+300 \mathrm{mV}$ for $250 \mathrm{ppb} \mathrm{Hg}^{2+}$; Solid symbols $=$ No electrochemical cleaning prior to the run; Open symbols $=+600 \mathrm{mV}$ was applied for 5 minutes prior to each trial. Unpolished BDD Electrode, $\mathrm{pH} \sim 5$, Deposition Potential $=-1.0 \mathrm{~V}$, Deposition Time $=5$ minutes, Final Potential $=+500$ $\mathrm{mV}$, Frequency $=15 \mathrm{~Hz}$, Pulse Amplitude $=25 \mathrm{mV}$, Step Potential $=4 \mathrm{mV}$, Quiet Deposition. 
blocked the active sites of the electrode. We proposed earlier that $\mathrm{HgO}$ particles attached to the electrode surface and blocked the active sites of the BDD surface. Application of $+600 \mathrm{mV}$, however, is not expected to unblock active sites by removal of $\mathrm{HgO}$, because the mercury is already fully oxidized. The cleaning potential must affect some other site on the electrode surface, making it more active to mercury deposition. It is not known why electrochemical cleaning loses its effectiveness in the subsequent runs.

The effect of increasing the deposition time from 5 to 10 minutes on $200 \mathrm{ppb}$ $\mathrm{Hg}^{2+}$ in $1 \mathrm{M} \mathrm{KNO}_{3}$ using a $-500 \mathrm{mV}$ deposition potential is shown in Figure 12. The first 10 runs were performed with a 5-minute deposition and the usual behavior was observed (with no cleaning potential). When the deposition time was increased from 5 to 10 minutes, the current increased, but never to the values obtained during the first runs at 5 minutes. This implies that sites on the electrode surface are not available for $\mathrm{Hg}^{2+}$ deposition, perhaps because they are covered with $\mathrm{HgO}$ precipitate. Three 20 -minute depositions were then performed (triangles in Figure 12), and the currents increased, almost approaching the currents obtained at the beginning of the experiment using the 5minute deposition time. Nucleation and growth are believed to occur during the 20minute deposition. Deposition is occurring on those sites uncovered by $\mathrm{HgO}$, where nuclei can form, and and then grow over the 20-minute period. As a result of this growth, it is likely that a mercury drop could grow large enough that it could come into contact with nearby $\mathrm{HgO}$, and begin to reduce the precipitate, too. After the three 20 -minute depositions, several 2-minute depositions were performed. As shown in Figure 12, the first 2-minute deposition had nearly the same current as the 20-minute deposition. A large amount of $\mathrm{Hg}^{0}$ had apparently remained on the surface after the 20-minute runs, 


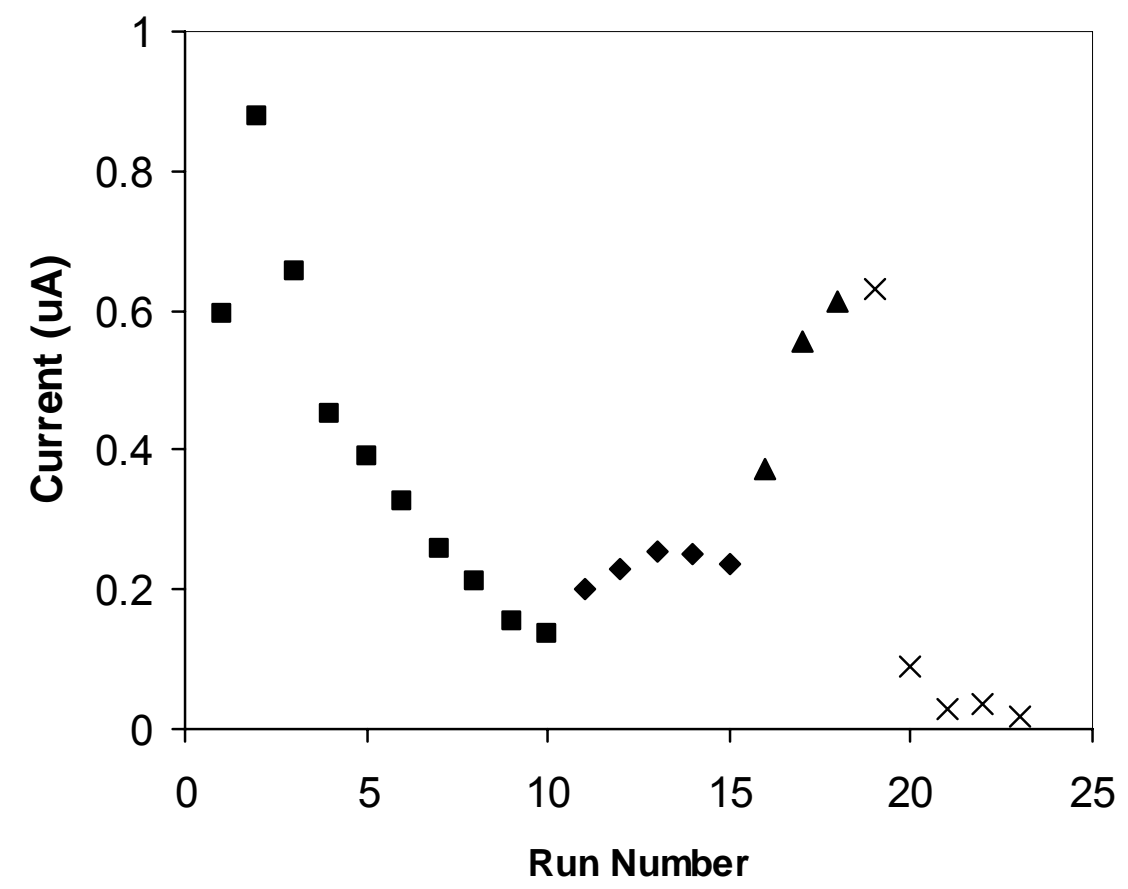

Figure 12. Effect of Deposition Time on $200 \mathrm{ppb} \mathrm{Hg}^{2+}$ in $1 \mathrm{M} \mathrm{KNO}_{3}$

Squares $=5$ minutes; Diamonds $=10$ minutes; Triangles $=20$ minutes $; x=2$ minutes. Unpolished BDD Electrode, $\mathrm{pH} \sim 5$, Deposition Potential $=-500 \mathrm{mV}$, Final Potential $=+500 \mathrm{mV}$, Frequency $=15 \mathrm{~Hz}$, Pulse Amplitude $=25 \mathrm{mV}$, Step Potential $=4 \mathrm{mV}$, Quiet Deposition. 
stayed there during the 2-minute run, and then was oxidized during the stripping step of the 2-minute run. Perhaps $\mathrm{Hg}^{0}$ adheres to the BDD surface more strongly when longer deposition times are used. The solution was stirred between the 20- and 2-minute depositions, so that a high concentration of recently stripped mercury ions did not exist near the electrode surface. Evidence of incomplete stripping of metals from the BDD surface has been reported by others for silver. ${ }^{6,28}$

\section{Behavior of Mercury in $\mathrm{KCl}$}

As shown previously in Figure 5, the peak obtained for $200 \mathrm{ppb} \mathrm{Hg}^{2+}$ in $1 \mathrm{M} \mathrm{KCl}$ was sharper and shifted negative relative to that in $\mathrm{KNO}_{3}$. The peak was sharper in $\mathrm{KCl}$ because of complex formation between $\mathrm{Hg}^{2+}$ ions liberated during the stripping step and $\mathrm{Cl}^{-}$ions in the bulk solution. (See equations $6 \mathrm{a}-\mathrm{d}$ for formation constants.)

Addition of $\mathrm{Cl}^{-}$ions to $200 \mathrm{ppb} \mathrm{Hg}^{2+}$ shifted the peak potential, $\mathrm{E}_{\mathrm{p}}$, negative. Figure 13 shows that $\mathrm{E}_{\mathrm{p}}$ and $\log \left[\mathrm{Cl}^{-}\right]$were linear $\left(\mathrm{R}^{2}=0.9991\right)$ for chloride concentrations from $0.08 \mathrm{mM}$ to $1 \mathrm{mM}$. The slope of the line in Figure 13 is proportional to the number of chloride ions involved in the stripping step, as shown in the equation below $^{75}$

$$
E_{p}=j 60 \log [L] / n+60 \log \beta_{j} / n
$$

where $\mathrm{j}=$ the coordination number of the complex, $[\mathrm{L}]=$ the concentration of the ligand, $\mathrm{n}=$ the number of electrons, and $\beta_{\mathrm{j}}=$ the stability constant of the complex. The slope equaled $67 \mathrm{mV} /$ decade, and indicated that two chloride ions were involved in the stripping step, assuming that the oxidation of mercury was a two-electron process. Thus, the following reaction probably occurred during stripping 


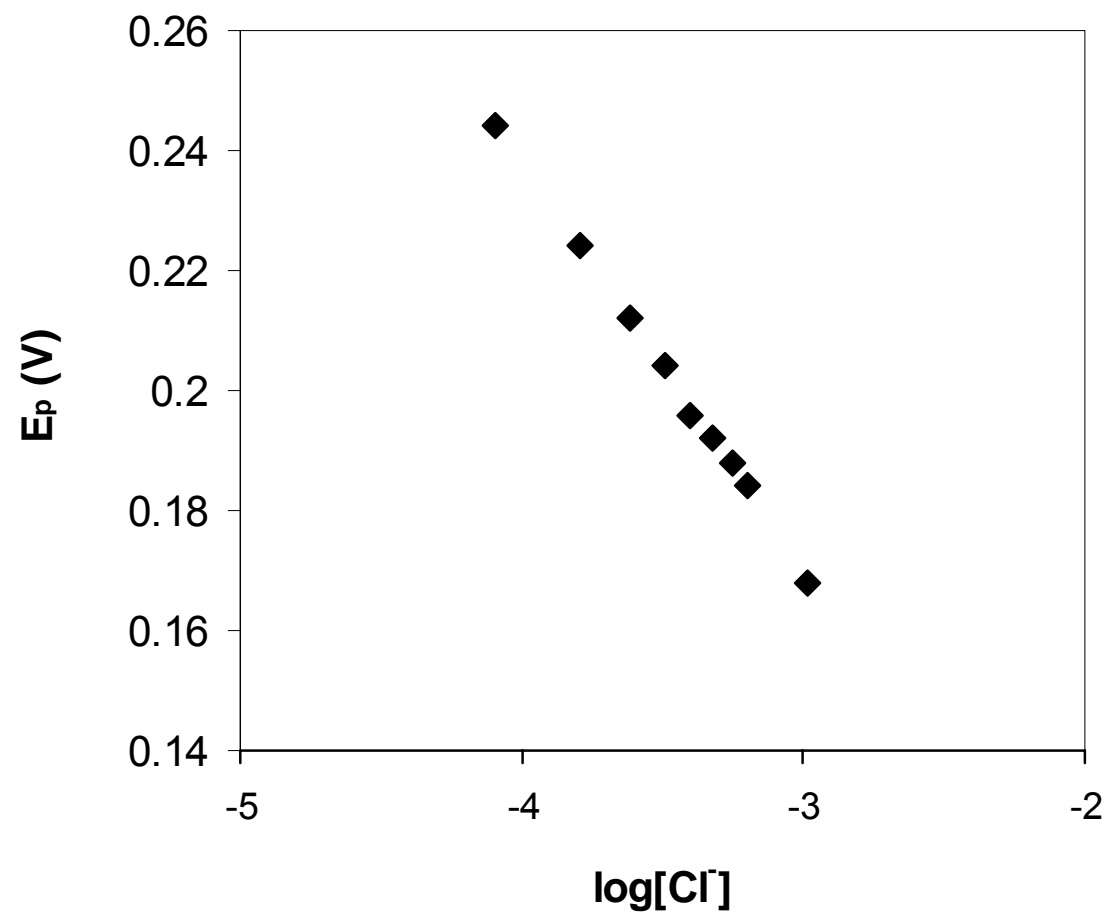

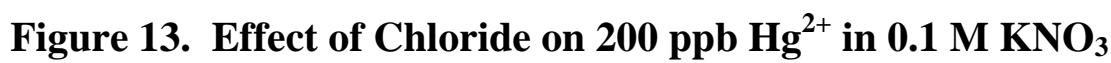

$\mathrm{pH} \sim 5$, Unpolished BDD Electrode, Deposition potential $=-500 \mathrm{mV}$, Deposition Time $=2.5$ minutes, Final Potential $=+500 \mathrm{mV}$, Frequency $=15$ $\mathrm{Hz}$, Pulse Amplitude $=25 \mathrm{mV}$, Step Potential $=4 \mathrm{mV}$, Stirred Deposition. 


$$
\mathrm{Hg}^{0}+2 \mathrm{Cl}^{-} \rightarrow\left[\mathrm{HgCl}_{2}\right]
$$

where $\left[\mathrm{HgCl}_{2}\right]$ is a neutral complex.

The behavior of $\mathrm{Hg}^{2+}$ in the presence of $\mathrm{Cl}^{-}$ions appeared promising, so experiments were performed in 1 and $4 \mathrm{M} \mathrm{KCl} \mathrm{electrolytes.} \mathrm{The} \mathrm{results} \mathrm{of} 4$ identical experiments performed in $1 \mathrm{M} \mathrm{KCl}$ using a $-500 \mathrm{mV}$ deposition are shown in Figure 14a, where it can be seen that there were slightly different results in each experiment. In experiment 1 , the current increased with each repetition and never reached a plateau. In experiment 2 , the current increased during the initial runs, but then reached a plateau after about the $10^{\text {th }}$ run. In experiments 3 and 4 , the current did not increase gradually during the initial runs; instead, there was a large increase between the first and second trials, followed by a rather stable current (13.1\% and 5.84 \% RSD for runs $2-10)$.

The increasing currents observed in $\mathrm{KCl}$ at the $\mathrm{BDD}$ electrode may be explained in a similar way as explained for the $\mathrm{GC}$ electrode in $\mathrm{KNO}_{3}$, which involved the formation of a reducible precipitate. In $\mathrm{KCl}$, however, the reducible precipitate which behaved as a nucleation site for $\mathrm{Hg}^{2+}$ deposition in subsequent runs is calomel, $\mathrm{Hg}_{2} \mathrm{Cl}_{2}$. It has been shown that in chloride (and other complexing electrolytes), $\mathrm{Hg}^{0}$ is oxidized directly to the mercuric ion, ${ }^{61}$ so the source of $\mathrm{Hg}_{2}{ }^{2+}$ in solution is the disproportionation of $\mathrm{Hg}^{2+}$, as shown in reaction 4. This could happen during the stripping step, or between runs if elemental $\mathrm{Hg}^{0}$ remained on the electrode surface after stripping. As mentioned in the Introduction, research using MTFE's suggested that calomel formed during the stripping step is reducible at negative potentials, ${ }^{70}$ while that formed between runs is not-until the potential is scanned positive to $-600 \mathrm{mV}$, and the calomel must be in contact with elemental mercury. ${ }^{71}$ Calomel formation can be eliminated if a complexing agent 

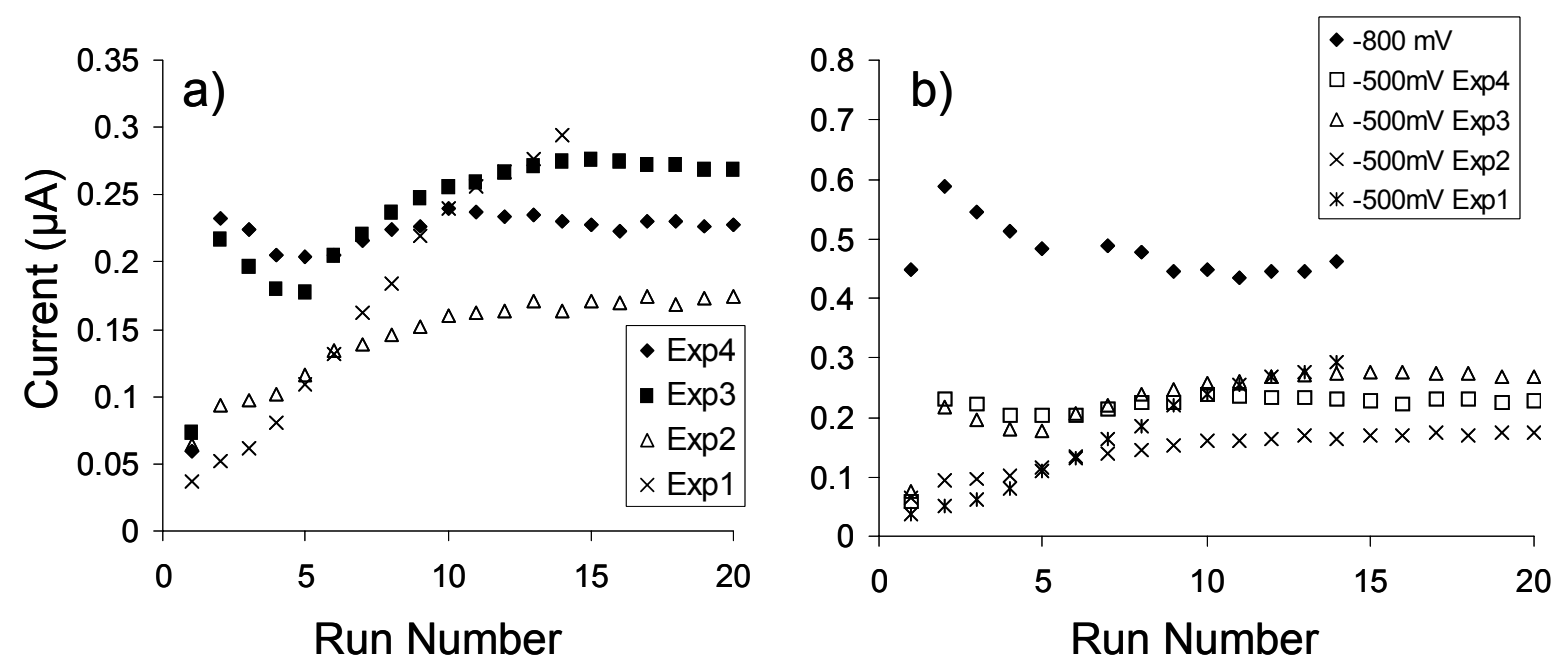

\section{Figure 14. Behavior of $200 \mathrm{ppb} \mathrm{Hg}^{2+}$ in $1 \mathrm{M} \mathrm{KCl}$ in Different Experiments}

In (a) the deposition potential was $-500 \mathrm{mV}$ for all experiments. In (b) the effect of a $-800 \mathrm{mV}$ deposition in shown. $\mathrm{pH} \sim 5$, Unpolished BDD Electrode, Deposition Time $=2$ minutes, Final Potential $=+500 \mathrm{mV}$, Frequency $=15 \mathrm{~Hz}$, Pulse Amplitude $=25 \mathrm{mV}$, Step Potential $=4 \mathrm{mV}$, Stirred Deposition, No Electrochemical Cleaning. 


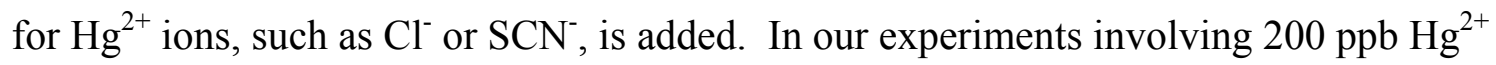
and $1 \mathrm{M} \mathrm{KCl}$, mass balance calculations predict the bulk, free $\mathrm{Hg}^{2+}$ concentration to be $7.5 \times 10^{-22} \mathrm{M}$, which means that at equilibrium, the $\mathrm{Hg}_{2}{ }^{2+}$ concentration is $9.7 \times 10^{-20} \mathrm{M}$, which is small enough to remain in solution in the presence of $1 \mathrm{M} \mathrm{Cl}^{-}$. (The Buffle criterion can't be applied in this case, because elemental $\mathrm{Hg}^{0}$ is oxidized directly to $\mathrm{Hg}^{2+}$ in the stripping step.) However, the concentration of $\mathrm{Hg}^{2+}$ will be higher at the electrode surface during the stripping step. This shifts reaction 4 to the right, which increases the mercurous ion concentration. On the other hand, $\mathrm{Cl}^{-}$ions are competing with $\mathrm{Hg}^{0}$ for the stripped $\mathrm{Hg}^{2+}$ ions to form the complexes shown in reactions $7 \mathrm{a}-\mathrm{d}$. It is difficult to predict what will happen to the $\mathrm{Hg}^{2+}$ ions at the electrode surface, especially since their concentration at the electrode surface is unknown. If calomel could form during the stripping step in $1 \mathrm{M} \mathrm{KCl}$ (Jagner ${ }^{71}$ observed calomel formation at this $\mathrm{Cl}^{-}$concentration), then, according to the work of Nolan ${ }^{70}$ at GC electrodes, this type of calomel could be reduced in a subsequent deposition step.

We must now explain why calomel promoted deposition of $\mathrm{Hg}^{2+}$ at the BDD in $\mathrm{KCl}$, whereas $\mathrm{HgO}$ inhibited the deposition of $\mathrm{Hg}^{2+}$ in $\mathrm{KNO}_{3}$. As mentioned earlier, the $\mathrm{HgO}$ formed in $\mathrm{KNO}_{3}$ was not reducible unless in contact with $\mathrm{Hg}^{0}$ or perhaps oxygencontaining functional groups on the GC surface. Therefore, the following statements are possible descriptions for the deposition of $\mathrm{Hg}^{2+}$ in $\mathrm{KCl}$ at the $\mathrm{BDD}$ electrode: (1) calomel is reducible at sites on the bare $\mathrm{BDD}$ and therefore does not block deposition of $\mathrm{Hg}^{2+}$, or (2) calomel is only reducible when in contact with $\mathrm{Hg}^{0}$, but the $\mathrm{Hg}^{0}$ nuclei are more uniformly distributed on the $\mathrm{BDD}$ when deposited from $\mathrm{KCl}$ solution. It is not known 
which of these statements (if either of them) describe the deposition of $\mathrm{Hg}^{2+}$ from $\mathrm{KCl}$ at the BDD more accurately.

Two explanations will now be proposed to account for the different behaviors observed in experiments 1 and 2 versus 3 and 4 (see Figure 14a). First, in keeping with calomel formation, it has been suggested that calomel particles are very difficult to remove from the BDD surface, even with concentrated acids. ${ }^{6}$ If this is the case, then after experiments 1 and 2, there may have been some calomel already on the surface at the beginning of experiment 3 . The calomel behaves as a nucleation site for reduction of $\mathrm{Hg}^{2+}$ ions in the first run of experiment 3, but doesn't lead to a big increase in the current for the first run relative to the other experiments. It isn't until the second run of experiments 3 and 4 in which there is a big jump in the current. Perhaps the calomel remaining on the electrode needs to be "conditioned" before it can behave effectively as a nucleation center, and one run is enough to do that. Another possible explanation for the disparate behaviors in the experiments shown in Figure 14a may be related to electrode history and use. Bouramane et al. ${ }^{36}$ found that extensively used BDD's behaved differently than freshly-grown BDD's, and we have observed similar results in our experiments with lead (see Chapter 3).

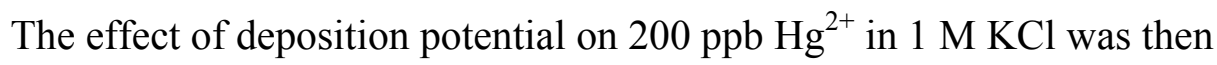
investigated, as shown in Figure 14b. A deposition potential of $-800 \mathrm{mV}$ resulted in currents almost twice as large as those obtained using a $-500 \mathrm{mV}$ deposition potential, but decreased with repetition. It is unknown why a more cathodic deposition potential caused the currents to decrease. 
The work of others ${ }^{71-72}$ showed that calomel formation can be avoided at high chloride concentrations. The behavior of $200 \mathrm{ppb} \mathrm{Hg}^{2+}$ in $4 \mathrm{M} \mathrm{KCl}$ is shown in Figure 15 , where it can be seen that the current increased gradually in $4 \mathrm{M} \mathrm{KCl}$, and then stabilized after about 7 runs. Perhaps unstripped $\mathrm{Hg}^{0}$ nuclei caused the currents to increase with repetition. Since the currents obtained in $4 \mathrm{M} \mathrm{Cl}^{-}$were about twice as large as those in $1 \mathrm{M} \mathrm{Cl}^{-}$, the behavior of $\mathrm{Hg}^{2+}$ in $4 \mathrm{M} \mathrm{Cl}^{-}$was investigated further. First, an attempt was made to detect a smaller amount of $\mathrm{Hg}^{2+}$, and the smallest amount detected in 5 minutes was $100 \mathrm{ppb} \mathrm{Hg}^{2+}$; however, the current was a factor of 100 less than that for $200 \mathrm{ppb}$. (This is similar to the observation of Yoshida, ${ }^{59}$ that low concentrations of $\mathrm{Hg}^{2+}$ were difficult to detect.) $\mathrm{Next}, 200 \mathrm{ppb} \mathrm{Hg}^{2+}$ was again investigated in $4 \mathrm{M} \mathrm{KCl}$, but the deposition time was doubled from 2 to 4 minutes. As shown in Figure 16, doubling the deposition time changed the behavior of the current with repetition, but did not result in higher currents.

All of the experiments performed in $\mathrm{KCl}$ thus far had one trait in common: after several runs, a stable current was obtained. We have tried to rationalize this in terms of either calomel formation in $1 \mathrm{M} \mathrm{KCl}$ or unstripped $\mathrm{Hg}^{0}$ nuclei in $4 \mathrm{M} \mathrm{KCl}$. Since stable currents were eventually obtained, this implies that the surface of the electrode--whether it is covered with calomel (or $\mathrm{HgO}$ ) or bare--is finally in the same condition before each run. If the electrode can be "forced" to be in this condition at the beginning of an experiment, then stable currents should be obtained beginning with the first run. Therefore, we deliberately obtained repeated measurements of $200 \mathrm{ppb} \mathrm{Hg}^{2+}$ in $1 \mathrm{M} \mathrm{KCl}$ as shown in Figure 17. The currents stabilized, indicating that the electrode surface was stable; in other words, the electrode surface was "conditioned." Next, the cell contents 


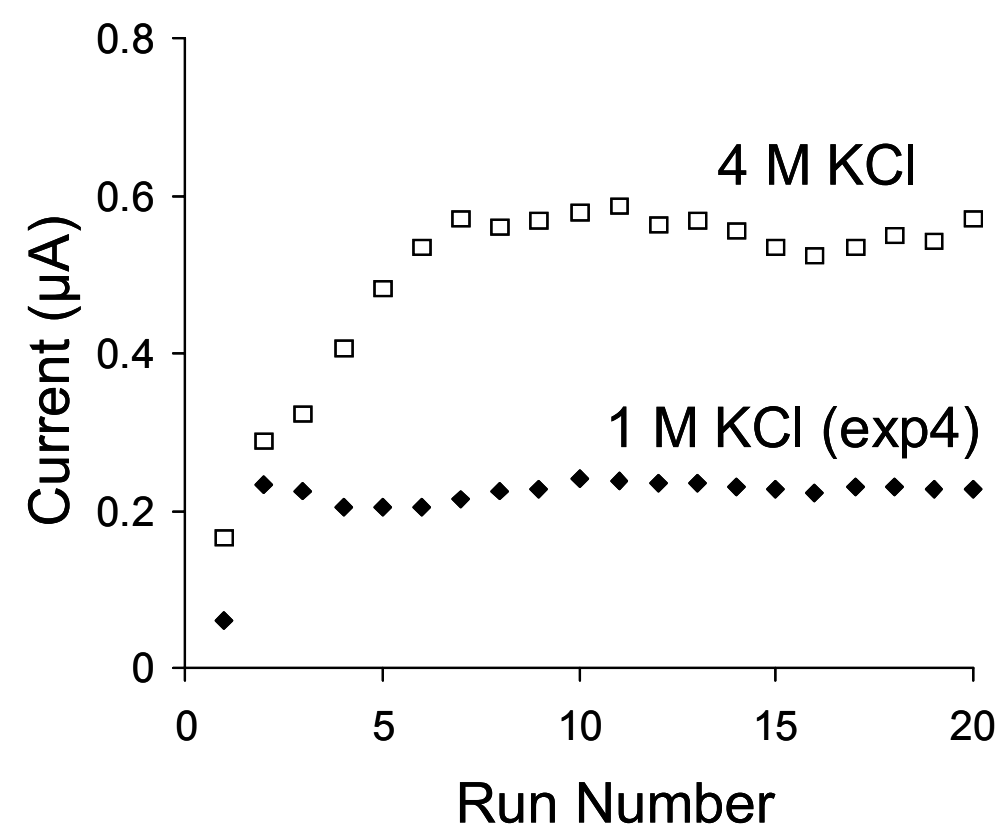

Figure 15. Behavior of $200 \mathrm{ppb} \mathrm{Hg}^{2+}$ in $4 \mathrm{M} \mathrm{KCl}$

The behavior in $1 \mathrm{M} \mathrm{KCl}$ is shown for comparison. $\mathrm{pH} \sim 5$, Unpolished BDD Electrode, Deposition Potential $=-500 \mathrm{mV}$, Deposition Time $=2$ minutes, Final Potential $=+500 \mathrm{mV}$, Frequency $=15 \mathrm{~Hz}$, Pulse Amplitude $=25 \mathrm{mV}$, Step Potential $=4 \mathrm{mV}$, Stirred Deposition, No Electrochemical Cleaning. 


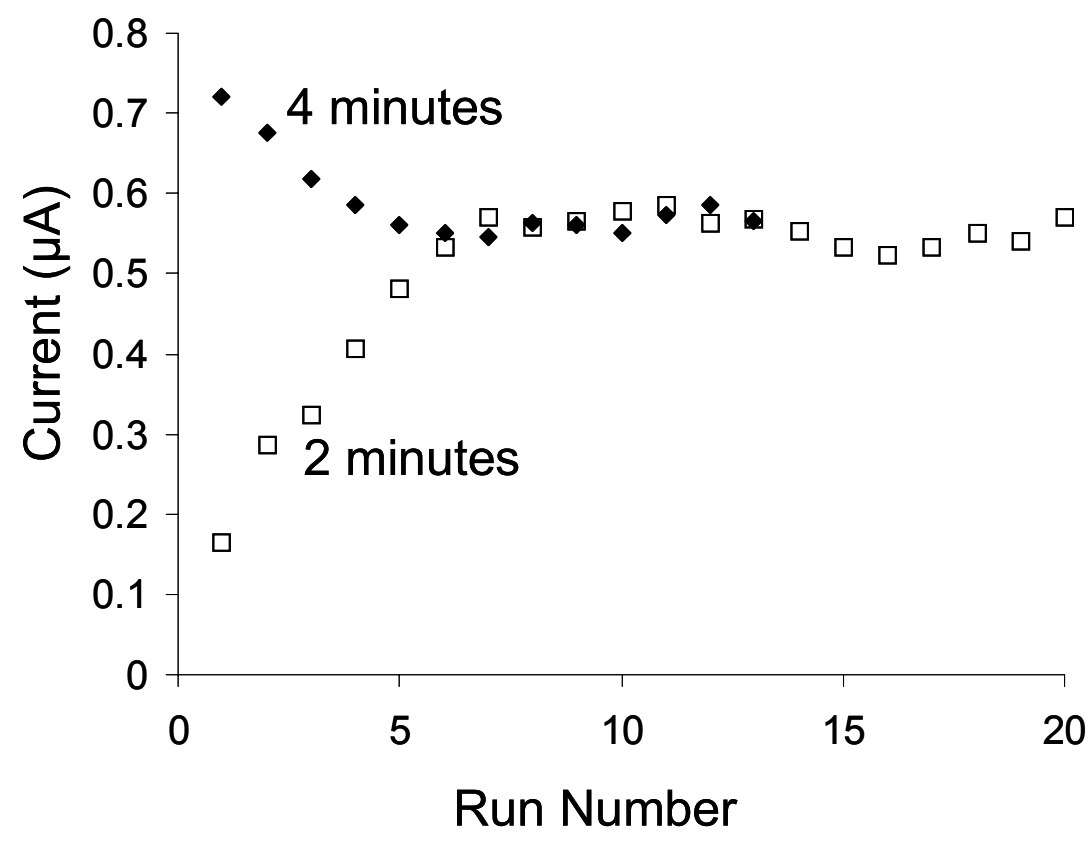

Figure 16. Effect of Deposition Time on $200 \mathrm{ppb} \mathrm{Hg}^{2+}$ in $4 \mathrm{M} \mathrm{KCl}$

$\mathrm{pH} \sim 5$, Unpolished BDD Electrode, Deposition Potential $=-500 \mathrm{mV}$, Final Potential $=+500 \mathrm{mV}$, Frequency $=15 \mathrm{~Hz}$, Pulse Amplitude $=25 \mathrm{mV}$, Step Potential $=4 \mathrm{mV}$, Stirred Deposition, No Electrochemical Cleaning. 


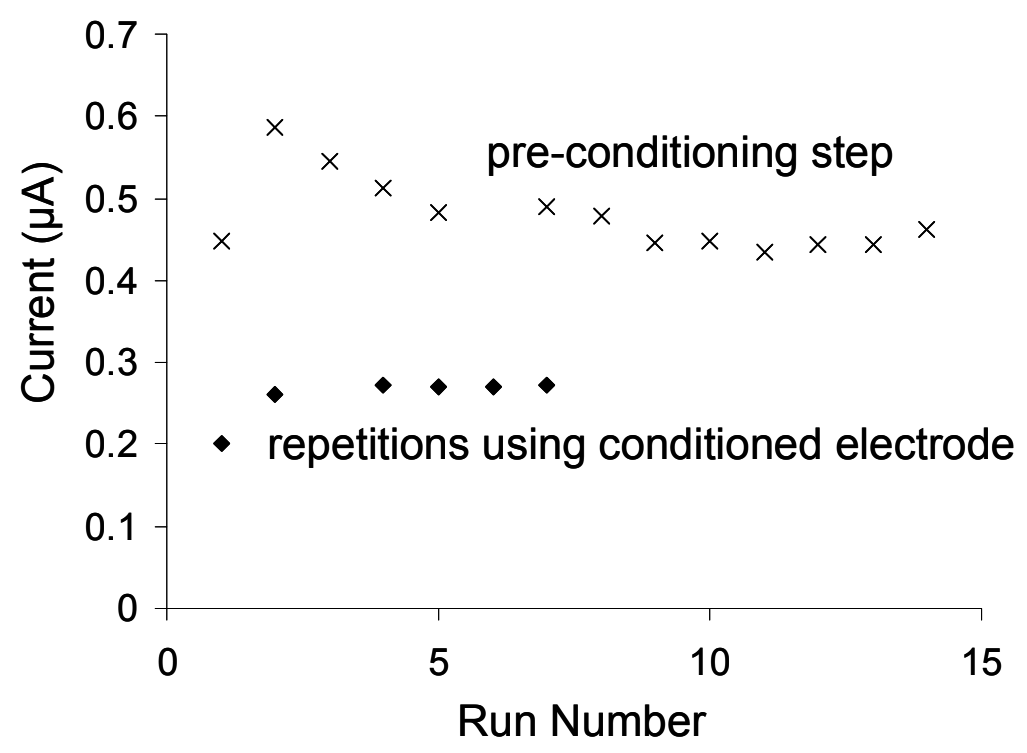

Figure 17. The Behavior of $200 \mathrm{ppb} \mathrm{Hg}^{2+}$ in $\mathbf{1} \mathrm{M} \mathrm{KCl}$ using a "PreConditioned" Electrode

$\mathrm{pH} \sim 5$, Unpolished BDD Electrode, Deposition Potential $=-500 \mathrm{mV}$, Deposition Time $=2$ minutes, Final Potential $=+500 \mathrm{mV}$, Frequency $=15 \mathrm{~Hz}$, Pulse Amplitude $=25 \mathrm{mV}$, Step Potential $=4 \mathrm{mV}$, Stirred Deposition, No Electrochemical Cleaning. 
were removed, and the electrode was rinsed with water only, with the intention of preserving this stable electrode surface. New $\mathrm{KCl}$ solution was added; two blanks were run, and no mercury stripping peak was observed. Standard addition of $200 \mathrm{ppb} \mathrm{Hg}^{2+}$ was then made, and the current was measured 6 times (diamonds in Figure 17). Stable currents were obtained after the first run (1.6\% RSD for the last 5 measurements.) This appeared promising, so more mercury was added to the cell, giving a total concentration of $300 \mathrm{ppb} \mathrm{Hg}^{2+}$. However, the currents for $300 \mathrm{ppb} \mathrm{Hg}^{2+}$ were not immediately stable; about 4 runs were necessary for the current to stablilize (data for $300 \mathrm{ppb} \mathrm{Hg}^{2+}$ not shown in Figure17). It appears, then, that the success of this pre-conditioning step depends on the concentration of mercury in the sample to be measured. In this experiment we preconditioned the electrode using $200 \mathrm{ppb} \mathrm{Hg}^{2+}$, and then obtained stable currents for that

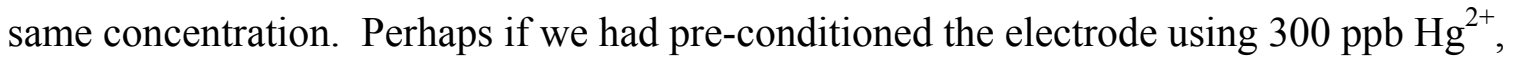
then stable currents would have been obtained for the first run of $300 \mathrm{ppb} \mathrm{Hg}^{2+}$. This is an inherent weakness of pre-conditioning the electrode in this manner. Several more attempts were made using different concentrations of $\mathrm{Hg}^{2+}$ in the pre-conditioning step, but reproducible currents were obtained only when the same concentration used to precondition the electrode was then measured.

Given that the pre-conditioning step described above worked at a limited concentration range and was time-consuming, the effect of electrochemical cleaning was investigated (as was done for $\mathrm{KNO}_{3}$ ). The results are shown in Figure 18a, where a cleaning potential of $+600 \mathrm{mV}$ was applied for 1 minute between each run, and the deposition potential and time were $-1.0 \mathrm{~V}$ and 4 minutes, respectively. Figure 18a shows that reproducible currents were obtained beginning with the first run of each mercury 

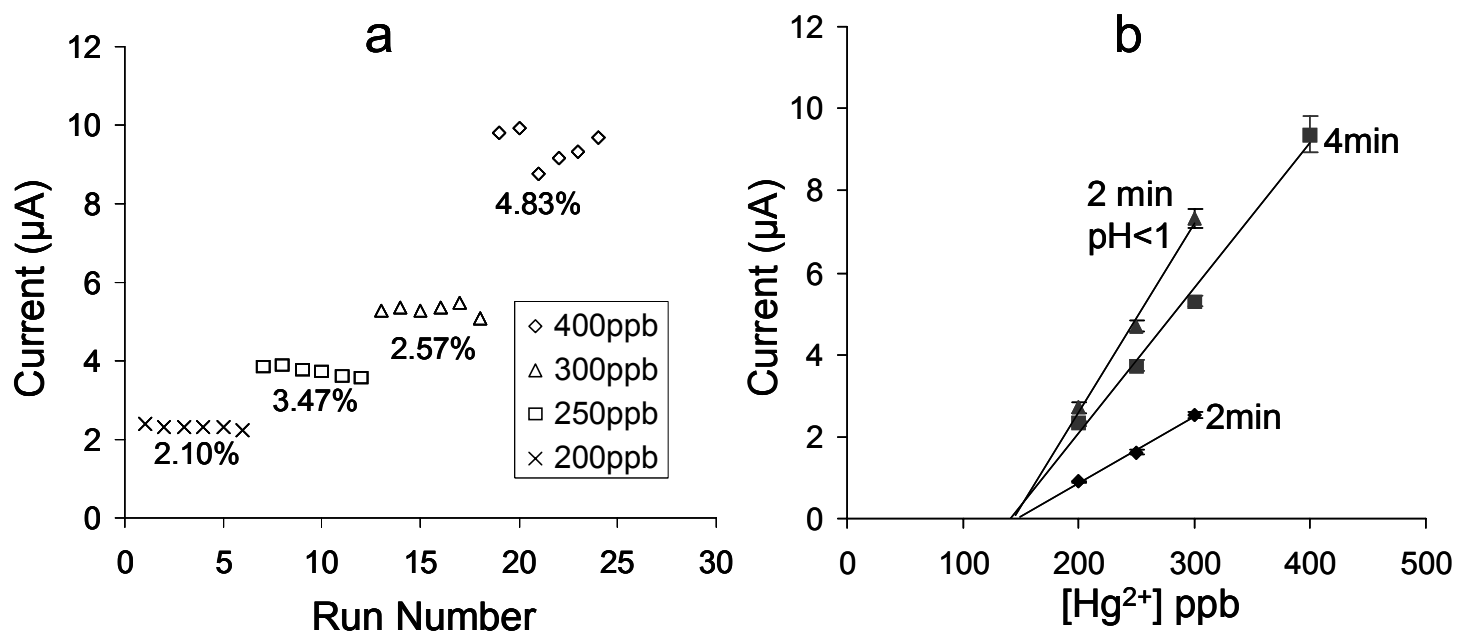

Figure 18. Effect of Electrochemical Cleaning on $\mathrm{Hg}^{2+}$ in $0.1 \mathrm{M} \mathrm{KCl}+0.9 \mathrm{M} \mathrm{KNO}_{3}$

a) Repeated measurements of $200-400 \mathrm{ppb} \mathrm{Hg}^{2+}$ using a deposition time of 4 minutes; b) Calibration curves obtained under various conditions. The cleaning potential was +600 $\mathrm{mV}$ applied for 1 minute before each run. $\mathrm{pH} \sim 5$, Unpolished BDD Electrode, Deposition Potential $=-1.0 \mathrm{~V}$, Final Potential $=+500 \mathrm{mV}$, Frequency $=15 \mathrm{~Hz}$, Pulse Amplitude $=25$ $\mathrm{mV}$, Step potential $=4 \mathrm{mV}$, Stirred Deposition. 
concentration. Electrochemical cleaning appears to get the electrode surface in the same condition before each run. Perhaps the cleaning potential oxidized unstripped $\mathrm{Hg}^{0}$ nuclei off the electrode surface, preventing formation of calomel between runs. It should be noted that during electrochemical cleaning, the solution was stirred, so that the local concentration of $\mathrm{Hg}^{2+}$ ions at the electrode surface should be close to that in the bulk; however, even if the concentration were higher at the surface and calomel did form during electrochemical cleaning, the same amount would form before each run. Therefore, the electrode surface would still be in the same condition before each run.

Figure $18 \mathrm{~b}$ shows the calibration curves obtained under various conditions using a cleaning potential between each run. The electrolyte, $0.1 \mathrm{M} \mathrm{KCl}+0.9 \mathrm{M} \mathrm{KNO}_{3}$, was studied using 2- and 4-minute deposition times at $\mathrm{pH}$ 's of $\sim 5$ and $<1$. The slopes for the calibration curves obtained using the 4- and 2-minute deposition times at $\mathrm{pH} 5$ were 35.3 and $16.3 \mathrm{nA} / \mathrm{ppb}$, respectively; the $\mathrm{R}^{2}$ values for 4- and 2-minute deposition times were 0.9989 and 0.9953 . A deposition potential of $-500 \mathrm{mV}$ was used in the acidic solution and the sensitivity and $\mathrm{R}^{2}$ were $46.1 \mathrm{nA} / \mathrm{ppb}$ and 0.9937 , respectively. Although the acidic solution yielded the most sensitive curve, note that it intersects the x-axis at nearly the same concentration as that obtained in the neutral solution using a deposition time of 2 minutes.

In an attempt to improve the detection limit without using long deposition times, the three stripping parameters, frequency, square wave amplitude, and step height, were investigated. The optimum parameters were as follows: frequency $=150 \mathrm{~Hz}$, square wave amplitude $=25 \mathrm{mV}$, and step height $=2 \mathrm{mV}$. Although stripping currents increased at frequencies greater than $150 \mathrm{~Hz}$, the reproducibility was poor. In general, changing 
each one of the stripping parameters lead to both advantages and disadvantages, which are summarized in Table 2. A calibration curve was prepared for $200-300 \mathrm{ppb} \mathrm{Hg}^{2+}$ in 1 $\mathrm{M} \mathrm{KCl}$ using the optimized stripping parameters, and the sensitivity was $115 \mathrm{nA} / \mathrm{ppb}$, which was the most sensitive thus far, but may have been a consequence of the higher chloride concentration (1 M compared to 0.1 M). Also, although currents for 200-300 ppb may have increased as a result of the "optimized" stripping parameters, the stripping parameters did not improve the detection limit. An attempt was made to detect $50 \mathrm{ppb}$ $\mathrm{Hg}^{2+}$ in chloride medium using the optimized stripping parameters. A stripping current was not detected until a 20-minute deposition time was used, but the signal was not reproducible.

The greatest success in detecting mercury in chloride medium was found by addition of an auxiliary element. In $1 \mathrm{M} \mathrm{KCl}$, with $100 \mathrm{ppb} \mathrm{Cu}^{2+}$ as the auxiliary

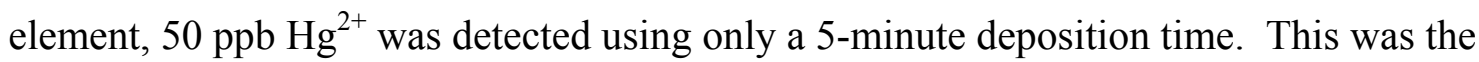
lowest amount of $\mathrm{Hg}^{2+}$ detected in 5 minutes in any of our experiments thus far. The calibration curve from 50-100 $\mathrm{ppb} \mathrm{Hg}^{2+}$ is shown in Figure 19. The RSD's were 10.6, 20.82, and $9.97 \%$, for 50,75 , and $100 \mathrm{ppb} \mathrm{Hg}^{2+}$, respectively. The RSD's for 75 and 100 ppb improved to $5.04 \%$ and $2.7 \%$, respectively, when only the last three runs were used in the calculation. Although the addition of an auxiliary element appeared promising, the composition of the samples collected from the smokestacks may limit the success of this approach. For example, there may be an element in the sample which forms an amalgam more strongly with copper than mercury, making copper unavailable to enhance the mercury current. Also, preliminary experiments would need to be performed to determine the best copper-mercury ratio in the sample matrix. 
Table 2. Effect of Stripping Parameters on Current and Background

\begin{tabular}{|c|l|l|l|}
\hline \multicolumn{2}{|c|}{ Parameter } & \multicolumn{1}{c|}{ Advantages } & \multicolumn{1}{c|}{ Disadvantages } \\
\hline \multirow{2}{*}{ Frequency } & increase & current increases; speed & $\begin{array}{l}\text { background increases; } \\
\text { baseline noisy }\end{array}$ \\
\cline { 2 - 4 } & decrease & $\begin{array}{l}\text { background decreases; } \\
\text { less noise }\end{array}$ & $\begin{array}{l}\text { current decreases; } \\
\text { slower scan }\end{array}$ \\
\hline \multirow{2}{*}{ Amplitude } & increase & current increases & peak may split \\
\cline { 2 - 4 } & decrease & background decreases & current decreases \\
\hline $\begin{array}{c}\text { Step } \\
\text { Potential }\end{array}$ & increase & speed & $\begin{array}{l}\text { current decreases; peak } \\
\text { width increases }\end{array}$ \\
\cline { 2 - 4 } & decrease & $\begin{array}{l}\text { current increases; peak } \\
\text { width decreases }\end{array}$ & slower scan \\
\hline
\end{tabular}

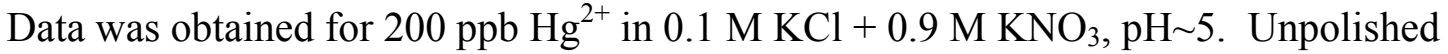
BDD Electrode, Deposition Potential $=-1.0 \mathrm{~V}$, Deposition Time $=2 \mathrm{~min}$, Final Potential $=+600 \mathrm{mV}$, Stirred Deposition. 


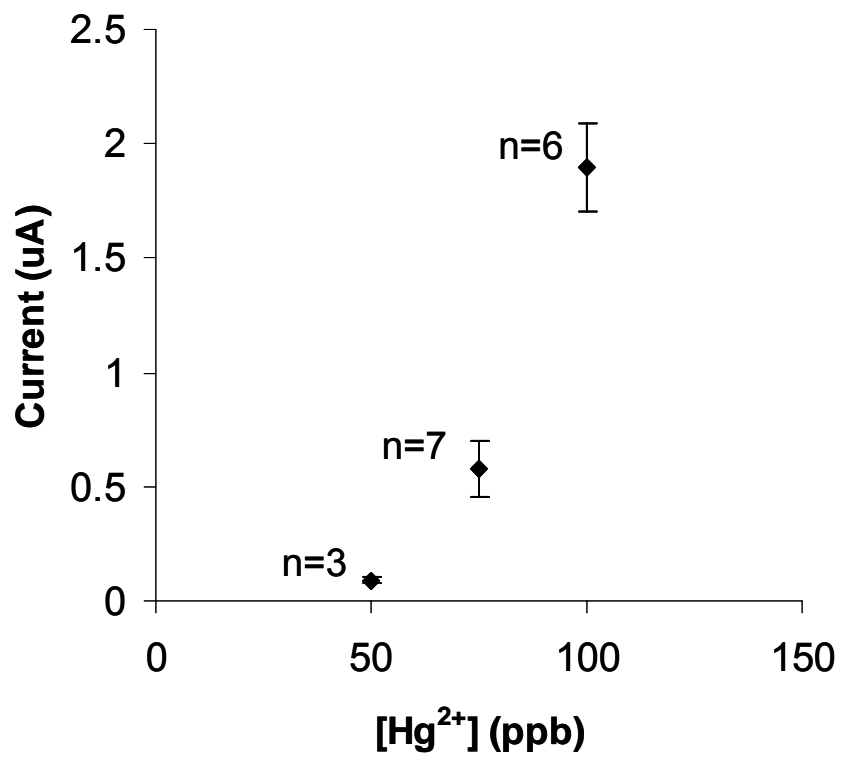

Figure 19. Calibration of 50-100 $\mathrm{ppb}^{\mathrm{Hg}} \mathrm{gg}^{2+}$ using an Auxiliary Element

The auxiliary element was $100 \mathrm{ppb} \mathrm{Cu}^{2+}$. $\mathrm{pH} \sim 5$, Unpolished BDD Electrode, Deposition Potential $=-1.1 \mathrm{~V}$, Deposition Time $=5 \mathrm{~min}$, Final Potential $=+600 \mathrm{mV}$, Frequency $=15 \mathrm{~Hz}$, Pulse Amplitude $=25 \mathrm{mV}$, Step potential $=4 \mathrm{mV}$, Stirred Deposition. 
The behavior of $\mathrm{Hg}^{2+}$ was then investigated in $0.6 \mathrm{M} \mathrm{Cl}^{-}, \mathrm{pH}<1$, which was a good approximation of the samples to be collected from power plants using the Ontario-Hydro Method. Instead of using an auxiliary element, the deposition time was increased to improve the detection limit. The results obtained using a 20 -minute deposition time in this medium were peculiar (and discouraging), as shown in Figure 20a. For concentrations less than or equal to $100 \mathrm{ppb} \mathrm{Hg}^{2+}$, only one peak at $+200 \mathrm{mV}$ was observed, and this was not the expected peak potential for mercury in this amount of $\mathrm{Cl}^{-}$. When $200 \mathrm{ppb} \mathrm{Hg}^{2+}$ was run, the broad peak at $\sim+200 \mathrm{mV}$ remained, and a new sharper peak appeared at $\sim-60 \mathrm{mV}$, which is the expected potential, given the amount of $\mathrm{Cl}^{-}$in solution. Figure $20 \mathrm{~b}$ shows that the reverse response of the peak at $-60 \mathrm{mV}$ is cathodic, while that at $+200 \mathrm{mV}$ is anodic. One final strange observation is worth mentioning.

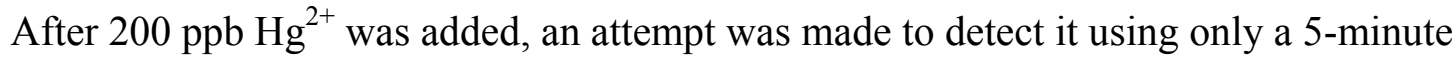
deposition time, and only the broad peak at $+200 \mathrm{mV}$ appeared. This was unexpected, since $200 \mathrm{ppb} \mathrm{Hg}^{2+}$ was detected at acidic pH's using a 4-minute deposition time (see Figure $18 \mathrm{~b}$ ), and the peak was sharp and located at $\sim 0 \mathrm{mV}$. Thus, it appears that repeated deposition for 20-minute durations desensitizes the electrode's response toward mercury. It implies that a non-reducible substance is coating the electrode, and blocking the active sites toward $\mathrm{Hg}^{2+}$ deposition; in this medium, that substance is expected to be $\mathrm{Hg}_{2} \mathrm{Cl}_{2}$. The identities of the peaks at $-60 \mathrm{mV}$ and $+200 \mathrm{mV}$ are hard to assign, but the same behavior was observed at polished BDD electrodes. Perhaps, during the course of this long deposition, the $\mathrm{HgCl}_{\mathrm{x}}$ complexes are dissociating as $\mathrm{Hg}^{2+}$ ions are reduced; maybe there is free $\mathrm{Hg}^{2+}$ that reacts with the $\mathrm{Hg}^{0}$ deposit during the deposition step, instead of 

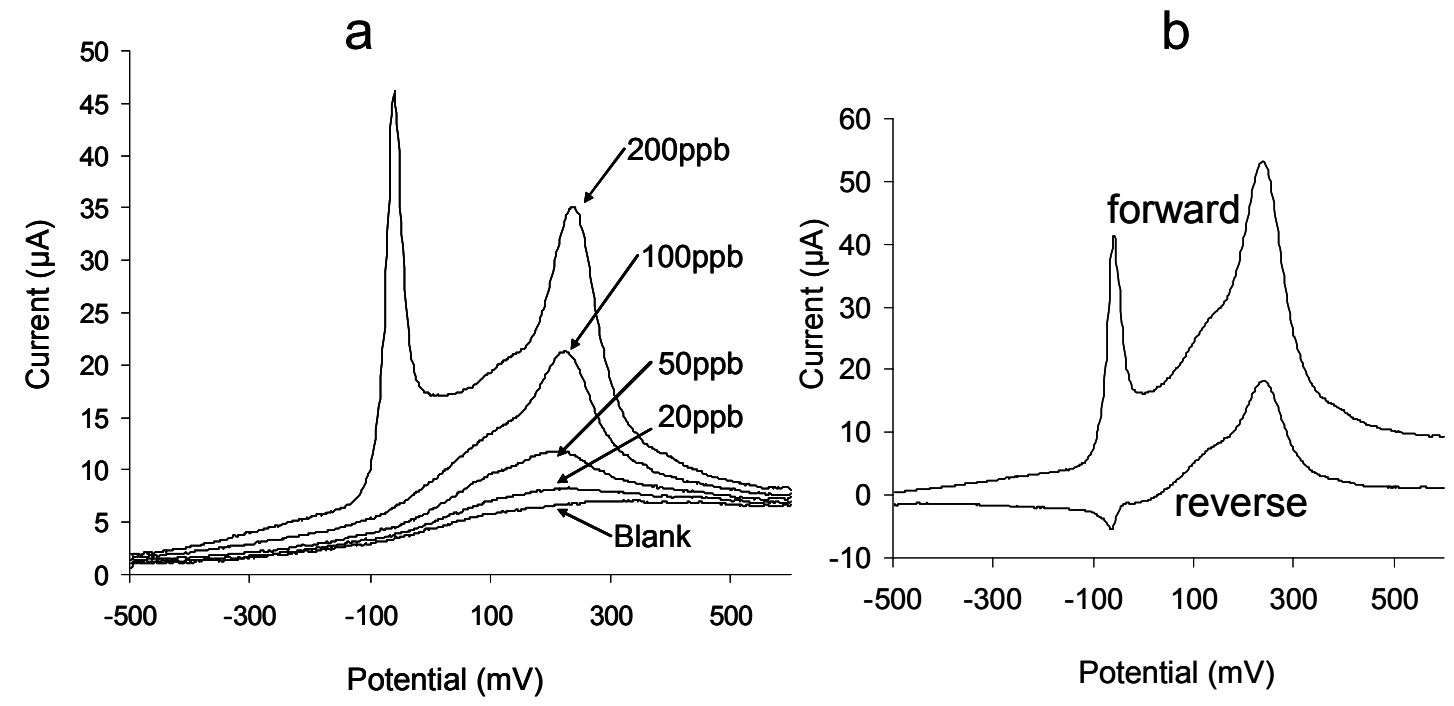

Figure 20. Behavior of $\mathrm{Hg}^{2+}$ in $0.6 \mathrm{M} \mathrm{KCl}, \mathrm{pH}<1$

a) Net responses of 20-200 ppb; b) Forward and reverse response of $200 \mathrm{ppb}$.

Unpolished BDD Electrode, Deposition Potential $=-500 \mathrm{mV}$, Deposition Time $=20 \mathrm{~min}$, Final Potential $=+600 \mathrm{mV}$, Frequency $=15 \mathrm{~Hz}$, Pulse Amplitude $=25 \mathrm{mV}$, Step Potential $=4 \mathrm{mV}$, Stirred Deposition. 
getting reduced. This would result in calomel formation. Perhaps, then, the peak at +200 $\mathrm{mV}$ is the oxidation of calomel formed during deposition (which wasn't reduced during the anodic scan because the potential was positive of $-600 \mathrm{mV}$ ), while that at $-60 \mathrm{mV}$ is the oxidation of elemental $\mathrm{Hg}^{0}$.

The Behavior of Mercury at the Glassy Carbon Electrode in $\mathrm{KCl}$

The behavior of $200 \mathrm{ppb} \mathrm{Hg}^{2+}$ was investigated in $\mathrm{KCl}$ at the $\mathrm{GC}$ electrode for comparison to the $\mathrm{BDD}$. Peculiar results were obtained at the $\mathrm{GC}$ electrode in $\mathrm{KCl}$, and were similar to those obtained at the $\mathrm{BDD}$ in $\mathrm{KNO}_{3}$. The voltammograms are shown in Figure 21, where it can be seen that for the first several runs, there was only one peak, at $-50 \mathrm{mV}$. As more runs were performed, this peak decreased, and a new peak appeared at $+200 \mathrm{mV}$. By the $10^{\text {th }}$ run, the peak at $-50 \mathrm{mV}$ was no longer detectable, and the peak at $+200 \mathrm{mV}$ increased with repetition. The identities of these peaks are difficult to assign. Clearly, the behavior of mercury in $\mathrm{KCl}$ at the GCE is unlike that at the BDD electrode.

\section{Behavior of Mercury in KSCN}

The literature contains some accounts ${ }^{60-61}$ of trace analysis of mercury in thiocyanate solution using glassy carbon electrodes. Thiocyanate forms a complex with mercuric ions, and has been used to prevent calomel formation on MTFE's. The complex formation reactions and $\mathrm{K}_{\mathrm{sp}}$ are shown in equations 15a-e: ${ }^{69}$

$$
\begin{array}{ll}
\mathrm{Hg}^{2+}+\mathrm{SCN}^{-} \leftrightarrow \mathrm{HgSCN}^{+} & \beta_{1}=1.2 \times 10^{9} \\
\mathrm{Hg}^{2+}+2 \mathrm{SCN}^{-} \leftrightarrow \mathrm{Hg}(\mathrm{SCN})_{2} & \beta_{2}=7.2 \times 10^{16} \\
\mathrm{Hg}^{2+}+3 \mathrm{SCN}^{-} \leftrightarrow \mathrm{Hg}(\mathrm{SCN})_{3}^{-} & \beta_{3}=5.0 \times 10^{19}
\end{array}
$$




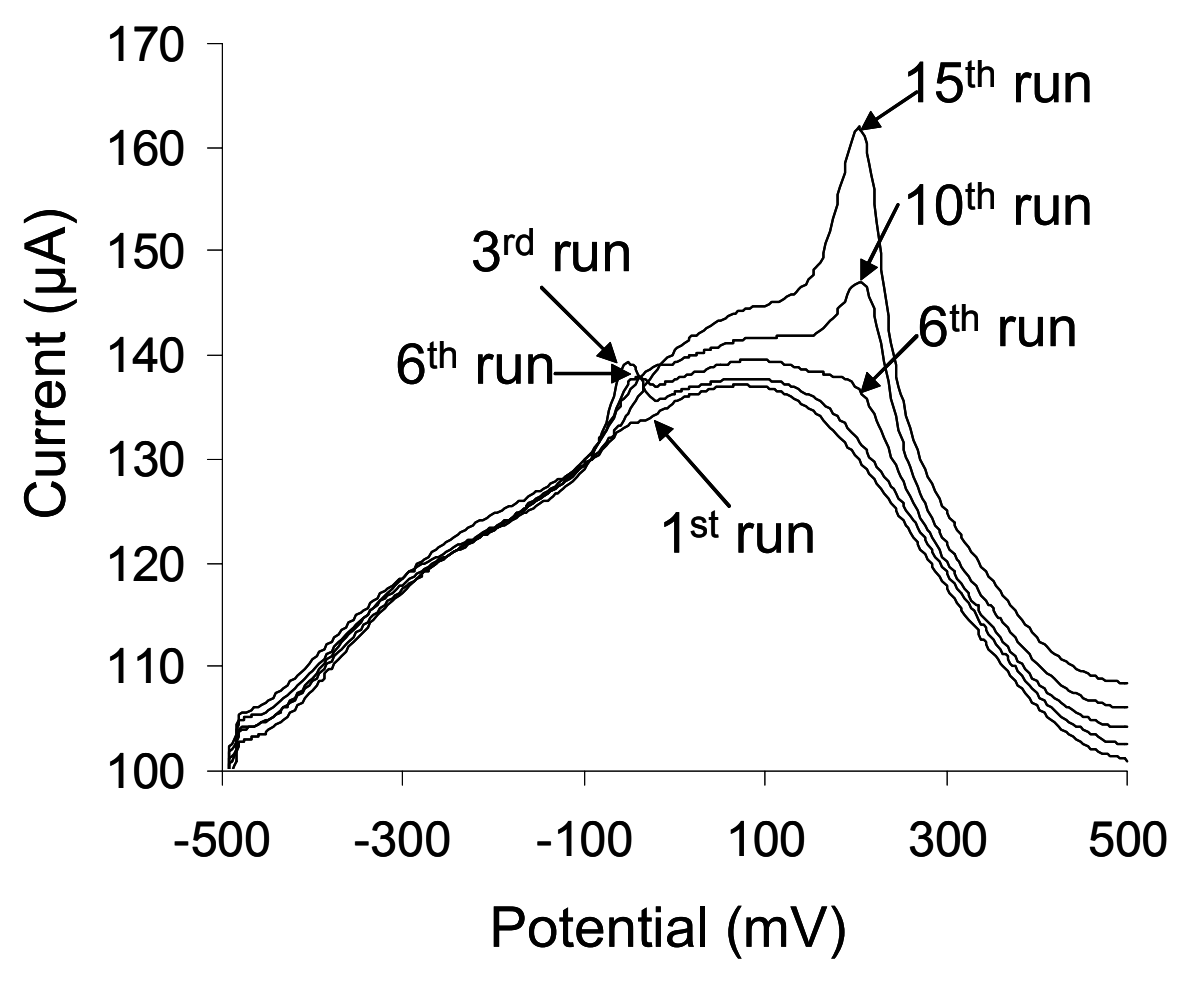

Figure 21. Voltammograms of $200 \mathrm{ppb} \mathrm{Hg}^{2+}$ in $1 \mathrm{M} \mathrm{KCl}$ at the Glassy Carbon Electrode

$\mathrm{pH} \sim 5$, Deposition Potential $=-500 \mathrm{mV}$, Deposition Time $=2 \mathrm{~min}$, Final Potential $=+600 \mathrm{mV}$, Frequency $=15 \mathrm{~Hz}$, Pulse Amplitude $=25 \mathrm{mV}$, Step potential $=4$ $\mathrm{mV}$, Stirred Deposition. 


$$
\begin{array}{ll}
\mathrm{Hg}^{2+}+4 \mathrm{SCN}^{-} \leftrightarrow \mathrm{Hg}(\mathrm{SCN})^{2-} & \beta_{4}=5.0 \times 10^{21} \\
\mathrm{Hg}(\mathrm{SCN})_{2(\mathrm{~s})} \leftrightarrow \mathrm{Hg}^{2+}+2 \mathrm{SCN}^{-} & \mathrm{K}_{\mathrm{sp}}=2.8 \times 10^{-20}
\end{array}
$$

In general, we found the detection limit of mercury was much poorer in $\mathrm{SCN}^{-}$ solutions than in $\mathrm{KCl}$ and $\mathrm{KNO}_{3}$ solutions. For example, in $1 \mathrm{M} \mathrm{KSCN}, 200 \mathrm{ppb} \mathrm{Hg}^{2+}$ was not detected at a deposition time of up to 10 minutes, whereas in $\mathrm{KCl}$, this same concentration of mercury was easily detected at a deposition time of only 2 minutes. In 1 $\mathrm{M} \mathrm{SCN}^{-}$, the peak potential for mercury was much more negative, located at $-280 \mathrm{mV}$ compared to $-100 \mathrm{mV}$ in $1 \mathrm{M} \mathrm{KCl}$. Even though the detection limit was poor in $\mathrm{SCN}^{-}$, a calibration curve was prepared for 400-600 ppb in $1 \mathrm{M} \mathrm{KSCN}$, resulting in an $\mathrm{R}^{2}$ of 0.9972 and sensitivity of $13.4 \mathrm{nA} / \mathrm{ppb}$ (2-minute deposition). The RSD's for 400, 500, and $600 \mathrm{ppb}$ were $10.2,13.9$, and $13.2 \%$, respectively, and the current at each concentration decreased over the three measurements. Increasing the $\left[\mathrm{SCN}^{-}\right]$to $3 \mathrm{M}$ did not improve the detection limit and reproducibility. Taking a similar approach as Meyer, et al., ${ }^{60}$ we then tried using a longer deposition time of 20 -minutes in $1 \mathrm{M} \mathrm{SCN}^{-}$, but did not achieve the same detection limits. We weren't able to deposit $\mathrm{Hg}^{0}$ at $-1.5 \mathrm{~V}$ as Meyer did, because hydrogen evolution was observed at the BDD electrode. The detection of $\mathrm{Hg}^{2+}$ in $\mathrm{SCN}^{-}$was better at the GC electrode compared to the BDD. Using a deposition time of 2 minutes, $200 \mathrm{ppb} \mathrm{Hg}^{2+}$ was detected in $1 \mathrm{M} \mathrm{KSCN}$ at the GC, compared to 400 ppb $\mathrm{Hg}^{2+}$ at the BDD (we did not attempt to reproduce the work of Meyer, et al. ${ }^{60}$ at the GC electrode). It is not known why the detection of $\mathrm{Hg}^{2+}$ in $\mathrm{SCN}^{-}$medium was better at the GC as opposed to the BDD electrode. Perhaps mercuric thiocyanate complexes 
adsorbed to the GC electrode more readily than at the BDD, and this resulted in more mercury deposition at the GC electrode.

\section{Analysis of a River Water Sample for Mercury}

Although the results obtained in $\mathrm{KNO}_{3}, \mathrm{KCl}$, and $\mathrm{KSCN}$ at the $\mathrm{BDD}$ electrode were complicated, an attempt was made to prepare a calibration curve for $\mathrm{Hg}^{2+}$ in a natural water sample matrix. A sample was collected from the Monongahela River according to standard procedures, ${ }^{76}$ filtered $(0.45 \mu \mathrm{m})$, acidified to $\mathrm{pH}<1$, and stored in a refrigerator. Figure 22a shows that the sample contained a broad stripping peak at about $+200 \mathrm{mV}$, which was very close to the stripping potential for $\mathrm{Hg}^{2+}$ in $\mathrm{KNO}_{3}$. The standard addition of mercury to the sample was located more positive, at about $+250 \mathrm{mV}$. The calibration curve prepared by standard additions is shown in Figure 22b, where it can be seen that the curve leveled off at about $300 \mathrm{ppb} \mathrm{Hg}^{2+}$, and that the errors bars for the standards overlapped. The current measured at each concentration decreased with repetition, which is similar to what happened in $\mathrm{KNO}_{3}$. It may be that the sample contained ligands which combined with $\mathrm{Hg}^{2+}$ ions during the stripping step to form a substance which fouled the electrode. A new aliquot of sample was obtained, and $0.05 \mathrm{M}$ $\mathrm{Cl}^{-}$was added. The voltammogram of the sample containing this amount of $\mathrm{Cl}^{-}$looked the same as that without $\mathrm{Cl}^{-}$, but the standard addition of $200 \mathrm{ppb} \mathrm{Hg}^{2+}$ was shifted negative (Figure 22a). Standard additions were made to the chloride-containing sample, and the calibration curve shown in Figure $22 \mathrm{~b}$ reveals that the linear range and reproducibility improved. Chloride has been added to natural water samples by others ${ }^{45}$ to improve the detection of trace metals. The identity of the peak in the sample is 

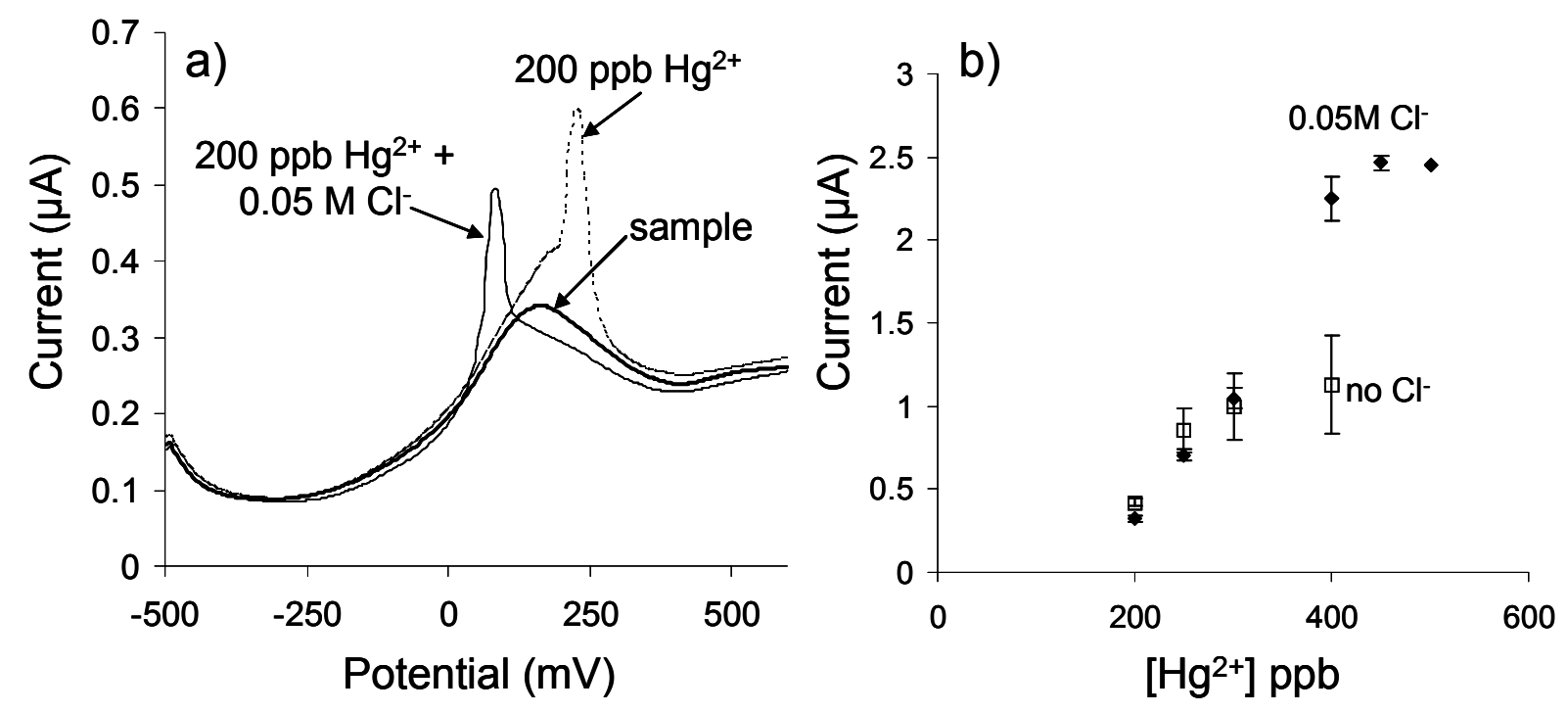

Figure 22. Standard Addition of $\mathrm{Hg}^{2+}$ to an Acidified River Water Sample in the Presence and Absence of Chloride

a) Voltammograms of river water and standard addition of $\mathrm{Hg}^{2+}$; b) Calibration curves in the presence and absence of chloride. $\mathrm{pH}<1$, Unpolished BDD Electrode, Deposition Potential $=-500 \mathrm{mV}$, Deposition Time $=5$ minutes, Final Potential $=+600 \mathrm{mV}$, Frequency $=15 \mathrm{~Hz}$, Pulse Amplitude $=25 \mathrm{mV}$, Step Potential $=4 \mathrm{mV}$, Stirred Deposition, Electrochemical cleaning of $(+600 \mathrm{mV}, 60$ seconds) was performed between each run. 
unknown, but probably isn't $\mathrm{Hg}^{2+}$. ICP analysis of the filtered, acidified samples for mercury were less than the MDL of the ICP ( $\lambda=194.163 \mathrm{~nm}, 54.8 \mathrm{ppb}$; and $\lambda=194.227 \mathrm{~nm}$, 76.5ppb), and in laboratory-prepared solutions, our electrochemical detection limits were never as low as those of the ICP.

\section{Summary of Chapter 2}

The behavior of mercury was investigated in nitrate, chloride, and thiocyanate media at unpolished BDD electrodes using ASV. The detection of mercury was difficult. In $\mathrm{KNO}_{3}$, the stripping current for $200 \mathrm{ppb} \mathrm{Hg}^{2+}$ decreased with repetition, and application of a cleaning potential did not stabilize the current. Formation of nonreducible $\mathrm{HgO}$ during the stripping step may have caused to current to decrease with repetition. This may indicate that the active sites for mercury deposition are less uniform at the $\mathrm{BDD}$ compared to the $\mathrm{GC}$ electrode. In $\mathrm{KCl}$, the stripping current for $200 \mathrm{ppb}$ $\mathrm{Hg}^{2+}$ increased with each trial until a plateau was reached. Although calomel formation could occur in $\mathrm{KCl}$, application of a cleaning potential yielded reproducible currents. Calibration curves were constructed in $\mathrm{KCl}$ under various conditions for 200-300 ppb. The best conditions were in the presence of an auxiliary element, $100 \mathrm{ppb} \mathrm{Cu}^{2+}$, where 50 ppb $\mathrm{Hg}^{2+}$ was detected using a deposition time of only 5 minutes. In a matrix of $0.6 \mathrm{M}$ $\mathrm{KCl}(\mathrm{pH}<1)$, two stripping peaks were observed for mercury using a 20-minute deposition time. The detection of mercury was attempted in thiocyanate medium, based on reports in the literature stating the advantages of this electrolyte when using GC electrodes. It was found that the BDD electrode performed poorly in thiocyanate compared to the GC electrode. 


\section{Chapter 3: Detection of Cadmium, Lead, and Copper using the Unpolished Boron-Doped Diamond Electrode}

\section{Introduction}

The behaviors of cadmium, lead, and copper were investigated using unpolished BDD electrodes for comparison to the unusual behavior observed for mercury. We also wanted to evaluate the possibility of using the BDD electrode to analyze natural water samples, and to study metal speciation in natural waters. The bulk of this chapter has been published in Electroanalysis, 2002, 16, 175-182. As pointed out in Chapter 1, applications of trace metal analysis using the BDD electrode are limited.

Metals can be found in the environment in a variety of forms. In natural waters, metals can be found in different oxidation states, as various solid oxides, as dissolved organic and inorganic complexes, or adsorbed to solid particles. The variety of metal species makes it difficult to assess the impact on the environment, because each species has a slightly different toxicity. For example, metals bound by dissolved organic matter (DOM) are less toxic, because they are less bioavailable; they are too large to permeate through the cell membranes of microorganisms. ${ }^{77}$

A metal must find its way into a cell via a channel, such as an ion or water channel, or by interacting with membrane proteins. Although nature has designed these channels and proteins to be specific for certain ions, metals which were not intended to enter the cell often do if they are the right size. It is generally accepted that the free metal ions are the most likely to enter, along with hydrated metals, small inorganic complexes, or small organometallic complexes. Therefore, it is important to determine how much of the metal is in its "free" form and how much is bound by dissolved organic matter. 
In natural waters, the free metal ion, $\mathrm{M}^{+}$, is in equilibrium with its complexed form as shown by the reaction below

$$
\mathrm{M}^{+}+\mathrm{L} \leftrightarrow \mathrm{ML}
$$

where $\mathrm{L}$ is a ligand, and ML is the complex. DOM behaves as a ligand in natural waters. Knowledge of the formation constant, $\mathrm{K}_{\mathrm{f}}$, for the above reaction would allow one to predict the concentrations of free and bound species in natural waters, and hence, the toxicity of the water. However, determining $\mathrm{K}_{\mathrm{f}}$ for dissolved organic complexes is a challenge, because natural water contains an unlimited variety of DOM, and the exact structure of DOM is not known. Further, the stoichiometry of the above reaction is not always clear. ${ }^{77}$

Although determination of formation constants is a daunting task due to so many unknowns, anodic stripping voltammetry (ASV) is well-suited for studies of metal speciation. First, the low detection limit of ASV allows "free" metal concentrations to be detected, which are often lower than total metal concentrations. Second, ASV can discriminate between the free and complexed forms of a metal, because the electrochemical activities of the two species are different. For example, the free metal may be reduced at a given potential, whereas the complexed form may require a greater overpotential. ${ }^{77}$

Speciation analysis as performed in ASV can be thought of as a titration, in which the DOM in a water sample is titrated by a metal standard. The equivalence point is when enough metal has been added to bind all of the DOM in the sample. Before the equivalence point, small currents are observed, because there is very little free metal available for electrochemical detection. Beyond the equivalence point, there is excess 
free metal, which can be detected electrochemically. From the endpoint of the titration, one can obtain the complexing capacity of the water sample for a given metal.

There are some limitations of performing speciation analysis using ASV. ${ }^{77}$ First, the endpoint of the titration may not be as sharp as desired, because the sample can contain different types of DOM. Even a single type of DOM can contain more than one metal-binding site, each of which binds the metal with different strength. Second, the free metal concentration at equilibrium, which is small in the presence of excess DOM, is measured before the endpoint; however, it has been observed that the equilibrium in reaction 16 can be shifted to the left by deposition of the metal. Finally, dissolved organic matter can adsorb to certain electrode surfaces such as mercury, which can impede the detection of the metal.

In this chapter, unpolished BDD electrodes were used to detect low-ppb levels of cadmium, lead and copper. The detection limits of these metals were much lower than that for mercury. To our knowledge, the calibration curves shown for cadmium contain the lowest concentrations yet obtained using a bare BDD electrode. The effects of chloride, ionic strength, and other metals were investigated. A river water sample was analyzed for cadmium and lead.

\section{Experimental}

The unpolished BDD electrodes, cell, and electrochemical analyzer have been described in Chapter 2. ASV experiments were performed according to the procedure also described in Chapter 2. The deposition potentials for cadmium and lead were $-1.1 \mathrm{~V}$ and $-1.0 \mathrm{~V}$, respectively. Unless stated otherwise, the final potential was $+500 \mathrm{mV}$; 
frequency, $15 \mathrm{~Hz}$; square wave amplitude, $25 \mathrm{mV}$; and step potential, $4 \mathrm{mV}$. All solutions were stirred by purging with nitrogen during the deposition step, and the stripping step was performed under quiet conditions.

Certified ACS grade salts were used to prepare the electrolyte solutions. Fulvic acid was obtained from the International Humic Substances Society. Microliter amounts of cadmium and lead stock solution (certified, Fisher) were added to the cell using an Eppendorf pipette with disposable tips.

A JY Horiba inductively coupled plasma atomic emission spectrometer (ICPAES) was used to analyze river water samples for cadmium and lead at $226.502 \mathrm{~nm}$ and $405.783 \mathrm{~nm}$, respectively.

\section{Results and Discussion}

\section{Calibration Curve and Detection Limit for Cadmium}

A calibration curve was prepared for $10-50 \mathrm{ppb} \mathrm{Cd}^{2+}$ in $0.1 \mathrm{M} \mathrm{KCl}$ using a 5minute deposition time and the experimental conditions stated previously. Linear behavior was observed $\left(\mathrm{R}^{2}=0.9946\right)$ and the reproducibility was good, as shown by the low RSD's provided in Table 3. The BDD electrode used to construct the calibration curve consistently gave the same currents for a given concentration of cadmium from day to day (Table 3), although we have observed different behavior with other BDD electrodes. Even though the stripping peak for cadmium appeared very negative (-900 $\mathrm{mV})$, it was found that the final potential must be very positive $(+500 \mathrm{mV})$ in order to obtain better sensitivity and reproducibility. When the final potential was only $-200 \mathrm{mV}$, a cleaning potential of $+500 \mathrm{mV}$, applied for 60 seconds between runs, was needed. 
Table 3. Reproducibility of Cadmium

\begin{tabular}{ccc}
\hline $\mathbf{C d}^{2+} \begin{array}{c}\text { Concentration } \\
(\mathbf{p p b})\end{array}$ & $\begin{array}{c}\text { Experiment 1 } \\
\text { \% RSD }\end{array}$ & $\begin{array}{c}\text { Experiment 2 } \\
\text { \% RSD }\end{array}$ \\
\hline 10 & 5.93 & 4.1 \\
20 & 1.52 & 4.20 \\
30 & 2.4 & 2.9 \\
50 & 2.4 & 2.4 \\
& $\mathbf{R}^{2}=0.9946, \mathrm{n}=5 \quad \mathbf{R}^{2}=0.9844, \mathrm{n}=5$ \\
\end{tabular}

Data obtained with the Unpolished BDD Electrode, $\mathrm{pH} \sim 5,0.1 \mathrm{M} \mathrm{KCl}$, Deposition Potential $=-1.1 \mathrm{~V}$, Deposition Time $=5 \mathrm{~min}$, Final Potential $=+500 \mathrm{mV}$, Frequency $=15 \mathrm{~Hz}$, Pulse Amplitude $=25 \mathrm{mV}$, Step Potential $=4 \mathrm{mV}$, Stirred Deposition. 
The voltammograms for $10-50 \mathrm{ppb} \mathrm{Cd}^{2+}$ (linear portion of the calibration curve) are shown in Figure 23. As seen in Figure 23a, the cadmium stripping peak was narrow in $0.1 \mathrm{M} \mathrm{KCl}$ electrolyte, and there was a small positive shift of the peak potential with increasing cadmium concentration. Closer inspection of the baseline (Figure 23b) revealed the presence of another stripping peak located at approximately $-450 \mathrm{mV}$ in the blank and at $-700 \mathrm{mV}$ in the cadmium standard addition. We have confirmed that this peak was lead, present as a trace impurity in the potassium chloride salt (certified ASC grade) used to prepare the electrolyte. According to the manufacturer, the salt contained $1 \mathrm{ppm}$ of heavy metals (as $\mathrm{Pb}$ ), which meant that a $0.1 \mathrm{M} \mathrm{KCl}$ solution may contain up to 7.5 ppb $\mathrm{Pb}$. Using standard additions ASV, we found that the $0.1 \mathrm{M} \mathrm{KCl}$ solution contained $6.60 \mathrm{ppb} \mathrm{Pb}$.

Figure 24 shows a calibration curve for $1-50 \mathrm{ppb} \mathrm{Cd}^{2+}$ using a 10-minute deposition time; a close-up of 1-5 ppb is shown in the inset. Although lower cadmium concentrations $(1-5 \mathrm{ppb})$ were measured, the results were non-linear, while at higher concentrations $(10-50 \mathrm{ppb})$ they were linear $\left(\mathrm{R}^{2}=0.9991\right)$. The non-linearity at low cadmium concentrations may be attributed to the manner in which cadmium deposits onto the diamond surface at low concentrations versus that at high concentrations.

Lead, ${ }^{3-5}$ copper, ${ }^{5}$ mercury, ${ }^{6,7}$ and silver ${ }^{6}$ deposit onto the electrode surface according to a nucleation and growth mechanism, and it is likely that cadmium follows the same mechanism. At high cadmium concentrations, all the active sites on the diamond surface were probably saturated by cadmium nuclei, and growth of these nuclei was the primary deposition mechanism. At the lower concentration range (Figure 24 inset), the number of active sites on the diamond surface may have been changing with 

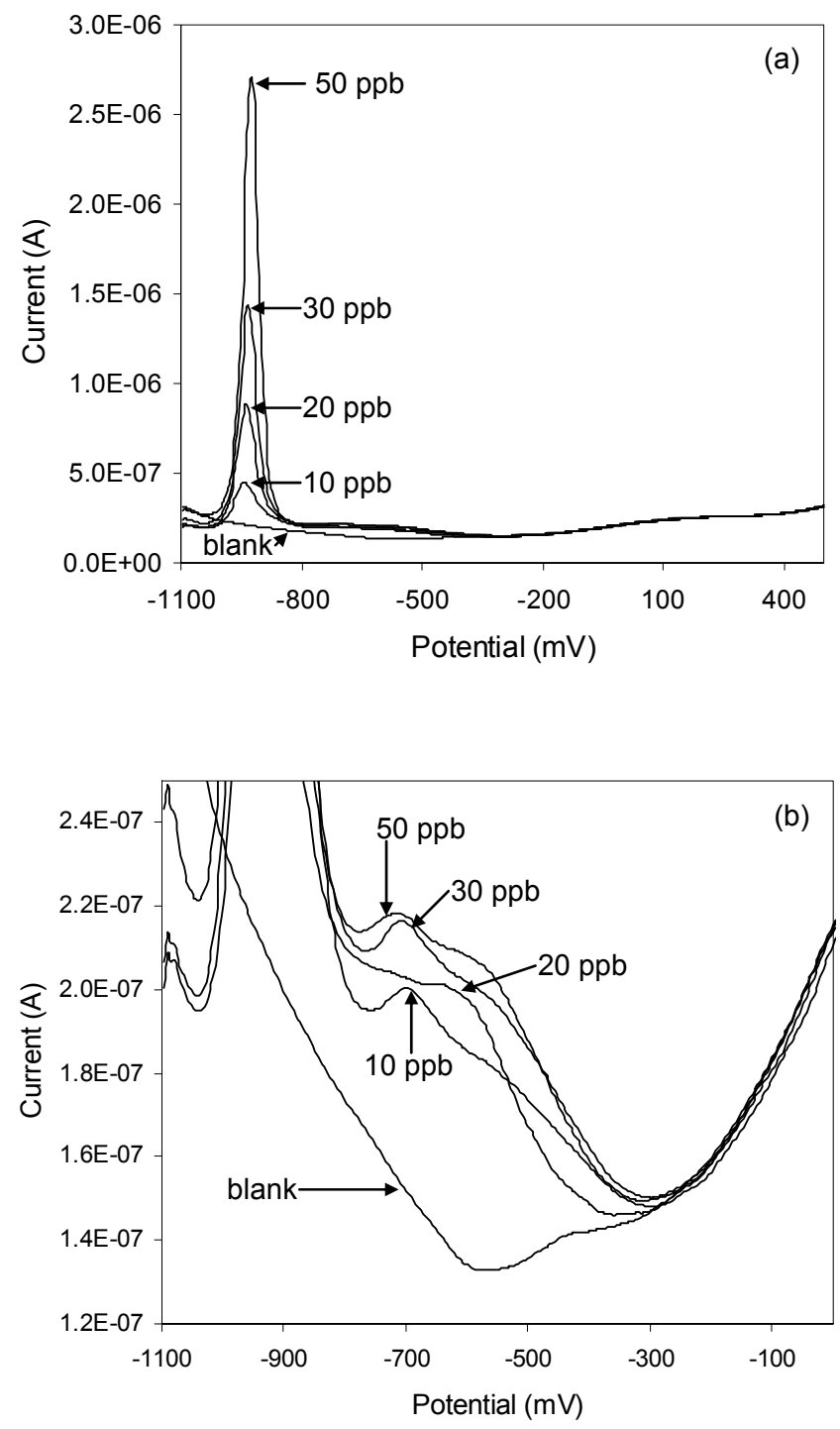

Figure 23. Voltammograms for 10-50 $\mathrm{ppb} \mathrm{Cd}^{2+}$ in $0.1 \mathrm{M} \mathrm{KCl}$

a) Entire peaks; b) Close-up of the baseline. $\mathrm{pH} \sim 5$, Unpolished BDD Electrode, Deposition Potential $=-1.1 \mathrm{~V}$, Deposition Time $=5 \mathrm{~min}$, Final Potential $=+500 \mathrm{mV}$, Frequency $=15 \mathrm{~Hz}$, Pulse Amplitude $=25 \mathrm{mV}$, Step Potential $=4 \mathrm{mV}$, Stirred Deposition. 


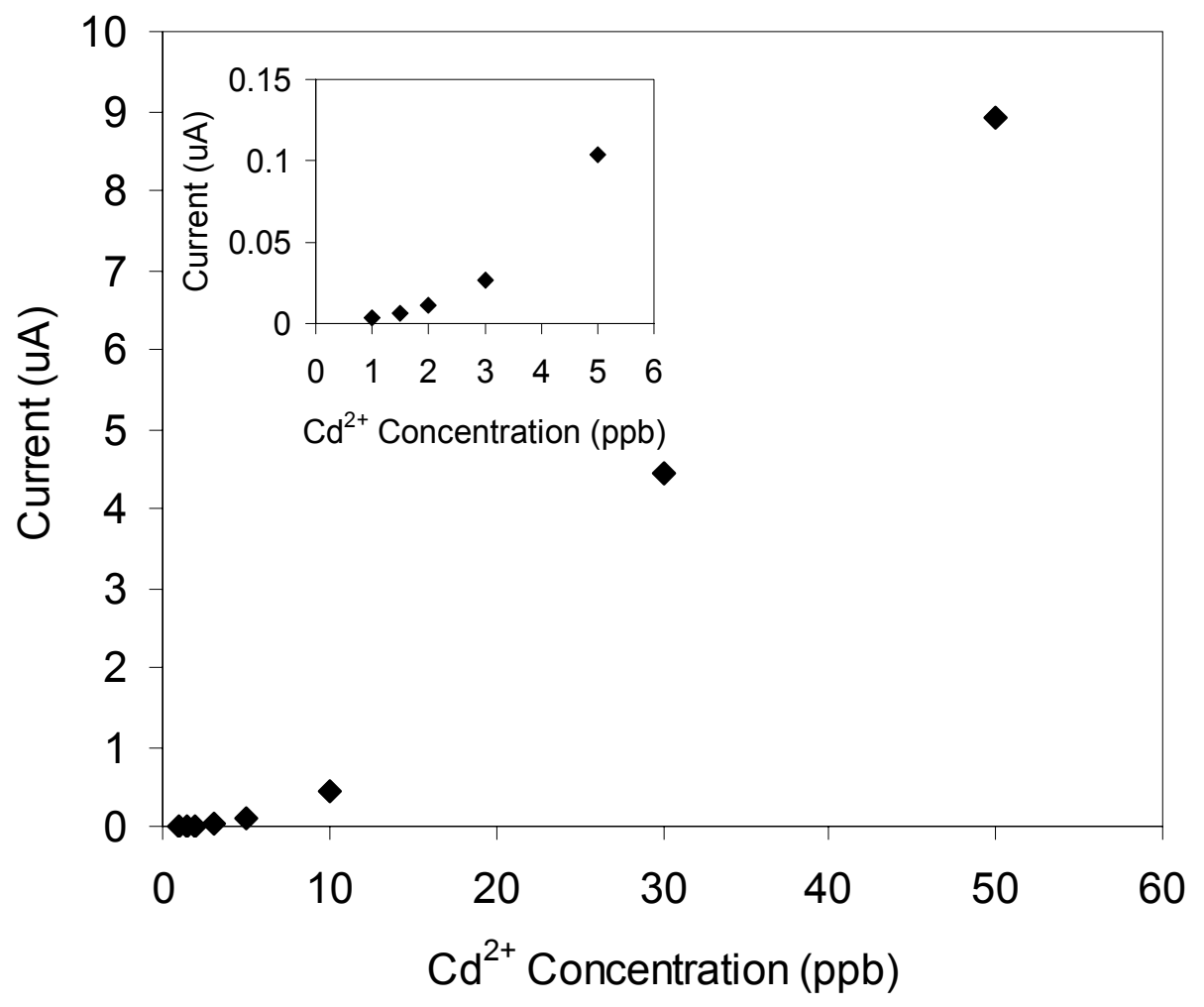

Figure 24. Calibration Curve for 1-50 $\mathrm{ppb} \mathrm{Cd}^{2+}$ in $0.1 \mathrm{M} \mathrm{KCl}$ using a 10-minute Deposition Time

Inset shows a close-up of 1-5 ppb $\mathrm{Cd}^{2+}$. $\mathrm{pH} \sim 5$, Unpolished BDD Electrode, Deposition potential $=-1.1 \mathrm{~V}$, Final Potential $=+500 \mathrm{mV}$, Frequency $=15 \mathrm{~Hz}$, Pulse Amplitude $=25$ $\mathrm{mV}$, Step Potential $=4 \mathrm{mV}$, Stirred Deposition. 
cadmium concentration, resulting in the curved calibration. It was previously reported that the number of active sites changed with silver concentration in studies of silver deposition from a $\mathrm{KCN} / \mathrm{K}_{2} \mathrm{CO}_{3}$ electrolyte. ${ }^{6}$ An alternative explanation for the non-linear behavior at low cadmium concentrations may be competition between cadmium and trace lead in the electrolyte for the active sites on the diamond electrode surface. To our knowledge, calibration curves for these low levels (1-50 ppb) of cadmium using the BDD electrode have not been reported in the literature to date.

\section{Calibration Curve and Detection Limit for Lead}

Calibration curves for lead were prepared in $0.1 \mathrm{M} \mathrm{KCl}$ using several different BDD electrodes at a deposition time of 5 minutes. Voltammograms for 1-15 $\mathrm{ppb}^{2+}$ and a calibration curve for 1-50 $\mathrm{ppb} \mathrm{Pb}^{2+}$ are shown in Figures 25 and 26, respectively.

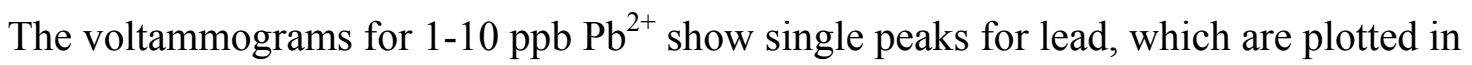
the calibration curve as the "nucleation peak," and which level off at greater lead

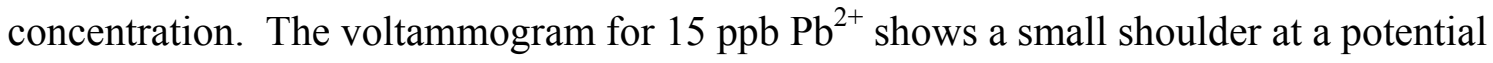
negative to the nucleation peak, which increases with lead concentration $\left(\mathrm{R}^{2}=0.9648\right.$ for

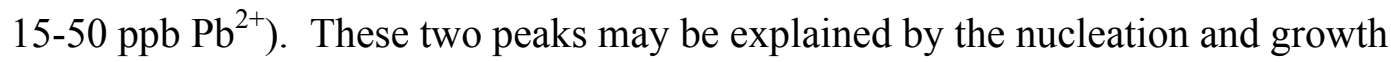
deposition mechanism for lead. The growth peak corresponds to the stripping of lead from a lead nucleation center, whereas the nucleation peak represents the stripping of lead nuclei from the bare diamond surface. This mechanism was used to explain the "current crossover" observed by others in cyclic voltammograms of higher (mM) concentrations of lead..$^{3-5}$

The appearance of both nucleation and growth peaks for lead was not observed on 


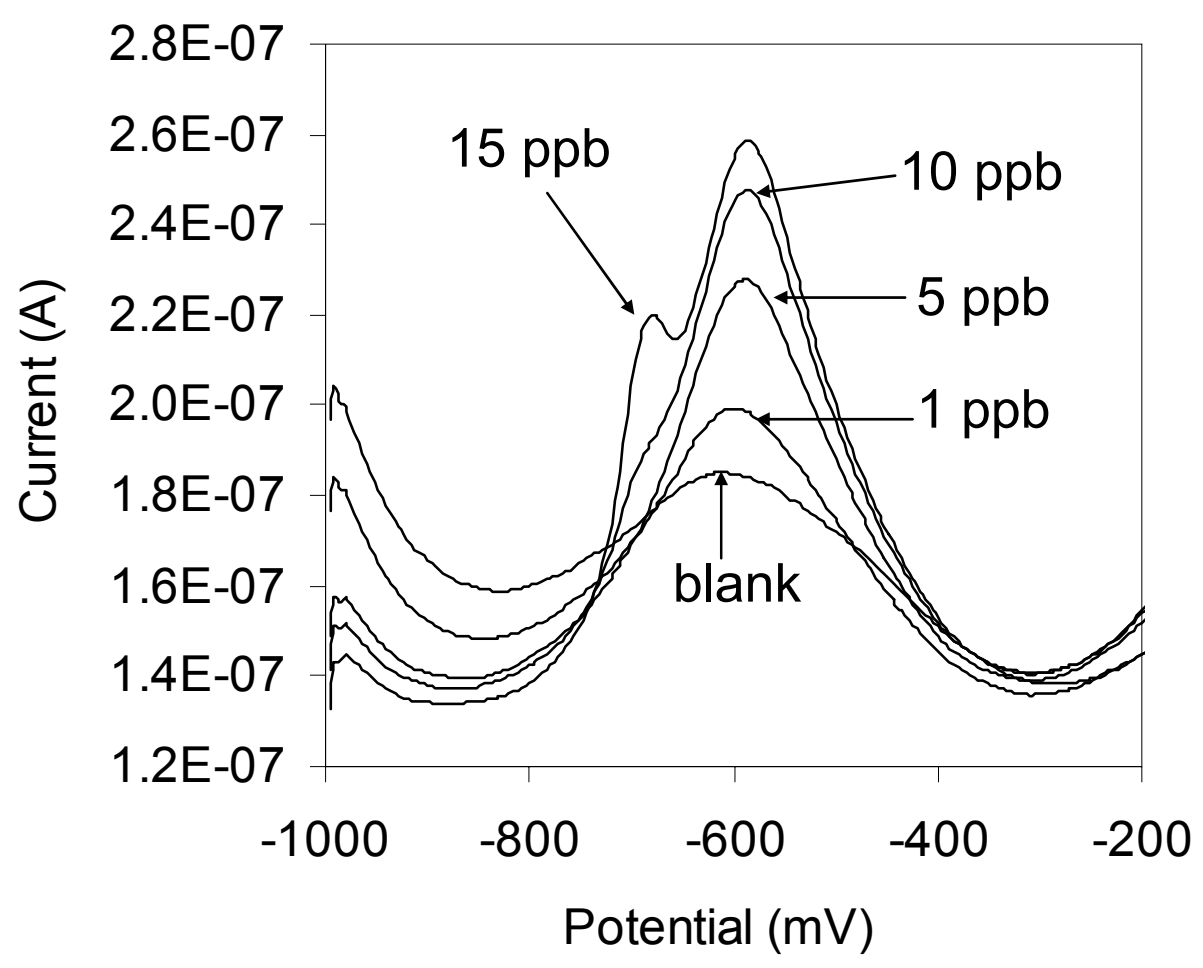

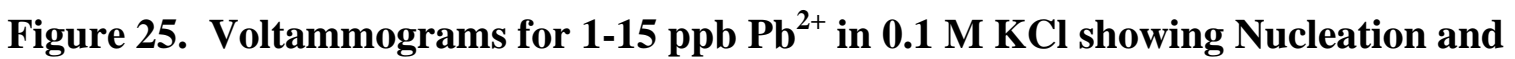
Growth

Nucleation occurs for 1-10 ppb, and growth begins to occur at $15 \mathrm{ppb}$. $\mathrm{pH} \sim 5$, Unpolished BDD Electrode, Deposition Potential $=-1.0 \mathrm{~V}$, Deposition Time $=5.0 \mathrm{~min}$, Final Potential $=+500 \mathrm{mV}$, Frequency $=15 \mathrm{~Hz}$, Pulse Amplitude $=25 \mathrm{mV}$, Step Potential $=4$ $\mathrm{mV}$, Stirred Deposition. 


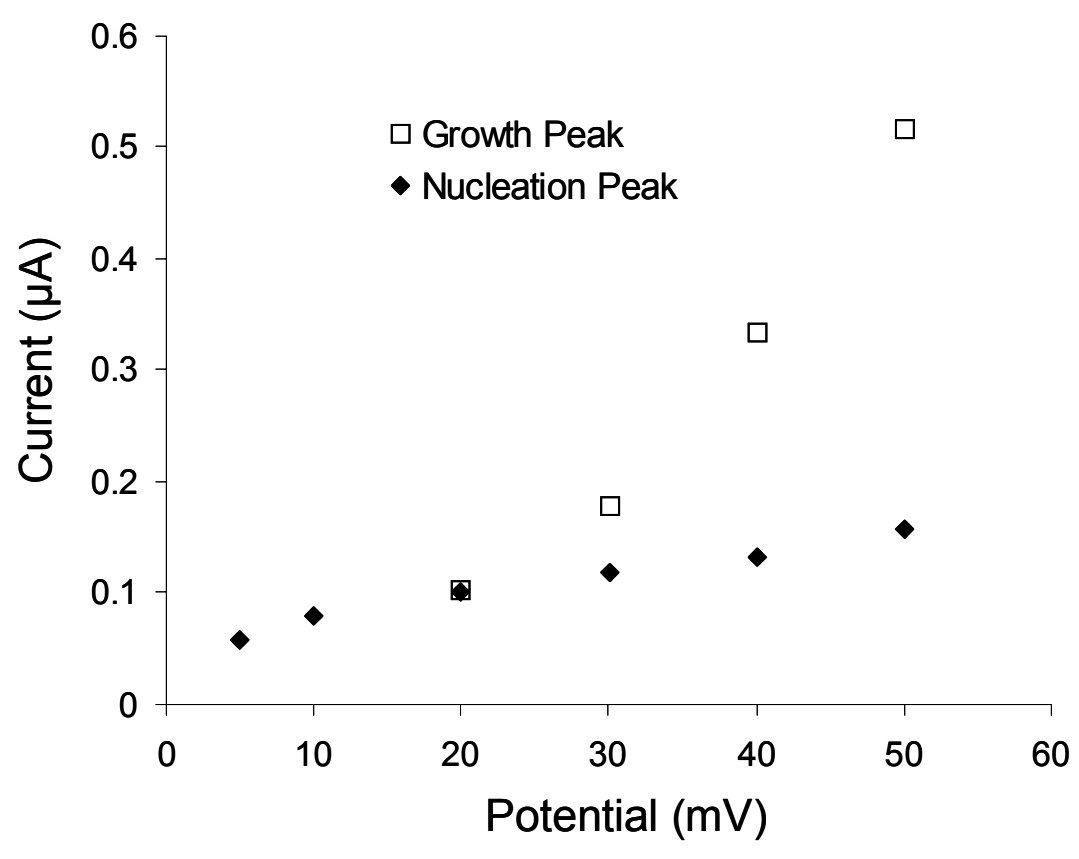

Figure 26. Calibration Curve for $\mathrm{Pb}^{2+}$ in $0.1 \mathrm{M} \mathrm{KCl}$

$\mathrm{pH} \sim 5$, Unpolished BDD Electrode, Deposition Potential $=-1.0 \mathrm{~V}$, Deposition Time $=5.0 \mathrm{~min}$, Final Potential $=+500 \mathrm{mV}$, Frequency $=15 \mathrm{~Hz}$, Pulse Amplitude $=25 \mathrm{mV}$, Step Potential $=4 \mathrm{mV}$, Stirred Deposition. 
every diamond we investigated; however, when only a single peak was observed, the calibration curve was still non-linear, as in Figure 26. The reason that distinct nucleation and growth peaks were not observed on every diamond studied may be attributed to differences between diamond electrodes. For those diamonds for which two distinct nucleation and growth peaks were observed, there probably were a greater number of active sites on the diamond surface for nucleation, and hence, a separate nucleation peak was observed.

It appeared as though there was some variety in the BDD electrodes used in this work for cadmium and lead. In addition, the behavior of a single BDD electrode was

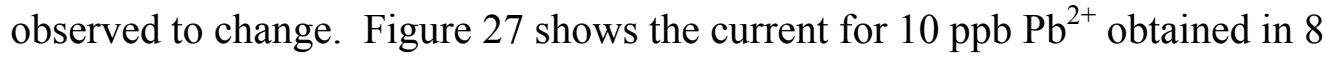
consecutive experiments (on 8 different days). The trend in Figure 27 indicates that the sensitivity of the BDD electrode increased with use. As previously mentioned in Chapter $1, \mathrm{sp}^{2}$ carbon appears to play a role in metal deposition; perhaps sites composed of $\mathrm{sp}^{2}$ carbon were gradually activated with use. At a higher concentration of $200 \mathrm{ppb} \mathrm{Pb}^{2+}$, the current was rather stable throughout the 8 experiments $(14.80 \pm 2.55 \mu \mathrm{A})$. It is not known why the current for $200 \mathrm{ppb} \mathrm{Pb}^{2+}$ didn't increase with use. If the number of active sites on the BDD had increased with use, then more nuclei should have formed even at higher concentrations.

A solution of $20 \mathrm{ppb} \mathrm{Pb}^{2+}$ in $0.1 \mathrm{M} \mathrm{KCl}$ was analyzed with a polished bare glassy carbon electrode for comparison to the diamond electrode, under the conditions shown in Figure 25. The currents obtained using the glassy carbon electrode were unstable, and the difference in the background current for the two electrodes was also significant. The baseline in blank $\mathrm{KCl}$ reached a maximum of $400 \mathrm{nA}$ for the diamond, as compared to 


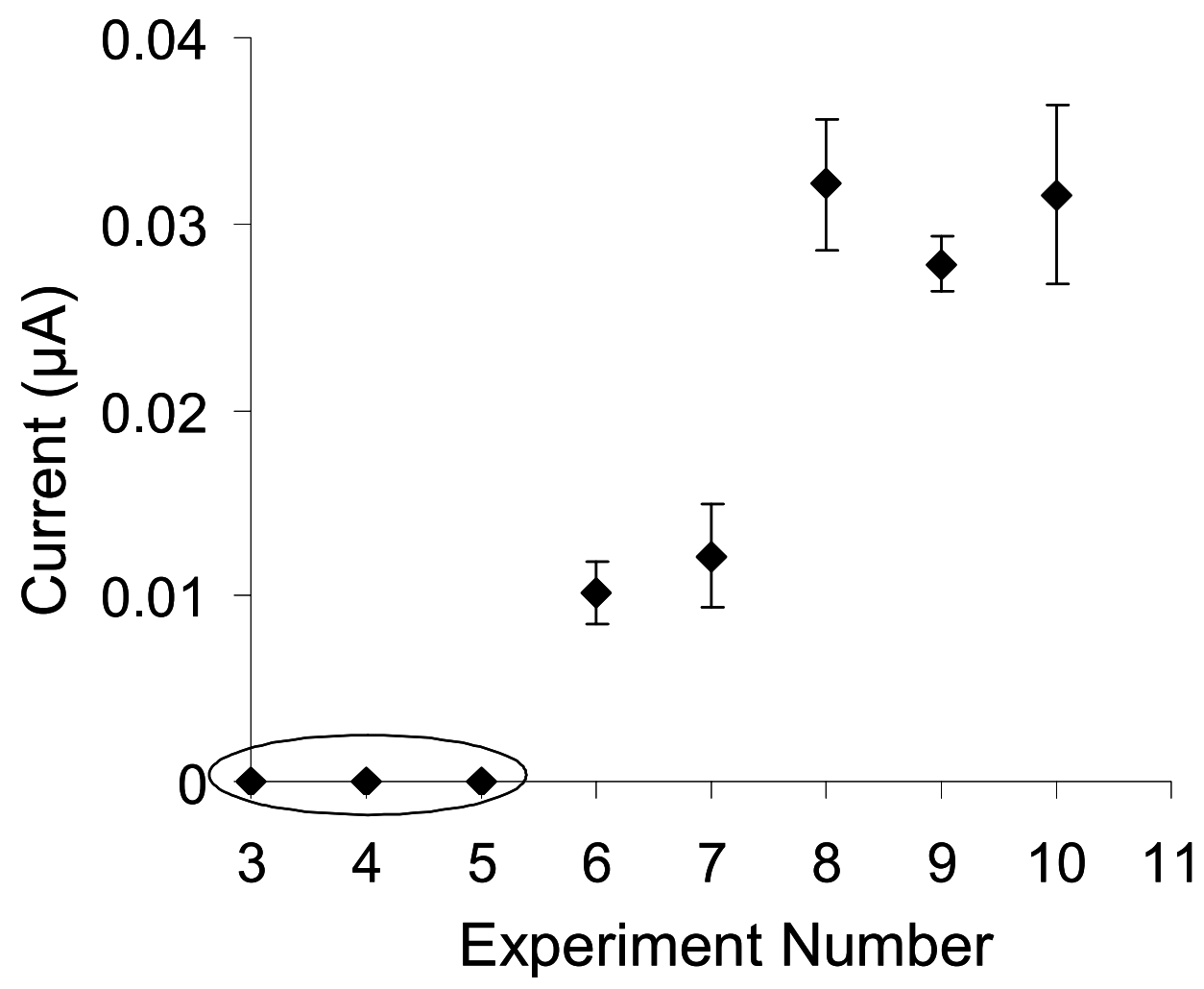

Figure 27. Reproducibility of $10 \mathrm{ppb} \mathrm{Pb}^{2+}$ in $0.1 \mathrm{M} \mathrm{KNO}_{3}$

The circled points indicated that $10 \mathrm{ppb}$ was not detected in those experiments. $\mathrm{pH} \sim 5$, Unpolished BDD Electrode, Deposition Potential $=-1.0 \mathrm{~V}$, Deposition Time $=5.0 \mathrm{~min}$, Final Potential $=+500 \mathrm{mV}$, Frequency $=15 \mathrm{~Hz}$, Pulse Amplitude $=25$ $\mathrm{mV}$, Step Potential $=4 \mathrm{mV}$, Stirred Deposition. 
$25 \mu \mathrm{A}$ for the glassy carbon electrode. This observation is in agreement with other reports in the literature that indicated lower background current for the boron-doped diamond electrode. ${ }^{78}$ The BDD electrode was thus superior to the glassy carbon for trace analysis of lead in $\mathrm{KCl}$ solutions, although others ${ }^{45}$ have found that when both electrodes are plated with mercury, the performance of the BDD and GC electrodes are equal.

\section{Effect of Electrolyte on Cadmium Response}

Potassium nitrate was investigated as a supporting electrolyte for cadmium because it contained less heavy metal impurities than potassium chloride. Using a deposition time of 5 minutes, a stripping current was not observed until a cadmium concentration of $50 \mathrm{ppb}$, unlike in $\mathrm{KCl}$ where a current was observed for $10 \mathrm{ppb} \mathrm{Cd}^{2+}$ (see Figure 23). The sensitivity in $\mathrm{KNO}_{3}(26 \mathrm{nA} / \mathrm{ppb})$ was also less than that in $\mathrm{KCl}(65$ $\mathrm{nA} / \mathrm{ppb}$ ). The background current near the deposition potential in $0.1 \mathrm{M} \mathrm{KNO}_{3}$ increased with each addition of cadmium, unlike in $0.1 \mathrm{M} \mathrm{KCl}$, where the background current actually decreased with each addition of cadmium (see Figure 23b). The reason for the increased background in $\mathrm{KNO}_{3}$ is not known; however, it was not a $\mathrm{pH}$ effect. In a separate experiment, microliter amounts of nitric acid with the same $\mathrm{pH}$ as the cadmium stock solution were added to the $\mathrm{KNO}_{3}$ electrolyte, and the background current did not increase. Also, "repetition" did not cause the background to increase; a blank solution of $0.1 \mathrm{M} \mathrm{KNO}_{3}$ was run repeatedly, and did not result in a higher background current.

Others ${ }^{79}$ have observed increased background in nitrate solution containing cadmium, and have attributed it to the reduction of nitrate on deposited cadmium. 
The effect of $\mathrm{KNO}_{3}$ was further studied in a supporting electrolyte of low ionic strength. The experiment began in a $1 \mathrm{mM}$ chloride solution to which microliter amounts of $3 \mathrm{M} \mathrm{KNO}_{3}$ were added. The resulting voltammograms in Figure 28 show that the stripping current for $50 \mathrm{ppb} \mathrm{Cd}{ }^{2+}$ was enhanced as $\mathrm{KNO}_{3}$ was added, up to an ionic strength of $10 \mathrm{mM}$. However, when the ionic strength was raised to $25 \mathrm{mM}$, the stripping peak for cadmium was suppressed by the higher background current, similar to what was seen in $0.1 \mathrm{M} \mathrm{KNO}_{3}$. When the experiment was repeated by adding $3 \mathrm{M} \mathrm{KCl}$ instead of 3 $\mathrm{M} \mathrm{KNO}_{3}$, the cadmium stripping peak was enhanced in a similar manner, but was never suppressed at higher ionic strengths. At chloride concentrations greater than $10 \mathrm{mM}$, the cadmium stripping peak $(2 \mathrm{uA})$ remained constant, similar to the current obtained in 0.1 $\mathrm{M} \mathrm{KCl}$. Thus, the addition of either $\mathrm{KNO}_{3}$ or $\mathrm{KCl}$ to a natural water sample will result in lower background current, and hence higher stripping currents for cadmium. However, $\mathrm{KNO}_{3}$ should be added only when the ionic strength of the sample is less than

approximately $10 \mathrm{mM}$. A similar method was used by Peilin et al., ${ }^{45}$ where the chloride concentration of water samples was adjusted to $0.1 \mathrm{M}$ in order to measure the lead concentration using a mercury-plated BDD.

\section{Effect of Electrolyte on Lead Response}

Calibration curves for lead were prepared in $0.1 \mathrm{M} \mathrm{KNO}_{3}$. Unlike the behavior of cadmium in $\mathrm{KNO}_{3}$, the background current near the deposition potential for lead did not increase with each addition of lead. Thus, the measurement of lead was similar in $\mathrm{KNO}_{3}$ and $\mathrm{KCl}$, and $10 \mathrm{ppb}$ was the lowest concentration which fell within the linear range of the calibration curve using a 5-minute deposition time. The lead stripping peak was 


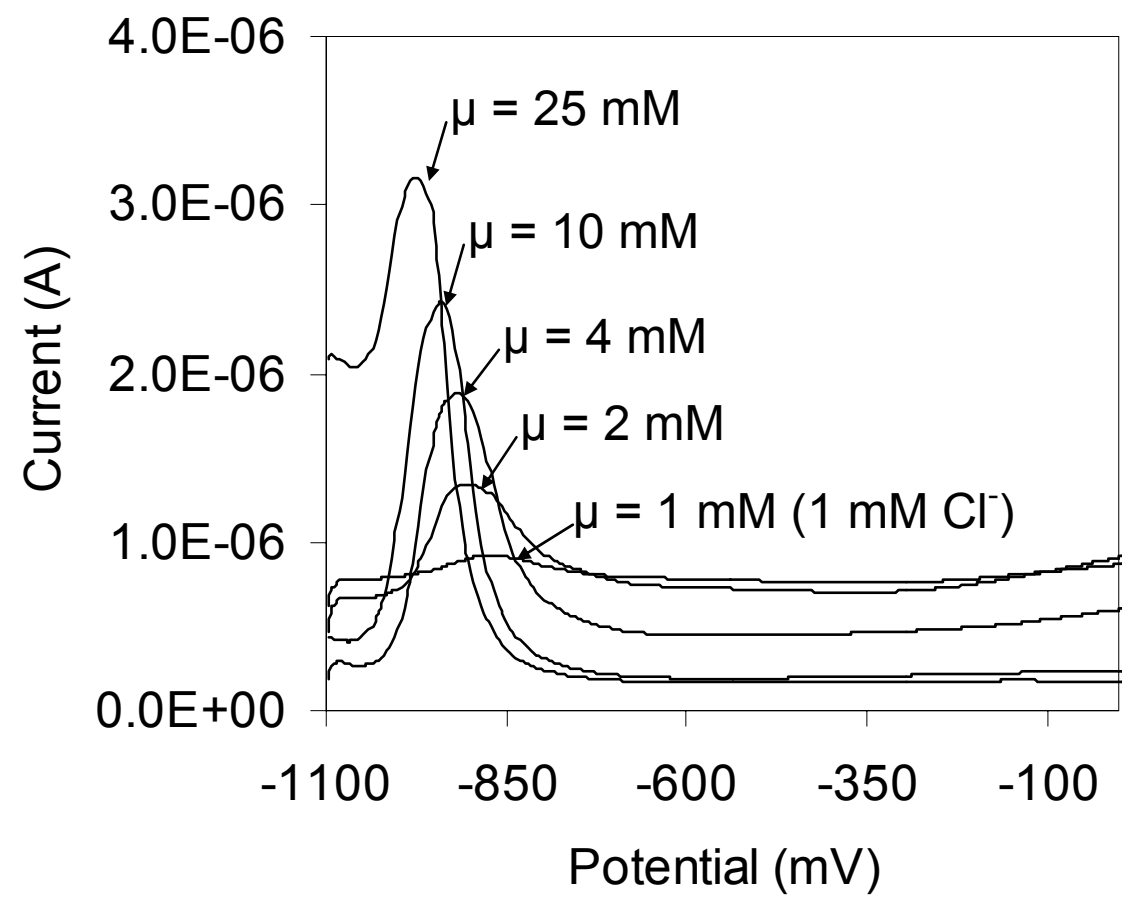

Figure 28. Effect of Increasing Ionic Strength on $50 \mathrm{ppb} \mathrm{Cd}^{2+}$

Ionic strength adjusted by adding $3 \mathrm{M} \mathrm{KNO}_{3}$. All solutions contained $1 \mathrm{mM} \mathrm{KCl}$. $\mathrm{pH} \sim 5$, Unpolished BDD Electrode, Deposition Potential $=-1.1 \mathrm{~V}$, Deposition Time $=5 \mathrm{~min}$, Final Potential $=+500 \mathrm{mV}$, Frequency $=15 \mathrm{~Hz}$, Pulse Amplitude $=25 \mathrm{mV}$, Step Potential $=4 \mathrm{mV}$, Stirred Deposition. 
enhanced at higher ionic strength, and either $\mathrm{KCl}$ or $\mathrm{KNO}_{3}$ could be used to adjust the ionic strength.

\section{Effect of Lead and Cadmium on Each Other}

The effect of lead on the cadmium stripping peak is shown in Figure 29. Low levels of cadmium ( $3 \mathrm{ppb}$ ) were completely suppressed if the lead concentration exceeded $40 \mathrm{ppb}$. As shown in the inset of Figure 29, higher levels of cadmium (50 ppb) were also suppressed by lead, but still yielded a small current at lead concentrations greater than 50 ppb. Although an intermetallic peak was never observed by us, others have suggested that intermetallic formation between cadmium and lead could explain cadmium peak suppression by lead when using a mercury-plated glassy carbon electrode. ${ }^{80-81}$ Competition between cadmium and lead for active sites on the diamond surface may also explain the observed peak suppression of cadmium. Lead may "out-compete" cadmium

for the active sites, because of its larger diffusivity ${ }^{82}$ and more positive standard reduction potential.

The effect of cadmium on $5 \mathrm{ppb}$ lead in $0.1 \mathrm{M} \mathrm{KCl}$ was investigated. In general,

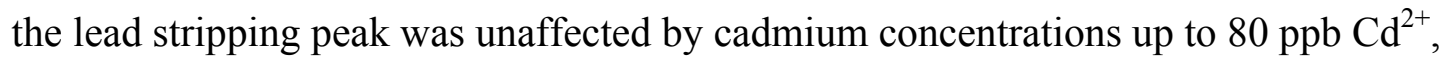
and peak suppression for lead was not observed until a cadmium concentration of 160 ppb. Although a slight enhancement (14\%) of the lead peak was initially observed when the cadmium concentration equaled $3 \mathrm{ppb}$, the lead peak returned to the initial values obtained without cadmium and then remained constant. Assuming that a $\mathrm{Cd}-\mathrm{Pb}$ intermetallic compound had the same stripping potential as lead, one would expect the lead peak to have increased due to the presence of dissolved cadmium. Since lead was 


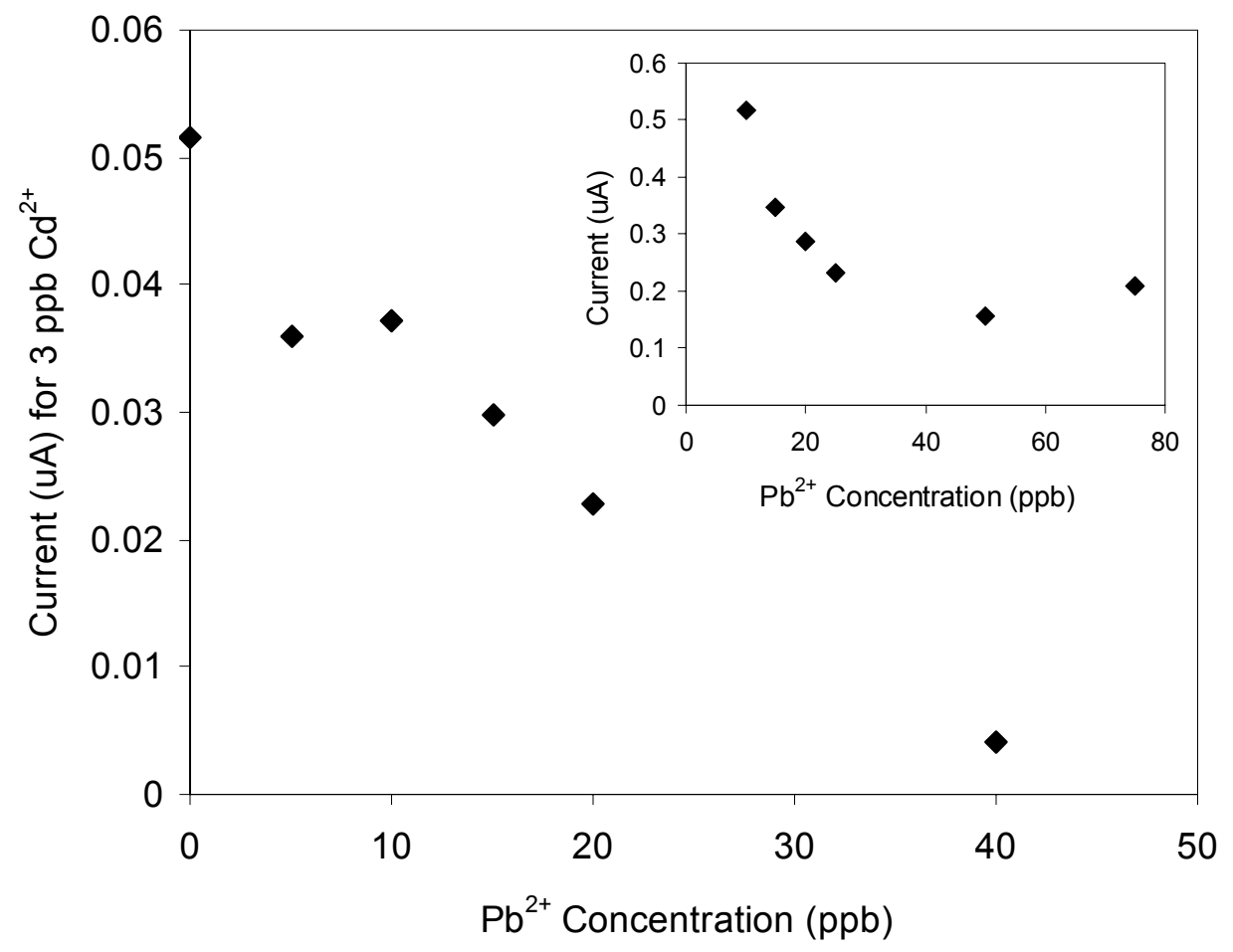

Figure 29. Effect of Increasing Lead Concentration on 3 ppb Cd ${ }^{2+}$

Inset shows the effect of increasing lead concentration on $50 \mathrm{ppb} \mathrm{Cd}^{2+}$. $\mathrm{pH} \sim 5,0.1 \mathrm{M}$ $\mathrm{KCl}$, Unpolished BDD Electrode, Deposition Potential $=-1.1 \mathrm{~V}$, Deposition Time $=5$ min, Final Potential $=+500 \mathrm{mV}$, Frequency $=15 \mathrm{~Hz}$, Pulse Amplitude $=25 \mathrm{mV}$, Step Potential $=4 \mathrm{mV}$, Stirred Deposition. 
largely unaffected by cadmium, intermetallic formation between the two was unlikely. Thus, we conclude that for the cadmium and lead concentrations we studied, peak suppression of cadmium by lead is probably caused by the larger diffusivity and standard reduction potential for lead, and not a $\mathrm{Cd}-\mathrm{Pb}$ intermetallic interference.

\section{Effect of Copper on the Cadmium and Lead Signals}

In $0.1 \mathrm{M} \mathrm{KCl}$, the addition of $5 \mathrm{ppb} \mathrm{Cu}^{2+}$ completely suppressed the $10 \mathrm{ppb}$ cadmium stripping peak. Although this was not further investigated by us, others using graphite electrodes have added mercury as a "third element" to overcome peak suppression of cadmium by copper. ${ }^{55}$

A comparison of the calibration curves for low levels of lead in the presence and absence of copper is shown in Figure 30. Clearly, when $80 \mathrm{ppb} \mathrm{Cu}^{2+}$ was present in the electrolyte, the stripping currents for lead were much greater and the calibration curve more sensitive ( $73 \mathrm{nA} / \mathrm{ppb}$ versus $17 \mathrm{nA} / \mathrm{ppb})$. Others have also observed an enhancement of the lead stripping peak upon the addition of copper. Using a bare glassy carbon electrode, $5 \mathrm{ppm} \mathrm{Pb}^{2+}$ was enhanced when the mole ratio of copper to lead equaled 1.8. ${ }^{54}$ Low-ppb levels of lead were enhanced $50 \%$ by the addition of $60 \mathrm{ppb}$ $\mathrm{Cu}^{2+}$ using a nafion-coated chemically modified glassy carbon electrode; however, the

lead peak shifted positive and broadened. ${ }^{83}$ We observed no shifting or broadening of the lead peak upon addition of copper using the BDD electrode.

Voltammograms for $5 \mathrm{ppb} \mathrm{Pb}^{2+}$ in $0.1 \mathrm{M} \mathrm{KCl}$ with and without copper are shown in Figure 31, and the peak potential for lead was the same in both cases. In the presence of $80 \mathrm{ppb}$ copper (trace b), the lead peak was enhanced, and two peaks representing the 


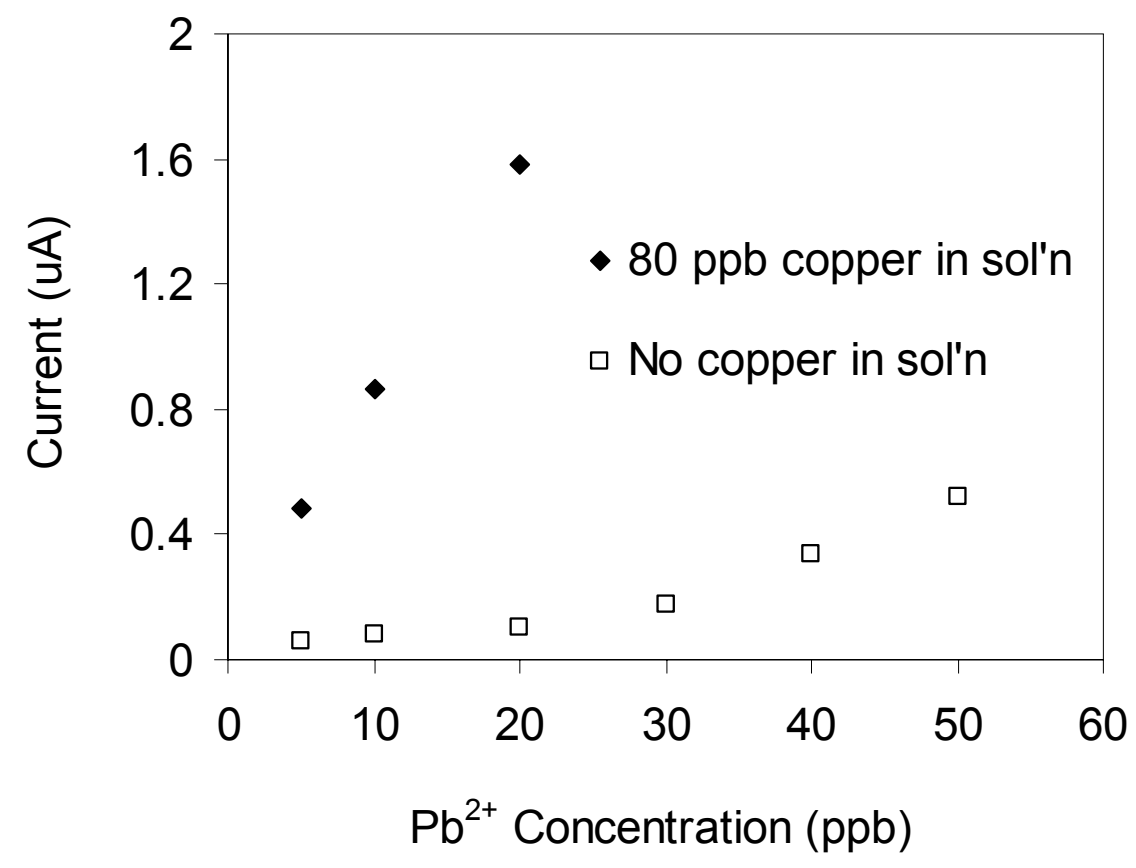

Figure 30. Effect of Copper on the Calibration of Lead

$0.1 \mathrm{M} \mathrm{KCl}, \mathrm{pH} \sim 5$, Unpolished BDD Electrode, Deposition Potential $=-1.0 \mathrm{~V}$, Deposition Time $=5.0 \mathrm{~min}$, Final Potential $=+500 \mathrm{mV}$, Frequency $=15 \mathrm{~Hz}$, Pulse Amplitude $=25 \mathrm{mV}$, Step Potential $=4 \mathrm{mV}$, Stirred Deposition. 


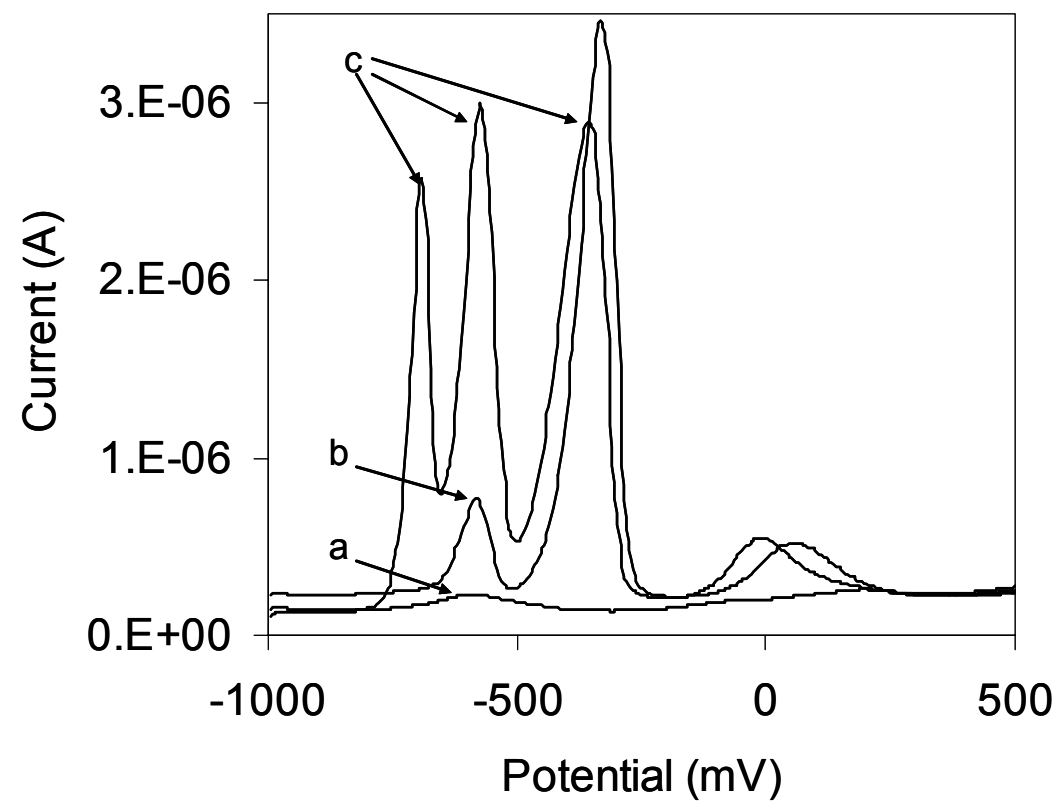

Figure 31. Voltammograms for Lead and Copper in $0.1 \mathrm{M} \mathrm{KCl}$

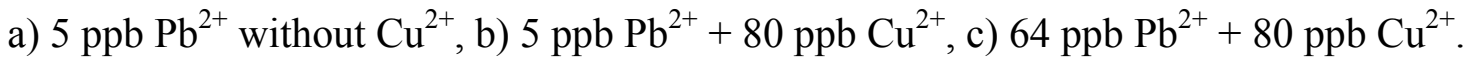
$0.1 \mathrm{M} \mathrm{KCl}, \mathrm{pH} \sim 5$, Unpolished BDD Electrode, Deposition Potential = -1.0 V, Deposition Time $=5.0 \mathrm{~min}$, Final Potential $=+500 \mathrm{mV}$, Frequency $=15 \mathrm{~Hz}$, Pulse Amplitude $=25$ $\mathrm{mV}$, Step Potential $=4 \mathrm{mV}$, Stirred Deposition. 
two-step oxidation of copper appeared at $-300 \mathrm{mV}$ and $0 \mathrm{mV} .^{84}$ It should be emphasized that the two copper oxidation peaks were also found in $\mathrm{KCl}$ solution containing no lead. The enhancement of the lead peak by copper may be explained either by the formation of a $\mathrm{Cu}-\mathrm{Pb}$ intermetallic compound which appeared at the same stripping potential as lead, or by the preferential deposition of lead onto copper nuclei.

The simultaneous deposition of lead and copper on glassy carbon surfaces has been studied, and three peaks due to (1) copper oxidation, (2) oxidation of a $\mathrm{Cu}-\mathrm{Pb}$ intermetallic compound, and (3) lead oxidation have been reported. ${ }^{52-55}$ At relatively high copper concentrations, the lead peak was absent, because the lead was dissolved in the $\mathrm{Cu}-\mathrm{Pb}$ intermetallic compound. Under these conditions, the intermetallic peak increased linearly with standard addition of small amounts of lead. When an excess of lead was added, a separate peak due to lead oxidation appeared, complicating the quantification of lead. This same behavior was observed at the BDD electrode as shown in trace $\mathrm{c}$ of Figure 31, where a new lead peak appeared at $-700 \mathrm{mV}$ at higher lead concentration. Although our lead-copper data appeared to be similar to that found with glassy carbon electrodes, we observed no distinct $\mathrm{Cu}-\mathrm{Pb}$ intermetallic peak; thus, the situation remained unclear.

In their study of lead and copper deposition on BDD electrodes using higher metal concentrations (typically low-ppm levels), Prado et al..$^{5}$ did not observe intermetallic formation between lead and copper, and proposed that the copper deposited onto the bare diamond surface as nuclei, which were then covered by a "shell" of deposited lead. Three peaks were observed, due to (1) oxidation of lead from the copper nuclei, (2) hydrogen evolution on the exposed copper nuclei, and (3) oxidation of copper 
from the bare diamond. Our data from cyclic voltammograms in $\mathrm{KCl}$ at both acidic and neutral pH's clearly did not contain the hydrogen evolution peak, which Prado et al. ${ }^{5}$ found in $\mathrm{HNO}_{3}$. The reason that we did not observe hydrogen evolution on the exposed copper nuclei may be due to the complexing nature of the chloride electrolyte. Lead chloride complexes formed in the stripping step may block accessibility of water or protons to the exposed copper nuclei. This blocking of the electrode surface was suggested by the work of Zak et al. ${ }^{85}$ in which AFM studies of copper stripping from BDD electrodes in complexing electrolytes showed that copper complexes could block the electrode surface. Thus, we propose that the two lead peaks found in trace $\mathrm{c}$ of Figure 31 represent stripping from two different surfaces, either the bare diamond surface or a copper nucleation center. In addition, trace $\mathrm{c}$ shows a slight decrease in the copper peak at $-300 \mathrm{mV}$, which was also observed by Prado et al., ${ }^{5}$ and indicates that the growth of copper nuclei was hindered by being covered with a lead deposit.

\section{Analysis of a River Water Sample for Cadmium and Lead}

Samples from the Monongahela River were filtered and preserved using standard methods. ${ }^{76}$ Since the samples were preserved with nitric acid to a $\mathrm{pH}<2$, the $\mathrm{pH}$ was adjusted to about 5 using sodium hydroxide prior to electrochemical analysis. Although the ionic strength of the sample was unknown, the acidification and neutralization steps probably resulted in an ionic strength greater than $0.02 \mathrm{M}$, which is required for optimum cadmium detection (see Figure 28). A voltammogram of the sample was obtained using a 5-minute deposition time, and contained a peak at the stripping potential for cadmium, which made it unnecessary to add chloride to enhance the cadmium peak. Using standard additions, the river water sample was found to contain $9.41 \mathrm{ppb} \mathrm{Cd}^{2+}$. ICP-AES was used 
to validate these results, and confirmed that the amount of cadmium in the sample was less than the detection limit of the ICP (36.4 ppb at $\lambda=226.502)$. Therefore, the acidified river sample was spiked with $50 \mathrm{ppb} \mathrm{Cd}^{2+}$ and again analyzed using both the BDD electrode and the ICP. The results were in good agreement, with $59.8 \mathrm{ppb}(\mathrm{RSD}=16.1 \%$, $\mathrm{n}=3)$ and $55 \mathrm{ppb} \mathrm{Cd}^{2+}(\mathrm{RSD}=21 \%, \mathrm{n}=3)$ determined using the BDD electrode and ICP, respectively.

Lead was not detected electrochemically in the river sample, nor with the ICP $(<27.2 \mathrm{ppb}, \lambda=405.783 \mathrm{~nm})$. In the standard addition curve for lead, the currents for concentrations less than $50 \mathrm{ppb}$ were much smaller than expected. We thought this was caused by complex formation between the added lead and DOM in the river water. Figure 32 compares the standard curves prepared in the river sample, $0.1 \mathrm{M} \mathrm{KNO}_{3}$, $1.25 \times 10^{-7} \mathrm{M}$ EDTA and $1.25 \times 10^{-7} \mathrm{M}$ fulvic acid. Figure $32 \mathrm{a}$ shows the entire concentration range from $10-200 \mathrm{ppb}$, where it can be seen that above $50 \mathrm{~Pb}^{2+}$, the current was linear with concentration in all solutions. In addition, Table 4 shows that the

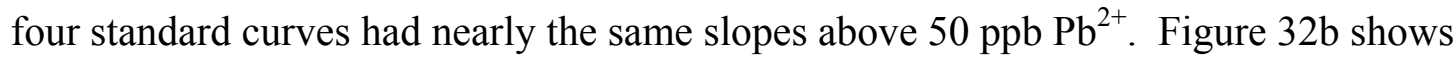

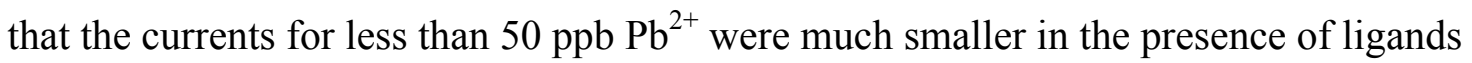
compared to those in the $\mathrm{KNO}_{3}$ solution. This suggested that the lead was complexed and electrochemically unavailable. Once the added lead concentration exceeded the binding capacity of the ligand, the "free" lead concentration increased and thus the current increased. In a separate experiment, the river sample was spiked with $100 \mathrm{ppb}$ $\mathrm{Pb}^{2+}$, and it was determined that about $75 \%$ of the spiked lead was complexed by ligands in the sample. Although it is not possible to determine total lead electrochemically in the presence of organic material at this $\mathrm{pH}$, these results indicate that useful data regarding 

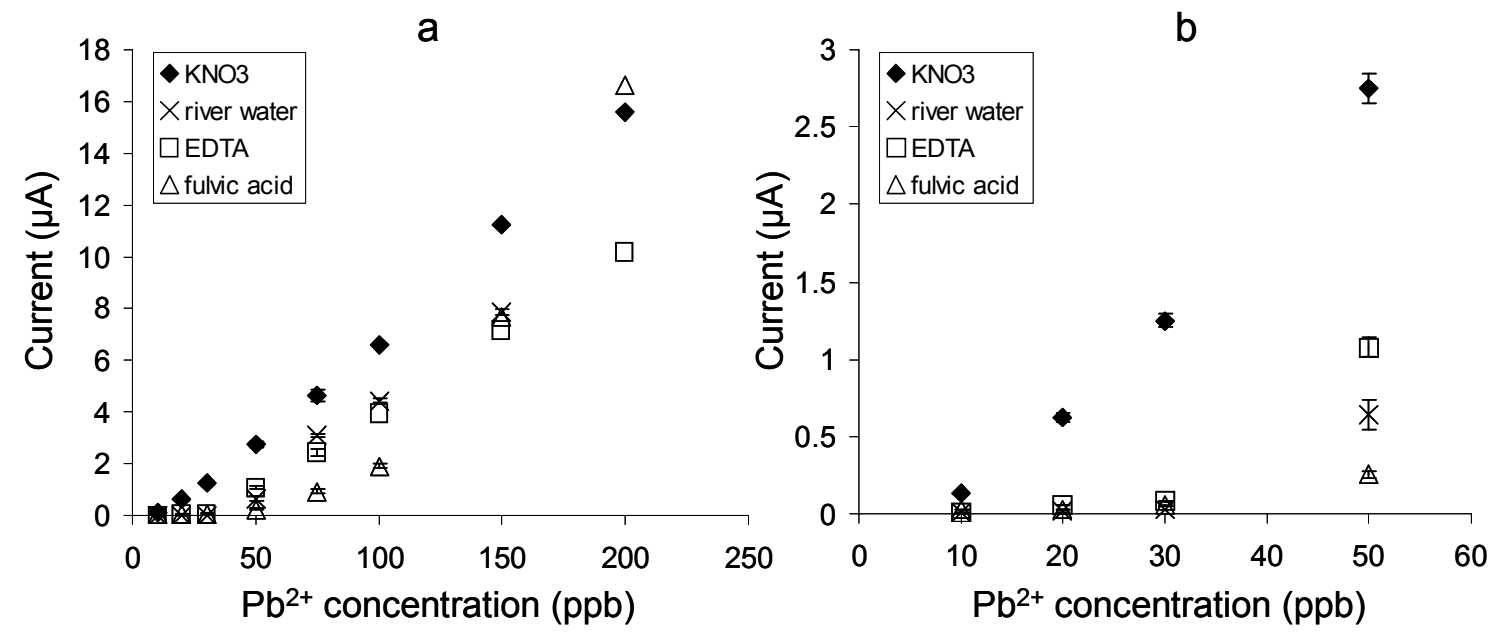

Figure 32. Standard Addition of Lead in Various Matrices

a) Entire concentration range; b) Close-up of $<50 \mathrm{ppb} \mathrm{Pb}^{2+}$. [EDTA] $=[$ Fulvic Acid] $=$ $1.25 \times 10^{-7} \mathrm{M}, \mathrm{pH} \sim 5$, Unpolished BDD Electrode, Deposition Potential $=-1.0 \mathrm{~V}$, Deposition Time $=5.0 \mathrm{~min}$, Final Potential $=+500 \mathrm{mV}$, Frequency $=15 \mathrm{~Hz}$, Pulse Amplitude $=25 \mathrm{mV}$, Step Potential $=4 \mathrm{mV}$, Stirred Deposition. 
Table 4. Slopes of Calibration Curves for Free Lead in Various Matrices

All other parameters as in Figure 32.

\begin{tabular}{lcc}
\hline Electrolyte & Slope nA/ppb & Conc. range \\
\hline $0.1 \mathrm{M} \mathrm{KNO}_{3}$ & 86.3 & $50-200$ \\
River Sample & 70.0 & $50-150$ \\
$1.25 \times 10^{-7} \mathrm{M}$ EDTA & 61.3 & $50-200$ \\
$1.25 \times 10^{-7}$ M Fulvic Acid & 67.5 & $50-100$ \\
\hline
\end{tabular}


the complexing ability of natural waters for trace metals may be obtained using the BDD electrode.

\section{Summary of Chapter 3}

Square wave anodic stripping voltammetry was used with a boron-doped diamond electrode to detect cadmium and lead in stirred solutions of $\mathrm{KNO}_{3}$ and $\mathrm{KCl}$. The calibration curves were non-linear at low concentrations (1-5 ppb), probably due to the nucleation and growth deposition mechanism for these metals. In $\mathrm{KCl}, 1 \mathrm{ppb}$ of cadmium was measured using a 10-minute deposition time, but $10 \mathrm{ppb}$ was the lowest concentration which fell within the linear portion of the calibration curve. The higher background current in $\mathrm{KNO}_{3}$ resulted in 50 ppb being the lowest cadmium concentration in the linear range. Measurement of lead was similar in both $\mathrm{KCl}$ and $\mathrm{KNO}_{3}$, and $10 \mathrm{ppb}$ was the lowest concentration linear with the rest of the calibration curve (5-minute deposition time). The cadmium stripping peak was suppressed by lead and copper, but the lead stripping peak was enhanced by copper, which may have provided nucleation sites for lead deposition. Cadmium was detected in a river water sample, and electrochemical analysis of a sample spiked with cadmium showed good agreement with ICP-AES. Lead was not detected in the river water sample; however, when lead was added to the sample, ligands in the sample formed a complex with the lead, which resulted in lower currents than expected. This work has demonstrated the feasibility of using ASV and the BDD electrode for detecting trace metals (1-50 ppb) in natural samples, as well as for the determination of the metal complexing capacity of natural waters. 


\section{Chapter 4: The Behavior of Mercury at the Polished Boron-Doped Diamond Electrodes in $\mathrm{KNO}_{3}, \mathrm{KCl}, \mathrm{KH}_{2} \mathrm{PO}_{4}$, and $\mathrm{K}_{2} \mathrm{SO}_{4}$ Electrolytes}

\section{Introduction}

A polished BDD electrode was evaluated as a working electrode for the detection of mercury in samples collected from power plants. This type of diamond, industrially polished smooth on a nanometer scale, has been used by others, ${ }^{30-36,76}$ especially in conjunction with ultrasound. In general, the behavior of polished and unpolished BDD's has been reported to be similar. ${ }^{76}$ The work described in this chapter focuses on the behavior of mercury in various electrolytes.

Previous experiments to detect lead in $\mathrm{KH}_{2} \mathrm{PO}_{4}$, and $\mathrm{K}_{2} \mathrm{SO}_{4}$ solutions using a glassy carbon electrode indicated the possibility of underpotential deposition (UPD). As mentioned in Chapter 1, UPD is the deposition of a metal at a potential more positive than its standard reduction potential, and this could have have been an advantage at low pH's. Although our goal was still to detect trace mercury in the presence of high chloride and low $\mathrm{pH}$, we investigated the behavior of mercury in $\mathrm{KNO}_{3}, \mathrm{KH}_{2} \mathrm{PO}_{4}$, and $\mathrm{K}_{2} \mathrm{SO}_{4}$ in addition to chloride. The UPD of mercury was not observed in any of the electrolytes, but unusual trends in the stripping current were observed.

\section{Experimental}

A free-standing polished BDD electrode with a thickness of $0.5 \mathrm{~mm}($ diameter $=$ $3 \mathrm{~mm}$ ) and mounted in Teflon (Windsor Scientific, Ltd., Berkshire, England) was used as the working electrode in these the experiments. The reference and auxiliary electrodes were a double junction $\mathrm{Ag} / \mathrm{AgCl} / \mathrm{saturated} \mathrm{KCl}$ and platinum wire, respectively. 
Osteryoung square wave anodic stripping voltammetry was performed on a Bioanalytical Systems Electrochemical Workstation (Lafayette, IN) and in the accompanying C3 cell stand. Unless stated otherwise, the deposition potential was $-800 \mathrm{mV}$, final potential $+500 \mathrm{mV}$, frequency $15 \mathrm{~Hz}$, square wave amplitude $25 \mathrm{mV}$, and step potential $4 \mathrm{mV}$. Supporting electrolytes were prepared from analytical grade $\mathrm{KNO}_{3}, \mathrm{KCl}, \mathrm{K}_{2} \mathrm{SO}_{4}$, and $\mathrm{KH}_{2} \mathrm{PO}_{4}$ salts in distilled water $(\Omega<18$ ohms) which was filtered through a Nanopure system. Prior to each experiment all electrodes and cell were washed with $50 \%(\mathrm{v} / \mathrm{v})$ nitric acid. A $15.0 \mathrm{~mL}$ aliquot of the solution was purged using regular grade nitrogen for about 15 minutes prior to each experiment, and the stirring rate was $400 \mathrm{rpm}$ during the deposition step.

\section{Results and Discussion}

\section{Calibration, Linear Ranges, and Reproducibility}

Calibration curves were constructed in $0.1 \mathrm{M} \mathrm{KNO}_{3}, \mathrm{KCl}, \mathrm{K}_{2} \mathrm{SO}_{4}$, and $\mathrm{KH}_{2} \mathrm{PO}_{4}$ electrolytes using 5-minute deposition times, and are shown in Figure 33. Each concentration was measured three times, and a cleaning potential of $+500 \mathrm{mV}$ was applied for 60 seconds between each run. In all electrolytes, the curves were non-linear below about $150 \mathrm{ppb} \mathrm{Hg}^{2+}$, but nearly equal in magnitude regardless of the electrolyte identity. This concentration was described by Yoshida et al. ${ }^{59}$ as the "cut-off" below which elemental mercury was not found on the surface of a glassy carbon surface due to its inability to form a lattice at these lower concentrations. The magnitude of the currents at concentrations greater than $150 \mathrm{ppb} \mathrm{Hg}^{2+}$ were affected by the identity of the electrolyte with the largest currents found in $\mathrm{K}_{2} \mathrm{SO}_{4}$, as shown in Figure 33. The slopes 


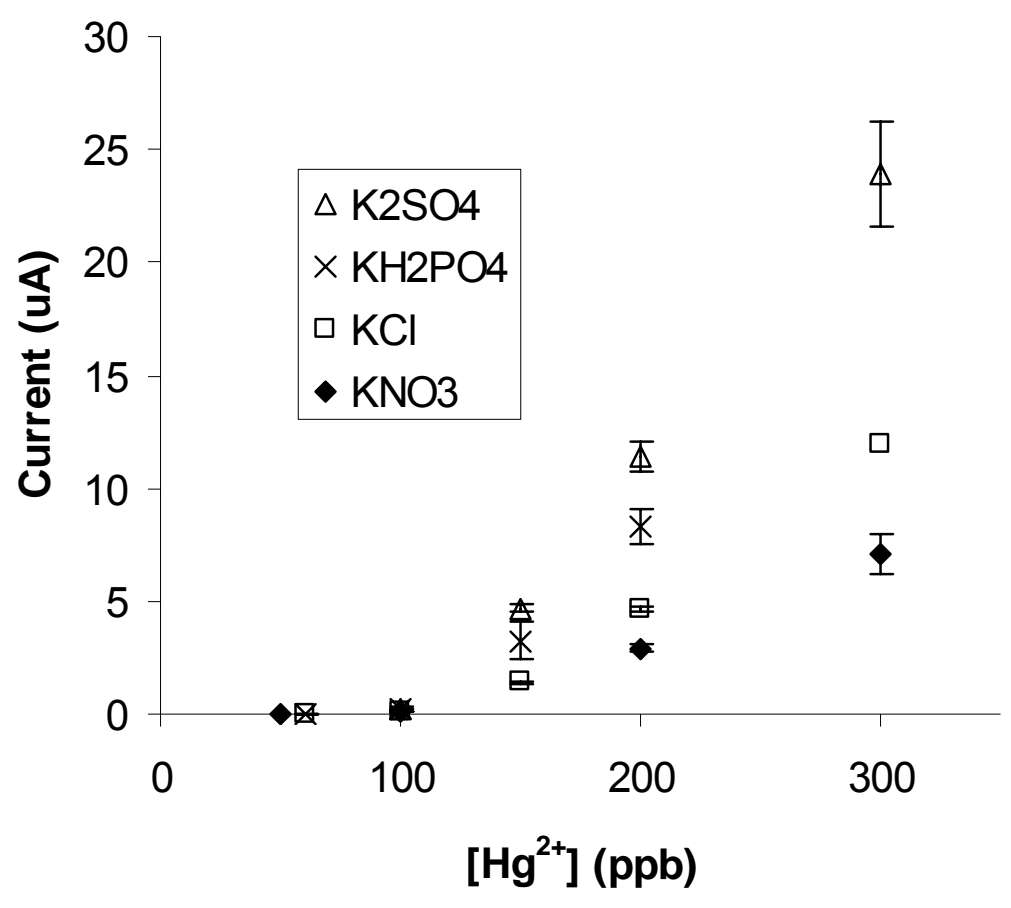

Figure 33. Calibration of $\mathrm{Hg}^{2+}$ in Various Electrolytes

$\mathrm{pH} \sim 5$, Polished BDD Electrode, Deposition Time $=5$ minutes, Deposition Potential $=$ $-1.0 \mathrm{~V}$ for $\mathrm{KCl},-600 \mathrm{mV}$ for $\mathrm{KNO}_{3}$, and $-800 \mathrm{mV}$ for $\mathrm{K}_{2} \mathrm{SO}_{4}$ and $\mathrm{KH}_{2} \mathrm{PO}_{4}$, Final Potential $=+500 \mathrm{mV}$, Frequency $=15 \mathrm{~Hz}$, Amplitude $=25 \mathrm{mV}$, Step Potential $=4 \mathrm{mV}$.

Electrochemical cleaning was perfomed between each run $\left(\mathrm{E}_{\text {clean }}=+500 \mathrm{mV}, 60 \mathrm{sec}\right)$. 
and $\mathrm{R}^{2}$ values for the linear portions of the calibration curves are provided in Table 5. The most sensitive slope and best $\mathrm{R}^{2}$ value were obtained in $0.1 \mathrm{M} \mathrm{K}_{2} \mathrm{SO}_{4}$ electrolyte, while the smallest currents and least sensitive slope were found in $\mathrm{KNO}_{3}$. Figure 34 shows that reproducibility was the poorest in $\mathrm{KH}_{2} \mathrm{PO}_{4}$, where the RSD ranged from 53.16 to $9.48 \%$ for various $\mathrm{Hg}^{2+}$ concentrations. The most reproducible currents (albeit not the largest) were obtained in $\mathrm{KCl}$, where the $\mathrm{RSD}$ ranged from 2.38 to $10.9 \%$.

The effect of deposition time on the current for $100 \mathrm{ppb} \mathrm{Hg}^{2+}$ in $0.1 \mathrm{M} \mathrm{KNO}_{3}$ is shown in Figure 35. An increase in deposition time had little effect on the magnitude of the stripping current. Yoshida et al. ${ }^{59}$ also observed that increasing the deposition time did not improve the detection of mercury at the glassy carbon electrode below the "cutoff" of $150 \mathrm{ppb}$. We also observed this behavior at the BDD electrode for $80 \mathrm{ppb} \mathrm{Hg}^{2+}$ in $0.1 \mathrm{M} \mathrm{K}_{2} \mathrm{SO}_{4}$. However, when a mercury concentration which fell within the linear portion of the calibration curve was investigated $\left(150 \mathrm{ppb} \mathrm{Hg}^{2+}\right.$ in $\left.0.1 \mathrm{M} \mathrm{KNO}_{3}\right)$, it was found that current and deposition time were linear $\left(\mathrm{R}^{2}=0.9992\right.$ for 5-15 min, data not shown in Figure 35).

In summary, at low mercury concentrations, the calibration curve was non-linear, and the electrolyte identity and deposition time had little effect on the magnitudes of the currents. At higher concentrations ( $\geq 150 \mathrm{ppb}$ ), where the mercury stripping current was linear with concentration, the identity of the electrolyte affected the magnitude of the current and the reproducibility. 
Table 5. Slopes and $\mathbf{R}^{2}$ Values for $100-300 \mathrm{ppb} \mathrm{Hg}^{2+}$ in Various Electrolytes Parameters as in Figure 33

\begin{tabular}{|c|c|c|}
\hline & $\begin{array}{c}\text { Slope } \\
(\boldsymbol{\mu A} / \mathbf{p p b})\end{array}$ & $\mathbf{R}^{2}$ \\
\hline $0.1 \mathrm{M} \mathrm{KNO}_{3}$ & 0.03460 & 0.9867 \\
\hline $0.1 \mathrm{M} \mathrm{KCl}$ & 0.06127 & 0.9714 \\
\hline $0.1 \mathrm{M} \mathrm{K}_{2} \mathrm{SO}_{4}$ & 0.1208 & 0.9959 \\
\hline $0.1 \mathrm{M} \mathrm{KH}_{2} \mathrm{PO}_{4}$ & 0.08041 & 0.9794 \\
\hline
\end{tabular}




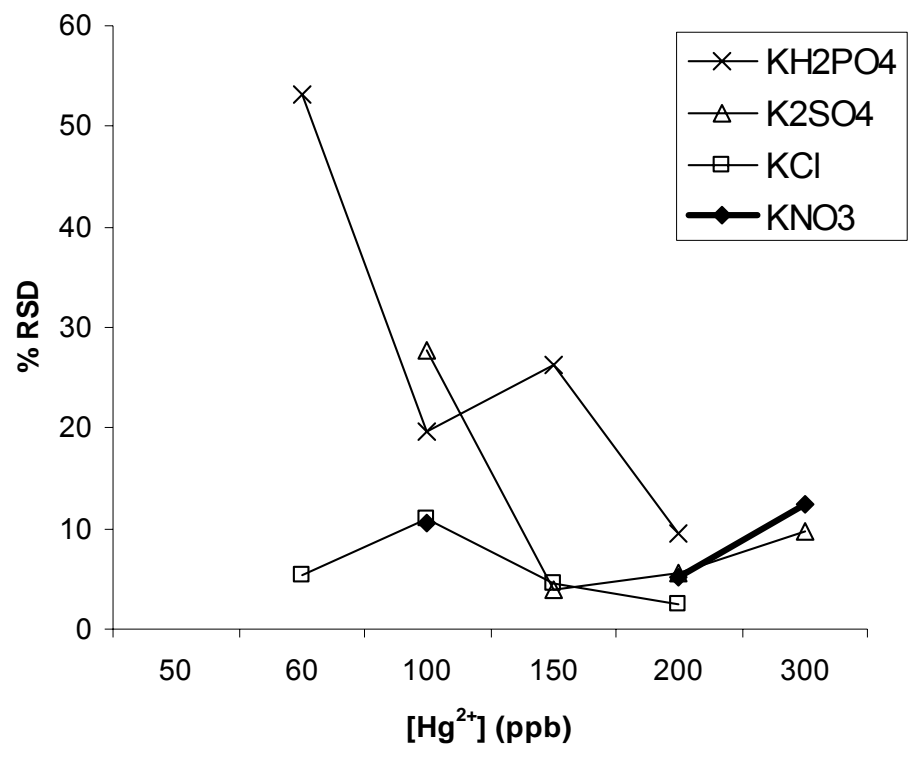

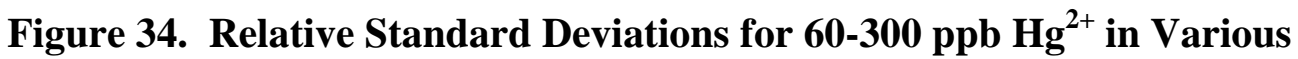
Electrolytes

Polished BDD Electrode, Deposition Time $=5 \mathrm{~min}$; Deposition Potential $=-1.0 \mathrm{~V}$ for $\mathrm{KCl},-600 \mathrm{mV}$ for $\mathrm{KNO}_{3}$, and $-800 \mathrm{mV}$ for $\mathrm{K}_{2} \mathrm{SO}_{4}$ and $\mathrm{KH}_{2} \mathrm{PO}_{4}$, Final Potential $=+500$ $\mathrm{mV}$, Frequency $=15 \mathrm{~Hz}$, Amplitude $=25 \mathrm{mV}$, Step Potential $=4 \mathrm{mV}$. Electrochemical cleaning was performed between each run $(+500 \mathrm{mV}, 60 \mathrm{sec})$. 


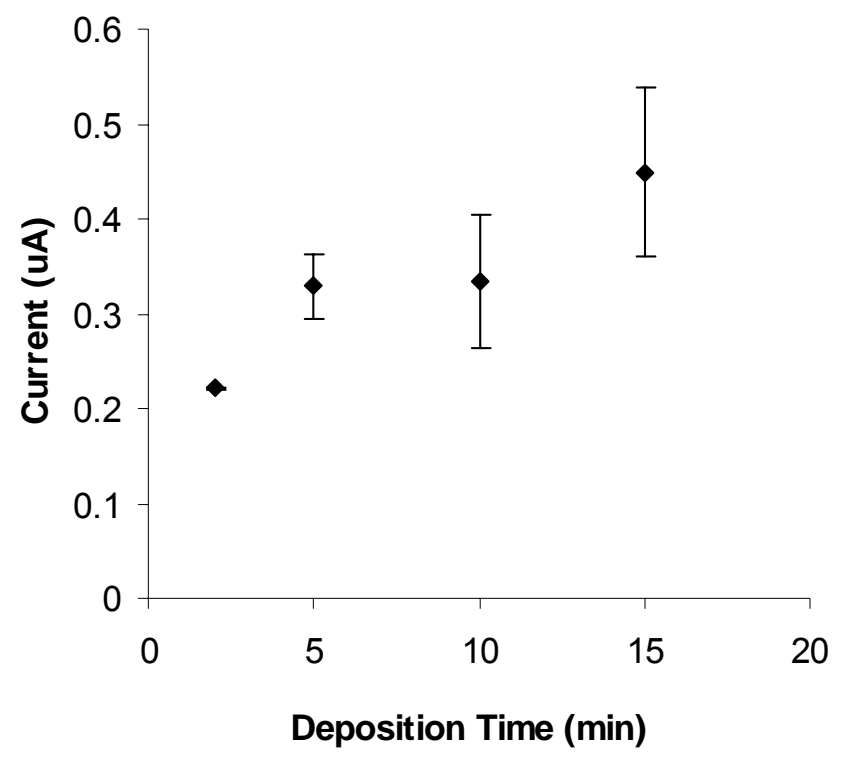

Figure 35. Effect of Deposition Time on $100 \mathrm{ppb} \mathrm{Hg}^{2+}$ in $0.1 \mathrm{M} \mathrm{KNO}_{3}$

Polished BDD Electrode, Deposition Potential $=-600 \mathrm{mV}$, Final Potential $=+500 \mathrm{mV}$, Frequency $=15 \mathrm{~Hz}$, Amplitude $=25 \mathrm{mV}$, Step Potential $=4 \mathrm{mV}$. Electrochemical cleaning was performed between each run $(+500 \mathrm{mV}, 60 \mathrm{sec}), \mathrm{n}=3$. 


\section{Trends of the Mercury Stripping Currents}

Each point in the calibration curves shown in Figure 33 was the average of three consecutive measurements, and a cleaning potential $(+500 \mathrm{mV}, 60 \mathrm{sec})$ was applied before each measurement. Although good precision was observed in some cases, RSD's were generally high (see Figure 34); however, certain trends were observed. For example, at the lower concentrations, the currents tended to decrease over the course of the three measurements, but at the higher concentrations ( $>150 \mathrm{ppb})$ they increased. This behavior was investigated in a series of experiments in which repeated measurements of the mercury stripping current were obtained. The effects of electrochemical cleaning, acid-washing, and waiting time before each run were investigated. These experiments are outlined in Table 6.

Each experiment began with repeated measurements of the current, and no electrochemical cleaning was performed before the measurements; five repetitions were usually obtained. In all of the electrolytes, the currents increased over the course of these five measurements. The possibility of precipitation was investigated according to the method developed by Buffle ${ }^{73}$ (see Chapter 2). The relevant reactions for mercury in all the electrolytes we investigated are shown in Table 7.

As shown in Table 7, precipitation of $\mathrm{HgO}$ may be possible in $\mathrm{KNO}_{3}$ and $\mathrm{Hg}_{2} \mathrm{HPO}_{4}$. It may also be possible for $\mathrm{Hg}_{2} \mathrm{Cl}_{2}, \mathrm{Hg}_{2} \mathrm{HPO}_{4}$, and $\mathrm{Hg}_{2} \mathrm{SO}_{4}$ to precipitate in the chloride, phosphate, and sulfate solutions, respectively, due to the disproportionation of $\mathrm{Hg}^{2+}$. We have already discussed the electrochemical activities of $\mathrm{Hg}_{2} \mathrm{Cl}_{2}$ and $\mathrm{HgO}$ in Chapter 2. The standard reduction potential of $\mathrm{Hg}_{2} \mathrm{SO}_{4}$ is $+0.614 \mathrm{~V}\left(\mathrm{Hg}_{2} \mathrm{SO}_{4}+2 \mathrm{e}^{-} \leftrightarrow\right.$ $\left.2 \mathrm{Hg}^{0}+\mathrm{SO}_{4}{ }^{2-}\right)$, but the electrochemical activity of $\mathrm{Hg}_{2} \mathrm{HPO}_{4}$ is not known. Given that the 
Table 6. Set of Experiments to Study the Trends in Current for Mercury in Various Electrolytes

Deposition Potential $=-800 \mathrm{mV}$, Deposition Time $=5 \mathrm{~min}$, Final Potential $=+500 \mathrm{mV}$, Frequency $=15 \mathrm{~Hz}$, Square Wave Amplitude $=25 \mathrm{mV}$, Step Potential $=4 \mathrm{mV}$, electrochemical cleaning was performed at $+500 \mathrm{mV}$, for 60 seconds.

\begin{tabular}{|c|l|l|l|}
\hline $\begin{array}{c}\text { Experiment } \\
\text { Number }\end{array}$ & \multicolumn{2}{|c|}{ Sequence of Events } \\
\hline 1 & $\begin{array}{l}\text { Obtain repeated measurements } \\
\text { (no electrochemical cleaning) }\end{array}$ & \multicolumn{2}{|l|}{ Acid-wash (and measure current) } \\
\hline 2 & $\begin{array}{l}\text { Obtain repeated measurements } \\
\text { (no electrochemical cleaning) }\end{array}$ & $\begin{array}{l}\text { Apply } E_{\text {clean }} \text { before } \\
\text { each run }\end{array}$ & Acid-wash \\
\hline 3 & $\begin{array}{l}\text { Obtain repeated measurements } \\
\text { (no electrochemical cleaning) }\end{array}$ & $\begin{array}{l}\text { Wait 10 minutes (and measure } \\
\text { current) }\end{array}$ \\
\hline 4 & $\begin{array}{l}\text { Obtain repeated measurements } \\
\text { (no electrochemical cleaning) }\end{array}$ & $\begin{array}{l}\text { Apply } E_{\text {clean }} \text { before } \\
\text { each run }\end{array}$ & $\begin{array}{l}\text { Wait 10 } \\
\text { minutes }\end{array}$ \\
\hline
\end{tabular}


Table 7. Relevant Reaction used to determine Precipitate Formation during the Stripping Step

Calculations were performed for $0.1 \mathrm{M}$ electrolyte, $200 \mathrm{ppb} \mathrm{Hg}^{2+}$ and a 5-minute deposition time

\begin{tabular}{|c|c|c|c|c|c|c|c|}
\hline Electrolyte & \multicolumn{2}{|c|}{$\mathrm{KCl}(\mathrm{pH}=5)$} & \multicolumn{2}{|l|}{$\mathrm{KNO}_{3}(\mathrm{pH}=5)$} & $\mathrm{KH}_{2} \mathrm{PO}_{4}(\mathrm{pH}=4.5)$ & \multicolumn{2}{|l|}{$\mathrm{K}_{2} \mathrm{SO}_{4}(\mathrm{pH}=4.5)$} \\
\hline \multirow{6}{*}{$\begin{array}{l}\text { Complex } \\
\text { Formation } \\
\text { Reactions }\end{array}$} & & $\beta_{1-4}{ }^{a}$ & & $\beta_{1-n}^{b}$ & \multirow{6}{*}{$\begin{array}{c}\text { No complex formation reactions } \\
\text { with } \mathrm{Hg}^{2+} \text { and } \mathrm{Hg}_{2}{ }^{2+}\end{array}$} & & $\beta_{1-n}{ }^{c}$ \\
\hline & $\mathrm{Hg}^{2+}+\mathrm{Cl}^{-} \rightarrow \mathrm{HgCl}^{+}$ & $5.5 \times 10^{6}$ & $\mathrm{Hg}^{2+}+\mathrm{OH}^{-} \rightarrow \mathrm{HgOH}^{+}$ & $4.0 \times 10^{10}$ & & $\mathrm{Hg}^{2+}+\mathrm{SO}_{4}^{2-} \rightarrow \mathrm{HgSO}_{4}$ & $2.19 \times 10^{1}$ \\
\hline & $\mathrm{Hg}^{2+}+2 \mathrm{Cl}^{-} \rightarrow \mathrm{HgCl}_{2}$ & $1.7 \times 10^{13}$ & $\mathrm{Hg}^{2+}+2 \mathrm{OH}^{-} \rightarrow \mathrm{Hg}(\mathrm{OH})_{2}$ & $6 .{ }_{3} \times 10^{21}$ & & 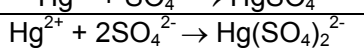 & $2.5 \times 10^{2}$ \\
\hline & $\mathrm{Hg}^{2+}+3 \mathrm{Cl}^{-} \rightarrow \mathrm{HgCl}_{3}^{-}$ & $1.2 \times 10^{14}$ & $\mathrm{Hg}^{2+}+3 \mathrm{OH}^{-} \rightarrow \mathrm{Hg}(\mathrm{OH})_{3}^{-}$ & $7.9 \times 10^{20}$ & & $\mathrm{Hg}_{2}{ }^{2+}+\mathrm{SO}_{4}^{2-} \rightarrow \mathrm{Hg}_{2} \mathrm{SO}_{4}^{+}$ & $2.0 \times 10^{1}$ \\
\hline & $\mathrm{Hg}^{2+}+4 \mathrm{Cl}^{-} \rightarrow \mathrm{HgCl}_{4}^{2-}$ & $1.3^{2} \times 10^{15}$ & $2 \mathrm{Hg}^{2+}+\mathrm{OH}^{-} \rightarrow \mathrm{Hg}_{2} \mathrm{OH}^{+}$ & $5.0 \times 10^{10}$ & & $\mathrm{Hg}_{2}{ }^{2+}+2 \mathrm{SO}_{4}{ }^{2-} \rightarrow \mathrm{Hg}_{2}\left(\mathrm{SO}_{4}\right)_{2}$ & $3.5 \times 10^{3}$ \\
\hline & & & $3 \mathrm{Hg}^{2+}+3 \mathrm{OH}^{-} \rightarrow \mathrm{Hg}_{3}(\mathrm{OH})_{3}{ }^{3+}$ & $4.0 \times 10^{35}$ & & & \\
\hline $\begin{array}{l}\text { Solubility } \\
\text { Equilibria }\end{array}$ & \multicolumn{2}{|c|}{$\begin{array}{c}\mathrm{Hg}_{2} \mathrm{Cl}_{2}(\mathrm{~s}) \leftrightarrow \mathrm{Hg}_{2}{ }^{2+}+2 \mathrm{Cl}^{-} \\
\mathrm{K}_{\mathrm{sp}}=1.2 \times 10^{-18}(0 \mathrm{M})\end{array}$} & \multicolumn{2}{|c|}{$\begin{array}{c}\mathrm{HgO}(\mathrm{s})+\mathrm{H}_{2} \mathrm{O} \leftrightarrow \mathrm{Hg}^{2+}+2 \mathrm{OH}^{-} \\
\mathrm{K}_{\mathrm{sp}}=3.6_{3} \times 10^{-26}(0 \mathrm{M})\end{array}$} & $\begin{array}{c}\mathrm{Hg}_{2} \mathrm{HPO}_{4}(\mathrm{~s}) \leftrightarrow \mathrm{Hg}_{2}{ }^{2+}+\mathrm{HPO}_{4}{ }^{2-} \\
\mathrm{K}_{\mathrm{sp}}=4.0 \times 10^{-13}(0 \mathrm{M})\end{array}$ & \multicolumn{2}{|c|}{$\begin{array}{c}\mathrm{Hg}_{2} \mathrm{SO}_{4}(\mathrm{~s}) \leftrightarrow \mathrm{Hg}_{2}{ }^{2+}+\mathrm{SO}_{4}{ }^{2-} \\
\mathrm{K}_{\mathrm{sp}}=7.4 \times 10^{-7}(0 \mathrm{M})\end{array}$} \\
\hline$\left[\mathrm{Hg}^{2+}\right]^{*}$ & \multicolumn{2}{|c|}{$2.4_{3} \times 10^{-18} \mathrm{M}$} & \multirow{2}{*}{\multicolumn{2}{|c|}{$1.54 \times 10^{-10} \mathrm{M}$}} & $1.26 \times 10^{-9} \mathrm{M}^{\star \star \star}$ & \multicolumn{2}{|l|}{$1.78 \times 10^{-10} \mathrm{M}$} \\
\hline$\left[\mathrm{Hg}_{2}{ }^{2+}\right]^{\star \star}$ & \multicolumn{2}{|c|}{$3.1_{6} \times 10^{-16} \mathrm{M}$} & & & $1.64 \times 10^{-1} \mathrm{M}$ & \multicolumn{2}{|l|}{$2.32 \times 10^{-8} \mathrm{M}$} \\
\hline Buffle result & \multicolumn{2}{|c|}{$\begin{array}{l}\text { can't be applied; } \\
\mathrm{Hg}_{2} \mathrm{Cl}_{2} \text { possible? }\end{array}$} & \multicolumn{2}{|c|}{$\begin{array}{l}4.62 \times 10^{-8}>3.30 \times 10^{-8} \\
\text { ppt'n of } \mathrm{HgO} \text { possible }\end{array}$} & $\begin{array}{l}3.79 \times 10^{-7}>3.21 \times 10^{-7} \\
\text { ppt'n of } \mathrm{HgO} \text { possible; } \\
\mathrm{Hg}_{2} \mathrm{HPO}_{4} \text { possible? }\end{array}$ & \multicolumn{2}{|c|}{$\begin{array}{c}5.34 \times 10^{-8}<3.22 \times 10^{-7} \\
\text { ppt'n of } \mathrm{HgO} \text { not possible; } \\
\mathrm{Hg}_{2} \mathrm{SO}_{4} \text { possible? }\end{array}$} \\
\hline
\end{tabular}

${ }^{*}$ Free, bulk concentration

${ }^{*}\left[\mathrm{Hg}_{2}{ }^{2+}\right]$ determined from the following equilibrium: $\mathrm{Hg}^{0}+\mathrm{Hg}^{2+} \leftrightarrow \mathrm{Hg}_{2}{ }^{2+} \mathrm{K}=1.3 \times 10^{-2}$

${ }^{* * *}$ based on complex formation reactions with $\mathrm{OH}^{-}$at $\mathrm{pH} 4.5$;

${ }^{\mathrm{a}} 0.5 \mathrm{M}$ Ionic strength; ${ }^{\mathrm{b}} 0 \mathrm{M}$ Ionic strength; ${ }^{\mathrm{c}} 0.5 \mathrm{M}$ Ionic strength

Buffle Equation:

$\left(C_{o x}\right)\left(t_{d e p}\right)<0.908\left(\frac{K_{s p}}{C_{A}^{b}}\right)^{1 / a}$

$\mathrm{C}_{\mathrm{ox}}=$ bulk concentration of $\mathrm{Ox}, \mathrm{t}_{\mathrm{dep}}=$ deposition time in seconds, $\mathrm{C}_{\mathrm{A}}=$ concentration of the anion, $\mathrm{a}$ and $\mathrm{b}$ are the number of moles of $\mathrm{Ox}$ and anion, respectively, in the precipitate, $\mathrm{Ox}_{\mathrm{a}} \mathrm{A}_{\mathrm{b}}$ 
currents increased in these electrolytes, and that precipitation of a solid (or solids in the case of $\mathrm{Hg}_{2} \mathrm{HPO}_{4}$ ) is possible in all of them, it can be speculated that the precipitates are behaving as nucleation centers for the reduction of $\mathrm{Hg}^{2+}$ to $\mathrm{Hg}^{0}$.

Another explanation for the current increase is that small $\mathrm{Hg}^{0}$ deposits remained on the electrode surface after the stripping step, and these deposits then acted as nucleation sites on which more mercury deposition could take place in the subsequent run. (Recall that this was suspected at the unpolished BDD when the current for a 2minute deposition was the same as that for a 20-minute deposition which preceded it.) Therefore, any of the precipitates mentioned above as well as unstripped $\mathrm{Hg}^{0}$ are two potential substances on the BDD surface which may increase currents in subsequent runs by acting as nucleation sites for $\mathrm{Hg}^{2+}$ deposition.

\section{Experiment 1}

It can be seen in Table 6 that the first experiment that was performed to study the electrode surface after deposition and stripping was to obtain repeated measurements, acid-wash the electrode, and then measure the current. Acid-washing the electrode surface should remove the nucleation sites--either the precipitate or unstripped $\mathrm{Hg}^{0}$--from the electrode surface, and the resulting current should be smaller. This was in fact observed in all the electrolytes, except $\mathrm{K}_{2} \mathrm{SO}_{4}$. In $\mathrm{K}_{2} \mathrm{SO}_{4}$, the current for the first run after acid-washing increased; however, after this initial increase, the current decreased for the subsequent measurements. Other than this peculiar behavior in $\mathrm{K}_{2} \mathrm{SO}_{4}$, it seems as if the action of acid washing removed either the precipitate or unstripped $\mathrm{Hg}^{0}$ and resulted in lower currents. 


\section{Experiment 2}

Electrochemical cleaning is often performed between measurements to ensure that the electrode is clean and in the same condition for each measurement. The effect of electrochemical cleaning (and later, acid-washing) was studied in the second set of experiments shown in Table 6, and it caused the current to decrease in all of the electrolytes, with the most dramatic decrease observed in $\mathrm{KH}_{2} \mathrm{PO}_{4}$. Representative behavior is shown in Figure 36 for $200 \mathrm{ppb} \mathrm{Hg}^{2+}$ in $0.1 \mathrm{M} \mathrm{KNO}_{3}$. The current increased as usual for the first 5 runs, but when electrochemical cleaning was performed before each run, the current decreased rather steadily. Two outcomes could occur in all the electrolytes during electrochemical cleaning: 1) any unstripped $\mathrm{Hg}^{0}$ could get oxidized to $\mathrm{Hg}^{2+}$ or $\mathrm{Hg}_{2}{ }^{2+}$; or 2) the precipitate formed during the stripping step could be oxidized to $\mathrm{Hg}^{2+}$ (other than $\mathrm{HgO}$, since the mercury is already in its fully oxidized form). These two possibilities will now be considered.

1) If unstripped $\mathrm{Hg}^{0}$ was oxidized to $\mathrm{Hg}^{2+}$ to yield a bare surface, the current would have decreased (as observed); however, in $\mathrm{KNO}_{3}$, the $\mathrm{Hg}^{2+}$ ions liberated during electrochemical cleaning, could have formed $\mathrm{HgO}$, which should have increased the current for subsequent runs. Precipitate formation is possible in the other electrolytes as well. However, it is not known if the concentrations of $\mathrm{Hg}^{2+}$ and $\mathrm{Hg}_{2}{ }^{2+}$ generated during electrochemical cleaning are high enough to precipitate with the anion in the electrolyte. Compared to the concentrations of $\mathrm{Hg}^{2+}$ or $\mathrm{Hg}_{2}{ }^{2+}$ generated in the stripping step, the concentrations generated during electrochemical cleaning are expected to be smaller. It is therefore difficult to conclude whether oxidation of unstripped $\mathrm{Hg}^{0}$ occurs during the electrochemical cleaning step, even though subsequent current decreases were observed. 


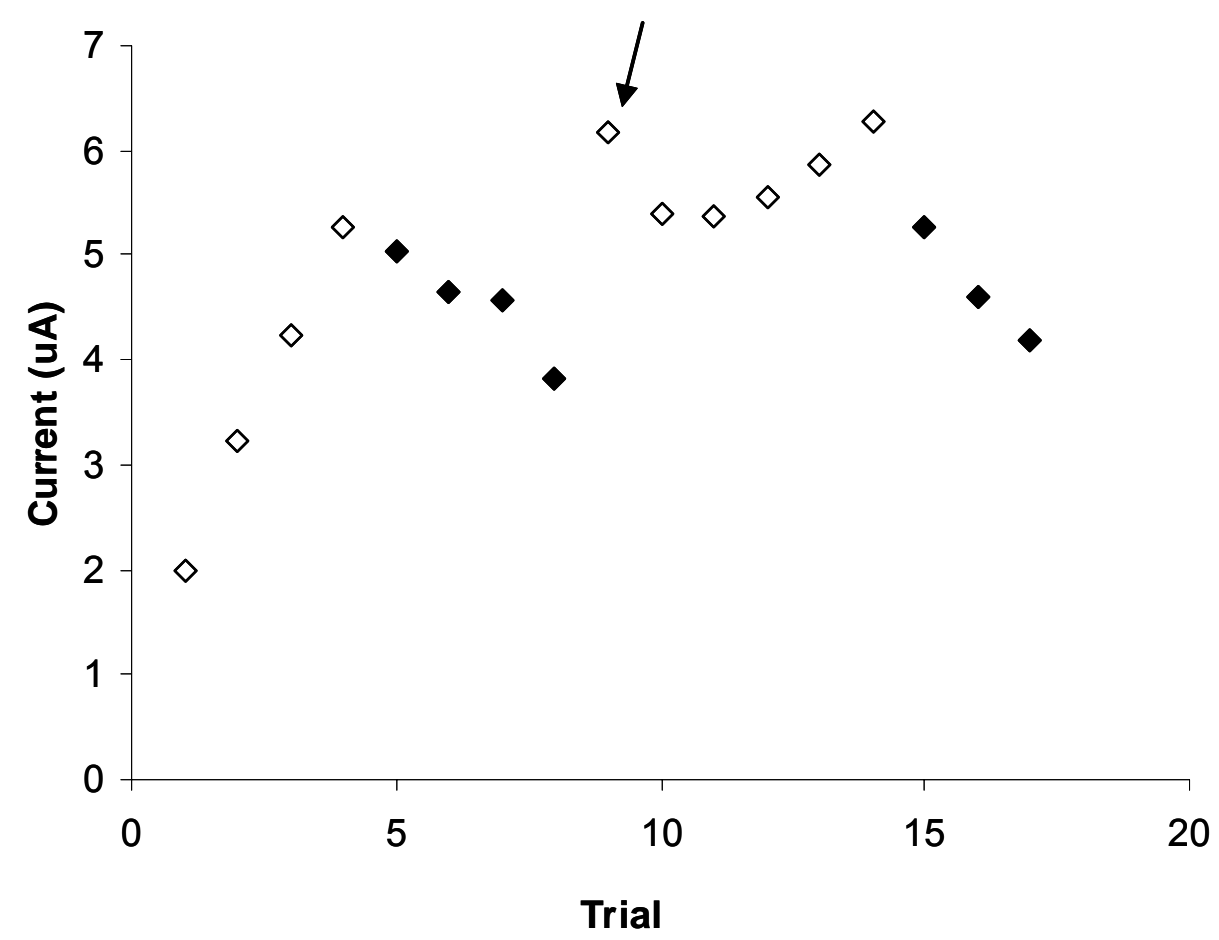

Figure 36. Effect of Electrochemical Cleaning and Acid-Washing on 200 ppb $\mathrm{Hg}^{2+}$ in $0.1 \mathrm{M} \mathrm{KNO}_{3}$

Open Diamonds: No electrochemical cleaning $\left(\mathrm{E}_{\text {clean }}\right)$ applied before the run; Solid Diamonds: $\mathrm{E}_{\text {clean }}$ of $+500 \mathrm{mV}$ applied for $60 \mathrm{sec}$ before the run; Arrow: before this run, the BDD was removed and acid-washed. $\mathrm{pH} \sim 5$, Polished BDD Electrode,

Deposition Potential $=-800 \mathrm{mV}$, Deposition Time $=5 \mathrm{~min}$, Final Potential $=+600$ $\mathrm{mV}$, Frequency $=15 \mathrm{~Hz}$, Amplitude $=25 \mathrm{mV}$, Step Potential $=4 \mathrm{mV}$, Stirred Deposition. 
2) If the precipitate was oxidized, and thus removed from the electrode surface, the current should have decreased after electrochemical cleaning (as observed). However, it is not known if the precipitates formed during the stripping step can be oxidized. If the precipitates were not oxidized, they should have remained on the electrode surface to increase the current for subsequent runs, which was not observed.

Although it is difficult to distinguish between either of these two possibilities, it will be assumed that an inhibiting substance remained on the electrode surface after electrochemical cleaning, which resulted in less $\mathrm{Hg}^{2+}$ deposited in the subsequent runs.

After several experimental runs were performed with electrochemical cleaning, the electrode was removed and acid-washed. The premise was that acid-washing would remove the inhibiting substance formed during electrochemical cleaning. As shown in Figure 36, the current increased after acid-washing (see point marked with and arrow), which indicated that the inhibiting substance had been removed. This result was observed in all of the electrolytes, except $\mathrm{KH}_{2} \mathrm{PO}_{4}$.

\section{Experiment 3}

The length of time between measurements was also found to affect the current for the subsequent run. After the usual five measurements were performed without electrochemical cleaning, a 10-minute time period elapsed before taking the next measurement. This caused the resulting current to increase more than usual. This effect is shown in Figure 37 for $100 \mathrm{ppb} \mathrm{Hg}^{2+}$ in $0.1 \mathrm{M} \mathrm{KH}_{2} \mathrm{PO}_{4}$. This behavior was seen in all electrolytes, except $\mathrm{KCl}$, where no unusual current increase was observed. 


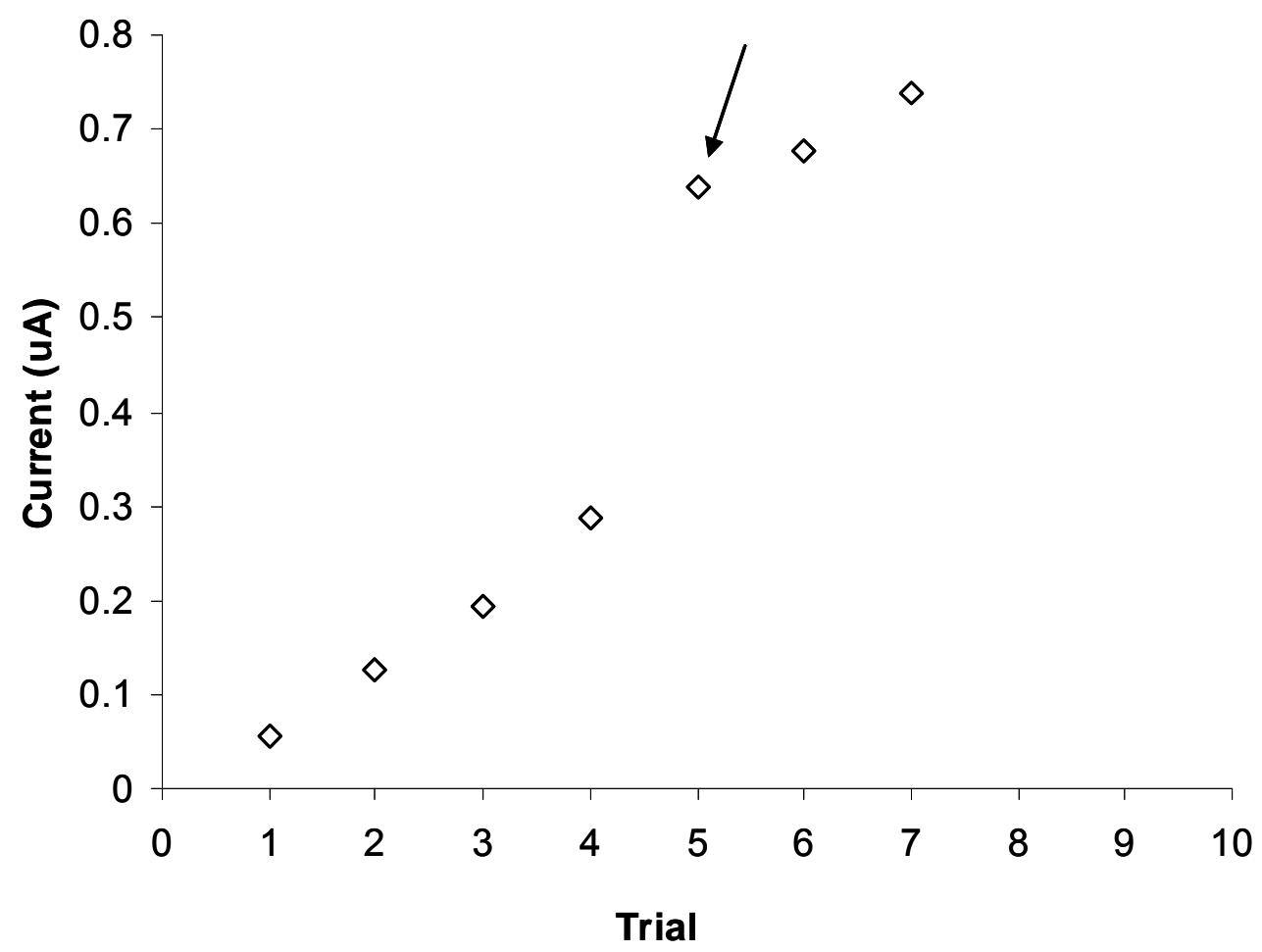

Figure 37. Effect of Waiting on an Un-Electrochemically Cleaned Surface

$100 \mathrm{ppb} \mathrm{Hg}^{2+}$ in $0.1 \mathrm{M} \mathrm{KH}_{2} \mathrm{PO}_{4}$. The first four points were obtained with no electrochemical cleaning. The arrow marks the current obtained after waiting with purging for 10 minutes. Deposition Potential $=-800 \mathrm{mV}$, Deposition Time $=5 \mathrm{~min}$, Final Potential $=+600 \mathrm{mV}$, Frequency $=15 \mathrm{~Hz}$, Amplitude $=25 \mathrm{mV}$, Step Potential $=4 \mathrm{mV}$, Stirred Deposition. 


\section{Experiment 4}

After several repetitions had been performed with electrochemical cleaning, a 10minute time period preceded the next repetition. The subsequent current increased, as shown in Figure 38 (see point marked with arrow) for $100 \mathrm{ppb} \mathrm{Hg}^{2+}$ in $0.1 \mathrm{M} \mathrm{KH}_{2} \mathrm{PO}_{4}$. This was observed in all the electrolytes, which indicated that the inhibiting substance formed during electrochemical cleaning had either been removed or had changed during the waiting period.

Another possibility was that anion-induced adsorption of mercuric ions had occurred during the waiting period, and resulted in the increased current shown in Figures 37 and 38. Anion induced adsorption could occur during the waiting period on four types of surfaces: the bare diamond, any precipitate formed during the stripping step, any unstripped $\mathrm{Hg}^{0}$ deposits, or the inhibiting substance formed during electrochemical cleaning. The data shown in Figure 37 suggested that adsorption had occurred on either the unstripped $\mathrm{Hg}^{0}$ or the precipitate; however, the data in Figure 38 implied that adsorption had occurred on the inhibiting substance formed during electrochemical cleaning.

\section{Comparison of Polished and Unpolished BDD Electrodes}

Recall from Chapter 2 that the current for $200 \mathrm{ppb} \mathrm{Hg}^{2+}$ decreased with repetition in $\mathrm{KNO}_{3}$ at the unpolished $\mathrm{BDD}$ electrode, and was explained in terms of formation of $\mathrm{HgO}$ precipitate during the stripping step which blocked active sites for subsequent runs. It is expected that $\mathrm{HgO}$ should also form at the polished BDD electrode, since the same conditions ( $\mathrm{pH}$, deposition time, and $\mathrm{Hg}^{2+}$ concentration) were used. The increased 


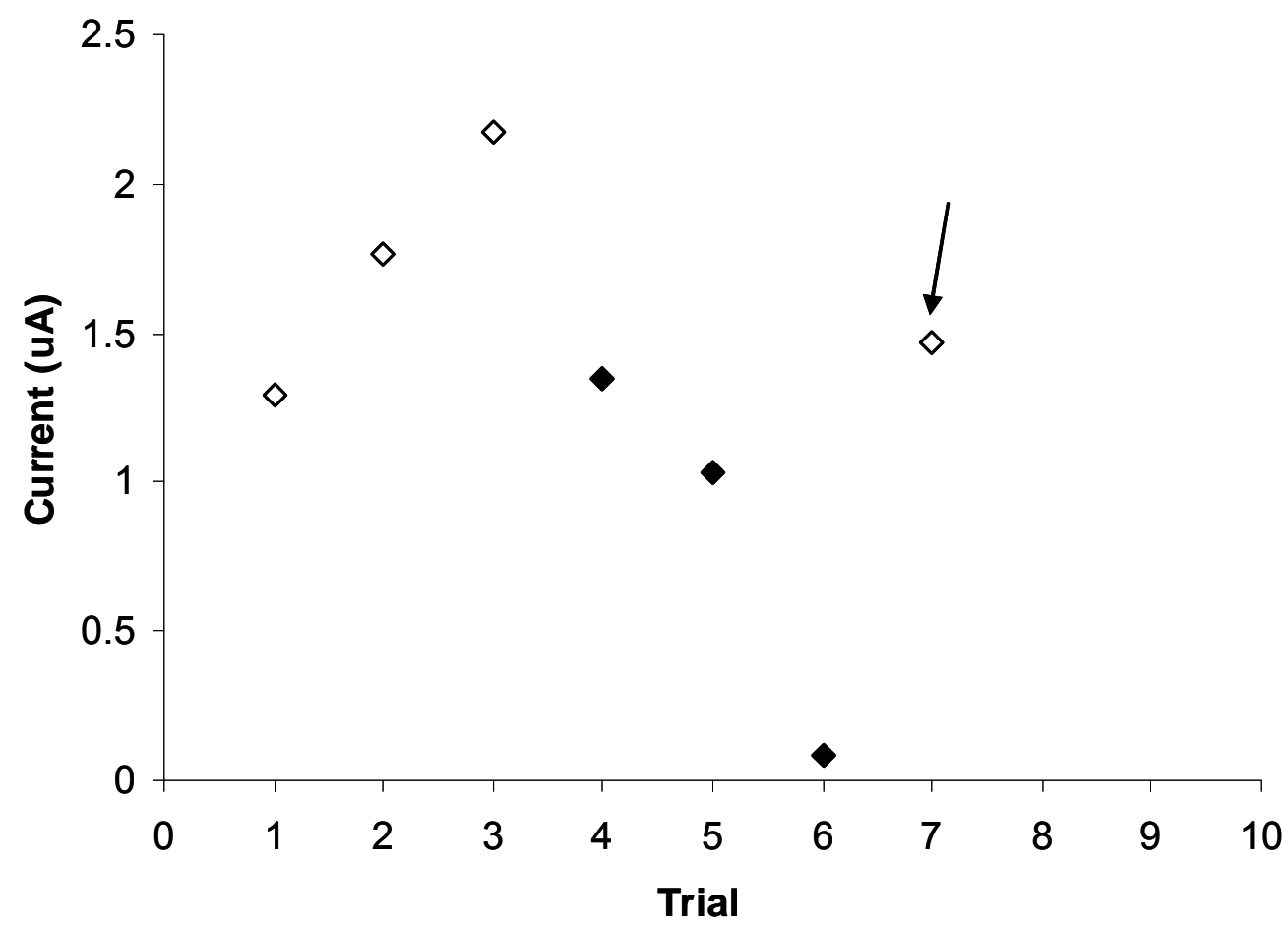

Figure 38. Effect of Waiting on an Electrochemically Cleaned Surface

$100 \mathrm{ppb} \mathrm{Hg}{ }^{2+}$ in $0.1 \mathrm{M} \mathrm{KH}_{2} \mathrm{PO}_{4}$. Open Diamonds: $\mathrm{No} \mathrm{E}_{\text {clean }}$ applied before the run; Solid Diamonds: $\mathrm{E}_{\text {clean }}$ of $+500 \mathrm{mV}$ applied for $60 \mathrm{sec}$ before each run; The arrow indicates a waiting period of 10 minutes had elapsed before the run. Deposition Potential $=-800$ $\mathrm{mV}$, Deposition Time $=5 \mathrm{~min}$, Final Potential $=+600 \mathrm{mV}$, Frequency $=15 \mathrm{~Hz}$, Amplitude $=25 \mathrm{mV}$, Step Potential $=4 \mathrm{mV}$, Stirred Deposition. 
current observed in $\mathrm{KNO}_{3}$ for the polished $\mathrm{BDD}$ implies that if $\mathrm{HgO}$ did form, it was reducible at the polished surface. It is not known why the $\mathrm{HgO}$ is reducible at the

polished surface. The sites for $\mathrm{Hg}^{2+}$ deposition may be more uniform at the polished $\mathrm{BDD}$, allowing reduction of $\mathrm{HgO}$ which is in contact with $\mathrm{Hg}^{0}$. The act of polishing an electrode can introduce defects such as vacancies, interstitials, and dislocations, ${ }^{86}$ and maybe these defects act as active sites for mercury deposition. The behavior of mercury in $\mathrm{KCl}$ at the polished and unpolished BDD electrodes appeared to be similar (the currents increased with repetition).

\section{Detection of Hg Concentrations Below the Linear Range ( $\leq 20 \mathrm{ppb})$}

Mercury concentrations as low as $20 \mathrm{ppb}$ were detected in $0.1 \mathrm{M} \mathrm{KH}_{2} \mathrm{PO}_{4}$ using a deposition time of 5 minutes, but this was not possible in the other electrolytes with this deposition time. The current for 20 ppb wasn't stable, and increased with repetition and after a waiting period had elapsed. Electrochemical cleaning caused the current for 20 $\mathrm{ppb}$ to decrease, similar to the observation at higher (100ppb) mercury concentrations.

\section{Detection of $\mathrm{Hg}^{2+}$ in $0.6 \mathrm{MKCl}$ at $\mathrm{pH}<1$}

The performance of the polished BDD was evaluated in solutions which had compositions similar to those of the samples collected from power plants using the Ontario-Hydro Method. ${ }^{57}$ The behavior of $\mathrm{Hg}^{2+}$ in $0.6 \mathrm{M} \mathrm{KCl}+0.2 \mathrm{M} \mathrm{HNO}_{3}(\mathrm{pH}<1)$ using the polished BDD was similar to that of the unpolished BDD, and a comparison of the voltammograms is shown in Figure 39. At both electrodes, two stripping peaks were observed for mercury, although the deposition times were 20 and 5 minutes at the 

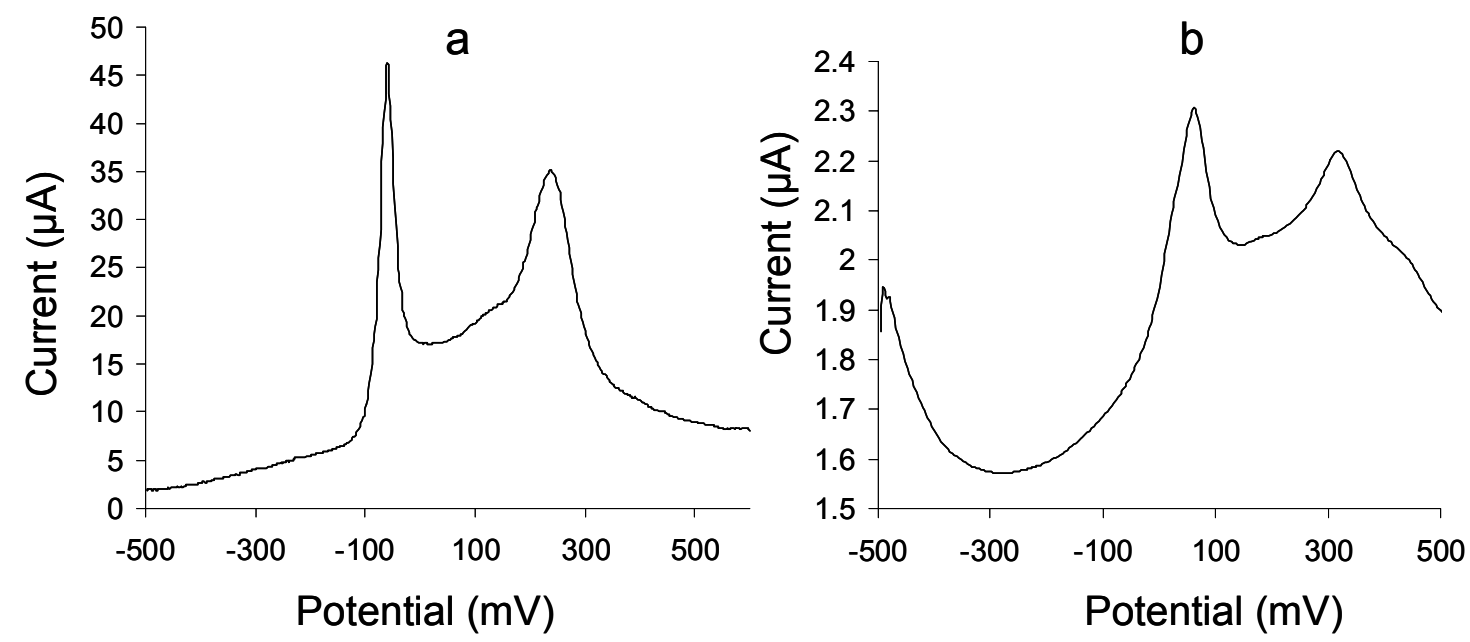

Figure 39. Comparison of $\mathrm{Hg}^{2+}$ in $0.6 \mathrm{M} \mathrm{KCl}(\mathrm{pH}<1)$ at the Unpolished and Polished BDD Electrodes

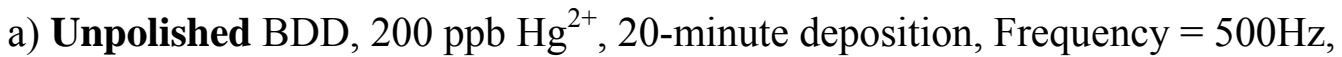
Amplitude $=20 \mathrm{mV}$, Step $=2 \mathrm{mV}$.

b) Polished BDD, $150 \mathrm{ppb} \mathrm{\textrm {Hg } ^ { 2 + }}$, 5-minute deposition, Frequency $=15 \mathrm{~Hz}$, Pulse Amplitude $=25 \mathrm{mV}$, Step Potential $=4 \mathrm{mV}$.

Deposition Potential $=-500 \mathrm{mV}$ for both (a) and (b). 
unpolished and polished BDD's, respectively. The identities of these peaks are still hard to assign. It was speculated in Chapter 2 that the peak at $0 \mathrm{mV}$ was due to the $2 \mathrm{e}^{-}$ oxidation of $\mathrm{Hg}^{0}$ to $\mathrm{Hg}^{2+}$, and that the peak at $\sim+300$ may have been the oxidation of $\mathrm{Hg}_{2} \mathrm{Cl}_{2}$ formed during the deposition step. This $\mathrm{Hg}_{2} \mathrm{Cl}_{2}$ wasn't reduced during the deposition step, because the deposition occurred at a potential positive of $-600 \mathrm{mV}$.

Although it isn't certain that $\mathrm{Hg}_{2} \mathrm{Cl}_{2}$ forms during the deposition step, evidence for its formation in $0.6 \mathrm{M} \mathrm{KCl}$ at the polished $\mathrm{BDD}$ has been seen. The net, forward, and reverse responses of $150 \mathrm{ppb} \mathrm{Hg}^{2+}$ in $0.6 \mathrm{M} \mathrm{KCl}(\mathrm{pH} \sim 5)$ are given in Figure 40. The forward and reverse responses both contained a cathodic peak at $\sim-250 \mathrm{mV}$, which is due to the reduction of calomel ${ }^{70-72}\left(\mathrm{Hg}_{2} \mathrm{Cl}_{2}+2 \mathrm{e}^{-} \rightarrow 2 \mathrm{Hg}^{0}+2 \mathrm{Cl}^{-}\right)$, and was cancelled out in the net response. This reduction peak was observed at the polished BDD only when the chloride concentration was $0.6 \mathrm{M}$, but not in every experiment involving $0.6 \mathrm{M} \mathrm{Cl}^{-}$. It was never observed at the unpolished BDD. The example shown in Figure 40 was the first run for mercury in that experiment, implying that calomel formed during the deposition step. It couldn't have formed under open-circuit conditions before the run, because at that point, all the mercury theoretically should have been in the form of $\mathrm{HgCl}_{\mathrm{x}}$ complexes. It is not known why this peak was observed in only some experiments, but as mentioned in Chapter 2, Nolan ${ }^{72}$ observed that calomel formation wasn't always necessarily accompanied by the reduction peak. We found that the magnitude of the cathodic peak increased when more $\mathrm{Hg}^{2+}$ was added, and that it disappeared when acid was added $\left(0.2 \mathrm{M} \mathrm{HNO}_{3}\right)$. 


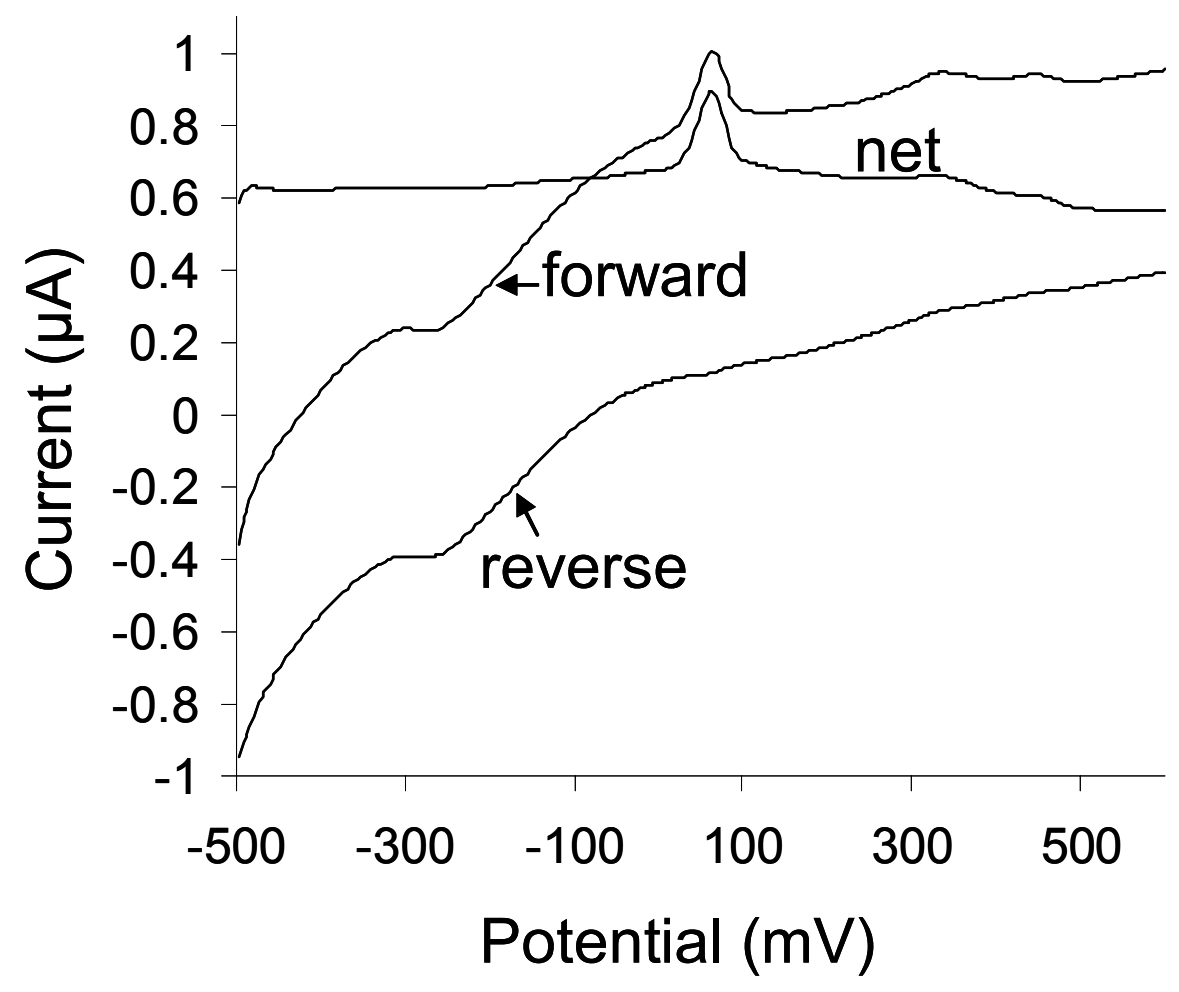

Figure 40. The Behavior of $\mathrm{Hg}^{2+}$ in $0.6 \mathrm{M} \mathrm{KCl}$ showing the Reduction of Calomel $150 \mathrm{ppb} \mathrm{Hg}^{2+}, \mathrm{pH} \sim 5$, Polished BDD Electrode, Deposition Potential $=-500 \mathrm{mV}$, Deposition Time $=5$ minutes, Frequency $=15 \mathrm{~Hz}$, Pulse Amplitude $=25 \mathrm{mV}$, Step Potential $=4 \mathrm{mV}$, Stirred Deposition. 


\section{Summary of Chapter 4}

The detection of mercury was studied in $0.1 \mathrm{M} \mathrm{KNO}_{3}, \mathrm{KCl}, \mathrm{K}_{2} \mathrm{SO}_{4}$, and $\mathrm{KH}_{2} \mathrm{PO}_{4}$ supporting electrolytes at pH's of around 5. The lowest amount of mercury detected with stirring during the deposition step was $20 \mathrm{ppb}$ in $\mathrm{KH}_{2} \mathrm{PO}_{4}$ at deposition times of 5 minutes. In all of the electrolytes, the calibration curves were non-linear at concentrations below $100 \mathrm{ppb}$, and reproducibility was also a problem in all of the electrolytes. In all of the electrolytes, the current increased with repetition, and decreased after electrochemical cleaning. When the electrode was removed and acid-washed, the currents increased in $\mathrm{KNO}_{3}, \mathrm{KCl}$, and $\mathrm{K}_{2} \mathrm{SO}_{4}$ electrolytes; however, in $\mathrm{KH}_{2} \mathrm{PO}_{4}$, acidwashing the electrode made the current decrease or disappear. The currents increased in all electrolytes except $\mathrm{KCl}$ if a waiting period elapsed between runs. The possibility of precipitation during the stripping step of either a mercurous or mercuric salt was considered in all electrolytes. The behavior of $\mathrm{Hg}^{2+}$ in $0.6 \mathrm{M} \mathrm{KCl}+0.2 \mathrm{M} \mathrm{HNO}_{3}$ was similar at the polished and unpolished BDD in that two stripping peaks were observed. Evidence of calomel formation was obtained in $0.6 \mathrm{M} \mathrm{KCl}$ only at the unpolished BDD. 


\section{Chapter 5: Effect of Ultrasound on the Electrochemical Detection of Cadmium and Mercury using Polished and Unpolished Boron-Doped Diamond Electrodes}

\section{Introduction}

As discussed previously in Chapters 2 and 4, the electrochemical detection of mercury was difficult at both unpolished and polished BDD electrodes. In an attempt to improve its detection, ultrasound mass transfer was used in conjunction with anodic stripping voltammetry (ASV). The behavior of cadmium in the presence of ultrasound was also investigated, because the cadmium behavior was more predictable than mercury. It was also desirable to determine if the use of ultrasound could improve the calibration curves obtained with stirring, which were non-linear at low concentration.

The role of ultrasound in these electrochemical experiments is to increase mass transport of the analyte to the electrode surface and to clean the electrode surface. Ultrasound is typically delivered to the electrochemical cell by placing a probe made of a titanium alloy above the electrode. The probes available from commercial manufacturers are designed to vibrate at set frequencies, usually $20 \mathrm{kHz}, 60 \mathrm{kHz}, 100 \mathrm{kHz}$, or $500 \mathrm{kHz}$, and come in different diameters. ${ }^{87}$ As the probe vibrates two processes occur: acoustic streaming and cavitation. Acoustic streaming, which is depicted in Figure 41, is defined as the flow of fluid induced by a sound field, and is responsible for increasing mass transport of the analyte to the electrode. ${ }^{87-88}$ Note that the acoustic stream is more concentrated when probes with smaller diameters are used.

Cavitation literally means "formation of cavities," and in ultrasound, the cavities are bubbles. As a sound wave travels through solution, solvent (water) molecules are 


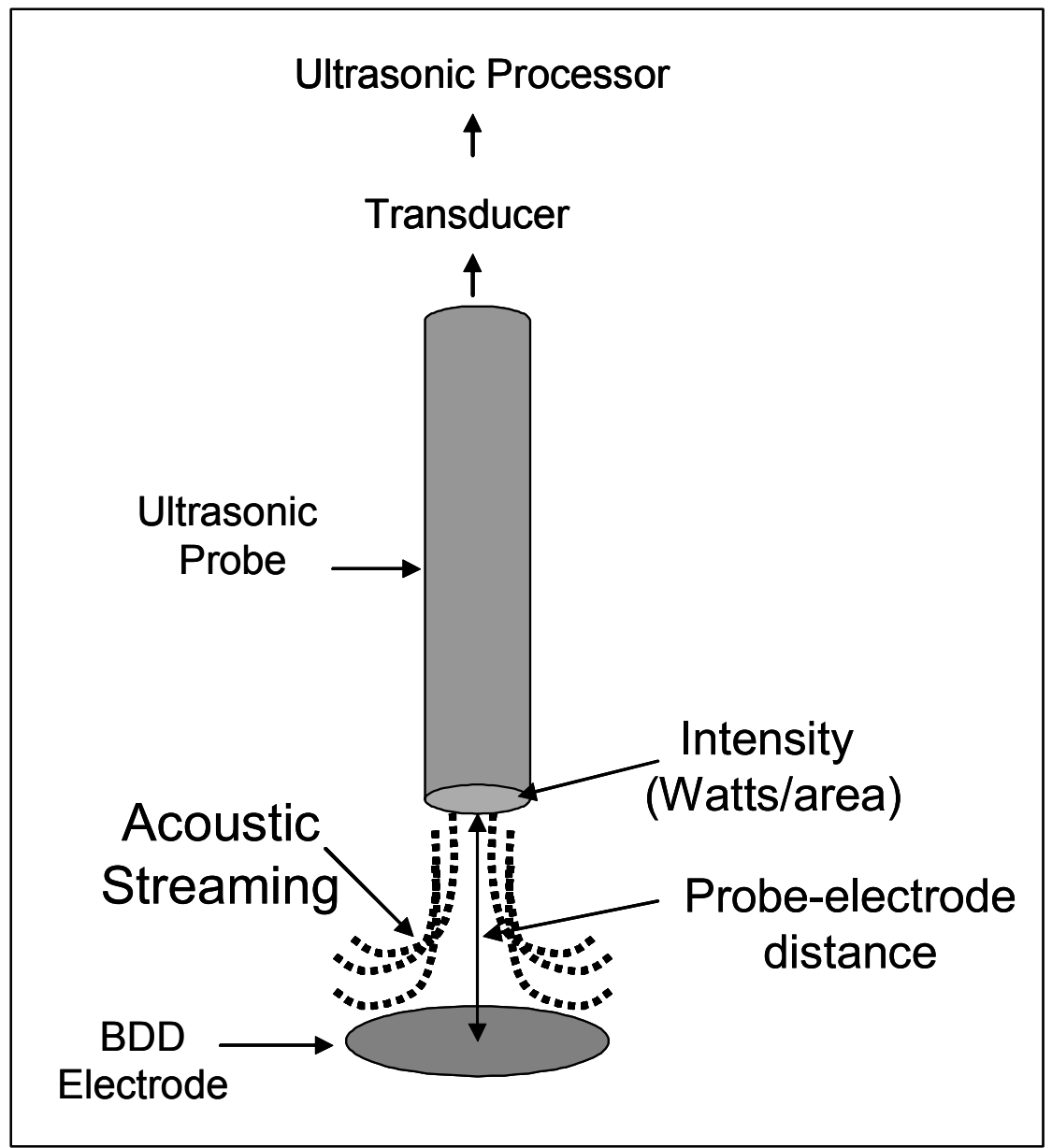

Figure 41. Illustration of Acoustic Streaming and the Variables in an Ultrasound Experiment 
periodically pushed close together, and then moved far apart. The solvent molecules can be moved far enough apart such that bubbles are formed. These bubbles may or may not contain dissolved gas, can vibrate and collapse in solution, or can collapse against the electrode surface. The collapse of a bubble in solution results in extremely high local temperatures and pressures. The collapse of a bubble against the electrode surface is referred to as a "cavitation event" in the literature, and is responsible for cleaning the electrode surface. As the bubble collapses, "microjets" of solution rush against the electrode at very high velocities, up to $100 \mathrm{~cm} / \mathrm{s}^{87-88}$

The variables in ultrasound that can be controlled are ultrasound intensity and the distance between the probe and electrode, as shown in Figure 41. Intensity has units of $\mathrm{W} / \mathrm{cm}^{2}$, where the area refers to the area of the probe tip. The power is set by the user at the ultrasonic processor. The distance may also be controlled by the user.

There have been many applications of ASV coupled to ultrasound using glassy carbon or mercury thin film electrodes. The detection of nitrite in egg, ${ }^{89}$ lead and cadmium in human saliva, ${ }^{90}$ copper in blood, ${ }^{91}$ lead in petrol, ${ }^{92}$ and lead in wine ${ }^{93}$ have been reported. All of these samples are challenging to analyze electrochemically, because they contain large organic molecules which can "foul" the electrode surface. Fouling refers to the blocking of the electrode surface by proteins, fats, polysaccharides, and other large organic molecules. The cavitation events during ultrasound remove these fouling species, and thus expose a "fresh" electrode surface to the sample. Relatively short deposition times $(<4$ minutes) were used in these analyses, and the results obtained electrochemically agreed well with those obtained from independent analysis. In some of the aforementioned examples, ultrasound was also used to extract the analyte from the 
sample matrix, which decreased the overall analysis time. For example, ultrasound was used to extract the lead from the saliva and petrol matrices.

Applications of ultrasound at BDD electrodes are less numerous but appear promising. Only three examples of trace metal analysis have been reported in the literature to this date, and they are listed in Table 8. Saterlay et al. ${ }^{25}$ achieved the detection of $10^{-9} \mathrm{M}(0.1 \mathrm{ppb}) \mathrm{Ag}^{+}$in $0.5 \mathrm{M} \mathrm{HNO}_{3}+12.5 \mathrm{mM} \mathrm{Cl}^{-}$using ASV. The chloride was added to sharpen the stripping peak. Deposition occurred for $5 \mathrm{~min}$ at 0.0 $\mathrm{mV}$, and the stripping peak for silver was observed at $+400 \mathrm{mV}$.

The next two examples in Table 8 involved the use of cathodic stripping voltammetry (CSV), in which the metal ion was deposited on the BDD surface as an oxide by application of a positive potential. The oxide was stripped from the electrode by scanning the potential negative, which reduced the oxide back to the metal ion. CSV is less likely to suffer from interferences due to intermetallic formation; unfortunately, in our work with cadmium and mercury, both metals are already fully oxidized and therefore were unable to be analyzed via CSV.

As shown in Table 8, CSV was used to detect as low as $10^{-11} \mathrm{M}(0.5 \mathrm{ppt}) \mathrm{Mn}^{2+}$ in

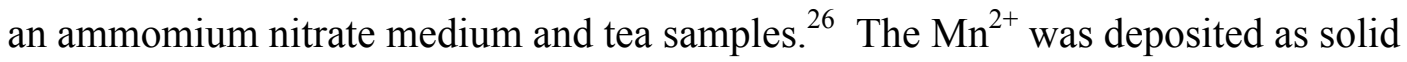
$\mathrm{MnO}_{2}$ for 2 minutes at $+850 \mathrm{mV}$, and the stripping of $\mathrm{MnO}_{2}$ occurred when the potential was scanned negative and the $\mathrm{MnO}_{2}$ was reduced at $+500 \mathrm{mV}$. Ultrasound was applied during both deposition and stripping, because application during the stripping step led to a sharper reduction peak for $\mathrm{MnO}_{2}$. The stripped $\mathrm{Mn}^{2+}$ ions were rapidly removed from the electrode surface in the presence of ultrasound. 
Table 8. Examples of Trace Metal Analysis using Ultrasound and Electrochemical Detection at BDD Electrodes

All the BDD's were polished and grown on graphite substrates.

\begin{tabular}{|c|c|c|c|c|c|c|}
\hline $\begin{array}{c}\text { Ultrasound } \\
\text { Intensity } \\
\text { W/cm }\end{array}$ & $\begin{array}{c}\text { Electrode- } \\
\text { probe } \\
\text { distance }\end{array}$ & Analyte & Matrix & LOD & $\begin{array}{c}\text { Deposition } \\
\text { Time (min) }\end{array}$ & $\begin{array}{c}\text { ASV } \\
\text { or } \\
\text { CSV }\end{array}$ \\
\hline 14 & $10 \mathrm{~mm}$ & $\mathrm{Ag}^{+}$ & $\mathrm{HNO}_{3}+\mathrm{Cl}^{-}$ & $10^{-9} \mathrm{M}$ & 5 & $\mathrm{ASV}$ \\
\hline 14 & $7 \mathrm{~mm}$ & $\mathrm{Mn}^{2+}$ & $\mathrm{NH}_{4} \mathrm{NO}_{3}$, tea & $10^{-11} \mathrm{M}$ & 2 & $\mathrm{CSV}$ \\
\hline 14 & $10 \mathrm{~mm}$ & $\mathrm{~Pb}^{2+}$ & $\begin{array}{c}\mathrm{HNO}_{3}, \\
\mathrm{HCIO}_{4} \text { (river } \\
\text { sediment } \\
\text { digest) }\end{array}$ & $10^{-7} \mathrm{M}$ & 1 & $\mathrm{CSV}$ \\
\hline
\end{tabular}


A similar approach was also used to detect lead in a river sediment digest. ${ }^{27}$ The $\mathrm{Pb}^{2+}$ was deposited as the $\mathrm{PbO}_{2}$ solid at $+5.0 \mathrm{~V}$ for 1 minute, and then stripped by scanning from $+1.5 \mathrm{~V}$ to $0.0 \mathrm{~V}$, with the reduction of $\mathrm{PbO}_{2}$ observed at $+1.26 \mathrm{~V}$. Before each run, the BDD electrode was electrochemically and ultrasonically cleaned for 2 minutes at $0.0 \mathrm{mV}$, and pre-conditioned at $-1.0 \mathrm{~V}$ for 60 seconds; however, the benefits of the cathodic pre-conditioning step weren't explained. It was noted that the LOD could have been lower if a longer deposition time and higher ultrasound intensity were used, but a compromise was made "to extend the mechanical life of the electrode housing." Ultrasound was also used in this work as the extraction method.

Other studies involving ultrasound at BDD electrodes were concerned with anodic deposition of either silver oxysalts ${ }^{28}$ or $\mathrm{PbO}_{2}{ }^{29}$, with subsequent use as catalysts for the oxidation of organic compounds. The stability of both solids was investigated and found to withstand considerable agitation by ultrasound.

The only example in the literature in which an organic molecule was analyzed at a BDD electrode with ultrasound was the detection of 4-chlorophenol (4-CP) in water. ${ }^{30}$ The potential of the BDD was simply scanned linearly from 0.0 to $+2.25 \mathrm{~V}$, and the oxidation of 4-CP was observed at $+1.15 \mathrm{~V}$. If ultrasound wasn't applied during the scan, the oxidation current of 4-CP decreased with each run, indicating that the BDD was fouled. Application of ultrasound therefore kept the BDD surface clean. The linear range of 4-CP was 1-300 $\mu \mathrm{M}$. The authors emphasized the potential of this method in the area of water pollution remediation, where pollutants like 4-CP could be degraded completely by oxidation at the BDD electrode in the presence of ultrasound. 
Although ultrasound can benefit trace metal analysis by ASV (and CSV) through increased mass transport and electrode cleaning, there are some possible disadvantages. It has been reported that ultrasound can erode or pit the surface of glassy carbon ${ }^{88,94-95}$ and platinum ${ }^{96}$ electrodes, and can also remove the mercury film from a mercury thin film electrode ${ }^{97}$. The extent of pitting depends on the solvent used, the probe-electrode distance, ultrasound intensity and duration, and presence of dissolved gases, which are thought to "cushion" the blow resulting from a cavitation event. ${ }^{98}$ Coury et al. ${ }^{94}$ reported that glassy carbon electrodes were pitted by ultrasound in aqueous solvent, but not in dioxane solvent. Marken et al.$^{99}$ found that glassy carbon could withstand ultrasound intensities of $30 \mathrm{~W} / \mathrm{cm}^{2}(10 \mathrm{~mm})$ for up to 30 minutes in aqueous solvent without pitting. The surface of the BDD electrode was examined using AFM after application of 190 $\mathrm{W} / \mathrm{cm}^{2}$ of ultrasound $(7 \mathrm{~mm})$, and no signs of pitting, erosion, or damage were found. ${ }^{31}$

In addition to the physical processes of acoustic streaming and cavitation, chemical reactions can also occur during ultrasound. As mentioned earlier, the collapse of bubbles results in extremely high local temperatures and pressures. These conditions favor radical formation, similar to the way radicals are formed at the high temperatures encountered in combustion. The species detected in the presence of ultrasound include $\mathrm{H} \cdot$ and $\mathrm{OH} \cdot$ radicals, $\mathrm{O}$-atoms, $\mathrm{NO}_{2}{ }^{-}$, and $\mathrm{NO}_{3}{ }^{-}$in aqueous solutions containing either dissolved oxygen or nitrogen. ${ }^{100}$ Coury ${ }^{94}$ suspected that the sonolysis products of water deactivated the surface of a glassy carbon electrode by forming surface oxides.

To summarize, the advantages of using ultrasound during the pre-concentration step in ASV are increased mass transport, and continuous electrode cleaning due to acoustic streaming and cavitation, respectively. The variables affecting the efficiency of 
the ultrasound are intensity, distance between the electrode and probe, solvent, and concentration of dissolved gases.

In this chapter, attempts to detect cadmium and mercury in the presence of ultrasound using both unpolished and polished BDD electrodes are discussed. Two ranges of ultrasound intensities were used, with the higher intensity severely damaging the unpolished BDD electrode, although it could be temporarily restored by cycling in $\mathrm{KOH}$. The majority of the work in this chapter was accomplished with the polished BDD electrode.

\section{Experimental}

Two types of BDD electrodes were used in the presence of ultrasound. An unpolished BDD grown on a silicon substrate was obtained, and the thickness of the BDD layer was estimated to be about 10-50 $\mu \mathrm{m}$. The unpolished BDD was mounted in the electrochemical cell as described earlier (Chapter 2, Figure 4). A free-standing, polished BDD was obtained from Windsor Scientific Ltd. (Berkshire, England), and had been industrially polished smooth on a nanometer scale. The BDD was $3 \mathrm{~mm}$ diameter and mounted in Teflon. The BDD electrode was placed at the bottom of an electrochemical cell, similar to that used with the unpolished BDD. The reference and auxiliary electrodes were a double junction $\mathrm{Ag} / \mathrm{AgCl} /$ saturated $\mathrm{KCl}$ and platinum wire, respectively, and entered the electrochemical cells from the top.

Ultrasound was delivered to the cell by placing either a microtip or macrotip probe above the electrode. The areas of the microtip or macrotip probes were 0.071 and $6.8 \mathrm{~cm}^{2}$, respectively. The distance between the probe and electrode was controlled by 
moving the cell up or down on a ring stand. The probes vibrated at a frequency of $20 \mathrm{~Hz}$, and the ultrasonic processor (Heat Systems XL2020, Farmingdale, NY) was capable of delivering $475 \mathrm{~W}$ (maximum) of ultrasound. The temperature of the cell was maintained at $25^{\circ} \mathrm{C}$ using a water bath (Fisher, Model 90).

Osteryoung square wave anodic stripping voltammetry was performed using a Bioanalytical Systems 100B electrochemical analyzer. The deposition and stripping parameters used for mercury and cadmium are listed in Table 9, unless stated otherwise.

The BDD electrodes and all cell components were washed with 50\% (v/v) nitric acid prior to each experiment. The electrolyte solution was purged with nitrogen for 20 minutes before each experiment to remove dissolved oxygen (and to provide stirring if ultrasound wasn't used during the deposition step). The stripping step was always performed under silent conditions.

Nanopure water $(\Omega<18$ ohms) was used throughout. Certified ACS grade salts were used to prepare the electrolyte solutions. Either 50.0 or $100.0 \mathrm{~mL}$ of electrolyte was delivered to the cell using a volumetric pipet. The standard addition method was used to prepare calibration curves. Microliter amounts of cadmium or mercury stock solution (certified, Fisher) were added to the cell using an Eppendorf pipette with disposable tips.

\section{Results and Discussion}

\section{The Unpolished Boron-Doped Diamond: Effects of Ultrasound on Electrode Performance}

In these experiments a microtip probe with an area of $0.071 \mathrm{~cm}^{2}$ was used to deliver ultrasound to the solution. The ultrasonic processor was set to 3 (or $18 \%$ of 475 $\mathrm{W}$ maximum output), which resulted in an ultrasound intensity of about $1,200 \mathrm{~W} / \mathrm{cm}^{2}$. 
Table 9. Deposition and Stripping Parameters used for Mercury and Cadmium

\begin{tabular}{|c|c|c|}
\hline Parameter & Mercury & Cadmium \\
\hline Deposition Time & varied & varied \\
\hline Deposition Potential & $-1.0 \mathrm{~V}$ or $-500 \mathrm{mV}$ & $-1.1 \mathrm{~V}$ \\
\hline Final Potential & $+600 \mathrm{mV}$ & $+500 \mathrm{mV}$ \\
\hline $\begin{array}{c}\text { Square Wave } \\
\text { Frequency }\end{array}$ & $150 \mathrm{~Hz}$ & $15 \mathrm{~Hz}$ \\
\hline $\begin{array}{c}\text { Square Wave Amplitude } \\
\text { Step Potential }\end{array}$ & $25 \mathrm{mV}$ & $25 \mathrm{mV}$ \\
\hline & $2 \mathrm{mV}$ & $4 \mathrm{mV}$ \\
\hline
\end{tabular}


This was much larger than any value reported in the literature in which ultrasound was used in conjunction with electrochemistry. Typical ultrasound intensities reported in the literature ranged from $14-200 \mathrm{~W} / \mathrm{cm}^{2} .{ }^{25-31,89-93}$ Nonetheless, several experiments were performed in which this extremely high ultrasound intensity was applied during the deposition step. The current for $200 \mathrm{ppb} \mathrm{Hg}^{2+}$ decreased to non-detectable levels within 4-5 repetitions. In some experiments, a signal was never detected with stirring after application of ultrasound, while in others, a current was observed, but was very unstable. Although this was the typical pattern observed when using this extremely high ultrasound intensity, there were two experiments in which mercury was detected and calibrated using a deposition time of 10 minutes with ultrasound. The voltammograms and calibration curve for one of these experiments are shown in Figure 42. The mercury peak was located at $\sim 175 \mathrm{mV}$, and increased from $50 \mathrm{ppb}$ to $150 \mathrm{ppb}$; the blank is not shown, because it was obtained using a deposition time of only 1 minute. Error bars are not provided, because each concentration (other than $50 \mathrm{ppb}$ ) was tested only twice due to the decreasing behavior typically observed in the presence of ultrasound. The calibration curve contains the lowest concentrations of mercury detected in $\mathrm{KCl}$ without addition of an auxiliary element, and is linear at concentrations which usually fell within the nonlinear portion of the calibration curve $\left(\mathrm{R}^{2}=0.9936\right)$. It should also be emphasized that at the beginning of this experiment, the BDD electrode had already begun to exhibit some signs of damage due to ultrasound, which are discussed below. Other than the BDD electrode used to obtain the results shown in Figure 42, most of the unpolished BDD's were altered or damaged after exposure to ultrasound. Evidence of damage or change was seen in cyclic and stripping voltammograms of the blank and metal-containing 

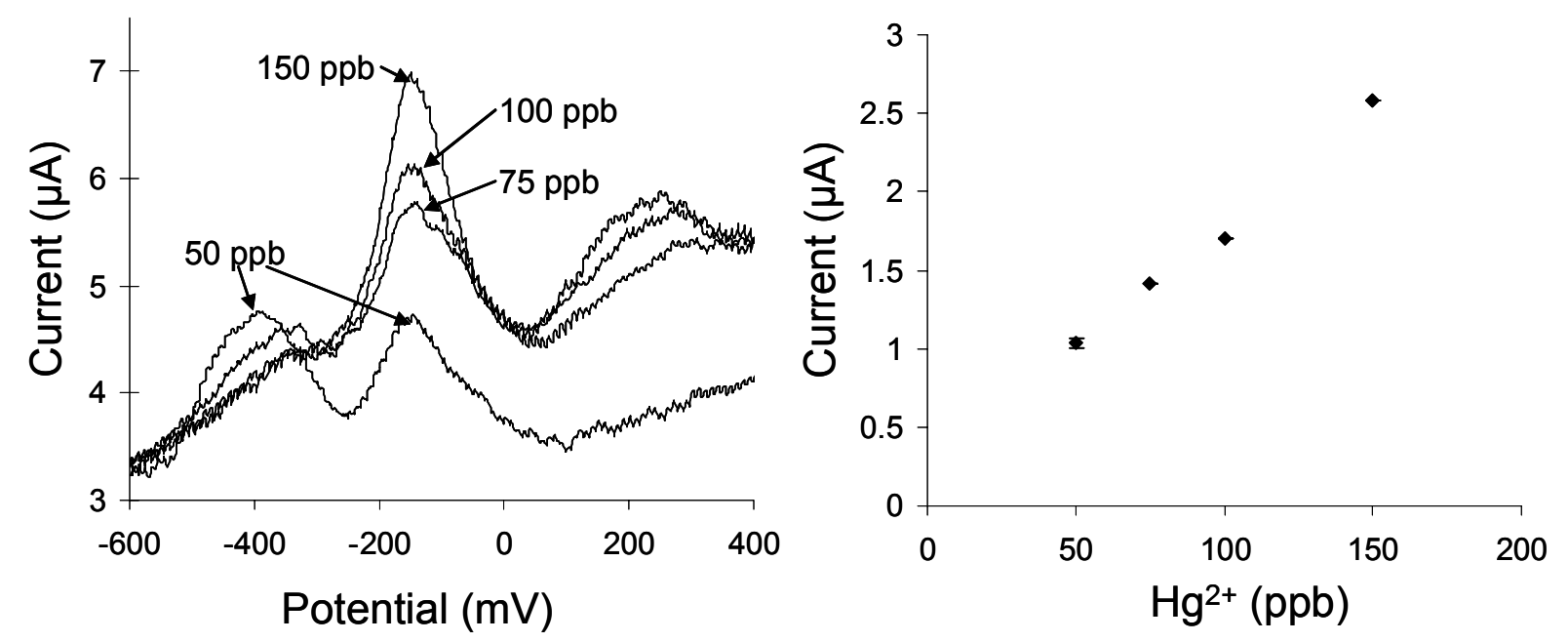

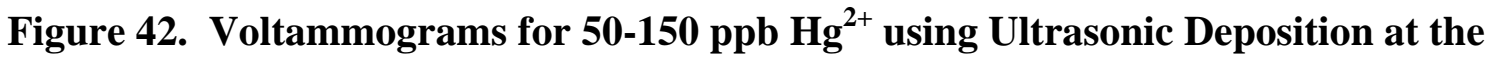
Unpolished BDD Electrode

Ultrasound Intensity $=1200 \mathrm{~W} / \mathrm{cm}^{2}$, Distance $=\sim 12 \mathrm{~mm}, 1 \mathrm{M} \mathrm{KCl}(\mathrm{pH} \sim 5)$, Deposition Potential $=-1.0 \mathrm{~V}$, Deposition Time $=10 \mathrm{~min}$, Final Potential $=+500 \mathrm{mV}$, Frequency $=$ $150 \mathrm{~Hz}$, Amplitude $=25 \mathrm{mV}$, Step Potential $=2 \mathrm{mV}$. 
solutions. Figure 43a shows the typical changes observed in the cyclic voltammogram (CV) of a blank $\mathrm{KCl}$ solution after ultrasound. The post-ultrasound $\mathrm{CV}$ contained a large cathodic peak at $\sim-600 \mathrm{mV}$, and a higher background current at $-1000 \mathrm{mV}$. The positive sweep exhibited two anodic peaks at $-900 \mathrm{mV}$ and $-400 \mathrm{mV}$. The $\mathrm{CV}$ obtained before ultrasound was featureless, other than the cathodic feature at $\sim-800 \mathrm{mV}$, whose identity is unknown. In Figure 43b, it can be seen that the stripping voltammogram of a blank $\mathrm{KCl}$ solution obtained after ultrasound contained an unidentifiable peak centered at $\sim-600 \mathrm{mV}$, and a higher background current at $-1.0 \mathrm{~V}$. Figure 44 shows that the BDD lost its sensitivity toward cadmium detection after exposure to ultrasound, and that the background current increased. The particular BDD electrode used to obtain the voltammograms in Figures 43 and 44 had been exposed to a total of 12 minutes of ultrasound (non-continuous) at an intensity of $1200 \mathrm{~W} / \mathrm{cm}^{2}$.

The possibility that ultrasound oxidized the surface of this BDD was investigated. The $\mathrm{Fe}^{2+/ 3+}$ redox couple can be used as a diagnostic to determine if an electrode surface has been oxidized, because it is sensitive to the presence of carbonyl groups. The peak separation will change from $900 \mathrm{mV}$ to $600 \mathrm{mV}$ upon oxidation of the BDD surface. ${ }^{44}$ Figure 45 shows cyclic voltammograms of $1 \mathrm{mM} \mathrm{Fe}\left(\mathrm{ClO}_{4}\right)_{2}$ in $0.1 \mathrm{M} \mathrm{H}_{2} \mathrm{SO}_{4}$ before and after exposure to ultrasound. Before ultrasound, cathodic and anodic peaks appeared at $+50 \mathrm{mV}$ and $+780 \mathrm{mV}$, respectively, giving a peak separation of about $730 \mathrm{mV}$ and indicating that the surface of this BDD was slightly oxidized prior to ultrasound. Unfortunately, diagnosis of the BDD surface after ultrasound was impossible using the $\mathrm{Fe}^{2+/ 3+}$ redox couple, as shown in Figure 45. After ultrasound, there was no cathodic peak due to $\mathrm{Fe}^{3+}+e^{-} \rightarrow \mathrm{Fe}^{2+}$, and the background current at $-600 \mathrm{mV}$ was nearly 10 

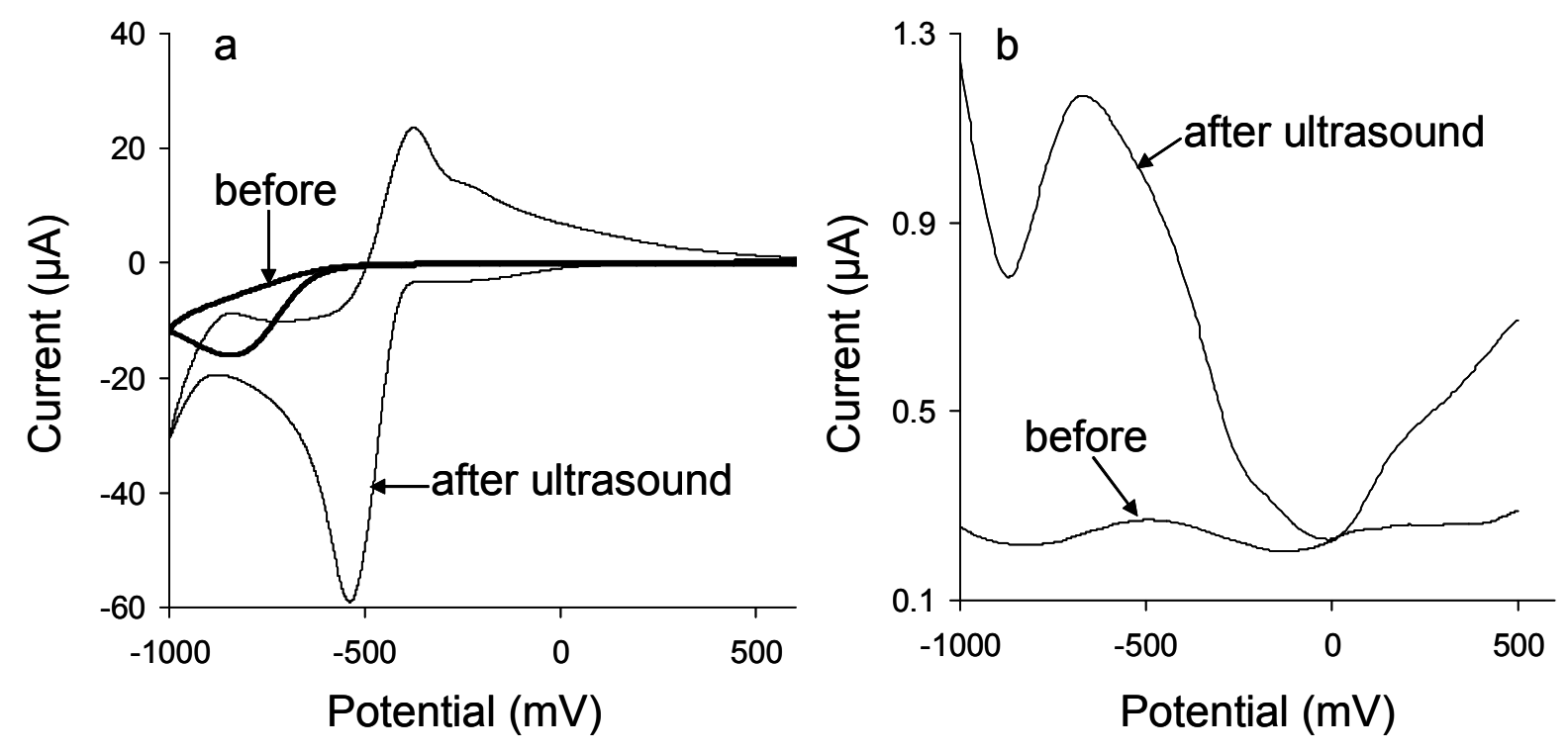

Figure 43. Effect of Ultrasound on the Unpolished BDD Electrode

Total exposure to ultrasound was $12 \mathrm{~min}$ at $1200 \mathrm{~W} / \mathrm{cm}^{2}$

a) Cyclic voltammogram of blank $0.1 \mathrm{M} \mathrm{KCl}$ before and after exposure to ultrasound, $v=100 \mathrm{mV} / \mathrm{s}$; b) ASV of blank 0.1 M KCl. Deposition Potential $=-1.0 \mathrm{~V}$, Deposition

Time $=5$ minutes, Frequency $=15 \mathrm{~Hz}$, Amplitude $=25 \mathrm{mV}$, Step $=4 \mathrm{mV}$, Stirred Deposition. 


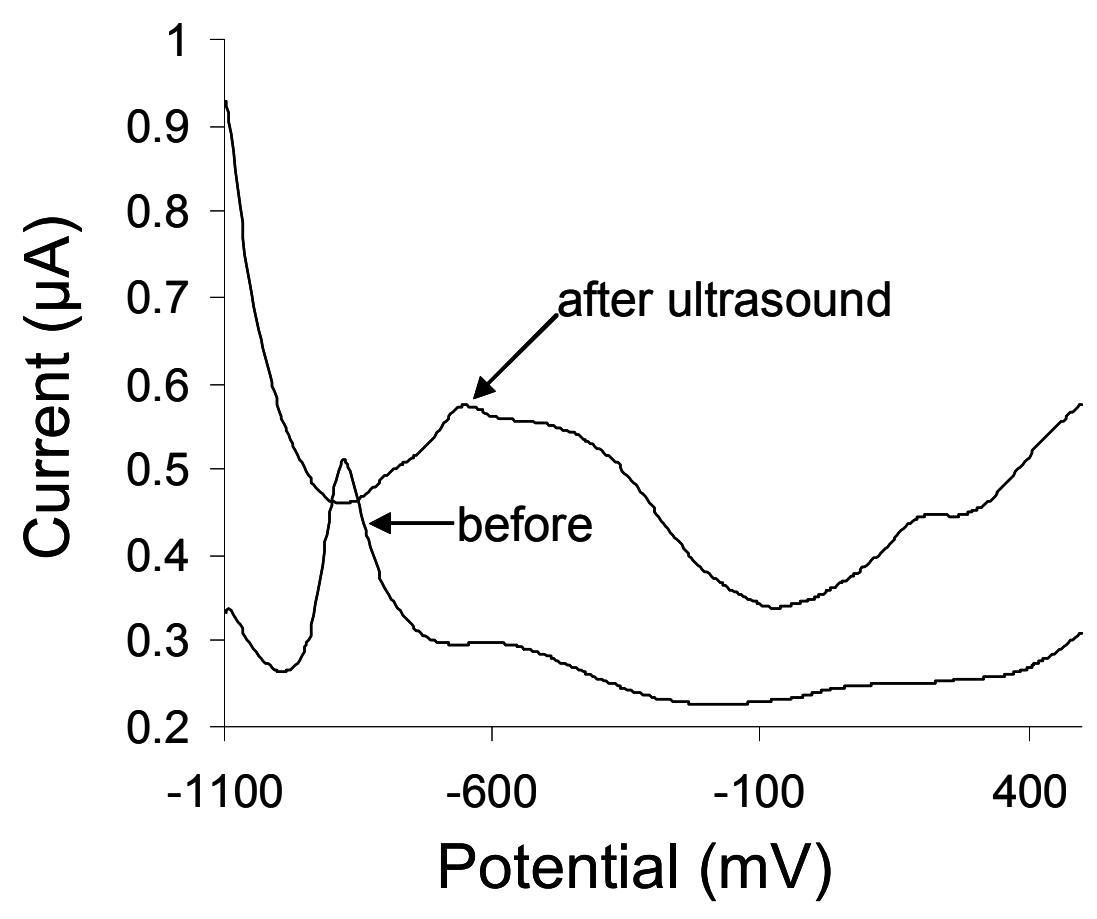

Figure 44. Comparison of $10 \mathrm{ppb} \mathrm{Cd^{2+ }}$ Before and After Exposure to Ultrasound

Total exposure to ultrasound was $12 \mathrm{~min}$ at $1200 \mathrm{~W} / \mathrm{cm}^{2}$. Unpolished BDD Electrode, $0.1 \mathrm{M} \mathrm{KCl}, \mathrm{pH} \sim 5$, Deposition Potential $=-1.1 \mathrm{~V}$, Deposition Time $=5 \mathrm{~min}$, Frequency $=$ $15 \mathrm{~Hz}$, Amplitude $=25 \mathrm{mV}$, Step $=4 \mathrm{mV}$, Stirred Deposition. 

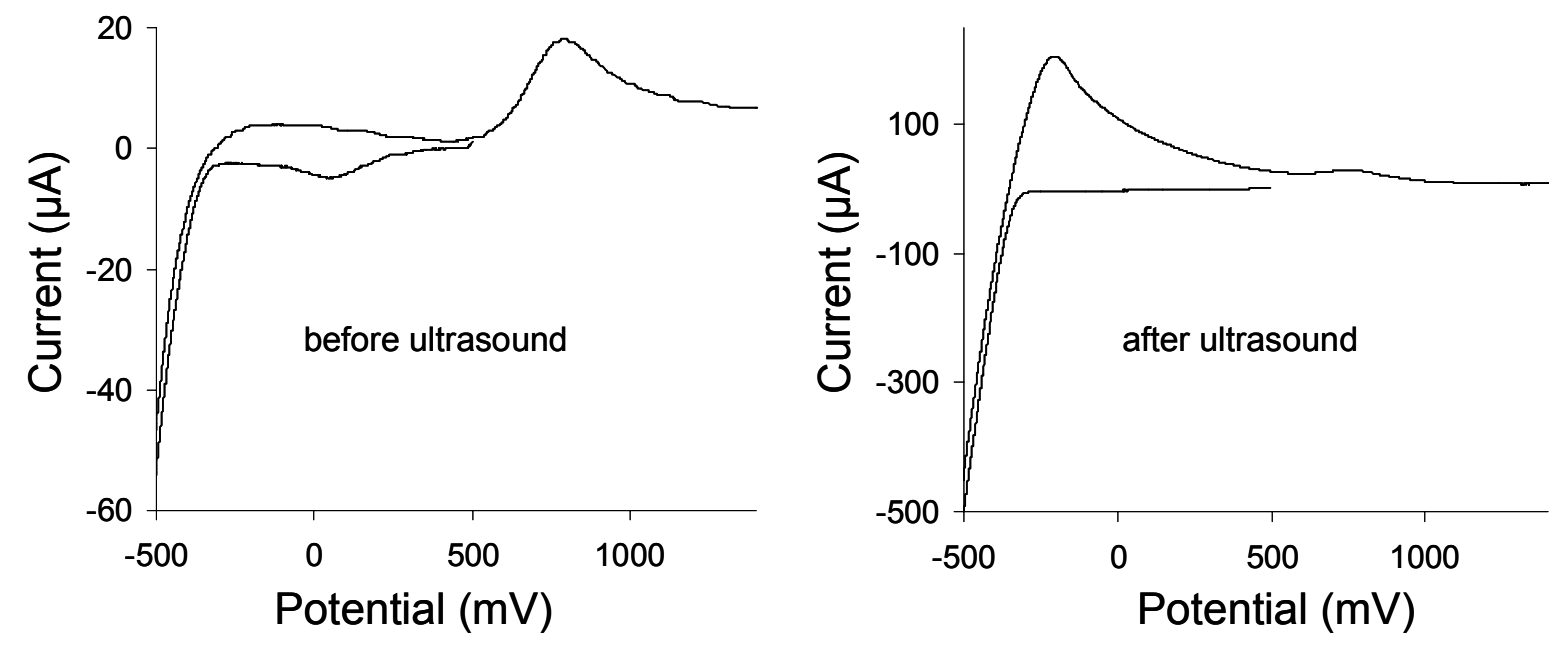

Figure 45. Cyclic Voltammograms of $0.001 \mathrm{M} \mathrm{Fe}(\mathrm{ClO} 4)_{2}$ in $0.1 \mathrm{M} \mathrm{H}_{2} \mathrm{SO}_{4}$ Before and After Ultrasound

Total exposure to ultrasound was $12 \mathrm{~min}$ at $1200 \mathrm{~W} / \mathrm{cm}^{2}$. Unpolished BDD Electrode. 
times larger than that before ultrasound. On the positive sweep a large unknown anodic peak appeared at $\sim-200 \mathrm{mV}$. The peak corresponding to oxidation of $\mathrm{Fe}^{2+}$ then appeared at nearly the same potential as that prior to ultrasound.

Ultrasound-induced damage to the unpolished BDD's can be summarized as follows: increased background current, the appearance of unknown peaks, and loss of sensitivity toward metal detection. The increased background current implies that the electrochemical active area of the BDD has increased due to erosion or the formation of electroactive functional groups. The high background at negative potentials is probably due to increased hydrogen evolution, which typically requires large overpotentials on the diamond electrode and is thought to involve an adsorbed intermediate species. ${ }^{13,16}$ Perhaps hydrogen evolution is facilitated after ultrasound through the creation of new "adsorption" sites. New adsorption sites may be created if ultrasound altered the functional groups on the diamond surface, or if pores are created on the diamond surface.

The appearance of new peaks in the voltammograms obtained after ultrasound are hard to explain. One may speculate that these peaks represent oxidation and reduction of oxygen-containing functional groups on the diamond surface, produced as a result of ultrasound. Perhaps cavitation events destroy the $\mathrm{sp}^{3}$, tetrahedral structure of the diamond, and amorphous carbon is formed, which could get oxidized and reduced. However, Martin et al. ${ }^{16}$ observed that $\mathrm{sp}^{2}$ carbon impurities in BDD electrodes exhibited a reversible redox couple at $+1.7 \mathrm{~V}$ in $0.5 \mathrm{M} \mathrm{H}_{2} \mathrm{SO}_{4}$, which is much more positive than the redox couple we observed in $\mathrm{KCl}$ after ultrasound (Figure 43a).

A more plausible explanation of the unknown peaks in post-ultrasound voltammograms could involve the erosion of the BDD layer, which would result in 
exposure of the $\mathrm{Si}$ substrate to the electrolyte. The unknown redox couple at $-500 \mathrm{mV}$ in the post-ultrasound $\mathrm{CV}$ of $0.1 \mathrm{M} \mathrm{KCl}$ might be the result of a redox reaction occurring on the $\mathrm{Si}$ surface; however, a $\mathrm{CV}$ of $\mathrm{KCl}$ using $\mathrm{Si}$ as the working electrode did not produce the "mystery" redox couple. (One must also ask what is the redox couple in blank $\mathrm{KCl}$ that could be active at a silicon surface). Therefore, it is proposed that the unknown redox couple in the post-ultrasound $\mathrm{CV}$ of $\mathrm{KCl}$ is due to some electrochemical activity of $\mathrm{SiO}_{2}$, which was deposited from the substrate to the diamond surface as a result of ultrasound. Reuben et al. ${ }^{34}$ reported this in alkaline nitrate solutions in the absence of ultrasound, and confirmed the presence of $\mathrm{SiO}_{2}$ on the BDD surface using XPS. Reuben stated that the electrolyte could "perforate" through the grain boundaries and interact with silicon. The cavitation events occurring during ultrasound may enable the electrolyte to interact with the $\mathrm{Si}$ substrate in a similar way. If this $\mathrm{SiO}_{2}$ is in fact deposited on the BDD surface as a result of ultrasound, this may explain why the BDD lost its sensitivity toward cadmium after ultrasound.

An attempt was made to restore this BDD which had been damaged by ultrasound. There have been many reports in the literature concerning the pre-treatment of BDD surfaces, and their subsequent electrochemical behavior. The pre-treatment utilized by Swain was chosen to rejuvenate the BDD surface which had been altered by ultrasound. The diamond was exposed to $15 \%(\mathrm{w} / \mathrm{v}) \mathrm{KOH}$ and cycled from $+700 \mathrm{mV}$ to $-700 \mathrm{mV}$ at $10 \mathrm{mV} / \mathrm{sec}$ for a total of 100 cycles (an 8-hr procedure). According to Swain, ${ }^{40}$ this process selectively etches $\mathrm{sp}^{2}$ carbon from the diamond surface, creating pores, thus increasing the electrochemical area. He also determined electrochemically that the diamond was oxidized by this treatment, but that the oxygen atoms were located 
deep inside the pores, rather than on the surface. It is not known what effect this treatment would have on the $\mathrm{SiO}_{2}$ proposed to be on the BDD surface.

Figure 46 compares voltammograms for $10 \mathrm{ppb} \mathrm{Cd}^{2+}$ taken before exposure to ultrasound (trace a), after exposure to ultrasound (trace b), and then after the $\mathrm{KOH}$ treatment (trace $\mathrm{c}$ ). Clearly, the $\mathrm{KOH}$ treatment restored the diamond to its original condition. Figure 47 shows how the $\mathrm{CV}$ of blank $\mathrm{KCl}$ returned to pre-ultrasound conditions after the $\mathrm{KOH}$ treatment. The $\mathrm{CV}$ of $\mathrm{Fe}\left(\mathrm{ClO}_{4}\right)_{2}$ was restored as well (data not shown), with a peak separation of $634 \mathrm{mV}$, compared to the $732 \mathrm{mV}$ prior to the $\mathrm{KOH}$ treatment (and ultrasound); therefore, the $\mathrm{KOH}$ treatment slightly oxidized the diamond surface as expected.

During the cadmium analysis after the $\mathrm{KOH}$ treatment (trace $\mathrm{c}$ in Figure 46), the stripping current for $10 \mathrm{ppb}$ was $0.33 \mu \mathrm{A}$ for the $1^{\text {st }}$ trial, but then decreased to an average of $0.25 \mu \mathrm{A}$ for the subsequent three trials ( $\mathrm{RSD}=4.17 \%$ for the last 3 trials). This decrease may have been a result of hydrogen bubbles (from the reduction of protons) getting trapped inside the pores created by the $\mathrm{KOH}$ treatment, thus blocking the deposition sites for cadmium. Ultrasound was then applied during the deposition step for one minute, resulting in an increased stripping current of $0.5 \mathrm{uA}(\mathrm{RSD}=11.2 \%$ for last 3 runs out of 6). Next, the deposition step was performed with stirring in the same solution, and the current decreased to $\sim 0.1 \mu \mathrm{A}$ (from the original $0.25 \mu \mathrm{A}$ obtained prior to ultrasound). It appeared as if ultrasound was again affecting the sensitivity of the diamond surface toward cadmium. The cell and electrode were acid washed, fresh electrolyte was added, and $10 \mathrm{ppb} \mathrm{Cd}^{2+}$ was measured again using a stirred deposition. The current seemed to be "restored", and the response behaved in a similar manner to the 


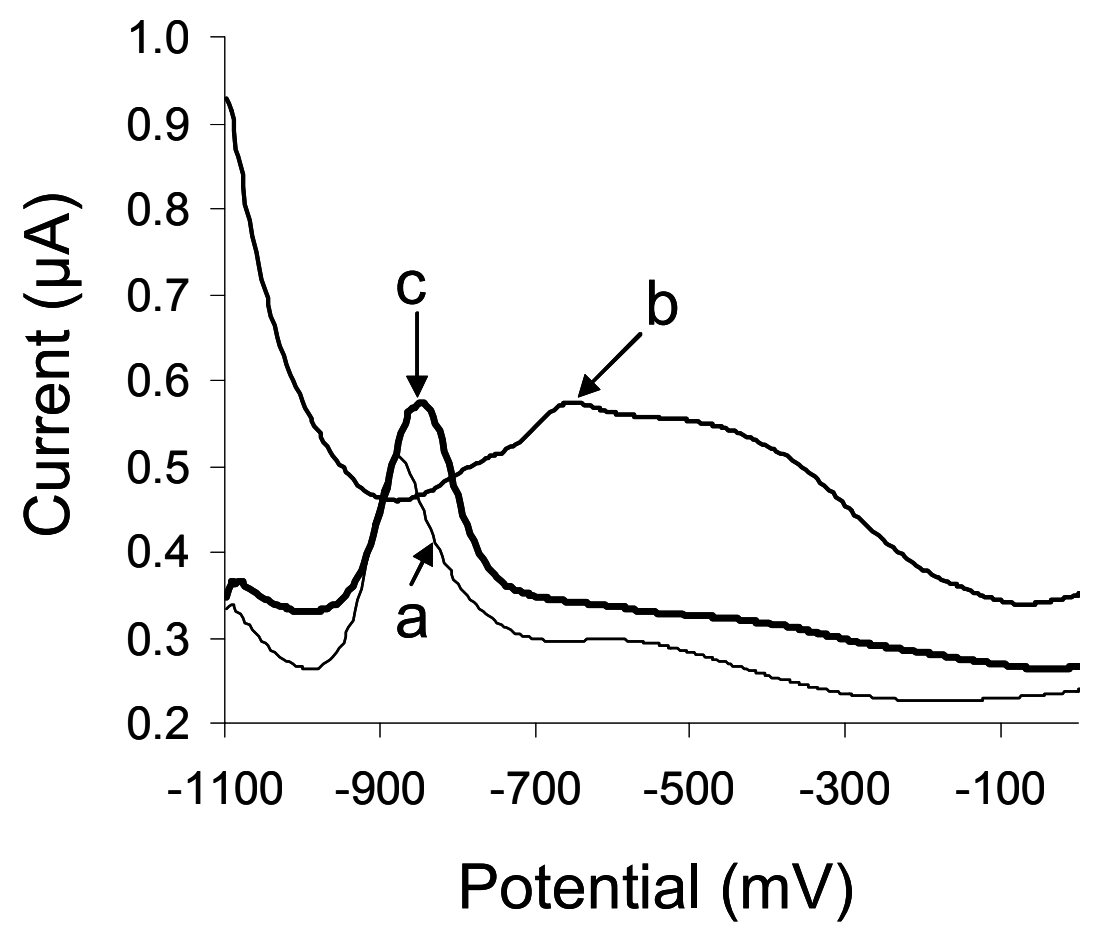

Figure 46. Rejuvenation of the Unpolished BDD Electrode: Effect on $10 \mathrm{ppb} \mathrm{Cd}^{2+}$ in $0.1 \mathrm{M} \mathrm{KCl}$

a) Before ultrasound, b) After ultrasound, c) After ultrasound and $\mathrm{KOH}$ treatment. See text for parameters used in $\mathrm{KOH}$ treatment (rejuvenation). Deposition Potential $=-1.1 \mathrm{~V}$, Deposition Time $=5 \mathrm{~min}$, Frequency $=15 \mathrm{~Hz}$, Amplitude $=25 \mathrm{mV}$, Step $=4 \mathrm{mV}$, Stirred Deposition. 


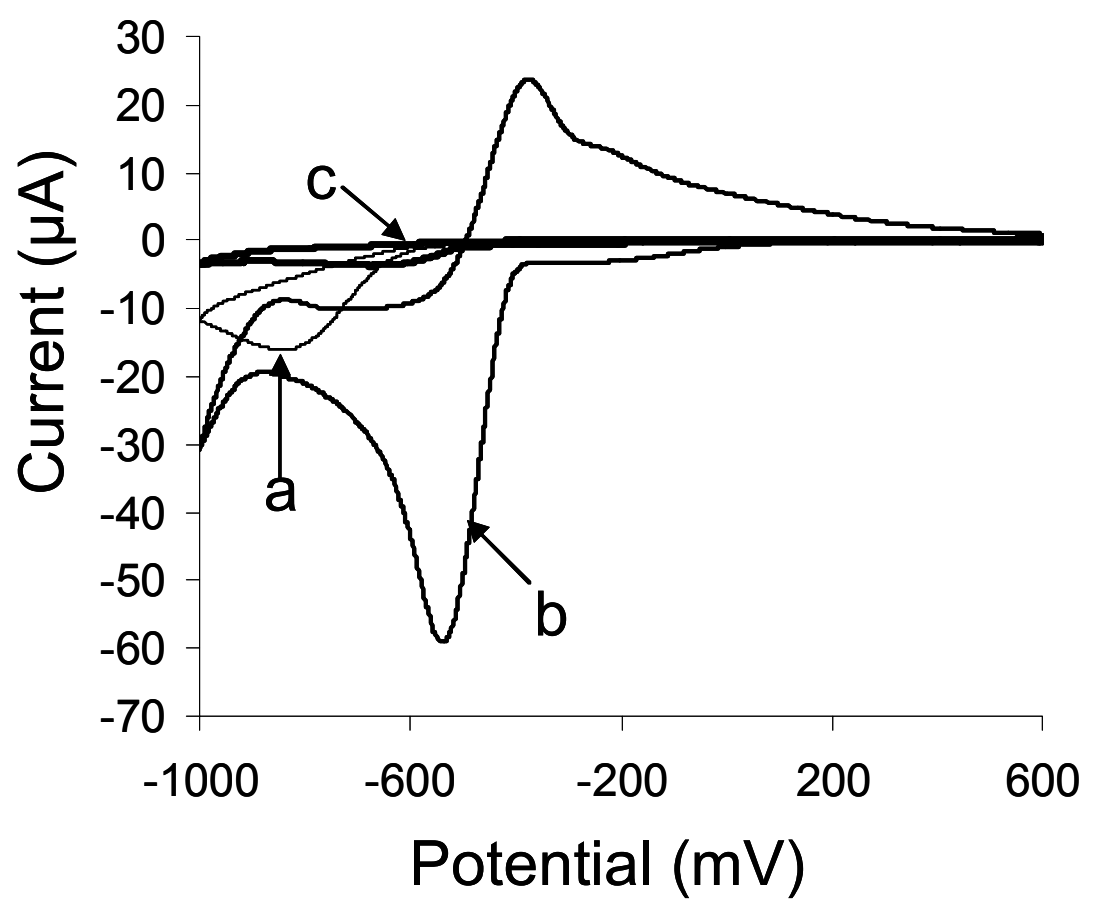

Figure 47. Rejuvenation of Unpolished BDD Electrode: Effect on the CV of $0.1 \mathrm{M}$ KCl

a) Before ultrasound; b) After ultrasound; c) After ultrasound and $\mathrm{KOH}$ treatment. See text for parameters used in $\mathrm{KOH}$ treatment (rejuvenation). 
first experiment with $\mathrm{Cd}^{2+}$ following the $\mathrm{KOH}$ treatment. The first run was $0.4123 \mu \mathrm{A}$, and following 3 runs decreased to an average of $0.3220 \mu \mathrm{A}(3.28 \% \mathrm{RSD})$.

Under the assumption that the diamond surface had been permanently restored by the $\mathrm{KOH}$ treatment, more experiments were performed with ultrasound in $0.1 \mathrm{M} \mathrm{KCl}$. At a deposition time of 3 minutes, $2 \mathrm{ppb} \mathrm{Cd}^{2+}$ was detected $(0.04892 \mu \mathrm{A})$, but reproducibility was poor $(\mathrm{RSD}=23.03 \%, \mathrm{n}=3)$. The signal for $2 \mathrm{ppb} \mathrm{Cd}^{2+}$ decreased with each repetition, and did not increase even when more cadmium was added. These experiments resulted in a total exposure to ultrasound of about 45 minutes after the $\mathrm{KOH}$ treatment. After the cadmium solution was replaced with fresh $\mathrm{KCl}$ solution, the same post-ultrasound symptoms (high background currents, unknown peaks, and loss of sensitivity toward cadmium) were observed. Therefore, the $\mathrm{KOH}$ treatment was only able to restore the diamond surface only temporarily.

In summary, exposing the unpolished BDD electrode to ultrasound during ASV experiments resulted in poor performance, with higher background currents, unknown peaks, and loss of sensitivity toward cadmium. The BDD electrode was temporarily rejuvenated by an 8 -hour cycling procedure in $\mathrm{KOH}$ which etched $\mathrm{sp}^{2}$ carbon impurities, but repeated exposure to ultrasound again lead to poor performance of the electrode.

\section{The Polished Boron-Doped Diamond Electrode}

Effects of Ultrasound on Electrode Performance

As previously mentioned, the ultrasound intensities applied to the unpolished BDD were extremely high compared to those reported in the literature. ${ }^{25-31,89-93}$ A few experiments were performed on the polished BDD using this same high ultrasound 
intensity. These experiments involved the detection of mercury in $0.1 \mathrm{M} \mathrm{KNO}_{3}$ (neutral and acidified). In the very first run of the blank using ultrasound, there were two broad peaks at $-600 \mathrm{mV}$ and $-400 \mathrm{mV}$, whose identities were unknown. When mercury was added, the current was non-detectable after about 5 runs, similar to what had been observed at the unpolished BDD; however, slightly different results were obtained in acidified $\mathrm{KNO}_{3}$. As shown in Figure 48, the blank still contained two unknown peaks, but the current for mercury was more stable. The voltammograms shown in Figure 48 were obtained using ultrasound $\left(1,000 \mathrm{~W} / \mathrm{cm}^{2}\right)$ during the 1-minute deposition step. Two stripping peaks at $0 \mathrm{mV}$ and $+500 \mathrm{mV}$ were observed for mercury, which had previously been observed for $20 \mathrm{ppb} \mathrm{Hg}^{2+}$ in acidified $\mathrm{KNO}_{3}$ using a 20-minute deposition time. Thus, similar behavior is observed at long deposition times with stirring and short deposition times with ultrasound. The peak at $+500 \mathrm{mV}$ may be due to the oxidation of $\mathrm{Hg}_{2}{ }^{2+}$ which had formed through disproportionation, or the stripping of mercury from a site on the BDD which was activated as a result of the long deposition time or exposure to ultrasound. In the presence of ultrasound, the peak at $+500 \mathrm{mV}$ was linear for mercury concentrations from $100-300 \mathrm{ppb}\left(\mathrm{R}^{2}=0.9907\right)$, which was an improvement over the usual calibration curves which were non-linear at concentrations below $150 \mathrm{ppb}$ (see Chapter 4, Figure 33).

The BDD electrode had now been exposed to a very high ultrasound intensity $\left(1,000-1,200 \mathrm{~W} / \mathrm{cm}^{2}\right)$ for a total of 73 minutes. Figure 49 shows that the polished BDD which had been exposed to ultrasound yielded a voltammogram containing unknown stripping peaks for blank $\mathrm{KNO}_{3}$, and this behavior was similar to that observed at the unpolished BDD (see Figure 43b). It should be emphasized that both voltammograms 

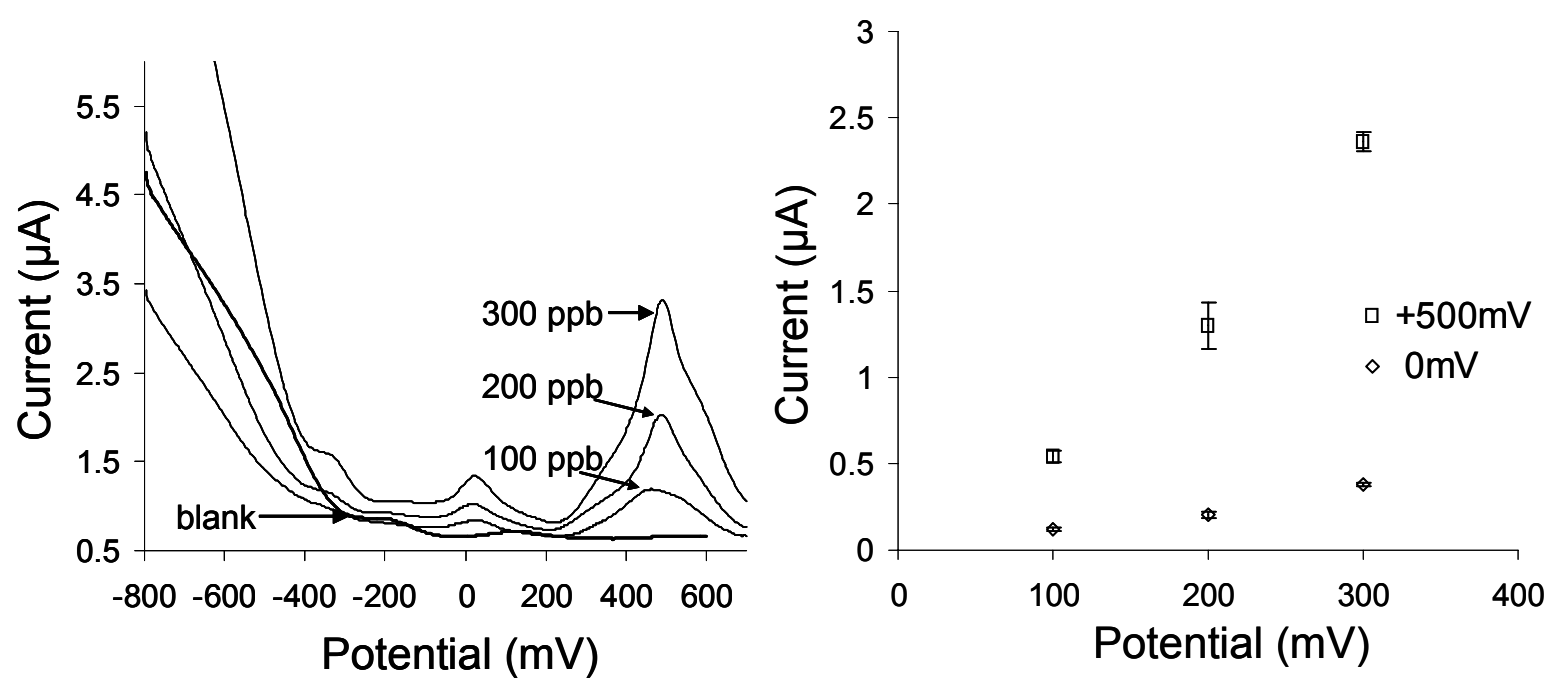

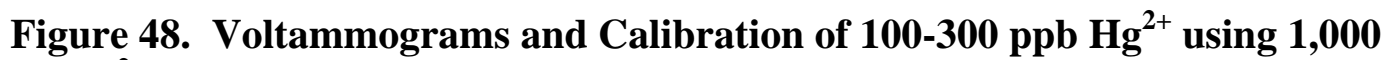
$\mathrm{W} / \mathrm{cm}^{2}$ Ultrasound at the Polished BDD Electrode

$0.1 \mathrm{M} \mathrm{KNO}_{3}, \mathrm{pH}<1$, Deposition Potential $=-800 \mathrm{mV}$, Deposition Time $=1$ minute, Frequency $=15 \mathrm{~Hz}$, Amplitude $=25 \mathrm{mV}$, Step $=4 \mathrm{mV}$, Ultrasonic Deposition. 


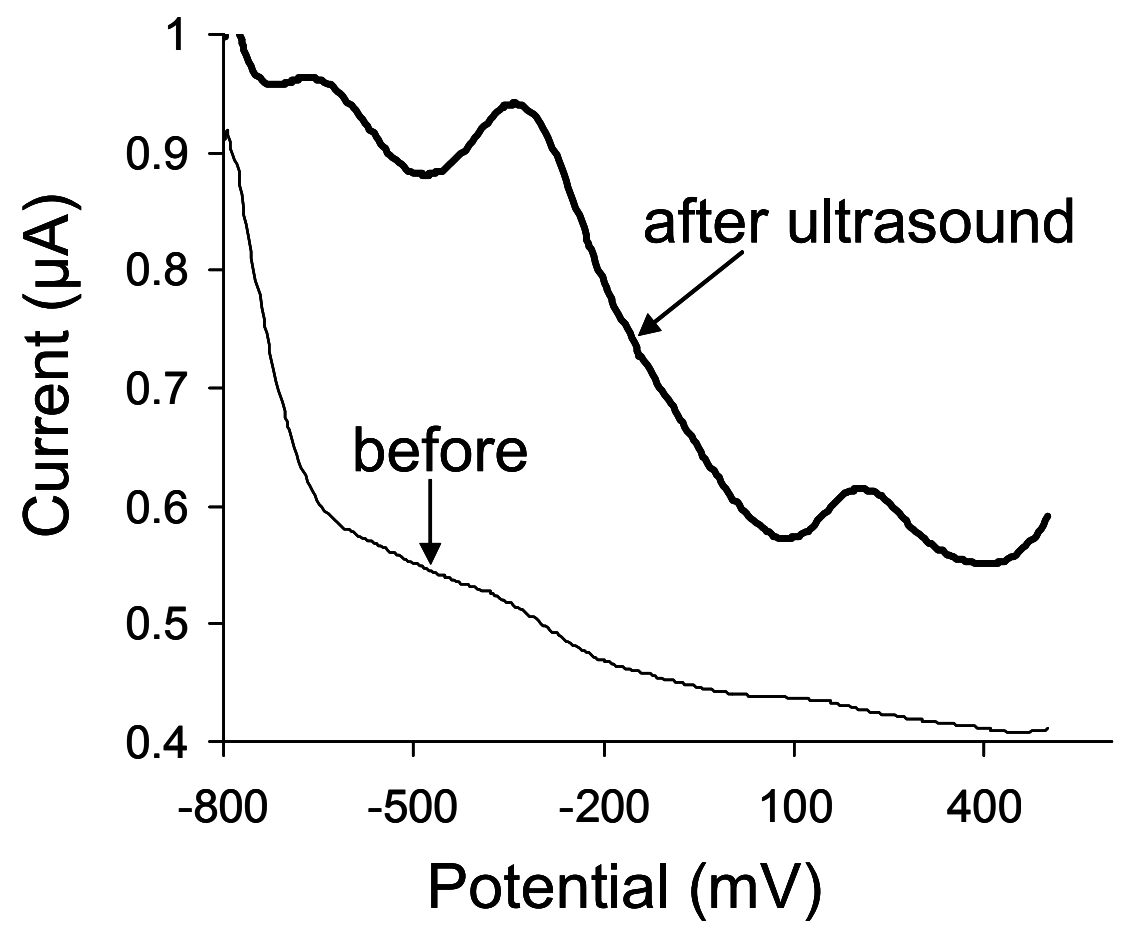

Figure 49. Effect of High-Intensity Ultrasound on the Polished BDD Electrode: Blank 0.1 M KNO

Total exposure to ultrasound was 73 minutes at 1,000-1,200 W/cm ${ }^{2}$. pH 5, Deposition Potential $=-800 \mathrm{mV}$, Deposition Time $=5$ minutes, Frequency $=15 \mathrm{~Hz}$, Amplitude $=25$ $\mathrm{mV}$, Step $=4 \mathrm{mV}$, Stirred Deposition. 
were obtained with stirring, so whatever changes occurred on the BDD surface due to ultrasound appear to be permanent.

The response of the ultrasound-exposed BDD toward mercury had also changed, as shown in Figure 50. Unlike the behavior of the unpolished BDD, in which sensitivity toward cadmium decreased significantly, the polished BDD still retained some activity toward mercury; however, the post-ultrasound voltammogram still contained the peak at $+500 \mathrm{mV}$, which was observed during ultrasound. Again, the changes that occurred on the diamond surface appeared to be permanent, and the forward and reverse responses of the peak at $+500 \mathrm{mV}$ were both anodic, as shown in Figure 50 .

The peak separation of the $\mathrm{Fe}^{2+/ 3+}$ redox couple was then examined to determine if ultrasound had oxidized the surface of the BDD. The peak separation was unchanged after exposure to ultrasound, as shown in Figure 51, indicating that the BDD surface was not oxidized as a result of ultrasound. However, it can be seen from the post-ultrasound $\mathrm{CV}$ in Figure 51 that the background current increased. This indicates that the electroactive area of the BDD increased, probably due to the eroding effect of ultrasound. If ultrasound had oxidized the BDD surface, the oxygen may have been located in pits or pores created by erosion, and therefore unavailable to the $\mathrm{Fe}^{2+/ 3+}$ redox couple. It is important to note that this $\mathrm{CV}$ did not contain the anodic peak at $-200 \mathrm{mV}$, which was observed at the unpolished BDD. This supports the proposition that the identity of that peak was due to the substrate, since this BDD was free-standing.

In general, although the behavior of the polished BDD had changed after exposure to high intensity ultrasound, it still appeared to function acceptably as a working electrode. It probably had been eroded, and possibly oxidized, but the changes were not 

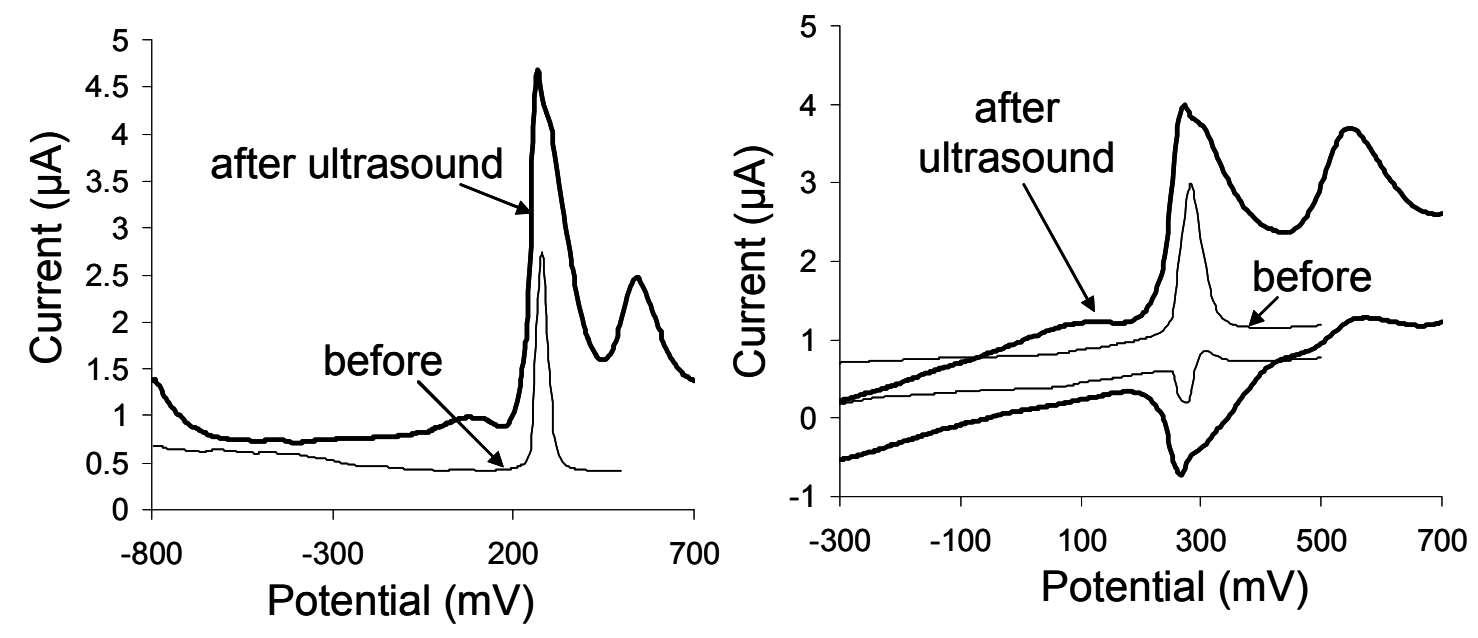

Figure 50. Effect of High-Intensity Ultrasound on $200 \mathrm{ppb} \mathbf{H g}^{2+}$

a) Net responses; b) Forward and reverse responses. Total exposure to ultrasound was 73 minutes at 1,000-1,200 W/cm ${ }^{2}$. $\mathrm{pH} \sim 5,0.1 \mathrm{M} \mathrm{KNO}_{3}$, Deposition Potential $=-800 \mathrm{mV}$, Deposition Time $=5$ minute, Frequency $=15 \mathrm{~Hz}$, Amplitude $=25 \mathrm{mV}$, Step $=4 \mathrm{mV}$, Stirred Deposition. 


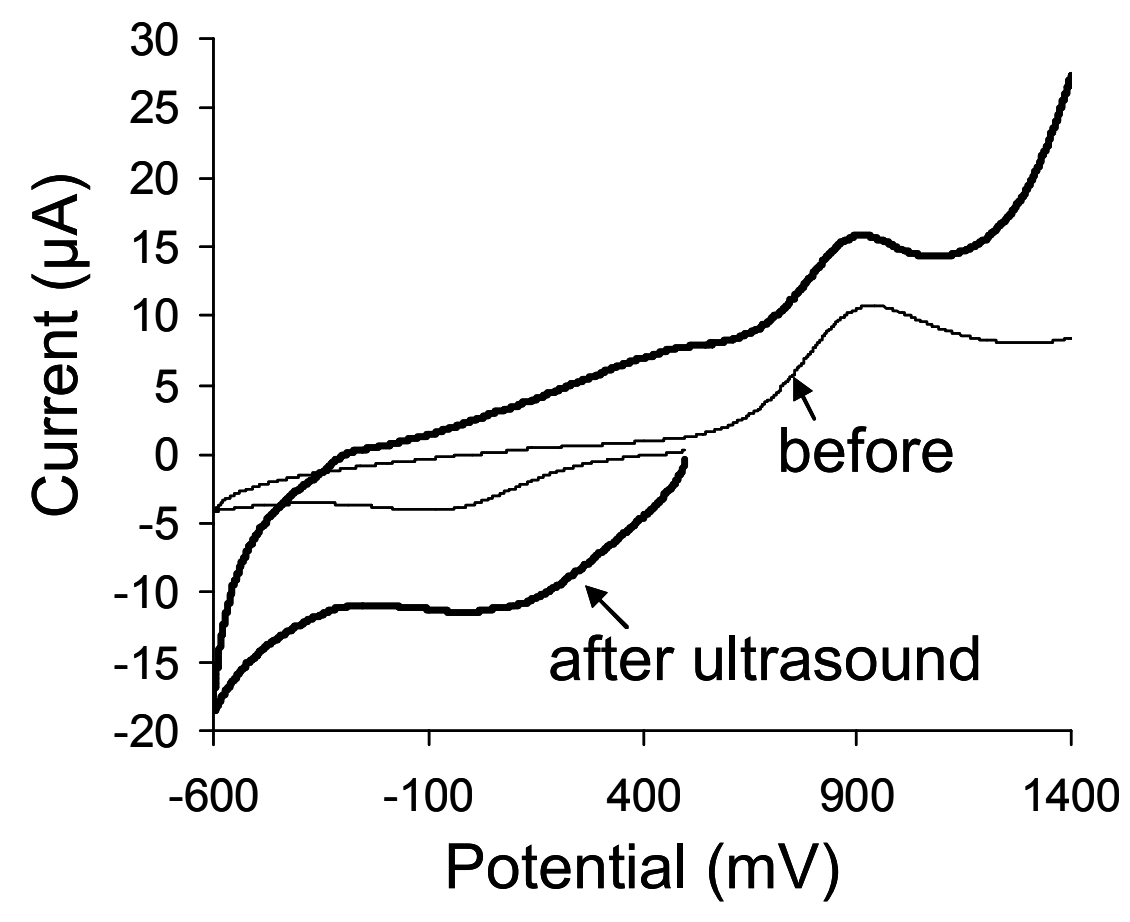

Figure 51. Cyclic Voltammogram of $0.001 \mathrm{M} \mathrm{Fe}\left(\mathrm{ClO}_{4}\right)_{2}$ in $0.1 \mathrm{M} \mathrm{H}_{2} \mathrm{SO}_{4}$ Before and After High-Intensity Ultrasound using the Polished BDD Electrode

Total exposure to ultrasound was 73 minutes at $1,000-1,200 \mathrm{~W} / \mathrm{cm}^{2}$. 
terminal, like those observed at the unpolished BDD. The ruggedness was most likely due to its thickness. Thus, this diamond was used in further studies involving the detection of cadmium and mercury with ultrasound at lower intensities. It should be pointed out, however, that after about 80 experiments involving low-intensity ultrasound, the cadmium stripping current was smaller and less reproducible. Therefore, the BDD was probably gradually being eroded by ultrasound.

\section{Effect of Ultrasound on Cadmium Detection}

A macrotip probe with diameter $6.38 \mathrm{~cm}^{2}$ was used to deliver low intensity ultrasound to cadmium-containing solutions. Cadmium results were investigated for comparison to mercury, since the behavior of cadmium was more predictable and explainable.

Figure 52 shows the effect of ultrasound intensity on the stripping current for 100 ppb $\mathrm{Cd}^{2+}$ in $0.1 \mathrm{M} \mathrm{KCl}$ at various electrode-macrotip separation distances. For electrodemacrotip separations of 10,20 , and $30 \mathrm{~mm}$, the current increased with ultrasound intensity until a maximum was reached. The higher current is explained by the acoustic streaming effect of the ultrasound, which increased mass transport to the electrode surface. Increasing the intensity beyond the maximum current, however, resulted in lower currents. This was due to a greater number of cavitation events which removed or "scrubbed" the deposited $\mathrm{Cd}^{0}$ from the electrode surface. Figure 52 also shows that when the electrode-macrotip separation was increased to $40 \mathrm{~mm}$, the maximum current was reached at a higher intensity.

When the same experiment was performed on $1 \mathrm{ppb} \mathrm{Cd}^{2+}$, a different trend was 


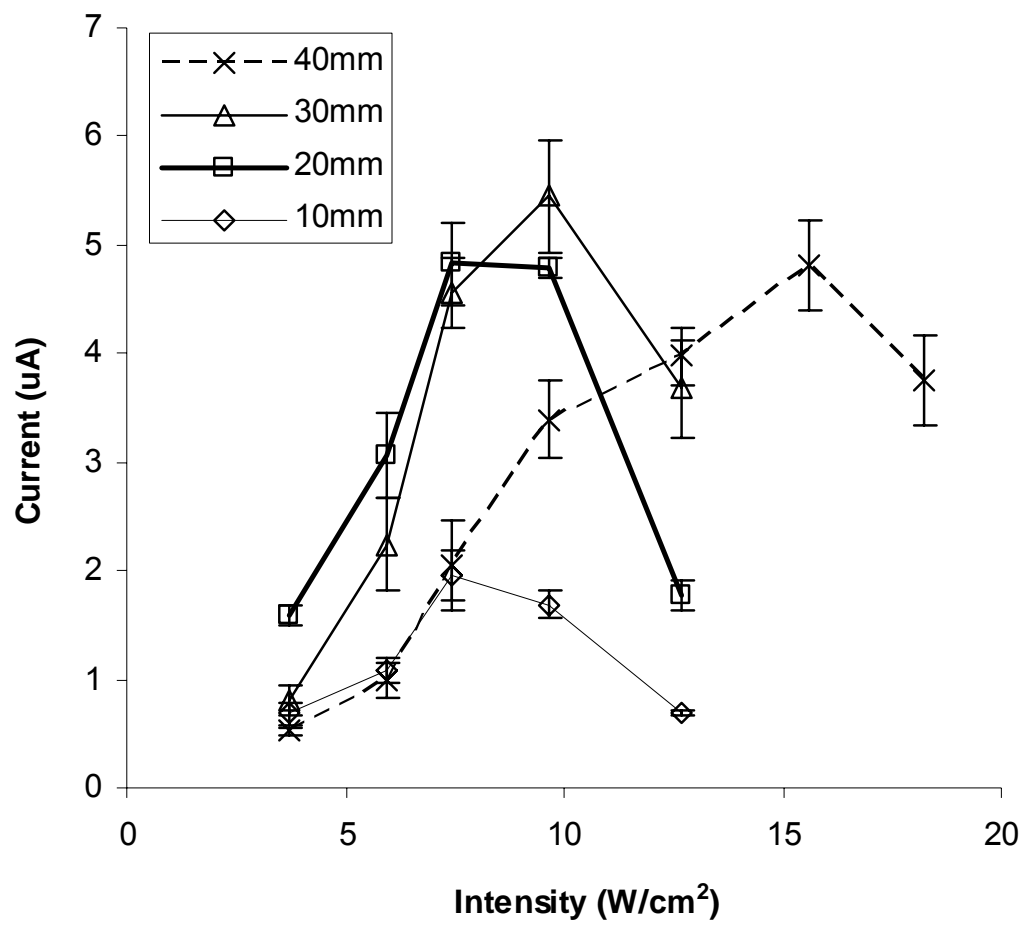

Figure 52. Effect of Ultrasound Intensity on $100 \mathrm{ppb} \mathrm{Cd}^{2+}$ in $0.1 \mathrm{M} \mathrm{KCl}$ at Various Distances using the Polished BDD Electrode

Deposition Potential $=-1.1 \mathrm{~V}$, Deposition Time $=2 \mathrm{~min}$, Final Potential $=+500 \mathrm{mV}$, Frequency $=15 \mathrm{~Hz}$, Pulse Amplitude $=25 \mathrm{mV}$, Step Potential $=4 \mathrm{mV}$, Macrotip Probe Area $=6.38 \mathrm{~cm}^{2}$, Ultrasonic Deposition. 
observed. The effect of ultrasound intensity on $1 \mathrm{ppb} \mathrm{Cd}^{2+}$ at an electrode-macrotip separation of $30 \mathrm{~mm}$ is shown in Figure 53. The maximum current for $1 \mathrm{ppb}$ was obtained at $13 \mathrm{~W} / \mathrm{cm}^{2}$, whereas the maximum for $100 \mathrm{ppb}$ was obtained at $10 \mathrm{~W} / \mathrm{cm}^{2}$. Apparently, lower concentrations can withstand the cavitation events produced by ultrasound better than higher concentrations. A plausible explanation is that at low concentration the cadmium nuclei are smaller than those at higher concentration. If the electrode surface was eroded due to ultrasound, perhaps the smaller nuclei can "hide" in the pits, as opposed to the larger nuclei which would be more exposed to cavitation events, as shown in Figure 54.

An attempt to verify this hypothesis was undertaken next. First, it should be noted that the data for $100 \mathrm{ppb}$ was obtained using a deposition time of 2 minutes, while that for $1 \mathrm{ppb}$ was obtained using a 7.5-minute deposition time. Therefore, the longer deposition time used at $1 \mathrm{ppb}$ could still have yielded $\mathrm{Cd}^{0}$ nuclei that were comparable in size to the larger $\mathrm{Cd}^{0}$ nuclei believed to exist for $100 \mathrm{ppb}$. An experiment in which the nuclei size was controlled needed to be performed. Therefore, the effect of ultrasound intensity at different deposition times was examined using $100 \mathrm{ppb} \mathrm{Cd}^{2+}$. If the hypothesis were valid, the current maxima should depend on deposition time, since deposition time affects the size of the nuclei. Specifically, the current maximum for the shortest deposition time should shift to higher ultrasound intensity, since these nuclei are theoretically the smallest and therefore able to resist cavitation better than the larger nuclei produced at longer deposition times. The results are shown in Figure 55, where the current maximum for the shortest deposition time, 30 seconds, was in fact shifted to higher ultrasound intensity. This trend was observed when only the first run at the 


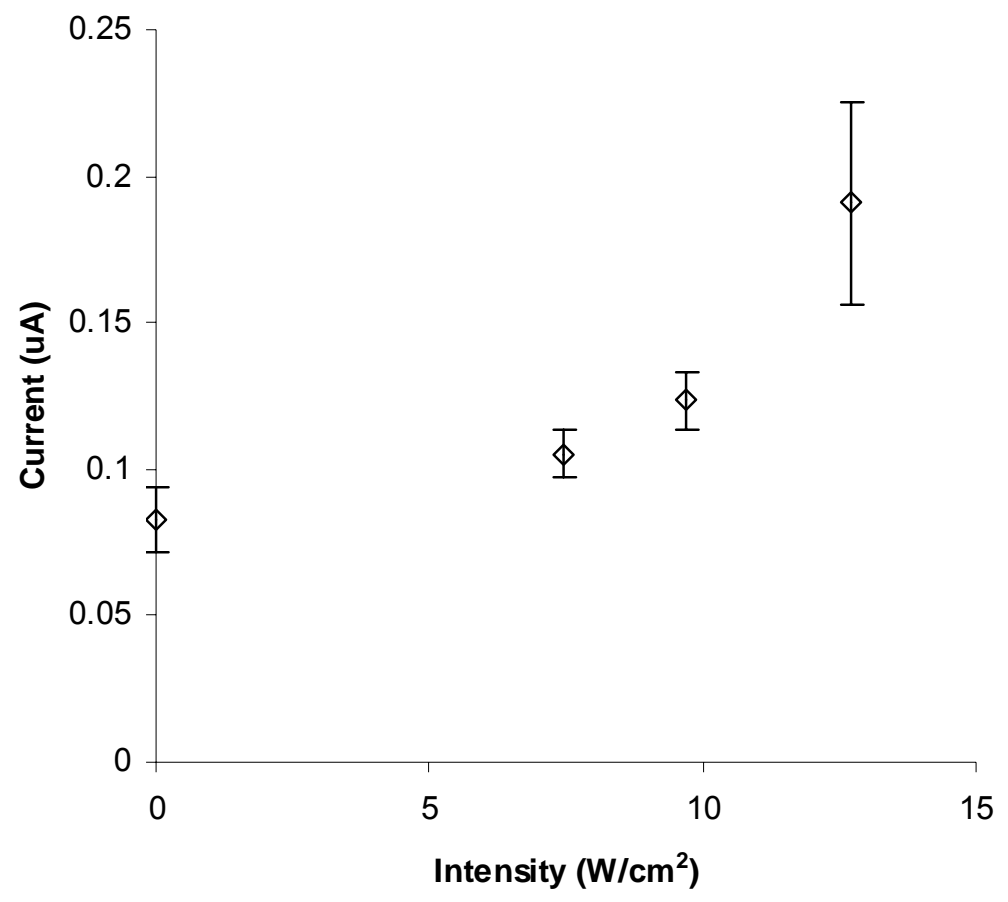

Figure 53. Effect of Ultrasound Intensity on $1 \mathrm{ppb} \mathrm{Cd}^{2+}$ in $0.1 \mathrm{M} \mathrm{KCl}$ using the Polished BDD Electrode

Distance $=30 \mathrm{~mm}$, Deposition Time $=7.5 \mathrm{~min}$, All other conditions as in Figure 52. The point at 0 Intensity was obtained with stirring via nitrogen purging. 


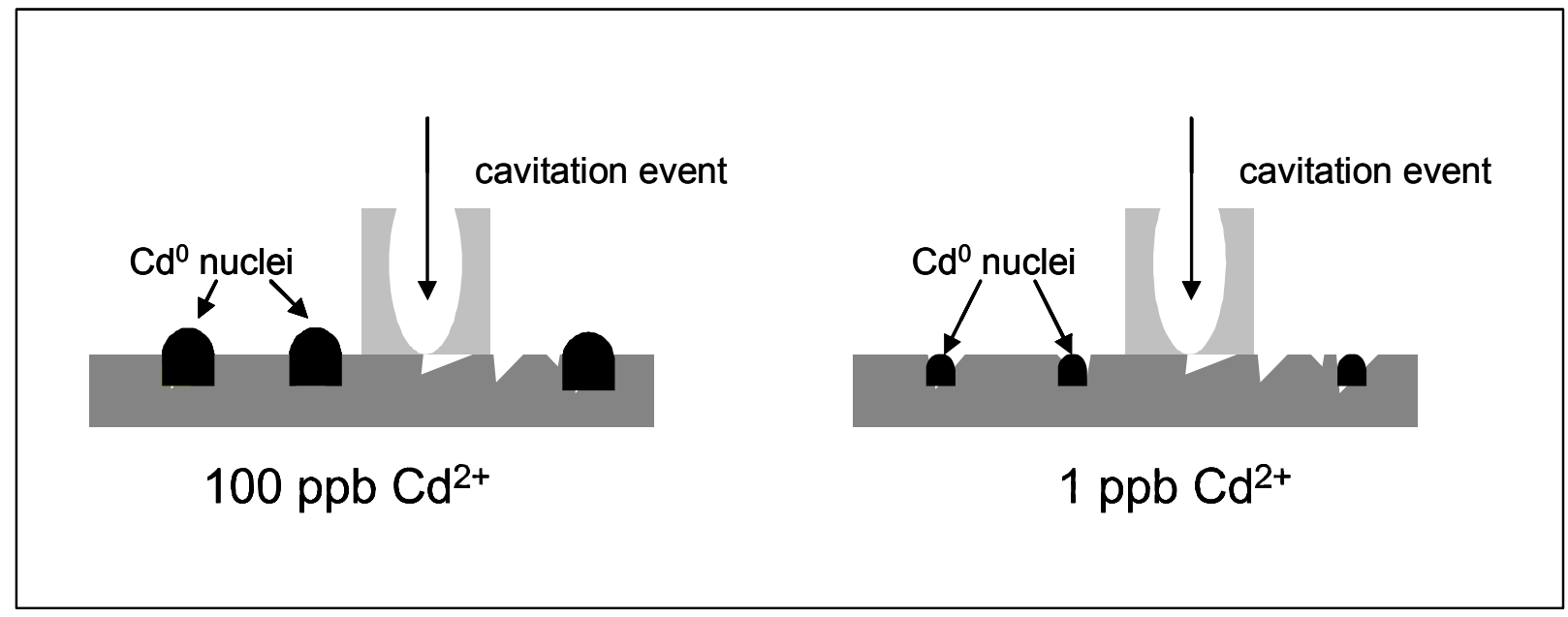

Figure 54. Effect of Ultrasound on Large and Small Nuclei

Lower concentrations with smaller nuclei resist cavitation events better than higher concentrations. 

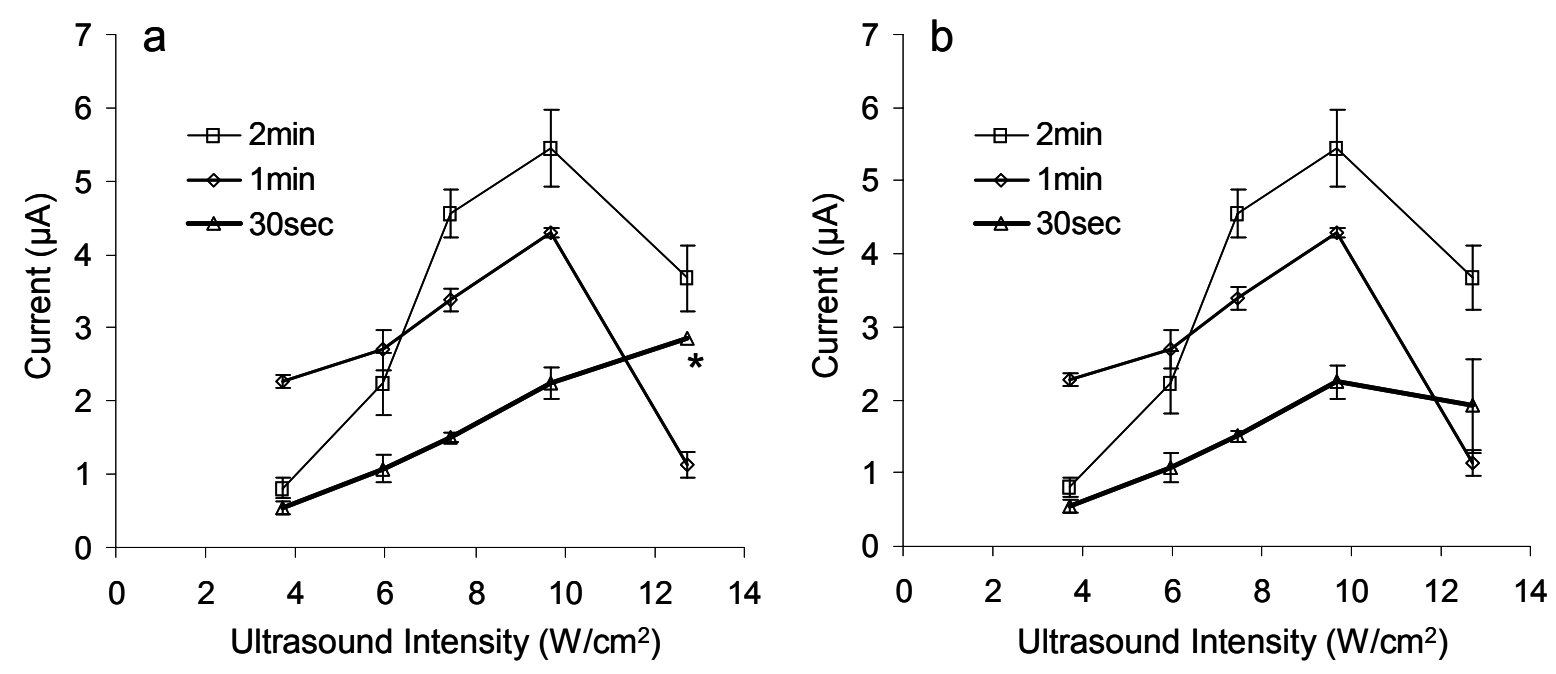

Figure 55. Effect of Ultrasound Intensity on $100 \mathrm{ppb} \mathrm{Cd}^{2+}$ at Different Deposition Times

a) The point labeled with an asterisk was the first measurement of 5 .

b) The average of 5 measurements are shown for all points.

$0.1 \mathrm{M} \mathrm{KCl}$, Deposition Potential $=-1.1 \mathrm{~V}$, Final Potential $=+500 \mathrm{mV}$, Frequency $=15$ $\mathrm{Hz}$, Pulse Amplitude $=25 \mathrm{mV}$, Step Potential $=4 \mathrm{mV}$, Ultrasonic Deposition. 
highest intensity was considered (see point marked with an asterisk in Figure 55a). When all five measurements at the highest intensity were averaged (Figure 55b), it is difficult to say at what intensity the current maximum actually is found, since the error bars for 10 and $13 \mathrm{~W} / \mathrm{cm}^{2}$ overlap. Therefore, the hypothesis could not be verified.

The data shown in Figure 53 indicated that 1ppb of cadmium could be detected with an ultrasound intensity of $13 \mathrm{~W} / \mathrm{cm}^{2}$ and an electrode-macrotip separation of $30 \mathrm{~mm}$. Although a distance of $20 \mathrm{~mm}$ was also investigated and yielded higher currents for 1 ppb, the current didn't increase when more $\mathrm{Cd}^{2+}$ was added. Therefore, a calibration curve for 1-10 ppb Cd ${ }^{2+}$ was prepared using an intensity of $13 \mathrm{~W} / \mathrm{cm}^{2}$, separation distance of $30 \mathrm{~mm}$, and deposition time of 10 minutes, and is shown in Figure 56. A calibration curve for 1-16 ppb Cd prepared with stirring during a 10-minute deposition at an unpolished BDD electrode is also shown for comparison. Clearly, the curve obtained using ultrasonic deposition yielded larger currents and greater sensitivity.

\section{Effect of Ultrasound on Mercury Detection}

A macrotip probe was used to deliver low intensity ultrasound to solutions containing mercury, with the hope of achieving results similar to those for cadmium (ie, detection of 1-10 ppb). A new polished BDD was used for these experiments, because the previously used BDD had been exposed to extremely high ultrasound intensity, which resulted in a permanent change in the behavior of mercury on this BDD (see Figure 50). The effect of ultrasound intensity on $200 \mathrm{ppb} \mathrm{Hg}^{2+}$ in $\mathrm{KCl}$ at various distances was investigated and is shown in Figure 57. The current decreased with ultrasound intensity, and never went through a maximum as it did for cadmium; however, when the probe was 


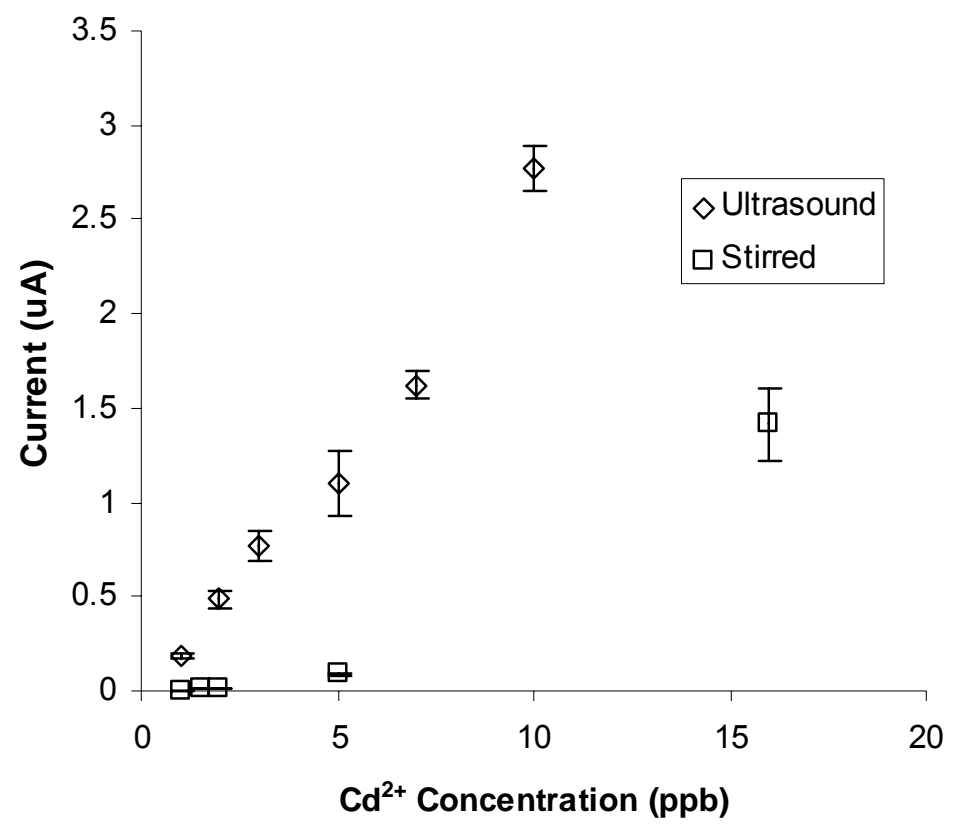

Figure 56. Calibration Curves for 1-10 ppb $\mathrm{Cd}^{2+}$ in $0.1 \mathrm{M} \mathrm{KCl}$ using Ultrasound and Stirred Deposition

Ultrasound Intensity $=13 \mathrm{~W} / \mathrm{cm}^{2}$, Distance $=30 \mathrm{~mm}$. Ultrasound was performed at the polished BDD electrode, and stirring was performed at the unpolished BDD. Deposition Potential $=-1.1 \mathrm{~V}$, Deposition Time $=10$ minutes, Final Potential $=+500 \mathrm{mV}$, Frequency $=15 \mathrm{~Hz}$, Pulse Amplitude $=25 \mathrm{mV}$, Step Potential $=4 \mathrm{mV}$. 


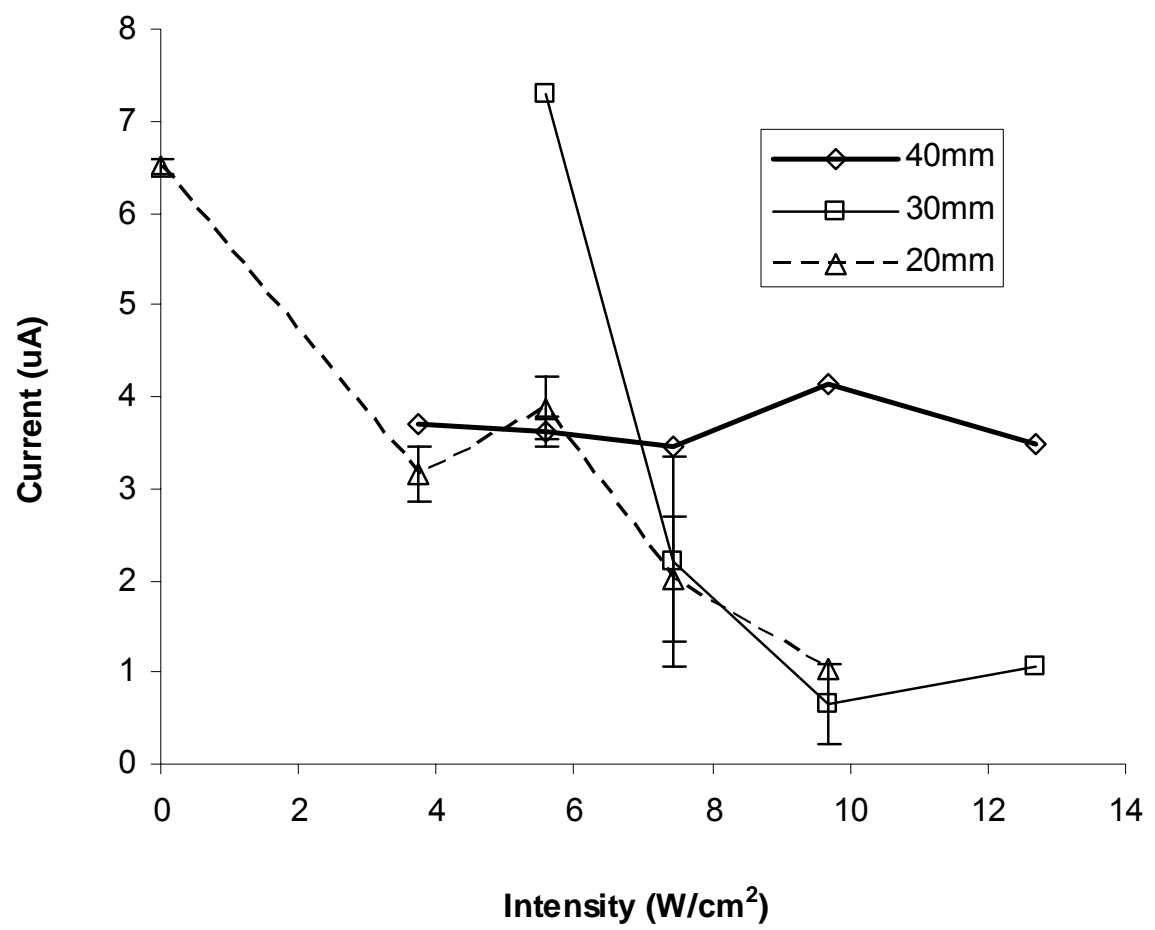

Figure 57. Effect of Ultrasound Intensity on $200 \mathrm{ppb} \mathrm{Hg}^{2+}$ in $0.1 \mathrm{M} \mathrm{KCl}$ at Various Distances using the Polished BDD Electrode

Deposition Potential $=-1.0 \mathrm{~V}$, Deposition Time $=5 \mathrm{~min}$, Final Potential $=+600 \mathrm{mV}$, Frequency $=150 \mathrm{~Hz}$, Pulse Amplitude $=25 \mathrm{mV}$, Step Potential $=2 \mathrm{mV}$, Macrotip Probe Area $=6.38 \mathrm{~cm}^{2}$. The point marked as 0 Intensity was obtained with stirring using nitrogen purging at the beginning of the experiment. 
moved far away from the electrode at $40 \mathrm{~mm}$, the current remained fairly constant with ultrasound intensity. It appears that mercury is more strongly affected by cavitation events rather than acoustic streaming. It should be noted that the maximum current obtained with an ultrasound intensity of $7 \mathrm{~W} / \mathrm{cm}^{2}$ at $30 \mathrm{~mm}$ was only slightly larger than that obtained with stirring.

A calibration curve for $200-400 \mathrm{ppb} \mathrm{Hg}^{2+}$ in $0.1 \mathrm{M} \mathrm{KCl}$ was prepared using an ultrasound intensity of $7 \mathrm{~W} / \mathrm{cm}^{2}$ and a separation of $30 \mathrm{~mm}$, and was compared to one obtained with stirred deposition. The results are shown in Figure 58, where it can be seen that stirring gave larger currents and better sensitivity. The sensitivities for stirred and ultrasonic deposition were $0.294 \mu \mathrm{A} / \mathrm{ppb}$ and $0.201 \mu \mathrm{A} / \mathrm{ppb}$, respectively. The calibration curve obtained with stirring was also more linear $\left(\mathrm{R}^{2}=0.9987\right)$ than that obtained with ultrasound (0.9681) for 200-300 ppb. The curve prepared using ultrasound also plateaued at $350 \mathrm{ppb}$, which indicated that this deposition time was too long for this mercury concentration.

A typical experiment began with stirring, followed by repeated measurements using ultrasound at various intensities, and ended with a few measurements that were obtained with stirring. It was observed that the currents obtained with stirring after the application of ultrasound at the end of an experiment were larger than those obtained with stirring at the beginning of an experiment. Table 10 summarizes how the current obtained with stirring at the end of various experiments increased after ultrasound. It should be emphasized that the increased current could not be "preserved" for the next experiment; that is, the current increase seen within an experiment was temporary and was "erased" by acid-washing. 


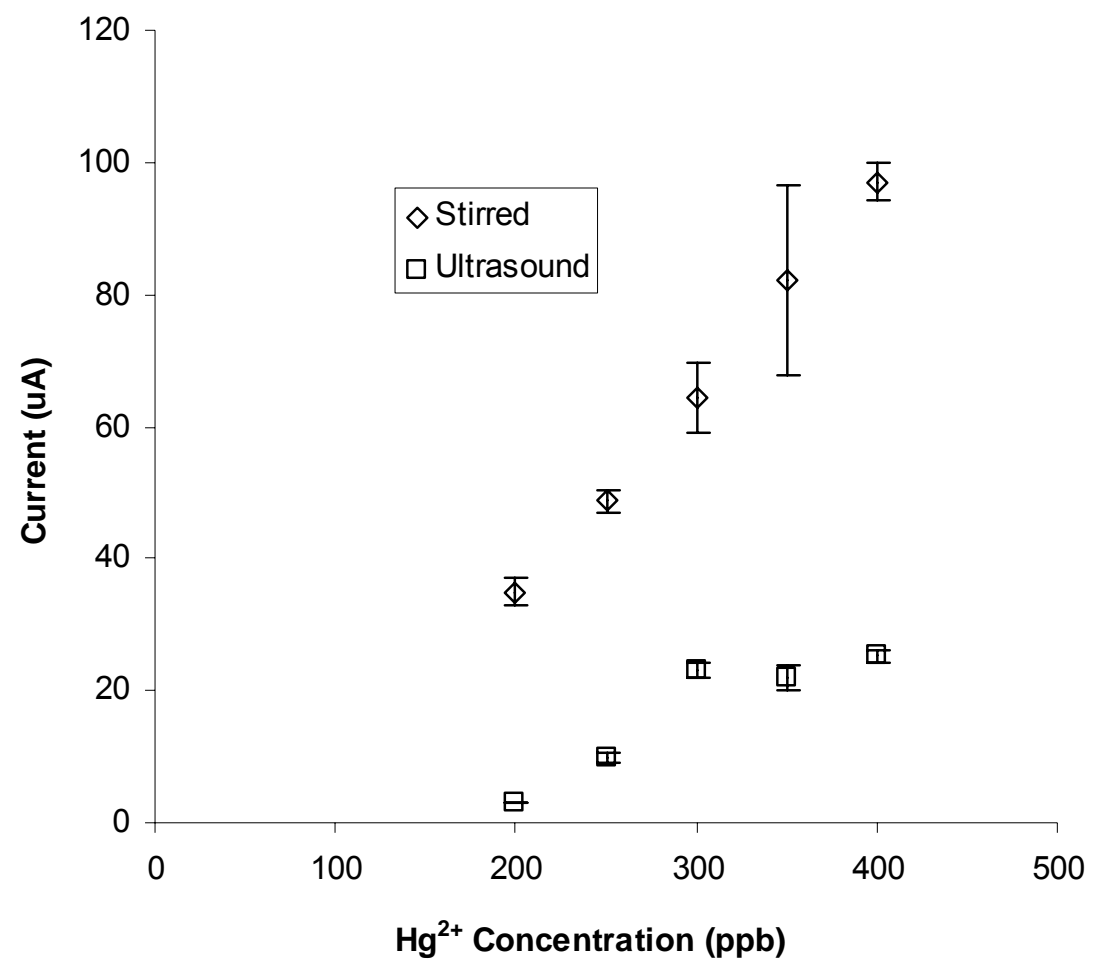

Figure 58. Calibration Curves for 200-400 $\mathrm{ppb} \mathrm{Hg}^{2+}$ in $0.1 \mathrm{M} \mathrm{KCl}$ using Ultrasound and Stirring at the Polished BDD Electrode

Ultrasound Intensity $=6 \mathrm{~W} / \mathrm{cm}^{2}$, Distance $=30 \mathrm{~mm}$, Deposition Potential $=-1.0 \mathrm{~V}$, Deposition Time $=5 \mathrm{~min}$, Final Potential $=+600 \mathrm{mV}$, Frequency $=150 \mathrm{~Hz}$, Pulse Amplitude $=25 \mathrm{mV}$, Step Potential $=2 \mathrm{mV}$, Macrotip Probe Area $=6.38 \mathrm{~cm}^{2}$. 
Table 10. Effect of Ultrasound on Currents obtained with Stirring using the Polished BDD Electrode

Mercury: $200 \mathrm{ppb}$ in $0.1 \mathrm{M} \mathrm{KCl}$, Deposition Potential $=-1.0 \mathrm{~V}$, Deposition Time $=5$ min, Final Potential $=+600 \mathrm{mV}$, Frequency $=150 \mathrm{~Hz}$, Pulse Amplitude $=25 \mathrm{mV}$, Step Potential $=2 \mathrm{mV}, \mathrm{n}=5$.

Cadmium: $100 \mathrm{ppb}$ in $0.1 \mathrm{M} \mathrm{KCl}$, Deposition Potential $=-1.1 \mathrm{~V}$, Deposition Time $=2$ min, Final Potential $=+500 \mathrm{mV}$, Frequency $=15 \mathrm{~Hz}$, Pulse Amplitude $=25 \mathrm{mV}$, Step Potential $=4 \mathrm{mV}, \mathrm{n}=3$.

\begin{tabular}{|c|c|c|}
\hline \multicolumn{3}{|c|}{ Mercury Current $(\mu \mathrm{A})$} \\
\hline Experiment & Before Ultrasound & After Ultrasound \\
\hline 1 & $2.036(\mathrm{n}=2)$ & $19.17(\mathrm{n}=2)$ \\
\hline 2 & $2.951 \pm 0.697$ & $13.95 \pm 0.95$ \\
\hline 3 & $5.978 \pm 3.243$ & $24.20 \pm 1.54$ \\
\hline \multicolumn{3}{|c|}{ Cadmium Current $(\mu \mathrm{A})$} \\
\hline Experiment & Before Ultrasound & After Ultrasound \\
\hline 1 & $1.062 \pm 0.167$ & $2.514 \pm 0.151$ \\
\hline 2 & $2.932 \pm 0.807$ & $6.565 \pm 0.393$ \\
\hline 3 & $2.099 \pm 0.437$ & $4.923 \pm 0.161$ \\
\hline
\end{tabular}


Several attempts have been made to use ultrasound as a pre-treatment. For example, a given solution of mercury was measured repeatedly with ultrasound. The BDD was then removed from the solution, rinsed with water only, and fresh mercury solution was placed in the cell; however, all attempts at pre-treating the electrode this way failed. When the "pre-treated" electrode was placed in a fresh solution of blank electrolyte, the first voltammogram indicated that unstripped $\mathrm{Hg}^{0}$ had remained on the surface. Surprisingly, ultrasound also caused the currents obtained for cadmium to increase, as shown in Table 10. Perhaps the metal deposits formed with ultrasound were harder to oxidize and remained on the electrode surface. If stirring was used in the subsequent run, these deposits acted as nucleation sites for further deposition. If ultrasound was used, cavitation events may "scrub" them off.

Although the application of ultrasound increased the currents subsequently obtained with stirring for mercury and cadmium, unlike cadmium, the shape of the mercury peak had changed, as shown in Figure 59. The voltammograms for $200 \mathrm{ppb}$ $\mathrm{Hg}^{2+}$ obtained with stirring at the beginning of the experiment (trace 1), with ultrasound (trace 2), and with stirring after exposure to ultrasound (trace 3) are shown in Figure 59a. It can be seen that a shoulder had formed at $\sim 90 \mathrm{mV}$ during ultrasound, and remained there when stirring was used in the subsequent runs. It should be noted that when a new experiment was performed, the mercury peak was restored to its normal shape, as in trace 1. (In Figure 50, we showed that the voltammogram for mercury had changed permanently; however, that BDD had been exposed to $1,000 \mathrm{~W} / \mathrm{cm}^{2}$ intensity, and the BDD being discussed now was exposed to much lower intensities.) The forward and reverse responses of voltammograms 1 and 3 are shown in Figure 59b. After ultrasound, 

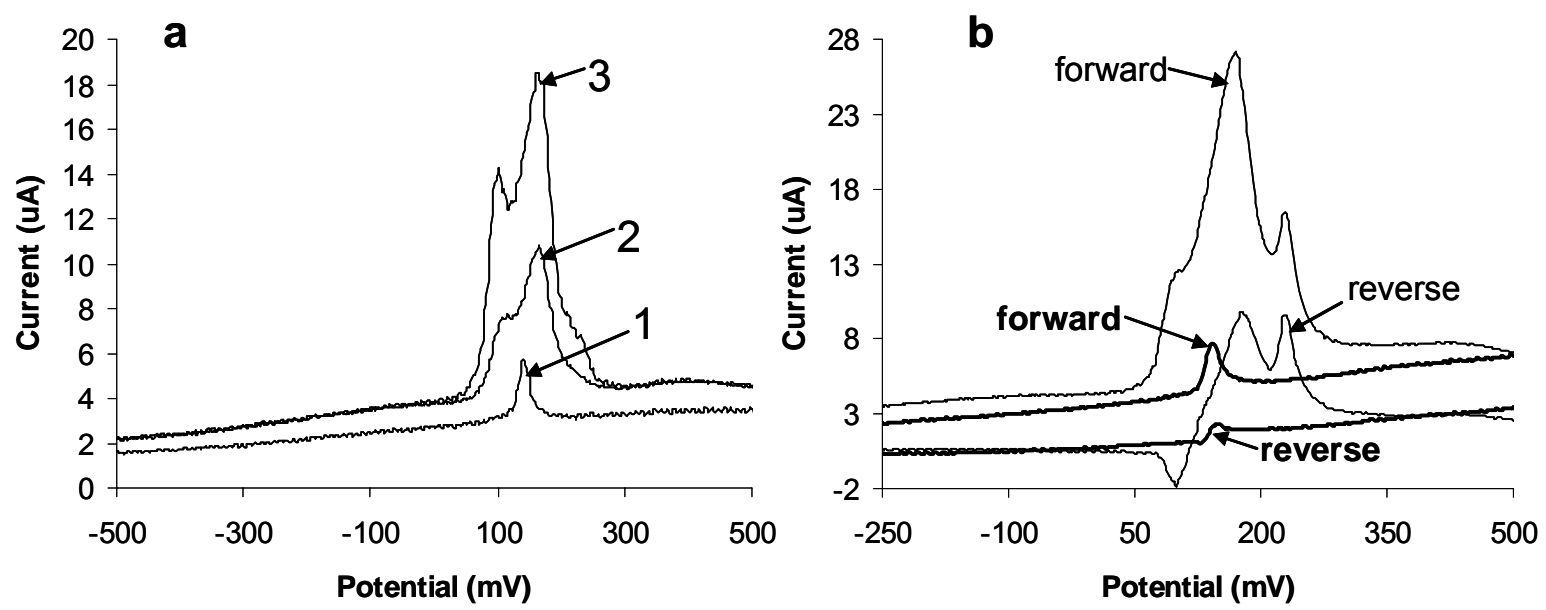

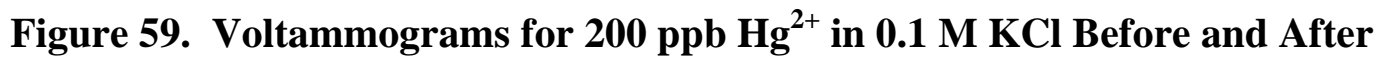
Ultrasound

a) Net responses. $1=$ Stirred current obtained before ultrasound, $2=$ Current obtained with ultrasonic deposition, 3 = Stirred current obtained after ultrasound

b) Forward and reverse responses of voltammograms obtained with stirring before and after ultrasound. Bold trace $=$ Before ultrasound.

Ultrasound Intensity $=6 \mathrm{~W} / \mathrm{cm}^{2}$, Macrotip-Electrode Separation $=30 \mathrm{~mm}$, All other conditions as in Figure 58. 
the reverse response of the mercury stripping peak contained a cathodic feature ( $\sim+90$ $\mathrm{mV}$ ), which explains the shoulder observed in the net response (trace 3, Figure 59a). Two additional anodic features were observed at +175 and $+225 \mathrm{mV}$ in the reverse response obtained after ultrasound. The anodic peak at $+175 \mathrm{mV}$ decreased the magnitude of the main stripping peak. The peak at $+225 \mathrm{mV}$ did not appear in the net response since it was cancelled out by an anodic peak in the forward response.

Thus, two stripping peaks for mercury have been observed on several occasions, under the conditions summarized in Table 11. It seems possible that in nitrate electrolyte, the more positive peak $(+500 \mathrm{mV})$ was due to oxidation of mercurous ion which had formed via disproportionation. This was favored at long deposition times with stirring and short deposition times with ultrasound. This is reasonable assuming that both conditions result in a large amount of $\mathrm{Hg}^{0}$ deposited on the electrode surface. This would result in a large concentration of $\mathrm{Hg}^{2+}$ in the diffusion layer during the stripping step, which can undergo the disproportionation reaction. It is also possible that another type of site on the BDD electrode was activated as a result of the long deposition time or ultrasound exposure.

In chloride, the more positive peak $(+300 \mathrm{mV})$ was probably due to oxidation of $\mathrm{Hg}_{2} \mathrm{Cl}_{2}$ which had formed either during the stripping step, under open circuit conditions, or even during the deposition step. It was favored in $0.6 \mathrm{M} \mathrm{Cl}^{-}$with stirring or in $0.1 \mathrm{M}$ $\mathrm{Cl}^{-}$with ultrasound. If this peak is in fact due to oxidation of calomel, it appears to be strongly affected by chloride concentration; for example, this peak was not observed in 1 $\mathrm{M} \mathrm{Cl}^{-}$. For some reason calomel formed at $0.6 \mathrm{M} \mathrm{KCl}$ with stirring, but not at $0.1 \mathrm{M} \mathrm{KCl}$ with stirring; it did form at $0.1 \mathrm{M} \mathrm{KCl}$ with ultrasound. Mass balance calculations predict 
Table 11. Conditions under which Two Stripping Peaks have been observed for Mercury

\begin{tabular}{|c|c|c|c|c|}
\hline Electrolyte & Diamond & $t_{\text {dep }}$ & $\begin{array}{l}\text { Mass } \\
\text { Transport }\end{array}$ & Chapter/Figure \\
\hline \multirow{2}{*}{$0.1 \mathrm{M} \mathrm{KNO}_{3}(\mathrm{pH} \sim 1)$} & \multirow{2}{*}{ polished } & $20 \mathrm{~min}$ & stirring & not shown \\
\hline & & $1 \mathrm{~min}$ & ultrasound & Ch5 Fig. 48,50 \\
\hline $0.6 \mathrm{M} \mathrm{KCl}(\mathrm{pH}<1)$ & unpolished & $20 \mathrm{~min}$ & stirring & Ch2 Fig20 \\
\hline $\begin{array}{c}0.6 \mathrm{M} \mathrm{KCl}(\mathrm{pH}<1 \text {, and } \\
\mathrm{pH} \sim 5)\end{array}$ & polished & $5 \mathrm{~min}$ & stirring & Ch4 Fig. 39 \\
\hline $0.1 \mathrm{M} \mathrm{KCl}$ & polished & $5 \min$ & ultrasound & Ch5 Fig 59 \\
\hline
\end{tabular}


that most of the $\mathrm{Hg}^{2+}$ should be complexed by chloride at both $0.6 \mathrm{M}$ and $0.1 \mathrm{M} \mathrm{Cl}^{-}$, and

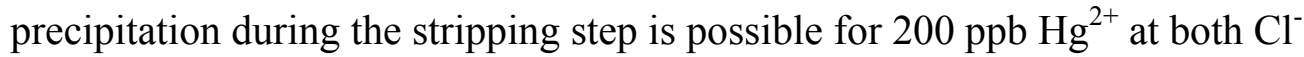
concentrations. The presence of higher chloride concentration may decrease the solubility of $\mathrm{Hg}_{2} \mathrm{Cl}_{2}$ due to the common ion effect, but it should also favor the formation of a soluble complex. Perhaps $\mathrm{Hg}_{2} \mathrm{Cl}_{2}$ is forming at both chloride concentrations, but its oxidation in $0.1 \mathrm{M} \mathrm{Cl}^{-}$is observed only in the presence of ultrasound.

It can be seen in Figure 59b that the reverse response for the main stripping peak $(\sim+100 \mathrm{mV})$ obtained with both stirring and ultrasound was anodic for $200 \mathrm{ppb} \mathrm{Hg}^{2+}$. The frequency used in the stripping step was increased to make the reverse response cathodic, because this would result in a larger stripping current. The higher frequency would give the recently stripped $\mathrm{Hg}^{2+}$ ions less time to diffuse out of the diffusion layer, because as soon as they are oxidized, they are immediately re-reduced. This also gives them less time to participate in chemical reactions in the diffusion layer, such as complex formation, disproportionation, and precipitation. In stirred solutions, the frequency was increased from $150 \mathrm{~Hz}$ to $2,000 \mathrm{~Hz}$, but this did not result in a cathodic current in the reverse response. In solutions to which ultrasound was applied, increasing the frequency did not yield a cathodic response for the main stripping peak, or the more positive peak which appears as a result of ultrasound. The only affect of increasing the frequency was to increase the separation between the main stripping peak and the unknown stripping peak. The use of a larger square wave amplitude may have resulted in a cathodic reverse response; however, this wasn't attempted because previous experiments showed that larger square wave amplitudes had the effect of splitting the peak (see Chapter 2, Table 2). 
Our studies with cadmium showed that lower concentrations could withstand higher ultrasound intensities; the same might be true for mercury. Therefore, an attempt was made to detect $5 \mathrm{ppb} \mathrm{Hg}^{2+}$ at either higher intensity or closer distance between the macrotip and electrode. This was possible for $5 \mathrm{ppb} \mathrm{Hg}^{2+}$ in $0.1 \mathrm{M} \mathrm{KCl}$ at a deposition time of 20 minutes, a separation of $10 \mathrm{~mm}$, and an intensity of $\sim 13 \mathrm{~W} / \mathrm{cm}^{2}$; however, with repeated measurements on the same solution, the signal decreased drastically. The loss of signal implied that the deposited $\mathrm{Hg}^{0}$ was removed from the BDD electrode by ultrasound, and probably evaporating from the solution, due to the de-gassing effect of ultrasound. We were unable to repeat the detection of $5 \mathrm{ppb} \mathrm{Hg}^{2+}$ again using the same deposition time and ultrasound conditions on other occasions. This is probably due to both the loss (evaporation) of $\mathrm{Hg}^{0}$ during deposition, and to microscopic differences in condition of the electrode surface.

To improve the adhesion of the $\mathrm{Hg}^{0}$ deposits to the BDD electrode, we tried codepositing the mercury with cadmium, which wasn't as prone to the cavitation events of ultrasound. With $100 \mathrm{ppb} \mathrm{Cd}^{2+}$ in solution, detection of $15 \mathrm{ppb} \mathrm{Hg}^{2+}$ using a 5-minute deposition time and ultrasound $\left(10 \mathrm{~W} / \mathrm{cm}^{2}, 30 \mathrm{~mm}\right)$ was possible, but the current was very non-reproducible $(51.2 \% \mathrm{RSD}, \mathrm{n}=3)$. In stirred solutions, however, a calibration curve for $10-50 \mathrm{ppb} \mathrm{Hg}^{2+}$ was prepared by co-deposition with $\mathrm{Cd}^{2+}$. The sensitivity was good $(0.128 \mu \mathrm{A} / \mathrm{ppb})$, but linearity was poor $\left(\mathrm{R}^{2}=0.9785\right.$ for $\left.10-30 \mathrm{ppb} \mathrm{Hg}^{2+}\right)$. As discussed in Chapter 2, the addition of an auxiliary element to improve the detection of mercury appears promising, but may be limited, depending on the presence of other elements in the sample. 


\section{Summary of Chapter 5}

Ultrasound was applied during the deposition step of anodic stripping voltammetry experiments to improve the detection of cadmium and mercury at unpolished and polished BDD electrodes. Extended exposure to high-intensity ultrasound altered the behavior of both types of electrodes, but the effect on the unpolished BDD's was more damaging. Ultrasound probably eroded the BDD layer, which resulted in deposition of $\mathrm{SiO}_{2}$ on the electrode surface from the silicon substrate. The damaged BDD electrode was temporarily restored by repeated cycling in $\mathrm{KOH}$ solution. The polished BDD electrodes were more robust, probably because they were thicker and smoother; microjets may "flow" across the smoother electrode more easily, as opposed to the rougher surface of the unpolished electrode. Low-intensity ultrasound was used to prepare a calibration curve for $1-10 \mathrm{ppb} \mathrm{Cd}^{2+}$ at the polished BDD, which was more sensitive than one prepared with stirring. Mercury appeared to be more affected by the cavitation events of ultrasound. For both cadmium and mercury, it was observed that the currents obtained with stirring following repeated application of ultrasound were larger than those obtained with stirring prior to the repeated application of ultrasound. 


\section{Chapter 6: Future Work}

It was postulated that precipitation of $\mathrm{HgO}$ occurred during the analysis of mercury in nitrate medium. This should be a $\mathrm{pH}$-dependent process, so the effect of $\mathrm{pH}$ should be investigated on the peak potential for mercury in nitrate medium. It would be desirable to analyze the surface of an unpolished BDD after mercury analysis in nitrate medium using either AFM or XPS to look for the presence of the $\mathrm{HgO}$ precipitate.

The role of $\mathrm{sp}^{2}$ carbon on the BDD surface should also be investigated for its

effect on the detection of mercury. Studies similar to those of Nakabayashi et al., ${ }^{50-51}$ in which BDD electrodes were pre-treated cathodically to "trap" reduced copper, should be performed at both polished and unpolished BDD electrodes. An electrochemical pretreatment may be found which could improve the detection of mercury.

The analysis of samples for mercury collected from coal-burning power plants can be accomplished with BDD electrodes, but an auxiliary element must be added to the sample. Future work should determine the best auxiliary element and concentration. It should be possible to design a system which could be used on-site to gather real-time data.

It was proposed that anion-induced adsorption of $\mathrm{Hg}^{2+}$ might occur at the polished BDD electrodes in nitrate, phosphate, and sulfate medium. This should be verified by double potential step chronocoulometry experiments.

The BDD electrode can be used in further studies of metal speciation in natural waters. Further work should include the behavior of metals in the presence of wellcharacterized dissolved organic matter (DOM) for comparison to that in natural waters. 
Also, the results obtained with BDD electrodes should be compared to literature results reported with glassy carbon or mercury thin film electrodes. 


\section{References}

1 Bard, A.; Faulkner, L.R. Electrochemical Methods: Fundamentals and Applications; John Wiley \& Sons: New York, NY,1980.

2 Kissinger, P.T; Heineman, W.R. Laboratory Techniques in Analytical Chemistry; Marcel Dekker, Inc.: New York, NY, 1984.

3 Goeting, C.H.; Jones, F; Foord, J.S.; Eklund, J.C.; Marken, F.; Compton, R.G.; Chalker, P.R.; Johnston, C. J. Electroanal. Chem 1998, 442, 207-216.

4 Awada, M; Strojek, J.W.; Swain, G.M. J. Electrochem. Soc. 1995, 142, L42-L45.

5 Prado, C; Wilkins, S.J.; Marken, F.; Compton, R.G. Electroanal. 2002, 14, 262-272.

${ }^{6}$ Vinokur, N; Miller, B.; Avyigal, Y.; Kalish, R. J. Electrochem. Soc. 1999, 146, $125-$ 130.

7 Sahlin, E.; Jagner, D.; Ratana-ohpas, R.R. Anal. Chim. Acta. 1997, 346, 157-164.

8 M. Stulikova, Electroanal. Chem. Interfac. Chem. 1973, 48, 33-45.

9 Hackman, M.R.; Brooks, M.A. Anal. Chem. 1974, 57, 1075-1081.

10 Osteryoung, J.G.; Osteryoung, R.A. Anal. Chem. 1985, 57, 101A-110A.

11 Petrovic, S.C.; Dewald, H.C. Anal. Chim. Acta. 1997, 357, 33-39.

12 Agra-Gutierrez, C; Ball, J.C.; Compton, R.G. J. Phys. Chem. B 1998, 102, 7028-7032.

13 Xu, J.; Granger, M.C.; Chen, Q.; Strojek, J.W.; Lister, T.E.; Swain, G.M. Anal. Chem. 1997, 69, 591A-519A.

14 Celci, F.G.; Butler, J.E. Ann. Rev. Phys. Chem. 1991, 42, 643-684.

15 Angus, J.C.; Hayman, C.C. Science 1988, 241, 913-921.

16 Marin, H.B.; Argoitia, A.; Landau, U.; Anderson, A.B.; Angus, J.C. J Electrochem. Soc. 1996, 143, L133-L136.

17 Ferro, S.; De Battisti, A.; Duo, I.; Comninellis, Ch.; Haenni, W.; Perret, A. J Electrochem. Soc. 2000, 147, 2614-2619.

18 Pastor-Moreno, G.; Riley, J.D. Electrochim. Acta. 2002, 47, 2589-2595.

19 Latto, M.N.; Riley, J.D.; May, P.W. Diam. Rel. Mat. 2000, 9, 1181-1183. 
20 van de Lagemaat, J.; Vanmaekelbergh, D.; Kelly, J.J. J. Electroanal. Chem. 1999, 475, 139-151.

21 Yano, T.; Popa, E.; Tryk, D.A.; Hashimoto, K.; Fujishima, A.; J. Electrochem. Soc. 1999, 146, 1081-1087.

22 Alehashem, S.; Chambers, F.; Strojek, J.W.; Swain, G.M. Anal. Chem. 1995, 67, 2812-2821.

23 Xu, J.; Chen, Q.; Swain, G.M. Anal. Chem. 1998, 70, 3146-3154.

24 Bouamrane, F.; Tadjeddine, A.; Butler, J.E.; Tenne, R.; Levy-Clement, C. J. Electroanal. Chem. 1996, 405, 95-99.

25 Saterlay, A.J.; Marken, F.; Foord, J.S.; Compton, R.G.; Talanta 2000, 53, 403-415.

26 Saterlay, A.J.; Foord, J.S.; Compton, R.G. Analyst 1999, 124, 1791-1796.

27 Saterlay, A.J.; Agra-Gutierrez, C.; Taylor, M.P.; Marken, F.; Compton, R.G.; Electroanal. 1999, 11, 1083-1088.

28 Saterlay, A.J.; Wilkins, S.J.; Goeting, C.H.; Foord, J.S.; Compton, R.G.; Marken, R. J. Sol. State Electrochem. 2000, 4, 383-389.

29 Saterlay, A.J.; Wilkins, S.J.; Holt, K.B.; Foord, J.S.; Compton, R.G.; Marken, F. J. Electrochem Soc. 2001, 148, E66-E72.

${ }^{30}$ Saterlay, A.J.; Foord, J.S.; Compton, R.G. Electroanal. 2001, 13, 1065-1070.

31 Wadhawan, J.D.; Del Campo, F.J.; Compton, R.G.; Foord, J.S.; Marken, F.; Bull, S.D.; Davies, S.G.; Walton, D.J.; Ryley, S. J. Electroanal. Chem. 2001, 507, 135-143.

${ }^{32}$ Martin, H. B.; Morrison, P.W. Electrochem. Sol. State. Lett. 2001, 4, E17-E20.

33 Swain, G.M.; Ramesham, R. Anal. Chem. 1993, 65, 345-351.

34 Reuben, C.; Galun, E.; Cohen, H.; Tenne, R.; Kalish, R.; Muraki, Y.; Hashimoto, K.; Fujishima, A.; Butler, J.M.; Levy-Clement, C. J. Electroanal. Chem. 1995, 396, 233-239.

35 Li, L.; Totir, D.; Vinokur, N.; Miller, B.; Chottiner, G.; Evans, E.A.; Angus, J.C.; Scherson, D.A. J. Electrochem. Soc. 1998, 145, L85-L88.

36 Bouamrane, F.; Tadjeddine, A.; Tenne, R.; Butler, J.E.; Kalish, R.; Levy-Clement, C. J. Phys. Chem B. 1998, 102, 134-140. 
37 Meilunas, R.; Wong, M.S.; Sheng, K.; Chang, R.P.; Van Duyne, R.P. Appl. Phys. Lett. 1989, 54, 2204-2206.

38 Chen, P.; McCreery, R.L. Anal. Chem. 1996, 68, 3958-3956.

39 Swain, G.M. J. Electrochem. Soc. 1994, 141, 3382-3393.

40 DeClements, R.; Swain, G.M. J. Electrochem. Soc. 1997, 144, 856-866.

41 Popa, E.; Notsu, H.; Miwa, T.; Tryk, D.A.; Fujishima, A. Electrochem. Sol. State. Lett. 1999, 2, 49-51.

42 Notsu, H.; Yagi, I.; Tatsuma, T.; Tryk, D.; Fujishima, A. Electrochem. Sol. State. Lett. 1999, 2, 522-524.

43 Fujishima, A.; Rao, T.N.; Popa, E.; Sarada, B.V.; Yagi, I.; Tryk, D.A. J. Electroanal. Chem. 1999, 473, 179-185.

44 Tryk, D.A.; Fujishima, A. J. Electroanal. Chem. 2000, 492, 31-37.

45 Peilin, Z.; Jianzhong, Z.; Shenzhong, Y.; Xikang, Z.; Guoxiong. Z. Fres. J. Anal. Chem. 1995, 353, 171-173.

46 Manivannan, A.; Tryk, D.A.; Fujishima, A. Electrochem. Sol. State Lett. 1999, 2, $455-$ 456.

${ }^{47}$ Manivannan, A.; Seehra, M.S.; Tryk, D.A.; Fujishima, A. Anal. Lett. 2002, 35, 355368.

48 Madore, C.; Duret, A.; Haenni, W.; Perret, A. Electrochem. Soc. Proc. 2000, 19, 159168.

49 Rychen, Ph.; Perret, A.; Gobet, J.; Madore, C.; Haenni, W. Electrochem. Soc. Proc. 2001, 23, 97-107.

50 Nakabayashi, S.; Tryk, D.A.; Fujishima, A.; Ohta, N. Chem. Phys. Lett. 1999, 300, 409-413.

51 Ohta, N.; Nakabayashi, S.; Fujishima, A. Chem. Lett. 1999, 1147-1148.

52 Agra-Gutierrez, C.; Hardcastle, J.L.; Ball, J.C.; Compton, R.G. Analyst 1999, 124, 1053-1057.

53 Saterlay, A.; Tibbetts, D.F.; Compton, R.G. Anal. Sci. 2000, 16, 1055-1060.

54 Gunasingham, H.; Dalangin, H.H. Anal. Chim. Acta 1991, 246, 309-313. 
55 Neiman, E.Y.; Petrova, L.G.; Ignatov, V.I.; Dolgopolova,G.M. Anal. Chim. Acta 1980, $113,277-285$.

56 Brown, E. "Current Policy Developments and Directions Concerning Mercury Control of Air Emissions," Proceedings of Air Quality 3 Conference, Arlington, VA, 2002.

57 Standard Test Method for Elemental, Oxidized, Particle-Bound, and Total Mercury in Flue Gas from Coal-Fired Stationary Sources (Ontario Hydro Method), ASTM Committee D-22 on Sampling and Analysis of Atmospheres, 1999.

58 Laudal, D.; "Use of Continuous Emission Monitors for Mercury at Coal-Fired Utilities," Proceedings of Air Quality 3 Conference, Arlington, VA, 2002.

59 Yoshida, Z.; Kihara, S. J. Electroanal. Chem. 1979, 95, 159-168.

${ }^{60}$ Meyer, S.; Scholz, F.; Trittler, R.; Fres. J. Anal. Chem. 1996, 356, 247-252.

61 Kiekens, P.; Timmerman, E.; Verbeek, F.; Talanta 1984, 9, 693-701.

62 Fukai, R.; Huynh-Ngoc, L. Anal. Chim. Acta 1976, 83, 375-379.

63 Bilewicz, R.; Stojek, Z.; Kublik, Z. J. Electroanal. Chem. 1979, 96, 29-44.

${ }^{64}$ Method 7472, Mercury in Aqueous Samples and Extracts by Anodic Stripping Voltammetry, Revision 0, December, 1996, EPA.

65 Sipos, L.; Valenta, P.; Nurnberg, H.W.; Branica, M. J. Electroanal. Chem. 1977, 77, 263-266.

66 Scholz, F.; Nitschke, L.; Henrion, G. Anal. Chim. Acta 1987, 199, 167-171.

67 Yoshida, Z.; Kihara, S. J. Electroanal. Chem. 1978, 86, 167-177.

68 Dhaneshwar, R.G.; Kulkarni, A.V.; J. Electroanal. Chem. 1979, 99, 207-213.

69 Smith, R.M; Martell, A.E. Critical Stability Constants, Volume 4: Inorganic Complexes; Plenum Press: New York, 1976.

70 Nolan, M.A.; Kounaves, S.P. Electroanal. 2000, 12, 96-99.

71 Jagner, D.; Sahlin, E.; Renman, L. Anal. Chem. 1996, 68, 1616-1622.

72 Nolan, M.A.; Kounaves, S.P. Anal. Chem. 1999, 71, 1176-1182.

73 Buffle, J. J. Electroanal. Chem. 1981, 125, 273-294. 
74 Seo, K.; Kim, S.; Park, J. Anal. Chem. 1996, 70, 2936-2940.

75 Kolthoff, I.M.; Lingane, J.J. Polarography: Polarographic Analysis and Voltammetry, Amperometric Titrations; Interscience Publishers, Inc.: New York, NY, 1941.

76 Standard Methods for the Examination of Water and Wastewater, $20^{\text {th }}$ Edition (Eds: L.S. Clesceri, A.E. Greenburg, A.D. Eaton, M.H. Franson) American Public Health Association, American Water Works Association, Water Environment Federation, Washington, D.C. 1998, pp.1-27 to 1-35.

77 Tessier, A; Turner, D.R. Metal Speciation and Bioavailability in Aquatic Systems; John Wiley \& Sons: New York, NY, 1995.

78 Strojek, J.W.; Granger, M.C.; Swain, G.M.; Dallas, T.; Holtz, M.W. Anal. Chem. 1996, 68, 2031-2037.

79 Bonfil, Y.; Brand, M.; Kirowa-Eisner, E. Anal. Chim. Acta. 2002, 464, 99-114.

80 Bagel, O.; L'Hostis, E.; Lagger, G.; Osborne, M.D.; Seddon, B.J.; Girault, H.H.; Brack, D.; Loyall, U.; Schafer, H. J. Electroanal. Chem. 1999, 469, 189-195.

81 Schiewe, H.; Oldham, K.B.; Myland, J.C.; Bond, A.M.; Vicente-Beckett, V.A.; Fletcher, S. Anal. Chem. 1997, 69, 2673-2681.

82 Oldham, K.B; Myland, J.C. Fundamentals of Electrochemical Science; Academic Press: San Diego, 1994.

83 Dong, S.; Wang, Y. Talanta, 1988, 35, 819-821.

${ }^{84}$ Stulikova, M.; Vydra, F. J. Electroanal. Chem. 1973, 44, 117-127.

85 Zak, J.; Kolodziej-Sadlok, M. Electrochim. Acta. 2000, 45, 2803-2813.

86 Morrison, R.S. Electrochemistry at Semiconductor and Oxidized Metal Electrodes; Plenum Press: New York, NY, 1980.

87 Mason, T.J.; Lorimer, J.P. Applied Sonochemistry; Wiley-VCH: Germany, 2002.

${ }^{88}$ Compton, R.G.; Eklund, J.C.; Marken, F. Electroanal. 1996, 9, 509-521.

89 Davis, J.; Compton, R.G. Anal. Chim.. Acta. 2000, 404, 241-247.

${ }^{90}$ Hardcastle, J.L; West, C.E.; Compton, R.G. Analyst 2002, 127, 1495-1501.

91 Hardcastle, J.L; Murcott, G.G; Compton, R.G. Electroanal. 2000, 12, 559-563. 
92 Blythe, A.N; Akkermans, R.P.; Compton, R.G. Electroanal. 2000, 12, 16-19.

93 Akkermans, R.P.; Ball, J.C.; Rebbitt, T.O.; Marken, F; Compton, R.G. Electrochim. Acta 1998, 43, 3443-3449.

94 Zhang, H.; Coury, L.A. Anal. Chem. 1993, 65, 1552-1558.

95 Madigan, N.A.; Hagan, C.R.S.; Zhang, H.; Coury, L.A. Ultrasonics Sonochem. 1996, 3, S239-S247.

96 Compton, R.G.; Eklund, J.C.; Page, S.D.; Sanders, G.H.W; Booth, J. J. Phys. Chem. 1994, 98, 12410-12414.

97 Akkermans, R.P.; Ball, J.C.; Marken, F.; Compton, R.G. Electroanal. 1998, 10, 26-33.

98 Del Campo, J.F.; Coles, B.F; Marken, F.; Compton, R.G.; Cordesmans, E. Ultrasonics Sonchem. 1999, 6, 189-197.

99 Marken, F.; Kumbhat, S.; Sanders, G.H.W.; Compton, R.G. J. Electroanal. Chem. 1996, 414, 95-105.

100 Hart, E.J.; Fischer, C.H.; Henglein, A. J. Phys. Chem. 1986, 90, 5989-5996. 